UNIVERSIDADE DE SÃO PAULO

INSTITUTO DE GEOCIÊNCIAS

\title{
Proveniência das rochas do Grupo Península Trinity, Antártica, como ferramenta para reconstrução da margem Pacífica do Gondwana
}

\author{
Andrea Prendalia Harabari
}

Orientador: Prof. Dr. Renato de Moraes

DISSERTAÇÃO DE MESTRADO

Programa de Pós-Graduação em Mineralogia e Petrologia

SÃO PAULO

2014 
Autorizo a reprodução e divulgação total ou parcial deste trabalho por qualquer meio convencional ou eletrônico para fins de estudo e pesquisa, desde que citada a fonte.

Harabari, A. P. Proveniência das rochas do Grupo Península Trinity, Antártica, como ferramenta para reconstrução da margem Pacífica do Gondwana. 2014. 146p.

Dissertação de Mestrado em Geociências - Instituto de Geociências, Universidade de SãoPaulo, São Paulo. 
"Todos os nossos sonhos podem se realizar se tivermos a coragem de persegui-los." 
Aos meus pais Marlei e Carlos. Ao Renato Kahwage. 


\section{RESUMO}

As rochas do Grupo Península Trinity e das unidades equivalentes abrangem arenito, argilito e conglomerado, além de seus correspondentes metamórficos, e cuja formação é atribuída a correntes de turbidez. Afloram na parte norte da Península Antártica e arquipélagos adjacentes. Amostras de arenito, arcósio e conglomerado dessas unidades foram analisadas com intuito de traçar sua proveniência.

A partir da análise petrográfica de arenito foi constatada a similaridade entre as rochas das formações do Grupo Península Trinity, Formação Grauvaca-Folhelho e Formação Miers Bluff. As rochas apresentam composição quartzo-feldspática, com baixa porcentagem de fragmentos líticos de composição plutônica, vulcânica e metamórfica. Diferenças composicionais ocorrem na Formação View Point, na qual também ocorre subarcóseo; e na Formação Miers Bluff, arcóseo lítico.

As idades U-Pb de grãos detríticos de zircão para as rochas do Grupo Península Trinity da região de Botany Bay são concordantes e a mais jovem é $324 \pm 8 \mathrm{Ma}$, ainda com quantidade expressiva de grãos com idades de 512 a $541 \mathrm{Ma}$ e 1001 a $1091 \mathrm{Ma}$. Valores de $\varepsilon N d$ para rocha total, calculados para 220 Ma estão entre -5 e -8 , indicando influência de fontes crustais recicladas ou de razoável residência crustal. A extensa gama de idades para a área-fonte indica reciclagem sedimentar de fonte diversa, com idades carboníferas, cambrianas e pré-cambrianas. O $\varepsilon \mathrm{Hf}$ calculado para as idades de U$\mathrm{Pb}$ dos grãos de zircão detríticos mais jovens varia de $-1,2$ a $-5,7$, também indicam extensa residência crustal. A amostra da Formação Legoupil, que complementa os dados de idades U-Pb em grãos detríticos de zircão para o Grupo Península Trinity, apresenta idade mais jovem de $265 \pm 2$, restringindo a idade máxima de sedimentação ao Permiano. Para as amostras da Formação Grauvaca-Folhelho as idades U-Pb em grãos detríticos de zircão apresentam duas concentrações bem definidas, permo-triássica e cambriana, com idade concordante mais jovem de $216 \pm 2$ Ma e mais antiga de 1,8 \pm 0,13 Ga. Essas idades são condizentes com as dos grãos detríticos de zircão do Grupo Península Trinity.

A partir dos dados de idades de grãos detríticos de zircão pode-se definir como a idade máxima para deposição para as formações Legoupil e Grauvaca-Folhelho sendo permo-triássica, assim como para as rochas do Grupo Península Trinity em Botany Bay. Idades essas que levam a sugerir como fonte a Patagônia, no maciço Norte-patagônico, e Antártica Ocidental, na Terra de Mary Byrd. Estas condizem tanto em idade como em tipo de fonte, ígnea e metamórfica, com contribuição sedimentar.

Palavras-Chave: Grupo Península Trinity, proveniência sedimentar, geoquímica elemental, geocronologia: U-Pb, Lu-Hf, Sm-Nd 


\section{ABSTRACT}

The rocks of the Trinity Peninsula Group and equivalent units comprise sandstone, mudstone and conglomerate, as wel as their corresponding metamorphic rocks, whose formation is attributed to turbidity currents. They crop out in the northern Antarctic Peninsula and adjacent islands. Samples of sandstone, arkose and conglomerate of these units were analyzed in order to trace their provenance.

From the petrographic analysis of sandstone was found similarity between the rocks of the Trinity Peninsula Group, Greywacke-Shale Formation and Miers Bluff Formation. The rocks have quartz-feldspathic composition, low percentage of lithic fragments of plutonic, volcanic and metamorphic rocks. Compositional differences occur in View Point Formation, which also occurs subarkose, and Miers Bluff Formation, lithic arcóseo.

The U-Pb ages dates of detrital zircon grains in the rocks of the Trinity Peninsula Group region of Botany Bay are concordant and the youngest is $324 \pm 8 \mathrm{Ma}$, but concentrations around $512-541 \mathrm{Ma}$ and $1001-1091 \mathrm{Ma}$ are common. Values of $\varepsilon \mathrm{Nd}$ calculated for $220 \mathrm{Ma}$ are between -5 and -8 , indicating influence of recycled crustal sources or with reasonable crustal residence. With extensive range of ages for the source area, indicating sediment recycling of diverse source areas, with ages spread from Carboniferous to Cambrian and Precambrian. The $\varepsilon \mathrm{Hf}$ calculated for dates $\mathrm{U}-\mathrm{Pb}$ of younger detrital zircon ranges from -1.2 to -5.7 , also indicate extensive crustal residence. The sample of Legoupil Formation, which complements the $\mathrm{U}-\mathrm{Pb}$ dates for detrital zircon grains of the Trinity Peninsula Group, presents younger date of $265 \pm 2$, restricting the maximum age of the sedimentation as Permian. For samples of Greywacke-Shale Formation the U-Pb dates for detrital zircon grains exhibit two welldefined concentrations, permo-triassic and cambrian, with younger concordant date of $216 \pm 2 \mathrm{Ma}$ and older of $1.8 \pm 0,13 \mathrm{Ga}$. These dates are consistent with those of detrital zircon grains from the Peninsula Group Trinity.

From the data on detrital zircon grains can be defined as the maximum age for deposition for Legoupil and Greywacke-Shale formations being permo-triassic, as well as the rocks of the Trinity Peninsula Group in Botany Bay. Dates that suggest as a source area Patagonia, in Northern Patagonian massif and West Antarctica, in the Mary Byrd Land. These areas are consistent with both in age and rock types, igneous, metamorphic, and sedimentary, as the source area.

Key-Words: Trinity Peninsula Group, sedimentary provenance, elemental geochemistry, geochronology: U-Pb, Lu-Hf, Sm-Nd. 


\section{CAPÍTULO I - INTRODUÇÃO}

1

1. Considerações Iniciais 1

2. Objetivos 2

3. Justificativa 2

4. Localização da área de estudo e das amostras 3

CAPÍTULO 2 - MATERIAIS E MÉTODOS 4

1. Petrografia 4

2. Geoquímica Elemental 4

2.1. Análise de elementos maiores, menores e traço por Fluorescência de Raios X (FRX).

2.2. Análise de elementos terras raras por escptrometria de massa com plasma induzido (ICP-MS).

3. Geoquímica Isotópica 6

3.1. Geoquímica isotópica em rocha total 6

3.2. Datação de grãos detríticos de zircão 7

CAPÍTULO III - CONTEXTO GEOLÓGICO REGIONAL 9

1. Introdução 9

2. Quadro tectônico 11

3. Grupo Península Trinity e Unidades Correlatas 13

CAPÍTULO IV - PETROGRAFIA 16

1. Introdução 16

2. Análise petrográfica de rocha 16

2.1. Formação Legoupil 16

2.2. Formação View Point 18

2.3. Formação Hope Bay 19

2.4. Grupo Península Trinity em Botany Bay 20

2.5. Formação Grauvaca-Folhelho 22

2.6. Formação Miers Bluff 23

CAPÍTULO V - GEOQUÍMICA 27

1. Introdução 27

2. Elementos Maiores e Menores 28

2.1. Classificação 32 
2.2. Índice de alteração química (CIA) 33

3. Elementos Traço 35

CAPÍTULO VI - GEOQUÍMICA ISOTÓPICA 39

1. Introdução 39

2. Dados geocronológicos disponíveis do Trinity Península Group 39

3. Geoquímica isotópica de rocha total 41

3.1. Sistema Samário - Neodímio $(\mathrm{Sm}-\mathrm{Nd}) \quad 41$

3.2. Resultados Samário - Neodímio 42

4. Geoquímica isotópica mineral - datação de grãos detríticos de zircão 43

4.1. Sistema Urânio-Chumbo (U-Pb) 44

4.1.1. Resultado Urânio - Chumbo 45

4.2. Sistema Lutécio-Háfnio (Lu-Hf) 52

4.2.1. Resultado Lutécio-Háfnio 52

CAPÍTULO VII - PROVENIÊNCIA SEDIMENTAR 55

1. Petrografia 56

2. Geoquímica

3. Geocronologia 62

4. Áreas-fonte 62

4.1. América do Sul 62

4.2. Antártcia 63

CAPÍTULO VIII - CONCLUSÃO 65

CAPÍTULO IX - BIBLIOGRAFIA 66 


\section{ÍNDICE DE FIGURAS}

\section{Capítulo 1}

Figura 1. Localização das amostras coletadas utilizadas neste estudo. Península

Antártica e arquipélagos associados.

\section{Capítulo 3}

Figura 2A. Esquema representativo do Supercontinente Gondwana. B. Mapa geológico simplificado da região da Península Antártica e arquipélagos

adjacentes

Figura 3A. Compartimentação tectônica para a Península Antártica e arquipélagos adjacentes por Smellie, 1981. B. Compartimentação tectônica para a Península Antártica e arquipélagos adjacentes Barbeau et al., 2010 e Moraes et al. inédito.

\section{Capítulo 4}

Figura 4. Fotomicrografias das formações Legoupil e View Point.

Figura 5. Fotomicrografia da Formação Hope Bay e TPG em Botany Bay..... 25

Figura 6. Fotomicrografias das formações Gruvaca-Folhelho e Miers Bluff.

\section{Capítulo 5}

Figura 7. Diagramas de Harker com análises por FRX. Para o Grupo Península Trinity, Fm. Grauvaca-Folhelho e Fm. Miers Bluff.

Figura 8. A. Diagrama de classificação química de arenitos de Pettijohn et al. (1972); B. Diagrama de classificação química de rochas sedimentares de Herron (1988).

Figura 9. A. Gráfico de correlação CIA vs $\mathrm{SiO}_{2}$; B. Diagrama da evolução de alteração A-CN-K, extraído e modificado de McLennan et al. (1990).

Figura 10. Diagrama multielementar de elementos traço normalizados segundo valores para a crosta continental superior de Taylor e McLennan (1995).

Figura 11. Diagrama de elementos terras raras condrito-normalizados segundo os valores condríticos de Taylor \& McLennan (1985)....

Figura 12. Gráfico $\varepsilon N d$ vs tempo (Ga). Para as amostras do TPG em Botany Bay e a amostra da Formação Legoupil.

Figura 13. A. Diagrama da Concórdia U-Pb para a amostra IL-1. B.: Frequência das idades ${ }^{206} \mathrm{~Pb} /{ }^{238} \mathrm{U}$ obtidas em cristais de zircão detrítico da amostra IL-1. C. Imagem de catodoluminescência dos cristais de zircão detrítico analisados do Grupo A e C de idades estimadas.

Figura 14. A.e B Diagrama da Concórdia U-Pb para as amostras BBR-D-8A e BBR-D-10. C e D. Frequência das idades ${ }^{206} \mathrm{~Pb} /{ }^{238} \mathrm{U}$ obtidas em cristais de zircão detrítico das amostras BBR-D-8A e BBR-D-10. E e F. Imagem catodoluminescência dos cristais de zircão detrítico analisados para as amostras BBR-D-8A BBR-D-10, respectivamente..

Figura 15. A. Diagrama da Concórdia U-Pb para a amostra L-2-4, conglomerado da Fm. Grauvaca-Folhelho. B. Frequência das idades ${ }^{206} \mathrm{~Pb} /{ }^{238} \mathrm{U}$ obtidas em cristais de zircão detrítico da amostra L-2-4,.C. Imagem de catodoluminescência dos cristais de zircão detrítico para a amostra L-2-4... 
Figura 16. A e B Diagrama da Concórdia U-Pb para as amostras L-4-8 e L-4-12, respectivamente, da Fm. Grauvaca-Folhelho. C e D. Frequência das idades ${ }^{206} \mathrm{~Pb} /{ }^{238} \mathrm{U}$ obtidas em cristais de zircão detrítico da amostra L-4-8 e L-4-12, respectivamente. E e F. Imagem de catodoluminescência dos cristais de zircão detrítico analisados para as amostras L-4-8 e L-4-12, respectivamente.

Figura 17. A. e C. Gráfico com valores $\varepsilon_{\mathrm{Hf}}$ calculados para as idades pontuais U-Pb e valores das idades modelo $\mathrm{T}_{\mathrm{DM}(\mathrm{Hf})}$ por duplo-estágio para as amostras de arenito BBR-D-8A e BBR-D-10 do TPG em Botany Bay. B. e D. Gráfico de correlação entre $\varepsilon_{\mathrm{Hf}}$ e idades U-Pb para as amostras de arenito BBR-D-8A e BBRD-10.

Figura 18. A. Diagrama de tipos de proveniência tectônica de Dickinson (1985), com as amostras de todas as formações plotadas. B. Diagrama com todos os dados plotados acrescidos dos dados de Hervé, 1987 e 1991.

Figura 19. A. Diagrama de discriminação tectônica Roser \& Korsch (1986). B.

Diagrama de Roser \& Korsch (1988).

Figura 20. Amostras projetadas nos diagramas de discrimanação tectônica de Bathia (1983)

Figura 21. Diagrama discriminante modificado por Gu et al. (2002) a partir de Floyd \& Leveridge (1987).

Figura 22. Figura extraída e modificada de Hervé et al. 2003 com as idades do sul dos Andes, indicando as fontes prováveis ao Grupo Península Trinity..... 


\section{Capítulo 2}

\section{ÍNDICE DE TABELAS}

Tabela 1 - Relação das amostras analisadas petrograficamente.

Tabela 2 - Relação das amostras analisadas quimicamente para obtenção de

elementos maiores, menores, traços e Elementos Terras Raras.

Tabela 3 - Relação das amostras analisadas quimicamente pelo método de rocha total Sm-Nd.

Tabela 4 - Relação das amostras analisadas quimicamente pelo método de geoquímica mineral

\section{Capítulo 5}

Tabela 5. Rresultados obtidos para elementos maiores e menores por FRX. Os valores estão em \%de peso.

Tabela 6. Valores de CIA para as amostras analisadas

Tabela 7. Relação das amostras analisadas para $\mathrm{Sm}-\mathrm{Nd}$

Tabela 8. Dados isotópicos e elementais $\mathrm{Sm} / \mathrm{Nd}$ para as amostras analisadas

Tabela 9. $\varepsilon \mathrm{Nd}_{\mathrm{TDM}}$ e recalculado para $220 \mathrm{Ma}$. 43

Tabela 10. Relação das amostras analisadas e métodos respectivos. 


\section{CAPÍTULO I INTRODUÇÃO}

\section{Considerações Iniciais}

A Antártica é o continente com 14 milhões de $\mathrm{km}^{2}$, o quinto maior da Terra, mas apresenta a menor área de exposição de rochas pelo fato de estar quase que inteiramente coberto por gelo permanente. Os afloramentos rochosos estão concentrados em nunataks, cadeias de montanhas interiores e nas porções costeiras. Aliado a essa razão, o isolamento geográfico, o difícil acesso, e as temperaturas baixas ao longo do ano todo, fazem da Antártica o continente menos estudado geologicamente, o que gera dificuldades no entendimento da sua evolução geológica e geotectônica.

As montanhas Transantárticas dividem o Continente Antártico em duas províncias geológicas: o Cráton da Antártica Oriental e a Antártica Ocidental. Esta última é composta por diversos blocos tectônicos, dentro dos quais se encontra a Península Antártica (Dalziel \& Elliot, 1982) e, durante o Paleozóico, com o resto da Antártica Ocidental, a Oriental, assim como a América do Sul, África e Austrália, fazia parte do supercontinente Gondwana (Vaughan \& Pankhurst, 2008).

A Península Antártica está conectada, em sub-superfície, ao Microcontinente das Orcadas do Sul (King \& Barker, 1988; Ferris et al., 2000) e é o maior dos doze microcontinentes que se encontram a Sul da América do Sul, Leste da Antártica e Nova Zelândia (Willan, 2003). Sua formação antecede a quebra e separação do supercontinente, sendo que as sucessões turbidíticas do Grupo Península Trinity e unidades correlatas na Península Antártica e arquipélagos adjacentes fazem parte deste contexto geotectônico. Essas unidades registram a sedimentação na margem Pacífica do Supercontinente Gondwana, este registro é caracterizado por depósitos provenientes da erosão de rochas do supercontinente e a identificação das mesmas ajuda a entender a posição geotectônica dos fragmentos distribuídos em diversos continentes atuais.

As fontes dos sedimentos são as rochas das cadeias de montanhas e de seu embasamento formadas durante a aglutinação do Gondwana, no Neoproterozóico, que hoje correspondem à América do Sul, Antártica, Nova Zelândia, Austrália, Índia e África (Willan, 2003). Parte das rochas presentes no sul da Patagônia, Península Antártica e arquipélagos associados têm idade Triássica ou mais antigas e também 
podem ter servido como áreas fontes (Thomson, 1975; Dalziel, 1984). Os depósitos foram acrescidos tectonicamente à América do Sul e à Península Antártica no Jurássico (Dalziel, 1984; Trouw et al., 1997). Os eventos de compressão e extensão são registrados até o Cretáceo e a sedimentação estava ligada à bacias de ante-arco (forearc) e à zona de subducção da margem Pacífica do Gondwana (Dalziel, 1984).

Apesar de todos os dados existentes, a configuração da margem Pacífica do Gondwana antes do Jurássico ainda não é clara.

\section{Objetivos}

O interesse do projeto é investigar a proveniência das rochas do Grupo Península Trinity e da Formação Grauvaca-Folhelho e sua possível correlação com a Formação Miers Bluff. O projeto será desenvolvido com uso de petrografia, análise química de elementos maiores, menores e traço, datação de grãos detríticos de zircão e geoquímica isotópica de rocha total.

A partir dos dados coligidos e dos disponíveis em trabalhos anteriores, será investigada a hipótese de correlação das unidades, suas áreas fontes e com isso investigar a coerência dos modelos tectônicos da configuração da margem Pacífica do Gondwana no Mesozóico.

\section{Justificativa}

Embora a Península Antártica tenha se formado durante a separação do Supercontinente Gondwana, não se sabe ao certo sua posição antes da quebra. No entanto, as rochas que a compõem foram formadas durante a aglutinação do Gondwana ou pela erosão destas com subsequente acresção na sua margem Pacífica, durante evento pré-Andino. Com o estudo da proveniência dos sedimentos do Grupo Península Trinity e suas unidades correlacionadas, pretendem-se estabelecer a real correlação entre as unidades, identificar as possíveis áreas fontes e com isso contribuir para a reconstituição da margem Pacífica do Gondwana.

Outro fator importante na pesquisa é que a maior parte dos dados de idades de zircão detrítico está concentrada nas unidades do Grupo Península Trinity e Formação Miers Bluff. Os dados de idades de grãos detríticos de zircão de rochas da Formação Grauvaca-Folhelho são inexistentes, e escassos para seu equivalente metamórfico, Complexo Metamórfico de Scotia, sendo os primeiros recentemente levantados. A primeira determinação da idade do metamorfismo do Complexo Metamórfico de Scotia, 
admitida como válida para as rochas do Grupo Península Trinity, é de $213 \pm 38$ Ma e foi apresentada por Trouw et al. (1997b). Idade de isócrona $\mathrm{Rb}-\mathrm{Sr}$ de concentrados de muscovita indicam idade mais nova para o metamorfismo, de $190 \pm 4 \mathrm{Ma}$ (Flowerdew et al., 2007). Os grãos detríticos mais novos presentes nas rochas do Grupo Península Trinity apresentam idades de 245 Ma (Barbeau et al., 2010), enquanto nas rochas do Complexo Metamórfico de Scotia ocorrem grãos com idades de 200 Ma (Valadares, 2012). Assim se faz necessária maiores investigações para a correlação dessas unidades.

\section{Localização da Área de Estudo e das Amostras}

A região estudada encontra-se na parte mais setentrional do continente Antártico, a Península Antártica e arquipélagos associados (Figura1). A área de estudo compreende a ocorrência do Grupo Península Trinity e Formação Grauvaca-Folhelho. As amostras coletadas e utilizadas no presente trabalho vieram de duas ilhas no Arquipélago das Orcadas do Sul, Laurie e Powell; de uma ilha nas Shetlands do Sul, Livingston; e de quatro pontos na Península Antártica, Hope Bay, Botany Bay, Legoupil e View Point.

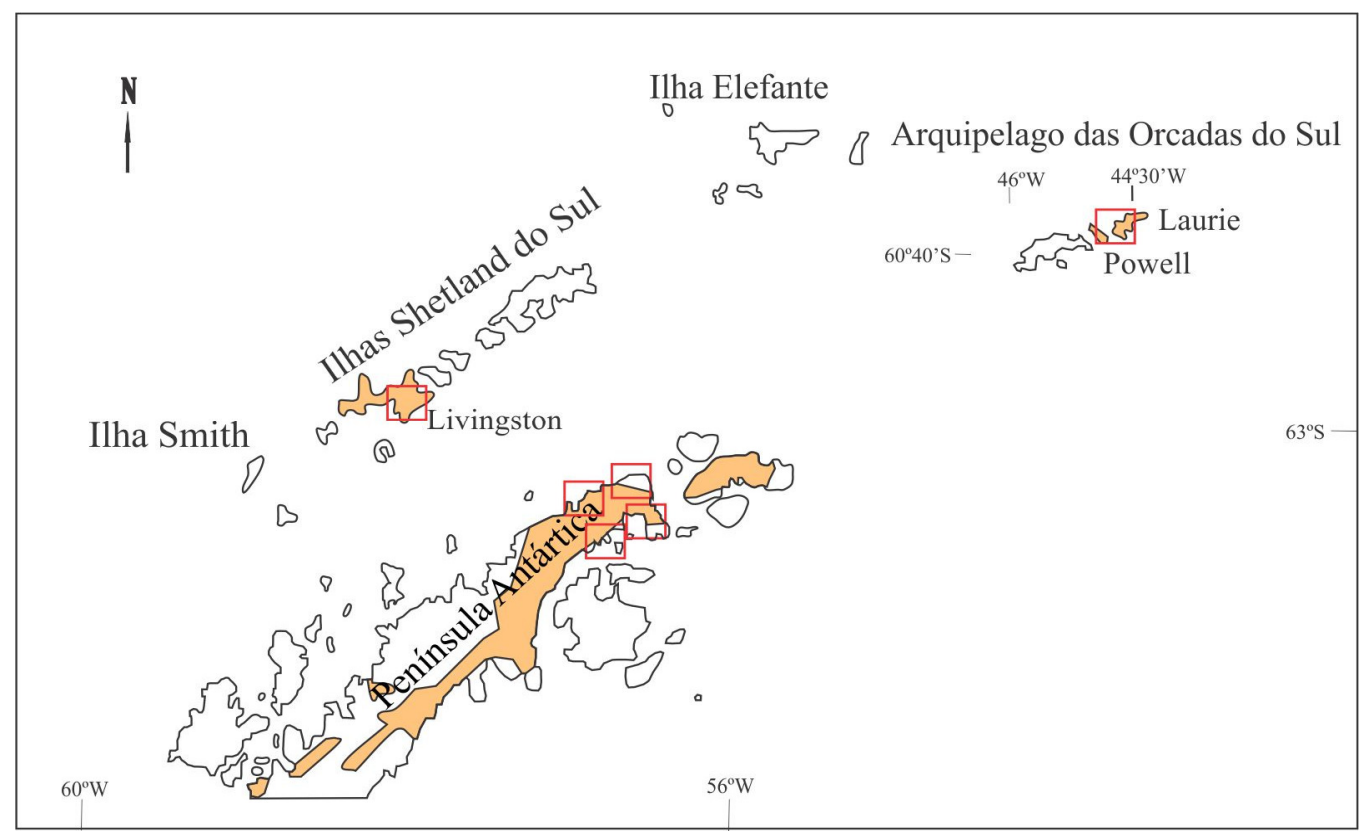

Figura 1. Península Antártica e arquipélagos associados. Áreas em laranja indicam a abrangência das formações de onde foram coletadas as amostras, os quadrados vermelhos mostram a região de coleta. A posição do Arquipélago das Orcadas está deslocada, mas suas coordenadas estão indicadas. 


\section{CAPÍTULO II MATERIAIS E MÉTODOS}

No presente projeto foram utilizadas amostras coletadas nas Expedições Brasileiras à Antártica entre os anos de 1983 e 2007 pelos projetos coordenados pelo Dr. Rudolph A. J. Trouw (UFRJ). Foram utilizadas 24 amostras de diferentes afloramentos do Grupo Península Trinity e unidades correlacionadas. Para a realização do projeto serão desenvolvidas as seguintes etapas:

\section{Petrografia}

No trabalho petrográfico são utilizadas 22 amostras de diferentes afloramentos do Grupo Península Trinity e unidades correlacionadas. A relação das amostras analisadas está na Tabela 1.

Estas amostras foram serradas em serra circular e enviadas para a Seção de Laminação do IGc - USP para a confecção de seções delgadas de $30 \mu \mathrm{m}$ de espessura. Depois de prontas, as seções foram descritas em microscópio petrográfico Olympus, modelo BXP - 50, no Laboratório de Microscopia Petrográfica do IGc - USP com ênfase na mineralogia, texturas e as possíveis reações metamórficas identificáveis.

Tabela 1 - Relação das amostras analisadas petrograficamente.

\begin{tabular}{l|l}
\hline \multicolumn{2}{c}{ RELAÇÃO DAS AMOSTRAS ANALISADAS } \\
\hline Fm. Legoupil & IL-1, IL-4-3, IL-P-1, PMI-7, GA-2 \\
Fm. View Point & KOP-4-I \\
Fm. Hope Bay & HB-94-87-2, HB-2-9, HB-MC-8-6 \\
GPT em Botany Bay & BBR-D-8A, BBR-D-10, BBR-19-1, BBR- \\
& 23-2, BBR-19-3, BBR-87-7 \\
Fm. Grauvaca-Folhelho & L-2-1, L-2-4, L-4-8, L-4-12, L-4a-2 \\
Fm. Miers Bluff & LV-RFS-21 \\
\hline
\end{tabular}

\section{Geoquímica Elemental}

Para a obtenção dos elementos maiores, menores, traços e elementos terras raras (ETR) foram analisadas quinze amostras, dentre estas quatro amostras da Formação Legoupil, uma da Formação View Point, três da Formação Hope Bay, duas da Formação Grauvaca-Folhelho, uma da Formação Miers Bluff e cinco do Grupo Península Trinity (GPT) em Botany Bay (Tabela 2). 
A preparação das amostras para as análises laboratoriais foi realizada no Laboratório de Tratamento de Amostras (LTA) do IGc - USP consistiu em:

(i) Limpeza das amostras que foram lavadas e serradas para extração das porções alteradas;

(ii) Cominuição em prensa hidráulica para obtenção de fragmentos menores que $1 \mathrm{~cm}$;

(iii) Quarteamento manual para retirada de aproximadamente $75 \mathrm{~g}$ representativos da amostra;

(iv) Moagem em moinho de anéis de ágata até obtenção de pó com tamanho de grão inferior a 200 mesh;

Tabela 2 - Relação das amostras analisadas quimicamente para obtenção de elementos maiores, menores, traços e Elementos Terras Raras.

\begin{tabular}{l|l}
\hline \multicolumn{2}{c}{ RELAÇÃO DAS AMOSTRAS ANALISADAS } \\
\hline Fm. Legoupil & IL-4-3, IL-P-1, PMI-7, GA-2 \\
Fm. View Point & KOP-4-I \\
Fm. Hope Bay & HB-94-87-2, HB-2-9, HB-MC-8-6 \\
GPT em Botany Bay & BBR-D-8A, BBR-19-1, BBR-23-2, BBR- \\
& 19-3, BBR-87-7 \\
Fm. Grauvaca-Folhelho & L-2-1, L4a-2 \\
Fm. Miers Bluff & LV-RFS-21 \\
\hline
\end{tabular}

2.1. Análise de elementos maiores, menores e traço por Fluorescência de RaiosX (FRX):

Os elementos maiores, menores e alguns traço foram analisados no laboratório de Fluorescência de Raios-X (FRX) do IGc - USP a partir de pastilhas fundidas e prensadas. Para tal finalidade utilizou-se o equipamento automático Philips, modelo PW2400, e a metodologia descrita em Mori et al.(1999).

As pastilhas prensadas foram confeccionadas no LTA. Após a moagem (I (iv)), é feita a micronização de cerca de 7,0 g de cada amostra, que posteriormente são levados para secagem na estufa. Na etapa seguinte, as amostras foram homogeneizadas manualmente com $20 \%$ de ligante em pó e depois levadas para prensa hidráulica.

As pastilhas fundidas foram produzidas no laboratório de Laboratório de Química e ICP-OES/MS do IGc - USP. Esta etapa consistiu, após a moagem, da pesagem e adição de fundente à amostra na proporção de 1:10 e posterior fundição em equipamento Claisse de fluxo automático de fusão.

Para o teste de exatidão, o material de referência geoquímica internacional utilizado foi o basalto JB-1a. A exatidão dos resultados obtidos é ideal, sendo que para os óxidos a diferença entre os valores recomendados e obtidos ficou abaixo de $5 \%$ em 
todas as etapas. Os valores obtidos para os elementos menores e traços também foram satisfatórios e no geral as diferenças entre valores recomendados e obtidos não ultrapassou os $10 \%$ em todas as etapas, com exceção de $\mathrm{Ga}, \mathrm{Pb}, \mathrm{Cl}$ e $\mathrm{Nd}$ que apresentaram diferenças de até $36,07 \%$.

As análises de duplicata foram feitas sempre na quinta amostra analisada, resultando em três duplicatas. Os resultados das análises químicas de rocha total estão apresentados no Anexo I.

\subsection{Análise de elementos terras raras por espectrometria de massa com plasma induzido acoplado (ICP-MS)}

Para obtenção de elementos traços e ETR, as amostras foram analisadas no Laboratório de Química e ICP-OES/MS do IGc - USP, utilizando critérios descritos em Navarro et al. (2004). O laboratório utiliza um espectrômetro do tipo quadrupolo, modelo ELAN 6100DRC da Perkin Elmer/Sciex para obtenção de elementos traço e terras raras.

Os materiais de referência utilizados para o teste de exatidão foram o basalto BR e o gabro JGb-1 para todas as amostras analisadas. Os valores obtidos foram coerentes, sendo que a diferença entre os resultados obtidos e os de referência não chegou a 5\% para nenhum dos padrões. Apenas uma análise de duplicata foi realizada, junto à décima amostra analisada. Os resultados das análises químicas de rocha total estão apresentados no Anexo II.

\section{Geoquímica Isotópica}

Para resultados isotópicos foram realizados dois diferentes tipos de análises de geoquímica isotópica: de rocha total $(\mathrm{Sm}-\mathrm{Nd})$ e mineral (U-Pb, Lu-Hf).

\subsection{Geoquímica isotópica em rocha total}

Foram analisadas cinco amostras de duas formações, consideradas relevantes e com material coletado em campo suficiente para todas as análises, listadas na Tabela 3.

A preparação das amostras foi efetuada no LTA do IGc - USP seguindo os quatro passos descritos no item II. Após esta etapa, as amostras foram enviadas ao Centro de Pesquisas Geocronológicas da USP onde foi realizada a análise isotópica de rocha total pelo método $\mathrm{Sm}-\mathrm{Nd}$ de acordo com o procedimento apresentado por Sato et al. (1995). 
Tabela 3 - Relação das amostras analisadas quimicamente pelo método de rocha total Sm-Nd.

\begin{tabular}{l|l}
\hline \multicolumn{2}{c}{ RELAÇÃO DAS AMOSTRAS ANALISADAS } \\
\hline Fm. Legoupil & PMI-7 \\
GPT em Botany Bay & BBR-19-1, BBR-19-3, BBR-23-2, BBR- \\
& $87-7$ \\
\hline
\end{tabular}

\subsection{Datação de grãos detríticos de zircão}

Seis amostras foram selecionadas e preparadas para a separação de cristais de grãos detríticos de zircão, sendo duas do Grupo Península Trinity na localidade de Botany Bay, três da Fm. Grauvaca - Folhelho e uma da Fm. Legoupil (Tabela 4).

A preparação das amostras foi realizada em dois laboratórios do IGc-USP, o LTA e o laboratório de Separação do Centro de Pesquisas Geocronológicas (CPGEO). Foram seguidas as seguintes etapas:

(i) Limpeza das amostras e fragmentação das amostras com marreta para obtenção de pedaços menores do que três centímetros;

(ii) Britagem em britador primário de mandíbulas de aço para cominuição das amostras em fragmentos menores do que um centímetro;

(iii) Moagem em moinho de disco de tungstênio e peneiramento para a separação de frações de granulação entre 100 e $200 \mu \mathrm{m}$ e fração de grãos menores do que $200 \mu \mathrm{m}$.

(iv) Concentração de minerais densos por pressão de água e vibração em mesa de concentração Wiffley;

(vi) Primeira separação e descarte dos minerais magnéticos, na porção de minerais densos concentrados, com imã de mão;

(vii) Segunda separação e descarte dos minerais magnéticos na porção não magnética em separador magnético do tipo Frantz, a 0,5A;

(viii) A porção não magnética foi levada para capela de exaustão para passagem em bromofórmio $(\mathrm{CHBr} 3$, densidade $=2,89 \mathrm{~g} / \mathrm{cm} 3)$ para separação dos minerais mais densos do que $2,89 \mathrm{~g} / \mathrm{cm} 3$;

(ix) Na porção de minerais mais densos que o bromofórmio, nova separação e descarte de minerais magnéticos a 0,5A foi realizada no Frantz a 0,5A;

(x) A porção não magnética foi levada a capela de exaustão para passagem em iodeto de metileno $(\mathrm{CH} 2 \mathrm{I} 2$, densidade $=3,32 \mathrm{~g} / \mathrm{cm} 3)$ para separação dos minerais mais densos do que $3,32 \mathrm{~g} / \mathrm{cm} 3$ 
(xi) A porção mais densa do que o iodeto de metileno foi analisada em uma lupa Leika para observar a existência (ou não) de grãos de zircão;

(xii) As amostras preparadas foram encaminhadas para separação dos grãos em lupa e posterior preparação de montagens (mounts) com utilização de resina epoxy;

(xiii) Imagens de catodoluminescência foram obtidas com Microscópio Eletrônico de Varredura com detector para elétrons secundários e catodoluminescência. $\mathrm{O}$ aparelho é da Oxford, modelo EDS-X-MAX, com detector CENTAUROS, para facilitar o posicionamento do feixe de laser durante as análises.

(xiv) Por fim as medidas das razões ${ }^{206} \mathrm{~Pb} /{ }^{238} \mathrm{U}$ e ${ }^{207} \mathrm{~Pb} /{ }^{235} \mathrm{U}$ em zircão foram obtidas por LA-MC-ICP MS, com feixe de $29 \mu \mathrm{m}$, no CPGEO do IGc-USP.

Tabela 4 - Relação das amostras analisadas quimicamente pelo método de geoquímica mineral.

\begin{tabular}{l|l}
\hline \multicolumn{2}{c}{ RELAÇÃO DAS AMOSTRAS ANALISADAS } \\
\hline Fm. Legoupil & IL-1 \\
GPT em Botany Bay & BBR-D-8A, BBR-D-10 \\
Fm. Grauvaca-Folhelho & L-2-4, L-4-8, L-4-12 \\
\hline
\end{tabular}




\section{CAPÍTULO III CONTEXTO GEOLÓGICO REGIONAL}

\section{Introdução}

Durante o Neoproterozóico ocorreu a aglutinação do Gondwana, evento relacionado ao Ciclo Orogenético Brasiliano-Pan-Africano (Brito Neves \& Cordani, 1991; Hoffman, 1991; Brito Neves et al., 1999).O Supercontinente Gondwana agregava as terras que hoje perfazem boa parte da América do Sul, Antártica, Austrália, Índia e África (Figura 2A). Entretanto as rochas hoje presentes no sul da Patagônia, Península Antártica e arquipélagos associados ainda não haviam sido formadas (Ramos, 2008).

Durante o início do Triássico, a maior parte da costa andina passou por processos extensionais e algumas bacias e depósitos turbidíticos, costeiros com fonte continental, foram formados. No Jurássico, vários desses depósitos foram acrescidos tectonicamente à América do Sul, no que hoje é o sul da Patagônia e a Península Antártica (Hervé et al., 2000; Ramos \& Aleman, 2000). A subsequente ruptura e desagregação do Gondwana foram responsáveis pela formação da Península Antártica e do microcontinente das Orcadas do Sul.

$\mathrm{Na}$ Península Antártica e arquipélagos adjacentes ocorrem unidades ígneas, sedimentares e metamórficas geradas no intervalo de tempo que vai do Permiano/Triássico até o Neógeno. De modo simplificado, estas unidades têm sido incluídas nos grupos Península Trinity, Botany Bay, Vulcânico da Península Antártica, Vulcânico das Ilhas James Ross e Complexo Metamórfico de Scotia (Figura 2B).

O Grupo Península Trinity (TPG) é composto por rochas interpretadas como turbiditos de leque submarino (Smellie, 1991; Andreis et al., 1997, Paciullo et al., 2001). O Grupo Botany Bay, conforme definido Farquharson (1984), é composto por conglomerados, arenitos, pelitos e intercalações de depósitos vulcânicos. O Grupo Vulcânico da Península Antártica (Adie, 1957) inclui andesitos, felsitos e rochas piroclásticas, enquanto o Complexo Metamórfico de Scotia (Tanner et al., 1982) engloba sucessões metamórficas contendo xistos azuis, metachert e metabasaltos oceânicos, subsequentemente foram adicionados xistos pelíticos e semi-pelíticos à unidade (Thomson,,1975; Trouw et al., 1997a; Flowerdew, 2008). 

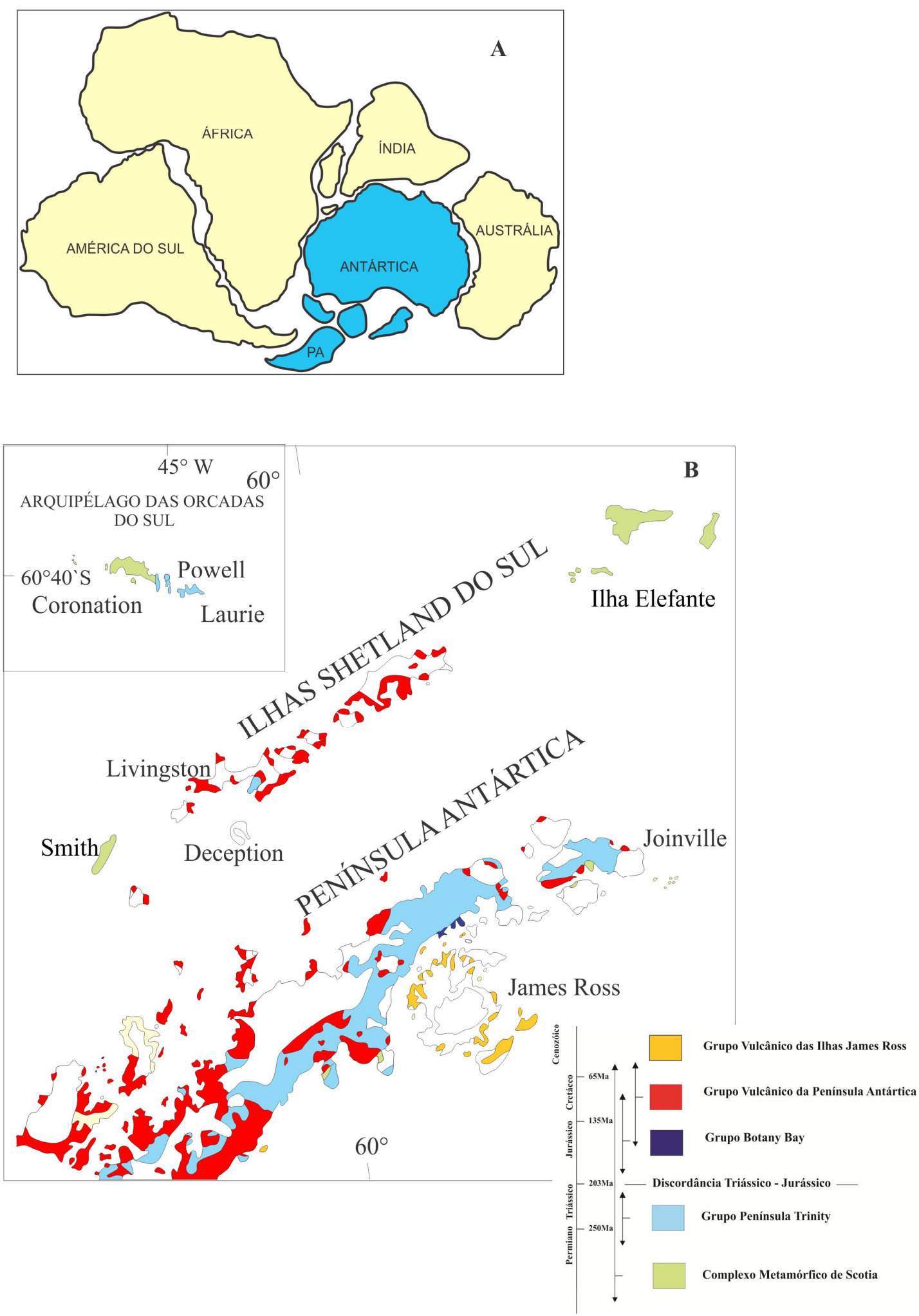

Figura 2A. Esquema representativo da disposição dos blocos continentais no Mesozóico, no Supercontinente Gondwana. B. Mapa geológico simplificado da região da Península Antártica e arquipélagos adjacentes. Baseado em Smellie, 1981; Hyden \& Tanner, 1981; Dalziel, 1984; Tanner et al., 1982; Paciullo et al., 2001; Trouw et al., 1997a. 


\section{Quadro Tectônico}

A disposição das rochas do Grupo Península Trinity reflete o que ficou preservado do sistema fossa-arco de ilha da Península Antártica, que pode ser interpretado de duas principais formas, a primeira e clássica, largamente discutida por vários autores, é a subdivisão da península em complexo de subducção, bacia de forearc e o arco magmático (Figura 3A, Smellie, 1981), e a nova proposta seria a subdivisão da península em domínios ocidental, central e oriental (Vaughan \& Storey, 2000), a partir da zona de cisalhamento de Palmer Land, que se desenvolveu durante os episódios compressionais do fim do Jurássico, início do Cretáceo (Figura 3B).

A interpretação tradicional da geologia mesosóica da Península Antártica foi descrita como completo sistema de arco - fossa do tipo Andino (Smellie, 1981), sendo que a subducção é interpretada como ativa antes e depois da separação parcial da Península Antártica do Gondwana pela expansão do assoalho oceânico no Mar de Weddell (Vaughan \& Storey, 2000).

Assim, a sequência de rochas que sustenta a visão tradicional é composta de oeste para leste pelas rochas do complexo de subducção, com metamorfismo nas fácies xisto azul, xisto verde e anfibolito (Dalziel, 1984), nas ilhas Smith, Elefante e Clarence. A leste, no mesmo contexto, são englobadas as rochas do Complexo Metamórfico de Scotia, expostas no Arquipélago das Orcadas do Sul (Trouw et al., 1997a). Na península, afloram turbiditos, com metamorfismo na fácies sub-xisto verde, pequena quantidade de rochas vulcânicas associadas, além de rochas plutônicas, sendo o sul da península dominado por rochas metamórficas e plutônicas de idade paleozóicas, e a leste, nas ilhas do Mar de Weddell, ocorrem rochas sedimentares, com intercalações de rochas vulcânicas (Smellie, 1981).

A proposta mais recente divide a Península Antártica em três domínios tectônicos, a partir da zona de cisalhamento de Palmer Land, que se desenvolveu durante os episódios compressionais do fim do Jurássico, início do Cretáceo. São eles separados pela origem tectônica de cada terreno ou domínio: autóctone, para-autóctone e alóctone (Vaughan \& Storey, 2000). O Domínio Leste é formado por rochas autóctones e para-autóctones, que representam parte da margem do Gondwana, rochas metamórficas e ígneas, e por rochas sedimentares ou metassedimentares de fontes continentais, e com contribuições de arcos de ilha. Está separado por uma zona de cisalhamento dúctil (ZCEPL) do Domínio Central. Este último, de origem intrusiva/extrusiva, é caracterizado por rochas magmáticas típicas de arco magmático, 
do Triássico ao Cretácio Inferior (Leat et al., 1995). O Domínio Oeste é formado por rochas de prisma acrescionário e plataforma oceânica, o que pode representar fragmento de crosta (Vaughan \& Storey, 2000). Embora a divisão proposta use nomes e denominações diferentes, a compartimentação tectônica não é desigual do que proposto anteriormente.
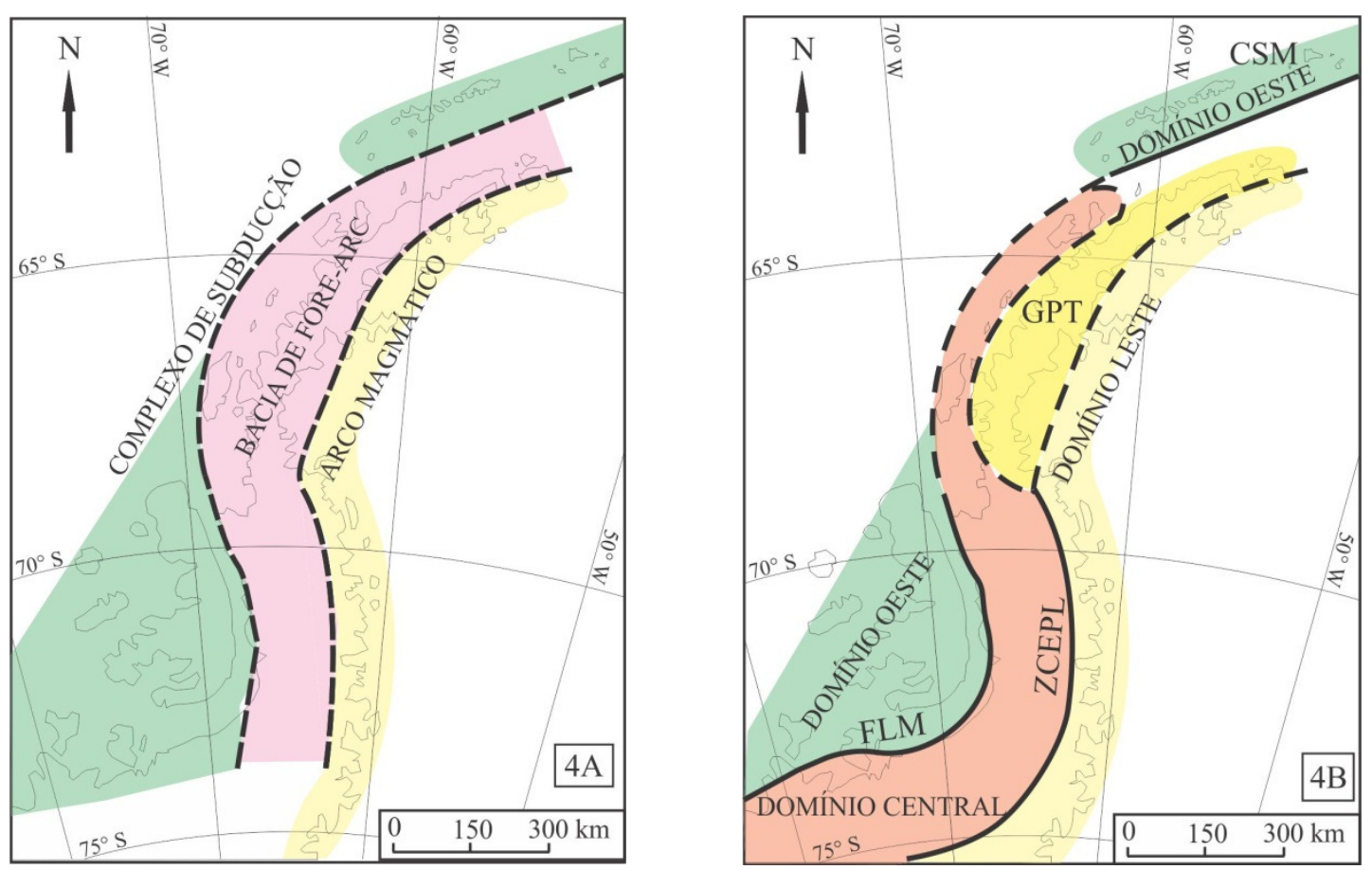

Figura 3A. Compartimentação do sistema fossa - arco na Península Antártica e arquipélagos. Extraído e modificado de Smellie, 1981. B. Compartimentação em domínios a partir da zona de cisalhamento de Palmer Land. Extraído e modificado de Barbeau et al., 2010 e Moraes et al. inédito.FLM - Falha LeMay; ZCEPL - Zona de Cisalhamento Eastern Palmer Land; GPT - Grupo Península Trinity; CSM - Complexo Metamórfico de Scotia.

As rochas do Complexo Metamórfico de Scotia estão associadas ao Domínio Oeste, por seu caráter acrescionário, mas as rochas do Grupo Península Trinity são consideradas para-autóctones e parte do Domínio Leste (Vaughan \& Storey, 2000), pois sua deposição teria ocorrido sobre crosta continental (Bradshaw et al., 2012). A posição do Grupo Península Trinity é questionada e atribuída ao Domínio Oeste, por essas rochas terem sofrido deformação e metamorfismo, devendo provavelmente integrar o conjunto que sofreu acresção (Moraes et al., inédito). 


\section{O Grupo Península Trinity e Unidades Correlatas}

O Grupo Península Trinity foi definido inicialmente como Série Península Trinity por Adie (1957), para descrever a sequência de grauvaca silicosa e folhelho do norte da Península Antártica. Posteriormente, essas rochas foram mapeadas nas décadas de 1960 e 1970 por geólogos do British Antarctic Survey e, após quase uma década de discussões, a partir do trabalho de Hyden \& Tanner (1981), passaram a ser denominadas de Grupo Península Trinity, subdivivdido nas Formações Hope Bay, View Point e Legoupil (Figura 2B).

A Formação Legoupil foi definida por Halpern (1965), e as Formações Hope Bay e View Point por Hyden\&Tanner (1981), sendo que o fator determinante na separação entre as formações está na variação de granulação dos sedimentos dentro de cada unidade. Mais recentemente, Del Valle et al. (2007) incluíram a formação Düse Bay, aflorante na Península Tabarin, no Grupo Península Trinity.

A sucessão estratigráfica dentro do Grupo Península Trinity é definida por Del Valle et al. (2007) baseada na posição geográfica das formações dentro da península, isso se deve ao fato de não existirem dados ou exposição contínua que permitam estabelecer com segurança a estratigrafia completa do grupo. Assim, o Grupo Península Trinity inclui desde a base até o topo a Formação Legoupil, Formação View Point, Formação Hope Bay e Formação Düse Bay.

A Formação Legoupil consiste da alternância de arenito fino e lamito maciço ou fracamente estratificado, em camadas subverticais. A rocha predominante é o lamito e o arenito ocorre em camadas menores em relação às outras. São encontradas também pequenas quantidades de conglomerados. Petrograficamente, o arenito é classificado como arcósio com alta porcentagem de plagioclásio, que varia entre 18 e 34\%, e feldspato potássico em porcentagem menor que 8\%. A proporção de quartzo é intermediária se comparada às outras duas formações, com grãos de extinção pronunciadamente ondulados (Hyden \& Tarner, 1981; Willan, 2003).

A Formação View Point apresenta duas principais alternâncias, entre arenito turbidítico fracamente estratificado e lamito, e entre quartzo arenito fracamente estratificado e lamito; ainda, em menores quantidades, ocorrem camadas de conglomerado polimíctico. A alternância entre quartzo arenito e lamito é característica da formação, com camadas com o topo invertido e abundantes dobras em "m" e " $z$ ". Petrograficamente, trata-se de arenito com alta porcentagem de quartzo (56-65\%), pronunciadamente com grãos com extinção ondulante, plagioclásio com porcentagem 
entre 7 e 16\% (oligoclásio - albita) e ortoclásio menor que 2\%. Em menores proporções, ocorrem biotita, muscovita, zircão e óxidos de Fe e Ti (Hyden \& Tarner, 1981; Willan, 2003).

A Formação Hope Bay consiste de porções iguais de arenito grosso e lamito maciço a fracamente estratificado, com fina alternância de siltito e argilito, em que as camadas encontram-se verticalizadas e com pouca deformação. Petrograficamente o arenito é classificado como arcósio, com porcentagens de plagioclásio entre 26 e 34\%, em sua maioria albita, ortoclásio, com concentração menor que $15 \%$, e entre 24 e $29 \%$ de quartzo, cujos grãos apresentam iguais proporções de extinção ondulante e não ondulante. Em menores quantidades, são observados hornblenda marrom, biotita, clorita, muscovita, titanita, óxidos de Fe-Ti, epidoto, clinozoisita e zircão (Hyden \& Tarner, 1981; Willan, 2003).

A Formação Düse Bay aflora na Península Tabarin, em sua Baía homônima e adjacências, e é composta por arenito e lamito com intercalações de conglomerado, calcário e rocha vulcânica. O conglomerado é mal selecionado, com clastos sedimentares e ígneos, com matriz arenosa vulcanoclástica, com grãos vulcânicos, sedimentares e metamórficos (Del Valle et al., 2007).

A idade dos turbiditos do Grupo Trinity Península, inferida a partir do raro conteúdo fossilífero de bivalves nos lamitos da Formação Legoupil (Thomson, 1975), é considerada Triássica. Os grãos detríticos de zircão datados pelo método U-Pb concentram-se em vários intervalos entre 245 e 350 Ma, entre 380 e $700 \mathrm{Ma}$ e grãos de idades esparsas até o Arqueano (Pankhurst, 1983; Loske \& Miller, 1991, Hervé et al., 2006, Barbeau et al., 2010). A deformação está associada a acresção no início do Jurássico (Storey \& Garret, 1985; Loske et al., 1990; Smellie \& Millar, 1995).

A base do Grupo Trinity Península não está exposta em nenhum afloramento conhecido, no entanto, no Cabo Douzet, em xenólitos de rochas metamóficas em rocha plutônica que corta as rochas do Grupo Trinity Península, foram determinadas idades de metamorfismo de 315 Ma (Loske et al., 1990; Loske \& Miller, 1991). Na parte superior do Grupo Trinity Península há discordância erosiva que o coloca em contato com o Grupo Vulcânico da Península Antártica. Já em Hope Bay, contrariamente, a Formação Mont Flora, do Grupo Botany Bay, sobrepõe-se ao Grupo Trinity Península em possível contato por falha (Birkenmajer, 1993a, 1993b) ou erosivo (Elliot \& Garacin, 1983).

O Complexo Metamórfico de Scotia é a unidade que constitui a parte aflorante do Microcontinente das Orcadas do Sul, e está exposto no arquipélago das Orcadas do 
Sul, entre a América do Sul e o Continente Antártico. Na parte oeste do arquipélago, estão as ilhas Coronation, Sign, Matthews, Powell e Fredriksen, e na parte leste, Weddell, Saddle, Laurie e ilhas menores (Dalziel, 1984). Estudos tectono-metamórficos realizados na Ilha Powell demostram que o Complexo Metamórfico de Scotia está em contato gradacional com a sucessão turbidítica da Formação Grauvaca-Folhelho (Trouw et al., 1997b). O contato foi mapeado como gradacional, pois as rochas passam de metassedimentos com baixo grau de metamorfismo com estruturas sedimentares ainda preservadas para filito e xisto, com maior grau metamórfico em exposição contínua. Assim, admiti-se que nesta localidade o Complexo Metamórfico de Scotia é a Formação Grauvaca-Folhelho em mais alto grau metamórfico.

A Ilha Livingston faz parte das Ilhas da Shetland do Sul e consiste de rochas do embasamento pré-vulcânico, com sequências de arco vulcânico e intrusões plutônicas (Xiguang et al. 2002). O embasamento pré-vulcânico é composto por rochas sedimentares com baixo grau de metamorfismo que foram denominadas de Formação Miers Bluff (Hobbs, 1968), e que aflora na Península Hurd, porção central da Ilha Livingston. As rochas da formação são interpretadas como sequência turbidítica e sua composição consiste de arenito maciço, lamito escuro, conglomerado de matriz argilosa, folhelho e ritmito (Xiguang et al. 2002). A Formação Miers Bluff é a unidade mais antiga do arquipélago, tendo sido correlacionada pela primeira vez com as rochas do Grupo Trinity Península, por similaridade litológica e conteúdo fossilífero (ver discussão em (Krauset al., 2008). O conteúdo fossilífero indica origem marinha e idades entre Carbonífero Superior e Jurássico Inferior, mas foram encontrados fósseis de ammonita do Jurássico Superior (Pimpirevet al., 2002), e palinomorfos de Classopollis e Praecirculina, característicos do fim do Triássico ao meio do Cretáceo (Xiguang et al., 2002), o que restringe seu intervalo de deposição. Estes dados permitem delimitar a idade da Formação Miers Bluff e questionar sua correlação com o Grupo Trinity Península, sendo reforçada pela presença de grãos detríticos com idades entre 165 e 170 Ma (Hervé et al., 2006). 


\section{CAPÍtULO IV PETROGRAFIA}

\section{Introdução}

A petrografia é ferramenta amplamente utilizada para estudos de proveniência e serve como primeira aproximação para conhecer a natureza da área-fonte, sobretudo nas análises de minerais em arenito, já que a composição mineralógica dos sedimentos se encontra estreitamente ligada com o regime tectônico (Dickinson, 1970; Dickinson \& Suczek, 1979).

No caso dos arenitos, se utilizam as proporções modais de minerais leves, ou seja, a quantidade relativa nas amostras. Para isso se realiza a contagem modal dos minerais nas rochas por diferentes métodos, dentro dos quais o mais usado é de GazziDickinson (1984), uma vez que sua contagem é independente do tamanho do grão. No entanto, existem vários limitantes, devido aos processos diagenéticos e metamórficos que mudam a textura das rochas, e que geralmente fazem com que os minerais menos resistentes ao intemperismo sejam subestimados se comparados aos minerais mais estáveis como o quartzo.

No caso dos conglomerados e das rochas líticas, cada clasto representa diretamente os tipos de rocha que ocorrem na fonte. No entanto devem ser analisados com cuidado, uma vez que podem representar somente fontes próximas e locais, e não necessariamente a fonte principal.

No presente trabalho a petrografia é realizada em amostras do Grupo Península Trinity, formações Legoupil, View Point, Hope Bay e amostras deste grupo da localidade de Botany Bay. São ainda analisadas amostras das formações GrauvacaFolhelho e Miers Bluff. A lista com o nome das amostras analisadas por formação está na Tabela 1.

\section{Análise petrográfica de rocha}

\subsection{Formação Legoupil}

Dois litotipos principais foram examinados da Formação Legoupil, arcósio e ardósia. O arcósio da Formação Legoupil apresenta cor cinza clara, granulação média, estrutura maciça a finamente estratificada, por vezes com lâminas carbonáticas intercaladas. Petrograficamente, a rocha tem pouca ou nenhuma porosidade, é 
sustentada pelo arcabouço e com cimento tardio de carbonato. O arcabouço tem composição quartzo-feldspática, com granulação fina a média, grãos subarredondados a subangulosos e, em menores proporções, angulosos. O grau de esfericidade dos grãos é baixo, com exceção de alguns cristais de quartzo perfeitamente esféricos.

O arcabouço é composto de quartzo monocristalino com proporções entre 20 a $25 \%$, o quartzo policristalino ocorre em menores proporções de 5 a $10 \%$, o plagioclásio com 20 a 28\%, sendo em sua maioria albita, o feldspato potássico em pequenas porcentagens, 5\%, e fragmentos líticos com proporções entre 3 a 5\% (Figura 4A). Em menores proporções biotita, estilpnomelano, muscovita, clorita, epídoto, titanita, apatita, zircão e carbonato.

Os cristais de quartzo monocristalino se apresentam em proporções praticamente iguais aos grãos com extinção ondulante pronunciada e grãos sem extinção ondulante, sendo ainda identificados cristais com feição de migração de borda de grão. A maior parte dos grãos de filossilicatos - muscovita, estilpnomelano, clorita e biotita apresentam feições de deformação, evidenciando a compactação mecânica, principalmente quando localizados entre três grãos mais resistentes, indicando que a maior parte dos grãos é detrítica (Figura 4B). Alguns cristais de muscovita e clorita estão bem formados e sem deformação, indicando serem diagenéticos. A clorita ainda ocorre junto aos veios com quartzo.

Os grãos de plagioclásio são arredondados e a composição é albita, sendo que em alguns grãos ocorre alteração carbonática; o feldspato potássico é o ortoclásio, com alguns grãos alterados para mica branca, e em menor proporção microclínio. Os fragmentos líticos têm formatos alongados e arredondados, com alto grau de esfericidade, e sua composição é vulcânica félsica, quartzo-feldspática; sedimentar, siltito, e metamórfico; xisto (Figura 4C). O zircão ocorre como grãos arredondados, semiarredondados e com tendência bipiramidal, indicando em sua maioria origem ígnea. O carbonato ocorre como produto de alteração do plagioclásio e entre os grãos detríticos, fazendo papel de cimento.

Macroscopicamente, a ardósia apresenta cor cinza escuro, granulação muito fina, estrutura foliada e, por vezes, ocorrem lâminas carbonáticas intercaladas. Em algumas amostras são observadas dobras assimétricas e micro falhas evidenciadas pelo deslocamento das camadas. Petrograficamente é rocha de granulação muito fina, composta de quartzo detrítico e mica branca, com pequenas quantidades de feldspato e 
carbonato. Clivagem ardosiana é observada e são numerosos os veios de quartzo que a cortam, de granulação fina a média, com feições de recristalização de grão e carbonato.

As rochas finas analisadas apresentam alternância entre camadas ricas em argilominerais e camadas quartzo-feldspáticas (Figura 4D). $\mathrm{Na}$ camada rica em argilominerais, metasiltito, apresenta granulometria muito fina, sem porosidade, alto grau de seleção e com grãos de mica alongados, levemente imbricados. Já a camada quartzo-feldspática apresenta granulação fina, baixa porosidade, baixo grau de seleção e grãos sub-angulosos a sub-aredondados.

A camada de granulação fina tem composição quartzo-feldspática, com grãos de quartzo monocristalino em parte com extinção ondulante, o feldspato predominante é o alcalino, por vezes com alteração para mica branca. A biotita se apresenta dobrada, por vezes em formato gaivota ou em kink-bands, quando em contato com grãos de maior dureza, evidenciando a compactação mecânica. Ocorrem ainda epídoto, rutilo e zircão.

\subsection{Formação View Point}

Na Formação View Point foram descritos petrograficamente amostras de arcósio e arenito.

O arenito apresenta cor cinza clara, granulação média, grãos bem selecionados e médio grau de arredondamento. Em algumas amostras há carbonato preenchendo fraturas. Petrograficamente a rocha é sustentada pelo arcabouço, com cimento tardio e baixa porosidade. O arcabouço é quartzoso, com grãos subarredondados a subangulosos, com esfericidade baixa a média e granulometria fina a média. Os sedimentos são originalmente imaturos e com médio grau de seleção.

$\mathrm{O}$ arcabouço tem porcentagem alta de quartzo, entre 50 e $55 \%$, sendo a maioria monocristalino, plagioclásio com porcentagem entre 5 e 15\%, albita e oligoclásio, o feldspato potássico, ocorre em pequenas porcentagens $(<5 \%)$ sendo ortoclásio, pertítico ou não e, em menores proporções, ocorrem muscovita, clorita, epídoto, rutilo, apatita, zircão, fragmentos líticos, granada e carbonato.

Os grãos de quartzo apresentam extinção ondulante pronunciada, enquanto na muscovita e clorita ocorrem dobras, quando os grãos estão acomodados entre três grãos mais resistentes, evidenciando serem detríticos e que a deformação é devido à compactação (Figura 4E). O carbonato está disposto entre os grãos fazendo papel de 
cimento e, em alguns pontos, está bem formado crescendo com hábito fibroso.

Os grãos de plagioclásio podem estar saussuritizados e o microclíneo é comum. Os fragmentos líticos são sedimentares, siltito; e vulcânico, granófiro. São comuns os veios de epídoto na rocha.

Macroscopicamente a ardósia apresenta cor cinza escuro, granulação muito fina, clivagem ardosiana, com presença de dobras simétricas, assimétrica e isoclinais, por vezes com clivagem de crenulação espaçada. Em algumas amostras ainda são observadas lâminas de carbonato intercaladas ao acamamento sedimentar.

Petrograficamente foi caracterizada a alternância característica da formação, pela intercalação entre arenito silicoso e lamito (Figura 4F). Rocha dividida em duas bandas, quartzosa, de granulação fina, com grãos de quartzo monocristalino com extinção ondulante, quartzo policristalino e, em menor porcentagem, clorita e óxidos. A outra banda apresenta granulação muito fina, com quartzo e mica branca em proporções quase iguais, ainda com a ocorrência local de carbonato. Ao microscópio petrográfico é evidente pelo menos uma fase de deformação, a responsável pela formação da foliação principal.

\subsection{Formação Hope Bay}

Da Formação Hope Bay foram selecionadas amostras de arcósio para petrografia. Macroscopicamente o arcósio apresenta cor cinza, granulação média a grossa, estrutura maciça a finamente estratificada, com veios de quartzo que cortam o acamamento sedimentar. A rocha é petrograficamente de baixa porosidade, com pequenas proporções de cimento e sustentada pelo arcabouço, o qual tem composição quartzo-feldspática, com granulação fina a média, cristais subarredondados a subangulosos, com baixo grau de esfericidade. Os sedimentos são originalmente imaturos e possuem baixo grau de seleção.

$\mathrm{O}$ arcabouço tem porcentagem de quartzo monocristalino entre 15 e $25 \%$ e de quartzo policristalino entre 5 e $8 \%$, o plagioclásio varia de 20 a $25 \%$, sendo em sua maioria albita e oligoclásio, e feldspato potássico ocorrendo em menores proporções, entre 10 a $15 \%$, é o ortoclásio, e os fragmentos líticos de 4 a 6\% (Figura 5A). Em menores quantidades são observados biotita, clorita, muscovita, epídoto, titanita, zircão, apatita e carbonato. 
Em quase metade dos grãos de quartzo monocristalino a extinção ondulante está presente e em proporção menor feições de recristalização de borda de grão. Para os cristais que não apresentam feições de recristalização é comum a feição de golfos de corrosão, indicando origem vulcânica. Os cristais de mica branca, clorita e biotita, apresentam dobras, quando localizados entre três grãos, isso indica que boa parte dos grãos é detrítica e que a deformação pode ser causada tanto por compactação durante a diagênese ou mesmo tectônica. A muscovita tem cristais bem formados, podendo ser diagenética. Os grãos de zircão apresentam formato alongado, subeuédrico e bipiramidal, indicando origem ígnea, e alguns cristais arredondados de origem metamórfica.

O ortoclásio é o feldspato potássico predominante, com alteração para mica branca e, em menores proporções, microclínio. Os cristais de plagioclásio estão saussuritizados e, em alguns casos, com alteração carbonática. O carbonato substituiu parcialmente o plagioclásio e também preenche espaços, na forma de cimento.

Os fragmentos líticos são abundantes e na maioria são de rocha vulcânica, entre eles granófiro, lava esferulítica e quartzo com golfo de corrosão (Figura 5B). Em menor proporção ocorrem os fragmentos líticos de rocha sedimentar, siltito, e líticos e rocha metassedimentar, filito e quartzito.

A ardósia apresenta cor cinza escura, granulação muito fina, estrutura foliada e, por vezes, ocorrem lâminas quartzo-carbonáticas intercaladas (Figura 5C). Petrograficamente é rocha de granulação muito fina, composta de mica branca e quartzo detrítico, com pequenas quantidades de feldspato e carbonato. Apresenta clivagem ardosiana e são numerosos os veios de quartzo de granulação fina a média, com feições de recristalização de grão.

\subsection{Grupo Península Trinity em Botany Bay}

Não existe consenso de qual formação do Grupo Península Trinity ocorre em Botany Bay. Na região ocorre turbidito com camadas arenosas de até $70 \mathrm{~cm}$ de espessura, turbidito laminado com alternância de camadas de 1 a 10 centímetros de espessura de arenito e lamito, na maior parte das vezes, já recristalizado para ardósia, e com camadas de chert vermelho ou verde. A petrografia foi concentrada nas camadas arenosas e ardósia. 
O arcósio é rocha sustentada pelo arcabouço, com pouca ou nenhuma pororsidade, cimento tardio e cortado por veios de carbonato. $\mathrm{O}$ arcabouço apresenta composição quartzo-feldspática, com granulação fina a média, cristais subarredondados com baixo grau de arredondamento a subangulosos, raramente ocorrem cristais alongados e angulosos. Os sedimentos são moderadamente selecionados, sendo assim submaturos.

Os grãos de quartzo monocristalino com proporções entre 20 e $25 \%$, o quartzo policristalino ocorre em proporções menores que 5\%, o plagioclásio entre 5 e $10 \%$, sendo em sua maioria oligoclásio, o feldspato potássico entre 15 e $20 \%$, e fragmentos líticos com proporções entre 5 e 10\% (Figura 5D). Em menores proporções biotita, muscovita, clorita, epídoto, titanita, apatita, zircão, rutilo e carbonato.

Os grãos de quartzo monocristalino se apresentam com extinção ondulante e contatos lobados, sendo ainda identificado grãos com feições de dissolução por pressão na diagênese. Quando em vênulas apresenta granulação maior que no resto da rocha e as feições de deformação são bem desenvolvidas, como extinção ondulante e migração de borda de grão.

Os filossilicatos, muscovita, clorita e biotita, se dividem em dois grupos, os bem formados, cristais grandes e alongados, e os com feições de deformação. A maior parte dos grãos de muscovita e clorita se enquadra no segundo grupo, evidenciando a compactação mecânica e indicando que a maior parte dos grãos é detrítica. Ainda assim, alguns grãos de muscovita e clorita estão bem formados e sem deformação, indicando serem pelo menos diagenéticos.

Os grãos de plagioclásio apresentam composição de oligoclásio a andesina, sendo que em alguns grãos ocorre alteração carbonática. O feldspato potássico é o ortoclásio, com alguns grãos alterados para mica branca. Os fragmentos líticos têm formatos alongados e arredondados e em alguns pontos deformados. Sua composição é vulcânica félsica, quartzo-feldspática, ou sedimentar, siltito. Os grãos de zircão ocorrem em formatos alongados, arredondados e semiarredondados, com tendência bipiramidal, indicando origem metamórfica. O carbonato ocorre principalmente em e entre os grãos detríticos, fazendo papel de cimento, e em menor ocorrência como alteração dos feldspatos.

As rochas finas são classificadas como ardósia, por apresentar clivagem ardosiana. Macroscopicamente ocorre com cor cinza escura, granulação muito fina e com lâminas 
quartzo-carbonáticas intercaladas. Petrograficamente é rocha de granulação muito fina, com foliação bem marcada, composta de mica branca, clorita e quartzo detrítico (Figura 5E). Apresenta veios de quartzo de granulação fina a média, e carbonáticos.

\subsection{Formação Grauvaca-Folhelho}

Da Formação Grauvaca-Folhelho foram analisadas amostras de arcósio. Petrograficamente, a rocha tem baixa porosidade, é sustentada pelo arcabouço e com pequenas proporções de cimento. O arcabouço tem composição quartzo-feldspática, granulação de fina a grossa, cristais subarredondados a subangulosos, com baixo a médio grau de esfericidade. Os sedimentos são imaturos e possuem baixo grau de seleção.

$\mathrm{O}$ arcabouço tem porcentagem alta de quartzo monocristalino, entre 5 e $35 \%$, plagioclásio com porcentagem entre 8 e 20\%, de composição variando entre oligoclásio e andesina. O ortoclásio ocorre em porcentagens entre 5 e 15\%, não sendo raros os grãos pertíticos. Em menores proporções ocorrem zircão, titanita, muscovita, epídoto, biotita, clorita, carbonato, estilpnomelano e fragmentos líticos (Figura 6A).

Os grãos de quartzo monocristalino podem apresentar extinção ondulante e os grãos de biotita, estilpnomelano e muscovita também apresentam dobras quando localizados entre três grãos, indicando origem detrítica. Os cristais de clorita estão bem formados, bem como alguns cristais de muscovita indicando origem diagenética. Os grãos de zircão apresentam-se em formatos alongados, subeuédricos e bipiramidais, indicando serem de origem ígnea.

O ortoclásio é o feldspato potássico predominante, com alteração para mica branca, e em menores proporções são identificados grãos pertíticos e o microclínio. Os cristais de plagioclásio estão saussuritizados, com ou sem carbonato, o qual também ocorre como cimento. Cortando a rocha são observados veios de epídoto.

Os fragmentos líticos apresentam formatos arredondados e alongados, são na maioria de rocha sedimentar, siltito, e rocha metassedimentar, filito, quartzito e xisto, ocorrendo pontualmente. Em menores proporções são observados fragmentos líticos de rocha vulcânica félsica. Pode ser observado pontualmente bioclasto (Figura 6B). 


\subsection{Formação Miers Bluff}

O arenito lítico da Formação Miers Bluff é rocha de baixa porosidade, sustentada pelo arcabouço e com cimento. $\mathrm{O}$ arcabouço é quartzo-feldspático, com granulometria média a grossa, grãos subarredondados a subangulosos, com baixo grau de esfericidade (Figura 6C). Os sedimentos são imaturos e com baixo grau de seleção.

$\mathrm{O}$ arcabouço tem porcentagem de quartzo monocristalino entre 15 e 30\%, plagioclásio com porcentagem entre 5 e $12 \%$, de composição predominante de oligoclásio, enquanto o feldspato potássico ocorre com porcentagens entre 2 e 10\%, é representado por ortoclásio e microclínio. Em menores proporções ocorrem muscovita, clorita, zircão, fragmentos líticos, biotita, granada e carbonato.

Os grãos de quartzo são monocristalinos, apresentando em raros grãos extinção ondulante, enquanto a muscovita e a biotita exibem dobras quando os grãos estão acomodados entre três grãos mais resistentes, evidenciando deformação devido à compactação. O zircão tem forma alongada com inclusões e bi-piramidais indicando origem ígnea.

Os cristais de plagioclásio estão saussuritizados, o feldspato potássico apresenta alteração para mica branca e pode ser pertítico. Os fragmentos líticos são dominantemente de rocha sedimentar, siltito, contendo também metassedimentares, quartzito e filito, e vulcânicos - quartzo-feldspáticos. O carbonato ocorre como cimento. 
Figura 4. Fotomicrografias das formações Legoupil e View Point.
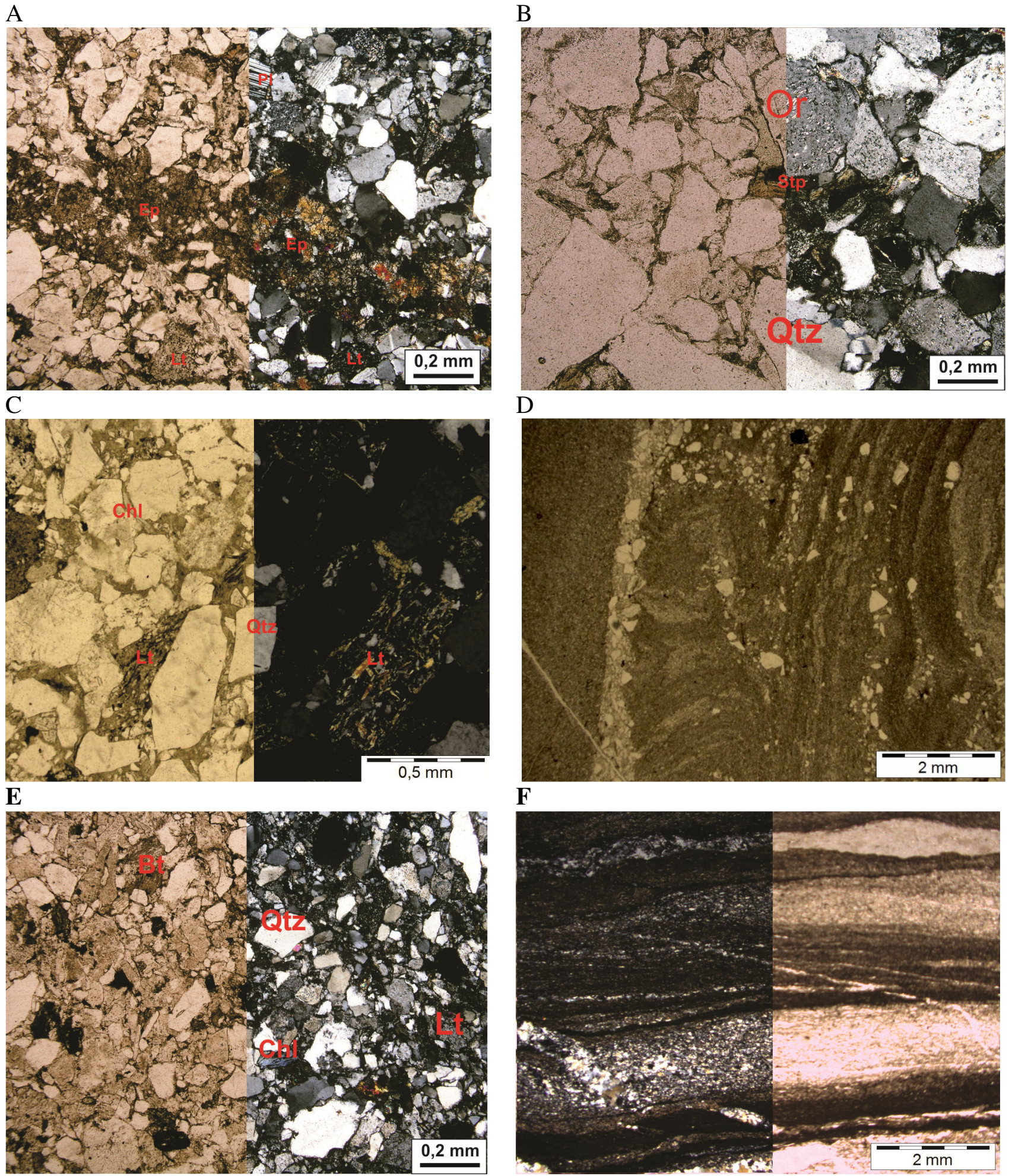

A. Lâmina PMI-7- Legoupil, epídoto (Ep) em veio, feldspato (Pl) e líticos (Lt). B. Deformação marcada pelo estilpnomelano dobrado (Stp) e quartzo (Qtz) com extinção ondulante, e ortoclásio (Or). C. Detalhe da lâmina IL-1 com presença de clorita (Chl) dobrada, e líticos metamórficos (Lt).D. . Lâmina IL-P-1, alternância entre camadas de granulação muito fina - argilomineriais- e fina - quartzo-feldspáticas - em ardósias. Notar a direção da foliação com cristais maiores intercalados. E. Formação View Point -KOP-4I - cristais de quartzo (Qtz), biotita (Bt) e clorita (Chl) deformados e presença de lítico.F. Alternância entre camadas finas - quartzo-feldspáticas- e muito finas - argilomireais. 
Figura 5. Fotomicrografia da Formação Hope Bay e TPG em Botany Bay.
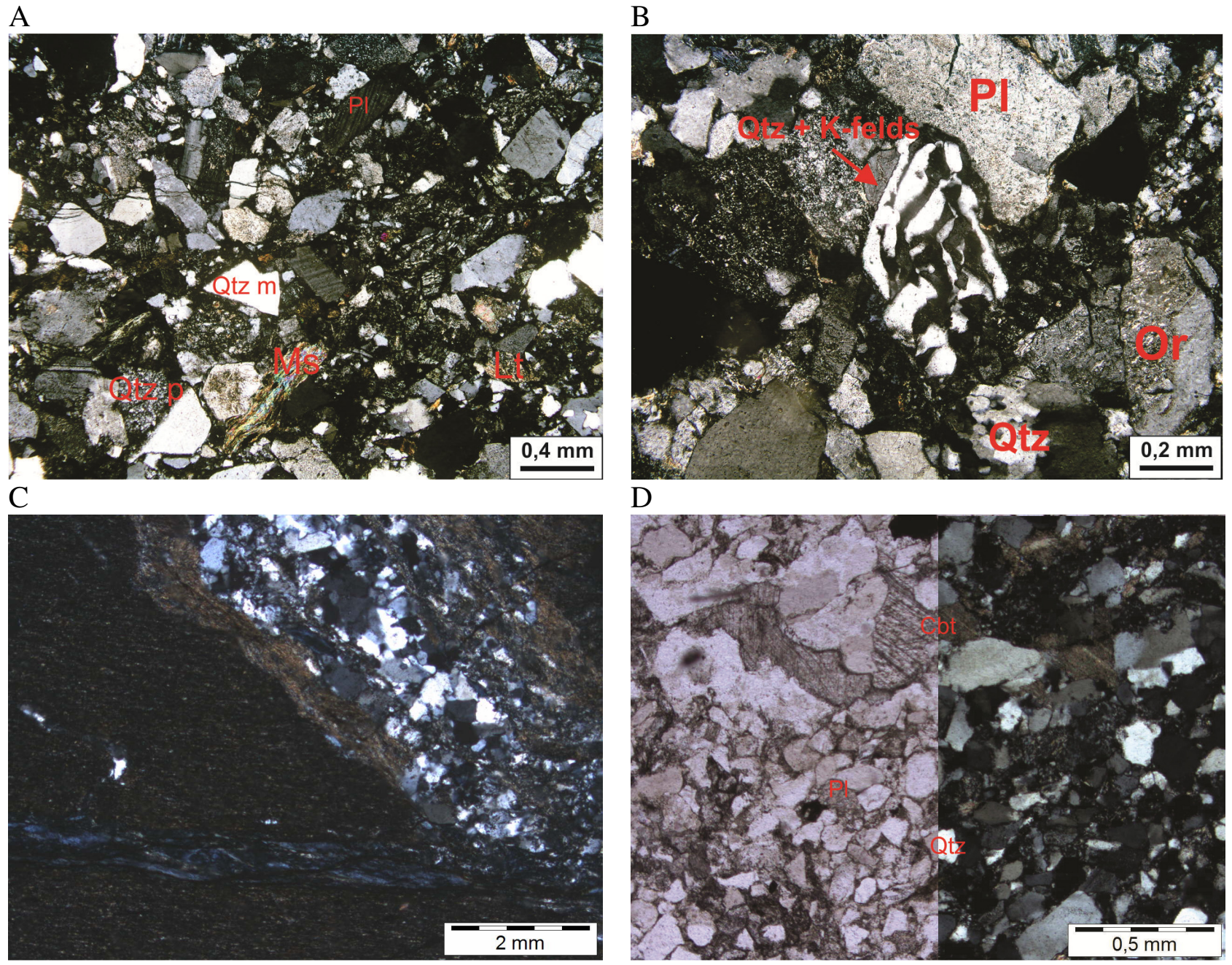

$\mathbf{E}$

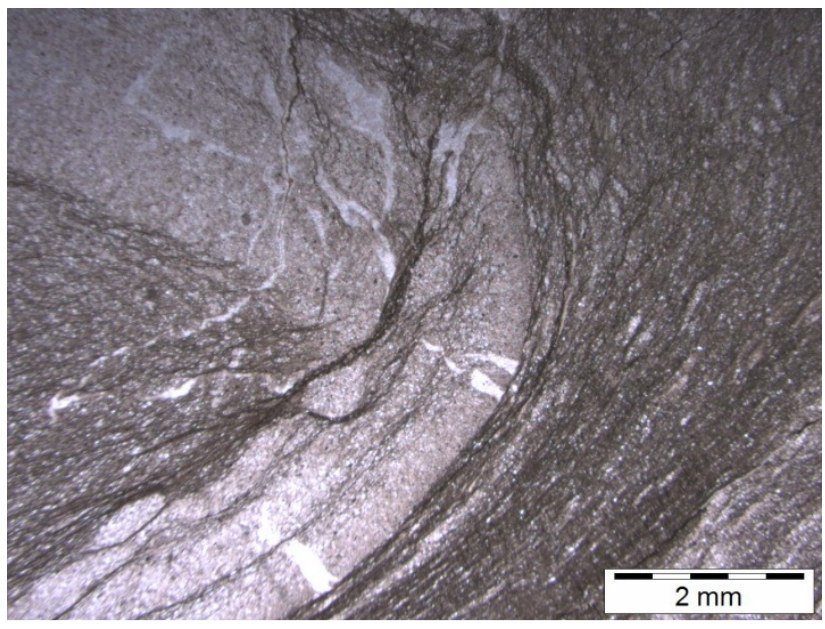

A. Formação Hope Bay -HB-2-9 - cristais de quartzo monocristalino (Qtz m) e policristalino (Qtz p), deformação na muscovita (Ms), presença de líticos (Lt) e feldspatos (Pl). B. Arcósio da Formação Hope Bay com presença de textura gráfica como lítico ( Qtzo + K-felds), feldspatos (Pl e Or) e quartzo com feição de deformação (Qtz).C. Ardósia da Formação Hope Bay com lâminas quartzofeldspáticas cortando a estrutura da rocha muito fina. D. Arcósio do TPG em Botany Bay, com carbonato (Cbt) tardio, quartzo monocristalino (Qtz) e plagioclásio (Pl). E. Ardósia do TPG em Botany Bay com pelo menos uma direção de foliação bem marcada. 
Figura 6. Fotomicrografias das formações Gruvaca-Folhelho e Miers Bluff.

A

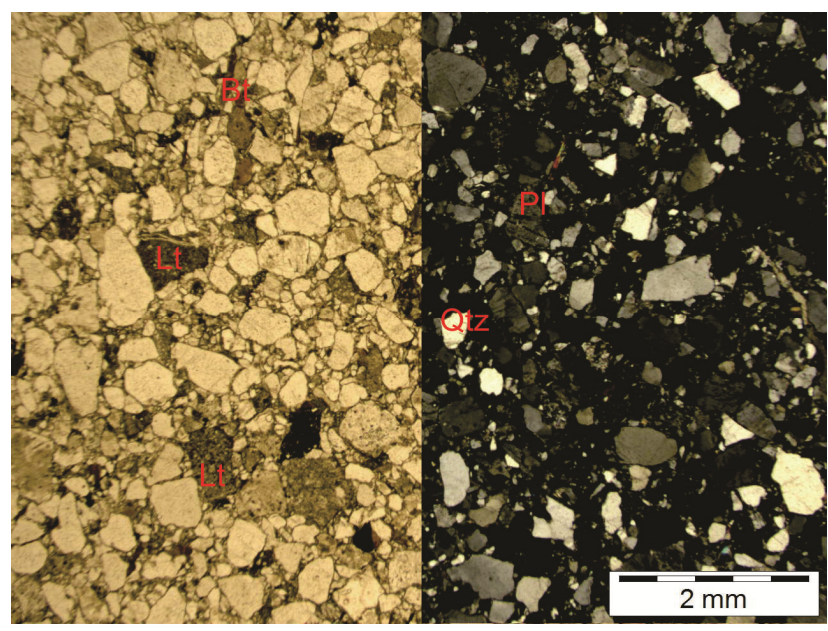

B

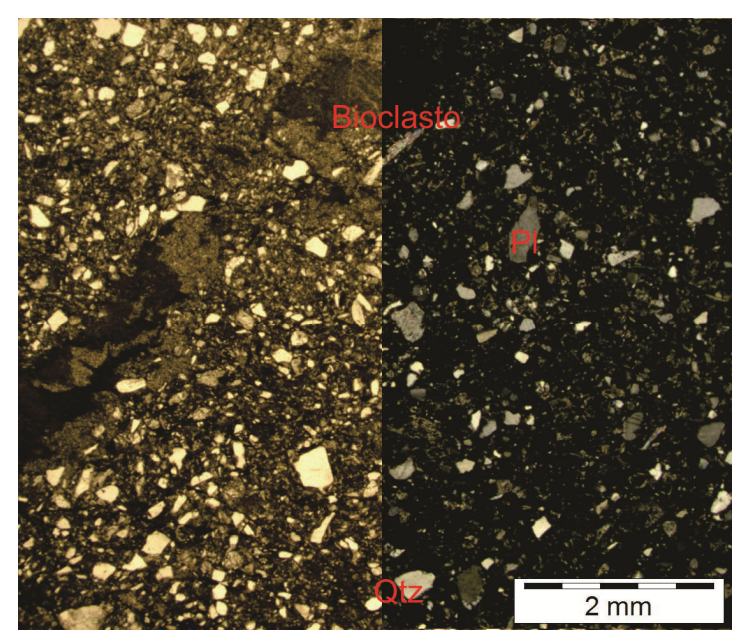

$\mathrm{C}$

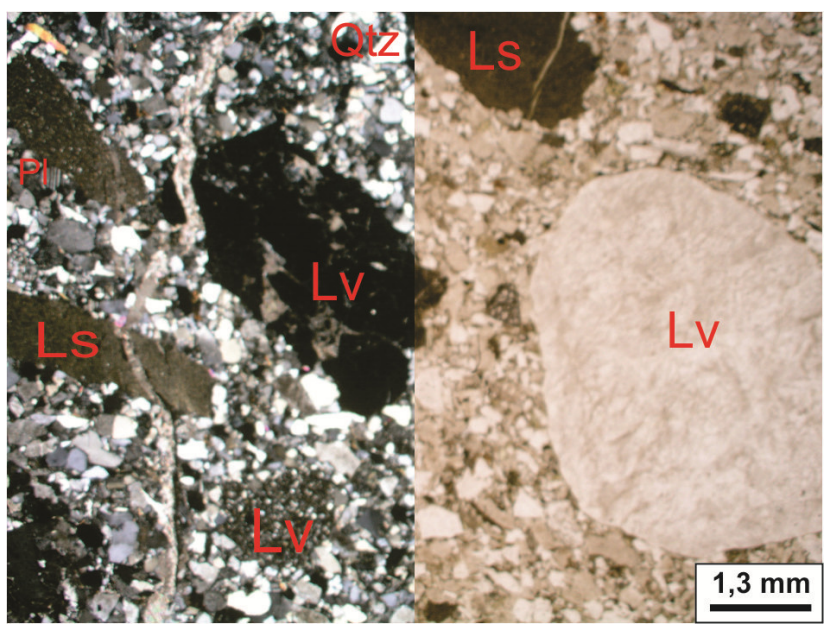

A. Arcósio da Formação Grauvaca-Folhelho com fragmentos líticos (Lt), quartzo (Qtz) e feldspato (Pl). B. Arósio da Formação Grauvaca-Folhelho com bioclasto. C. Arenito lítico da Formação Miers Bluff, evidenciando os líticos (Ls - sedimentar, Lv - vulcânico) e a matriz com quartzo (Qtz) e feldspato $(\mathrm{Pl})$. 


\section{CAPÍTULO V GEOQUÍMICA}

\section{Introdução}

A análise geoquímica de rochas sedimentares é ferramenta importante em estudos de proveniência, uma vez que a composição química da rocha reflete a natureza e proporção dos componentes detríticos gerados a partir das rochas fonte, e estas características estão ligadas ao ambiente tectônico do qual procedem (Roser \& Korsch, 1986). No entanto, há outros fatores que influenciam a natureza geoquímica da rocha, que devem ser considerados, como derivação a partir de diferentes fontes, tipo e intensidade do intemperismo físico e químico na área fonte, seleção durante transporte e diagênese (Bhatia, 1983; Nesbitt \& Young, 1984). Estes processos geológicos podem modificar a concentração de elementos químicos no sedimento em relação à rocha original, o que faz com que a composição química do sedimento ou da rocha sedimentar possa não representar a composição química original da rocha-fonte (McLennan et al., 1990).

Os elementos maiores têm alta suscetibilidade química e o uso destes, que têm sua concentração fortemente alterada por processos intempéricos, não é totalmente confiável em estudos de proveniência, sendo utilizado para a classificação de rochas e para identificar o índice de alteração química (CIA) a que estas foram submetidas. Por mais que não sejam os elementos mais importantes para a análise de proveniência, de um modo geral, pode-se discriminar as características da origem do sedimento, devendo sempre ser utilizados com precaução (Roser, 2000) e também complementados pelo uso dos elementos traço.

A geoquímica dos elementos traço em rochas sedimentares tem sido utilizada em estudos para estimar a composição da crosta continental superior, conhecer os processos responsáveis por sua diferenciação e inferir ambientes tectônicos de deposição de sedimentos (Taylor \& McLennan, 1985). O uso de elementos terras raras junto com Th e Sc é mais indicado, pois estes dois elementos não tendem a se concentrar em minerais pesados e não sofrem processo de fracionamento como ocorre com $\mathrm{Zr}$ e Hf (Bhatia, 1985; Bhatia \& Crook, 1986; McLennan, 2001; McLennan \& Taylor, 1991; McLennan et al., 1990; Taylor \& McLennan, 1985, 1995). Assim, enquanto os elementos maiores e 
menores refletem as proporções de quartzo e feldspato e grau de intemperismo, elementos traço de comportamento imóvel podem manter a assinatura geoquímica das rochas de origem.

No estudo de proveniência de rochas metassedimentares de baixo grau metamórfico feito com a geoquímica de rochas total, a amostra de rocha é considerada como um todo, incluindo cimento, matriz, clastos e litoclastos e assumindo que o metamorfismo foi isoquímico. Desta maneira, mesmo rochas que perderam suas características petrográficas, como algumas ardósias, filitos e meta-arenitos, ainda é feita a tentativa de interpretação do regime tectônico da deposição (Haughton et al., 1991). Assim o uso deste tipo de análise permite aplicar o método com êxito em rochas com metamorfismo em fácies xisto verde ao limite da fácies anfibolito (Roser \& Korsch, 1986; 1988).

Levando em consideração todas as adversidades, diversos autores discutem os dados geoquímicos a partir de gráficos binários, ternários e de funções discriminantes para a inferência do ambiente tectônico e das possíveis áreas fonte. No entanto diferentes quadros tectônicos não necessariamente geram rochas com a mesma assinatura geoquímica (McLennan et al., 1990). Assim, o maior limitante deste tipo de análise se deve ao fato de que a maior parte dos diagramas de discriminação geoquímica utilizados são construídos com base em conjunto de dados com representatividade predominantemente local (McLennan et al., 1990) e com base em tamanhos de grão, separando diagramas classificatórios por granulometria (Roser \& Korsch, 1986, 1988; Bathia, 1983). Assim sendo, os dados interpretados devem ser interpolados e complementados com diversas ferramentas analíticas em conjunto para a conclusão com a menor margem de erro possível.

\section{Elementos maiores e menores}

A análise das concentrações dos elementos maiores e menores não mostra diferenças significativas entre as amostras. As concentrações de $\mathrm{SiO}_{2}$ e $\mathrm{CaO}$ são moderadas, entre 59,51 e $78,54 \%$ e entre 0,34 e 2,49\%, as de $\mathrm{Na}_{2} \mathrm{O}$ e $\mathrm{Al}_{2} \mathrm{O}_{3}$ são intermediárias a altas, entre 1,70 e 4,78\% e entre 12,04 e 18,39\% e as de $\mathrm{Fe}_{2} \mathrm{O}_{3}, \mathrm{~K}_{2} \mathrm{O}$ e $\mathrm{MgO}$ estão, respectivamente entre 2,29 e 7,20\%, entre 1,76 e 4,0\% e 0,73 e 2,75\% (Tabela 5). Nas amostras as concentrações de $\mathrm{Na}_{2} \mathrm{O}$ e $\mathrm{CaO}$ aumentam junto à proporção de plagioclásio, fato este constatado pela petrografia. Analogamente, a alta quantidade de $\mathrm{Al}_{2} \mathrm{O}_{3}$ e $\mathrm{K}_{2} \mathrm{O}$ está relacionada com o aumento de feldspato potássico. Óxidos como 
$\mathrm{MgO}, \mathrm{Fe}_{2} \mathrm{O}_{3} \mathrm{Al}_{2} \mathrm{O}_{3}$ e $\mathrm{K}_{2} \mathrm{O}$ se relacionam com o aumento da proporção de filossilicatos, como muscovita, biotita e clorita. Valores altos de $\mathrm{Fe}_{2} \mathrm{O}_{3}$ também ocorrem para amostras com uma quantidade maior de fragmentos líticos vulcânicos, como para PMI-7 (Fm. Legoupil), HB-MC-8-6 (Fm. Hope Bay) e BBR-87-7 (TPG em Botany Bay). A única amostra que se apresenta diferente a esses padrões é a BBR-D-8A (TPG em Botany Bay), com maior quantidade de $\mathrm{SiO}_{2}$ e menor quantidade de $\mathrm{K}_{2} \mathrm{O}$, indicando maior proporção de quartzo e menor de feldspato.

Tabela 5. Resultados obtidos para elementos maiores e menores por FRX. Os valores estão em \%de peso.

\begin{tabular}{ccccccccccc}
\hline & $\mathrm{SiO}_{2}$ & $\mathrm{TiO}_{2}$ & $\mathrm{Al}_{2} \mathrm{O}_{3}$ & $\mathrm{Fe}_{2} \mathrm{O}_{3}$ & $\mathrm{MnO}$ & $\mathrm{MgO}$ & $\mathrm{CaO}$ & $\mathrm{Na}_{2} \mathrm{O}$ & $\mathrm{K}_{2} \mathrm{O}$ & $\mathrm{P}_{2} \mathrm{O}_{5}$ \\
\hline HB-2-9 & 61,03 & 0,636 & 13,20 & 3,81 & 0,170 & 1,60 & 6,98 & 3,90 & 1,9 & 0,117 \\
HB-94-87-2 & 68,67 & 0,531 & 15,25 & 3,40 & 0,053 & 1,48 & 2,42 & 4,09 & 2,66 & 0,113 \\
HB-MC-8-6 & 61,39 & 0,816 & 17,82 & 6,72 & 0,125 & 2,48 & 0,34 & 1,70 & 3,81 & 0,159 \\
KOP-4-I & 73,46 & 0,330 & 12,04 & 2,29 & 0,087 & 0,70 & 1,95 & 4,78 & 1,76 & 0,099 \\
PMI-7 & 59,51 & 0,852 & 17,10 & 6,40 & 0,088 & 2,75 & 2,23 & 2,53 & 4 & 0,205 \\
GA-2 & 77,77 & 0,204 & 11,43 & 1,35 & 0,022 & 0,73 & 0,42 & 3,20 & 2,38 & 0,034 \\
IL-P-1 & 71,76 & 0,420 & 13,39 & 2,75 & 0,053 & 1,06 & 1,90 & 3,69 & 2,54 & 0,112 \\
IL-4-3 & 70,92 & 0,478 & 13,71 & 3,03 & 0,040 & 1,10 & 1,89 & 3,51 & 2,6 & 0,144 \\
LV-RFS-21 & 69,74 & 0,642 & 13,18 & 4,69 & 0,070 & 1,78 & 0,42 & 2,56 & 3,29 & 0,156 \\
L-2-1 & 68,08 & 0,603 & 14,39 & 4,07 & 0,053 & 1,68 & 1,95 & 3,15 & 2,86 & 0,148 \\
L-4a-2 & 69,37 & 0,580 & 13,05 & 3,88 & 0,052 & 1,49 & 2,49 & 3,26 & 2,3 & 0,145 \\
BBR-87-7 & 59,45 & 0,861 & 18,39 & 7,92 & 0,085 & 2,67 & 0,27 & 1,73 & 3,55 & 0,179 \\
BBR-23-2 & 68,26 & 0,725 & 14,59 & 4,70 & 0,111 & 1,93 & 0,20 & 1,97 & 3,14 & 0,144 \\
BBR-19-1 & 62,64 & 0,801 & 16,34 & 6,66 & 0,090 & 2,40 & 0,95 & 2,09 & 3,5 & 0,229 \\
BBR-19-3 & 65,06 & 0,754 & 14,65 & 7,20 & 0,097 & 2,15 & 0,73 & 1,86 & 2,79 & 0,475 \\
BBR-D-8A & 78,54 & 0,418 & 7,15 & 2,63 & 0,094 & 1,05 & 2,26 & 2,92 & 0,43 & 0,074 \\
\hline
\end{tabular}

Os elementos maiores e menores foram plotados em diagramas de Harker (Figura 7) que, de um modo geral, demonstram que a correlação entre $\mathrm{SiO}_{2}$ e $\mathrm{TiO}_{2}$, $\mathrm{Al}_{2} \mathrm{O}_{3}, \mathrm{Fe}_{2} \mathrm{O}_{3}, \mathrm{MgO}, \mathrm{K}_{2} \mathrm{O}$ e $\mathrm{P}_{2} \mathrm{O}_{5}$ é negativa, e entre $\mathrm{SiO}_{2}$ e $\mathrm{CaO}$ e $\mathrm{Na}_{2} \mathrm{O}$ é positiva. Os processos de erosão, intemperismo, transporte e deposição de sedimentos podem ter sido responsáveis pela correlação negativa entre $\mathrm{SiO}_{2}$ e os demais elementos químicos, pois argilominerais, ricos em $\mathrm{Al}_{2} \mathrm{O}_{3}, \mathrm{Fe}_{2} \mathrm{O}_{3}, \mathrm{MgO}, \mathrm{K}_{2} \mathrm{O}$, tendem a se concentrar na 
fração silte/argila do sedimento, diferentemente de quartzo e feldspato que tendem a se concentrar em frações arenosas, resultando na diminuição de Si e $\mathrm{Na}$ fração silte/argila (Taylor \& McLennan, 1985). Assim sendo, pode-se inferir, que as amostras enriquecidas em $\mathrm{Al}_{2} \mathrm{O}_{3}, \mathrm{Fe}_{2} \mathrm{O}_{3}, \mathrm{MgO}, \mathrm{K}_{2} \mathrm{O}$, principalmente as amostras BBR-19-3, BBR-87-7 (TPG em Botany Bay), HB-MC-8-6 (Formação Hope Bay) e PMI-7 (Formação Legoupil) apresentam maior proporção de argilominerais, por estarem em depósitos de domínios mais distantes da área fonte, ou por terem sido depositadas em período tectonicamente mais estável. Analogamente as amostras enriquecidas em $\mathrm{SiO}_{2}$, $\mathrm{P}_{2} \mathrm{O}_{5}$ e CaO, principalmente as amostras GA-2, IL-P-1 (Formação Legoupil), KOP-4-I (View Point), HB-2-9 (Hope Bay), BBR-D-8A (TPG em Botany Bay), L-4a-2 (Formação Grauvaca-Folhelho) resultam de depósitos de granulação mais grossa, mais próximas à área-fonte, ou depositadas em períodos tectonicamente mais ativos. 

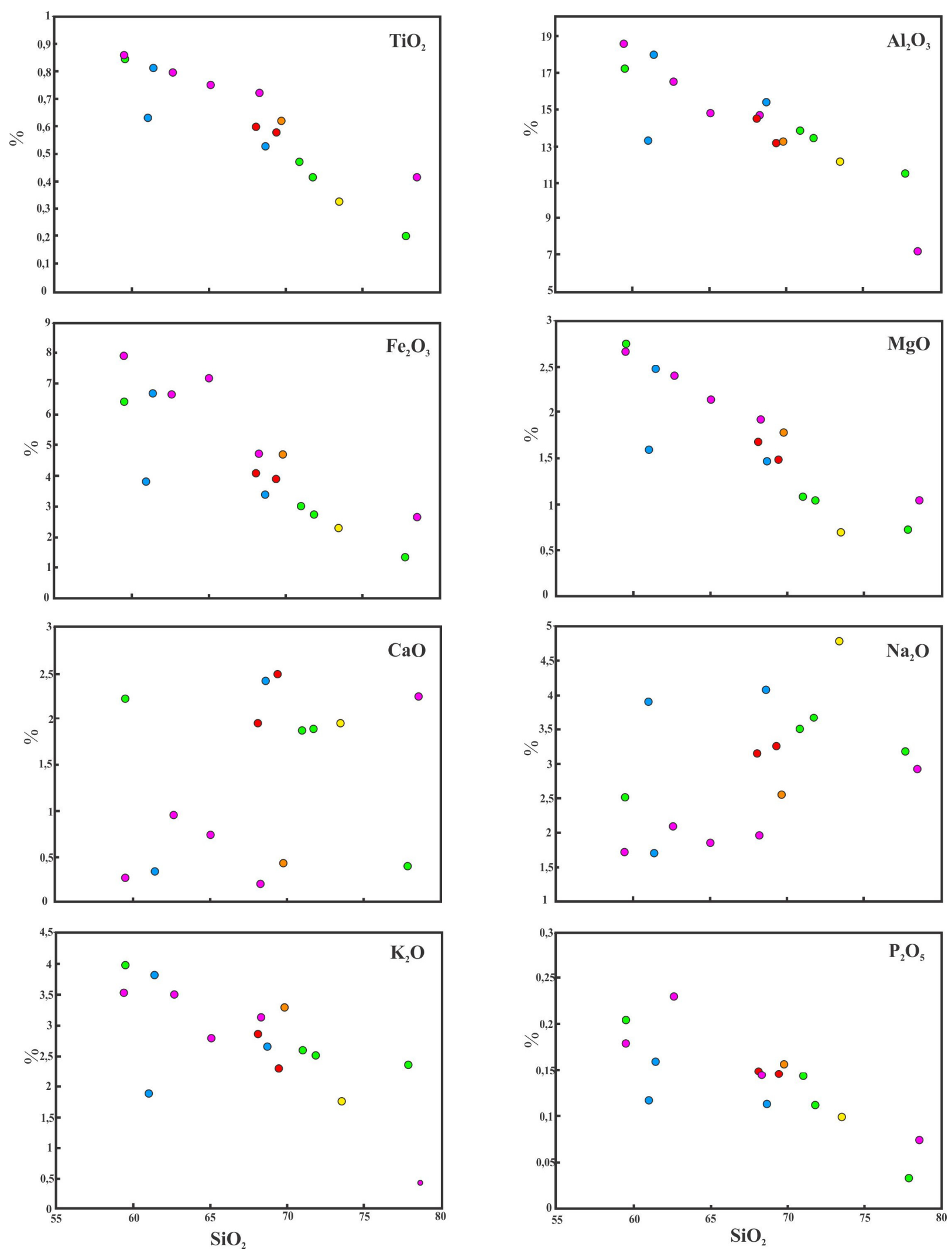

Figura 7. Diagramas de Harker de dispersão binária correlacionando $\mathrm{SiO}_{2}$ vs elementos maiores e menores analisados por FRX. Em laranja Fm. Miers Bluff, em vermelho Fm. Grauvaca-Folhelho, em rosa TPG em Botany Bay, em amarelo Fm. View Point e em verde Fm. Legoupil. 


\subsection{Classificação}

Em rochas sedimentares arenosas o que define os limites composicionais para sua classificação é a variedade composicional de matriz e fragmentos líticos, juntamente com as diferentes abundâncias destes e de feldspatos detríticos. Assim sendo não podem ser obtidos por nenhum esquema de classificação química (Herron, 1988). Ainda assim, alguns autores desenvolveram diagramas classificatórios com base na composição química de arenitos.

Os diagramas classificatórios mais utilizados são os de Pettijohn et al. (1972) e Herron (1988). O diagrama de Pettijohn et al. (1972) classifica os arenitos com base nas razões $\mathrm{Na}_{2} \mathrm{O} / \mathrm{K}_{2} \mathrm{O}$ e $\mathrm{SiO}_{2} / \mathrm{Al}_{2} \mathrm{O}_{3}$, sendo que a primeira diferencia rochas ricas em plagioclásio albítico de rochas ricas em feldspato potássico e a segunda razão diferencia rochas maturas de imaturas. Em contrapartida Herron (1988) usa a razão $\mathrm{Fe}_{2} \mathrm{O}_{3} / \mathrm{K}_{2} \mathrm{O}$ que distingue rochas com altas concentrações de minerais ricos em potássio e pobres em ferro, daquelas com altas concentrações de fragmentos líticos, que são comumente ricos em minerais ferromagnesianos. Utilizando a razão $\mathrm{Na}_{2} \mathrm{O} / \mathrm{K}_{2} \mathrm{O}$ é possível diferenciar o tipo de plagioclásio, classificando as rochas em grauvaca ou arcóseo.

Para a classificação das amostras foram utilizados, além da petrografia, os gráficos de Pettijohn et al.(1972) e Herron (1988) (Figura 8A e B). Os resultados dos gráficos não foram particularmente úteis para dar nome às rochas, mas sim para avaliar relações entre composição elementar, mineralogia e tipo de rocha.
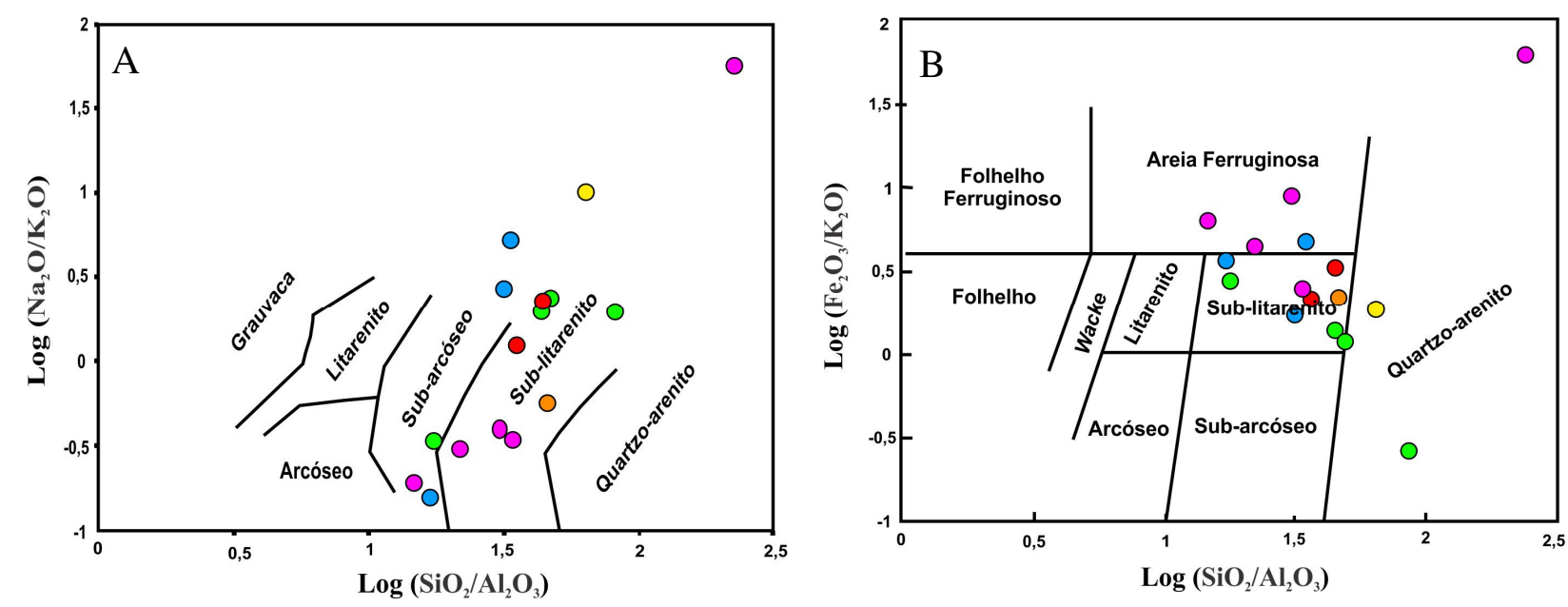

Figura 8. A. Diagrama de classificação química de arenitos de Pettijohn et al. (1972); B. Diagrama de classificação química de rochas sedimentares de Herron (1988). Em azul Fm. Hope Bay, em laranja Fm. Miers Bluff, em vermelho Fm. Grauvaca-Folhelho, em rosa TPG em Botany Bay, em amarelo Fm. View Point e em verde Fm. Legoupil. 
Em ambos os gráficos as amostras são classificadas como sendo de maturidade mineralógica alta, sub-litoarenito e quartzo-arenito, poucas sendo classificadas como sub-arcóseo, quando são petrograficamente arcóseos (Figura 8A e B). Este fato se deve à porcentagem de $\mathrm{SiO}_{2}$ que não está contida no quartzo, mas sim em feldspatos como albita, oligoclásio, andesina e microclínio que podem apresentar até $67 \%$ deste óxido em sua composição. Assim, por mais que a análise microscópica mostre que são rochas mineralogicamente imaturas, com porcentagens consideráveis de feldspato e fragmentos líticos, a classificação química diz o oposto.

\section{2. Índice de alteração química (CIA - chemical index of alteration)}

O intemperismo químico de rochas silicáticas ocasiona a perda de elementos maiores e menores, modificando a mineralogia da rocha e gerando a transformação de minerais primários em minerais secundários, mais estáveis às condições da superfície terrestre. A partir desta transformação química, são geradas rochas sedimentares mais ricas em argilominerais e óxidos e hidróxidos de ferro. A principal reação que ocorre nas rochas silicáticas é a degradação dos minerais do grupo dos feldspatos, simultaneamente com a formação dos argilominerais, por meio de reações que removem dos feldspatos elementos como $\mathrm{Ca}, \mathrm{Na}$ e $\mathrm{K}$, fazendo com que a proporção de $\mathrm{Al}$ aumente com relação aos álcalis, avançando assim o intemperismo. Partindo deste princípio Nesbitt \& Young (1982) consideram que os efeitos do intemperismo sofrido pela rocha podem ser quantificados a partir do uso do índice de alteração química (CIA), número adimensional, normalmente variando entre 50 e 100, que é utilizado como indicador de mudanças químicas na rocha total devido ao intemperismo na área fonte ou a reciclagem dos sedimentos. $\mathrm{O}$ índice de alteração química é calculado a partir das proporções moleculares dos óxidos $\mathrm{CaO}, \mathrm{Na}_{2} \mathrm{O}, \mathrm{K}_{2} \mathrm{O}, \mathrm{Al}_{2} \mathrm{O}_{3}$ e $\mathrm{CaO}$ *, este último é o $\mathrm{CaO}$ restrito aos silicatos:

$$
\mathrm{CIA}=\left[\mathrm{Al}_{2} \mathrm{O}_{3} /\left(\mathrm{Al}_{2} \mathrm{O}_{3}+\mathrm{CaO}^{*}+\mathrm{Na}_{2} \mathrm{O}+\mathrm{K}_{2} \mathrm{O}\right)\right] \times 100
$$

Altos valores de CIA, próximos de 100, refletem a remoção de cátions móveis, em relação aos cátions menos móveis, e composição rica em minerais secundários, ou seja, o intemperismo químico da área fonte ou a reciclagem dos depósitos sedimentares foi maior. Em contrapartida rochas ígneas frescas apresentam valores de CIA por volta 
de 50 ou menor e refletem intemperismo de intensidade e tempo menores. Já os folhelhos apresentam CIA entre 70 e 75 (McLennan et al.1993).

O CIA das amostras analisadas é intermediário, com valores entre 39 e 70, mas com a maior parte entre 47 e 67 (Tabela 6), sendo os valores maiores observados em rochas com alta porcentagem de argilominerais como HB-MC-8-6 (Formação. Hope Bay), BBR-87-7, BBR-23-2 e BBR-19-3(TPG em Botany Bay) e os menores em amostras ricas em quartzo e/ou plagioclásio HB-2-9 (Fm. Hope Bay), KOP-4-I (Fm. View Point) e BBR-D-8A (TPG em Botany Bay). Assim sendo, o grau de alteração química moderado, indica que o intemperismo não modificou substancialmente as propriedades químicas das rochas, justificando o uso de diagramas de discriminação geoquímica baseados em elementos maiores e menores.

Tabela 6. Valores de CIA para as amostras analisadas. CIA $=[\mathrm{Al} 2 \mathrm{O} 3 /(\mathrm{Al} 2 \mathrm{O} 3+\mathrm{CaO}+$ $\mathrm{Na} 2 \mathrm{O}+\mathrm{K} 2 \mathrm{O})] *$ 100; óxidos em proporção molecular.

\begin{tabular}{cc}
\hline AMOSTRA & CIA \\
\hline HB-2-9 & 39,21 \\
HB-94-87-2 & 51,91 \\
HB-MC-8-6 & 70,16 \\
KOP-4-I & 47,4 \\
PMI-7 & 57,6 \\
GA-2 & 57,16 \\
IL-P-1 & 52,5 \\
IL-4-3 & 53,33 \\
LV-RFS-21 & 61,51 \\
L-2-1 & 54,89 \\
L-4a-2 & 51,38 \\
BBR-87-7 & 71,82 \\
BBR-23-2 & 67,46 \\
BBR-19-1 & 64,59 \\
BBR-19-3 & 66,18 \\
BBR-D-8A & 43,26 \\
\hline
\end{tabular}

McLennan et al. (1990) sugerem outro método de avaliação da intensidade de intemperismo químico aliado a proveniência de rochas sedimentares, utilizando gráfico ternário A-CN-K $\left(\mathrm{A}=\mathrm{Al}_{2} \mathrm{O}_{3}, \mathrm{CN}=\mathrm{CaO}+\mathrm{Na}_{2} \mathrm{O}\right.$, e $\left.\mathrm{K}=\mathrm{K}_{2} \mathrm{O}\right)$ para representar as composições de elementos maiores em rochas coletadas de ambientes tectônicos ativos e passivos. Os autores compararam estas composições com a composição de minerais e de alguns tipos de rocha, como gabro e tonalito (extraídas de Nesbitt \& Young, 1984), e identificaram que amostras de margens passivas sofrem maior intemperismo químico 
(plotam próximo às composições enriquecidas em $\mathrm{Al}_{2} \mathrm{O}_{3}$ ) do que amostras de ambientes vulcanicamente ativos (plotam próximo a composições enriquecidas em $\mathrm{CaO}$ e $\mathrm{Na}_{2} \mathrm{O}$ ).

As concentrações de elementos maiores obtidas também foram plotadas no gráfico ternário A-CN-K (Figura 9). As rochas apresentaram tendência de intemperismo químico a partir de composições iniciais semelhantes, prioritariamente, à de granodioritos, e subordinadamente tonalitos (KOP-4-I) e gabros (BBR-D-8A). Como a intensidade de alteração, no diagrama, é pouco variável, os sedimentos precursores das amostras analisadas foram submetidos a condições intempéricas semelhantes.

A

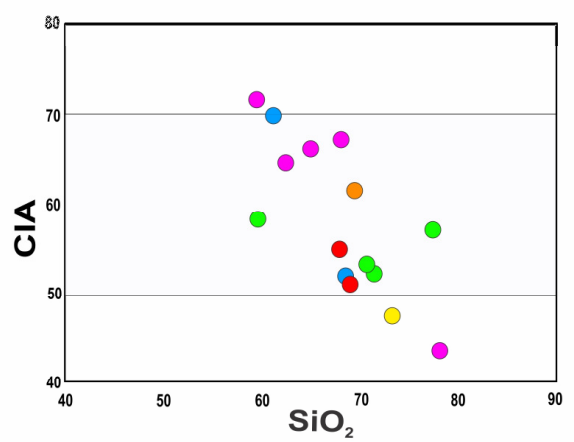

B

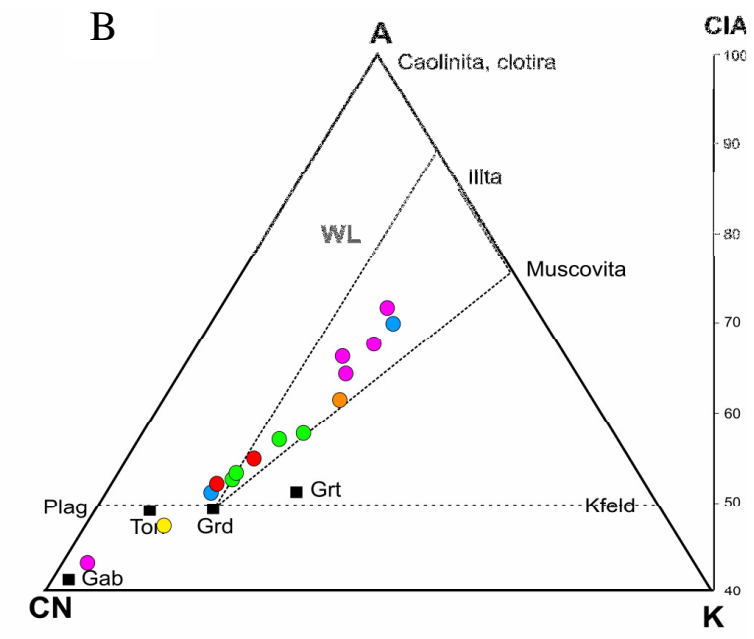

Figura 9. A. Gráfico de correlação CIA vs $\mathrm{SiO}_{2}$; B. Diagrama da evolução de alteração A-CN-K, extraído e modificado de McLennan et al. (1990). Em azul Fm. Hope Bay, em laranja Fm. Miers Bluff, em vermelho Fm. Grauvaca-Folhelho, em rosa TPG em Botany Bay, em amarelo Fm. View Point e em verde Fm. Legoupil.

\section{Elementos traço}

Os resultados das análises de elementos traço por fluorescência de raios X e ICPMS são apresentados nos Anexos I e II e foram aplicados inicialmente no estudo de caracterização geoquímica.

Os elementos traço foram normalizados pela composição da crosta superior de Taylor \& McLennan (1995) e plotados em diagramas multielementares (spidergram) para as diferentes formações (Figura 10). Nos diagramas multielementares as amostras do TPG são caracterizadas por padrão levemente côncavo, com valores próximos à média da crosta continental, mas com anomalias negativas, expressivas ou não, de Rb e anomalias negativas ou positivas de $\mathrm{Sr}$; os elementos terras raras médios e pesados e Y são algo mais enriquecidos do que a média da crosta, enquanto $\mathrm{Hf}$ e $\mathrm{Zr}$ são empobrecidos em relação a ela. 
A anomalia de Sr se dá como positiva para as amostras HB-94-87-2 (Formação Hope Bay), IL-4-3 e IL-p-1 (Formação Legoupil) e L-4A-2 (Formação GrauvacaFolhelho), que petrograficamente apresentam uma maior proporção de plagioclásio sobre os feldspatos alcalinos, sendo em muitas vezes saussuritizado. Já as amostras com uma maior proporção de feldspato alcalino apresentam uma clara anomalia de $\mathrm{Sr}$ negativa, e ocorre para todas as amostras do TPG em Botany Bay, para a amostra HBMC-8-6 (Formação Hope Bay), GA-2 (Formação Legoupil) e LV-RFS-21 (Formação Miers Bluff).

As amostras HB-94-87-2, Formação Hope Bay, e KOP-4-I, Formação View Point, fogem ao padrão das outras do TPG, sendo levemente empobrecidas em terras raras médios e Y em relação às outras amostras, mas apresentam valores próximos aos da crosta continental. As amostras GA-2, Formação Legoupil, e BBR-D-8A, TPG em Botany Bay, também apresentam padrão diferente ao das outras amostras, sendo que a somatória total de ETR é menos da metade da somatória de cada uma das amostras analisadas. A amostra GA-2 se mostra empobrecida em todos ETR analisados, e a amostra BBR-D-8A se diferencia com sensível perda de Rb e Ba. A amostra BBR-19-3 é a mais enriquecida em todos os elementos traço analisados.

Os elementos alcalinos e alcalinos terrosos, devido ao tamanho do seu raio iônico, são solubilizados durante o intemperismo. O mesmo não ocorre com Rb, Cs e $\mathrm{Ba}$, que apresentam raio iônico maior sendo então retidos nos argilominerais, apresentando comportamento imóvel durante o processo intempérico (Taylor \& McLennan, 1985). Assim sendo, as amostras de granulação mais grossa apresentam anomalia negativa de $\mathrm{Cs}$, empobrecimento em $\mathrm{Rb}$ e leve enriquecimento em $\mathrm{Sr}$, o oposto ocorre nas amostras de granulação fina. Diagramas de $\mathrm{Al}_{2} \mathrm{O}_{3}$ vs. $\mathrm{Rb}$, Cs e $\mathrm{Ba}$ (Figura 11) evidenciam a correlação positiva para $\mathrm{Rb}$ e Cs, confirmando a tendência de sua concentração em argilominerais, e explicando a anomalia negativa de Cs nas amostras de granulação areia. Somente o $\mathrm{Ba}$ não apresentou correlação definida. Petrograficamente as amostras com maior proporção de minerais micáceos, BBR-87-7, BBR-19-1 (TPG em Botany Bay), HB-MC-8-6 (Formação Hope Bay) e PMI-7 (Formação Legoupil) confirmam a correlação. 


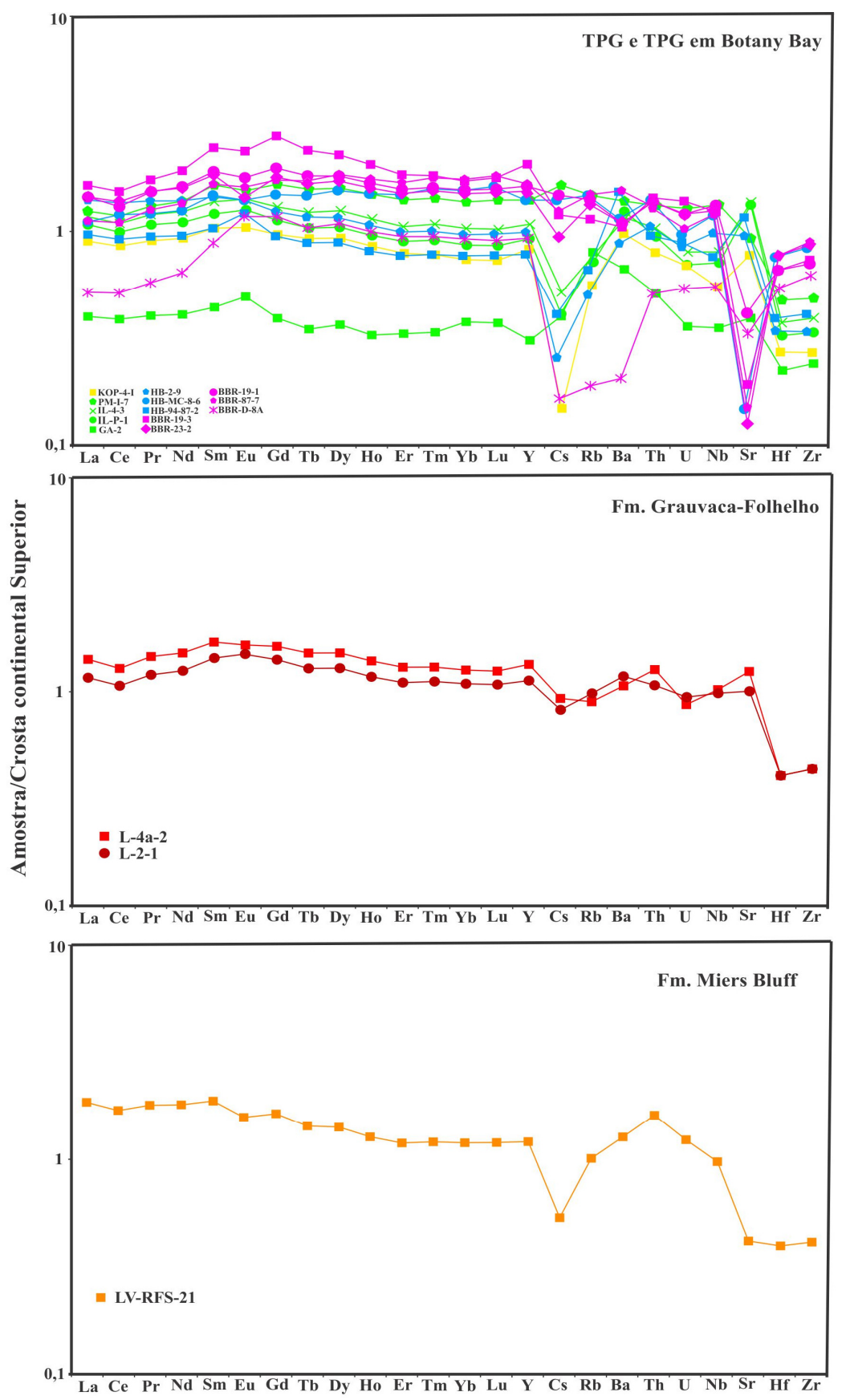

Figura 10. Diagrama multielementar de elementos traço normalizados segundo valores para a crosta continental superior de Taylor e McLennan (1995). Em azul Fm. Hope Bay, em laranja Fm. Miers Bluff, em vermelho Fm. Grauvaca-Folhelho, em rosa TPG em Botany Bay, em amarelo Fm. View Point e em verde Fm. Legoupil.

\section{Elementos Terras Raras (ETR)}

Rochas sedimentares de idade pós-arqueana se diferenciam dos sedimentos de idade arqueana principalmente pelos padrões de ETR (Bhatia, 1985; McLennan \& Taylor, 1991; McLennan et al., 1990). Pelitos do pós-Arqueano apresentam enriquecimento em ETRL, padrão condrito-normalizado plano e constante de ETRP e empobrecimento significativo de $\mathrm{Eu}$, com anomalia $\left(\mathrm{Eu} / \mathrm{Eu}^{*}\right)$ variável entre 0,60 e 0,70, com média de 
0,65 (McLennan et al., 1990). A presença recorrente de anomalias negativas de Eu na maioria dos sedimentos pós-arqueanos indicam que processos intracrosta dominam a diferenciação da crosta continental, diferentemente do ocorrido durante o Arqueano, pois valores semelhantes são escassos em análises químicas de sedimentos desta idade (McLennan et al., 1990).

O padrão dos elementos terras raras normalizados ao condrito (Figura 11) é do tipo "gaivota" com enriquecimento de terras raras leves com valores entre 100 e 300 vezes o do condrito para La até 50 a 100 vezes o condrito para Sm, anomalia negativa de Eu e padrão plano para os terras raras médios e pesados. O padrão é observado para as rochas do TPG, da Formação Grauvaca-Folhelho e Formação Miers Bluff, indicando idade pós-arqueana. Já os valores das anomalias de Eu contradizem o esperado, variando entre 0,95 e 1,03 para as rochas finas e arenosas respectivamente, indicando somente que os processos de diferenciação na crosta, relacionadas com cristalização fracionada de plagioclásio, não foram tão importantes na proveniência dos sedimentos fonte, fato este também constatado nos diagramas multielementares (Figura 10) que apresentam anomalia de Sr.
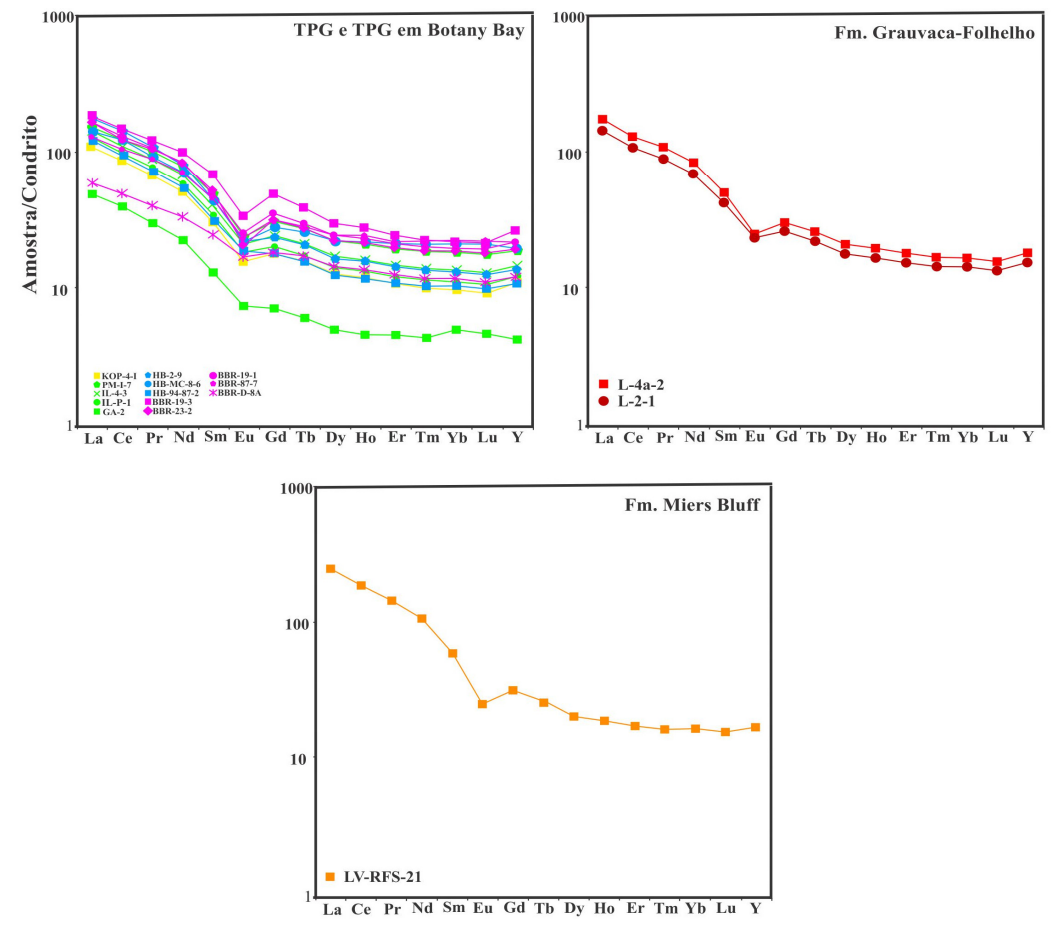

Figura 11. Diagrama de elementos terras raras condrito-normalizados segundo os valores condríticos de Taylor \& McLennan (1985). Em azul Fm. Hope Bay, em laranja Fm. Miers Bluff, em vermelho Fm. Grauvaca-Folhelho, em rosa TPG em Botany Bay, em amarelo Fm. View Point e em verde Fm. Legoupil. 


\section{CAPÍTULO VI GEOQUÍMICA ISOTÓPICA}

\section{Introdução}

A geoquímica isotópica pode fornecer, através de suas análises, além de idades, informações sobre as condições de formação da rocha estudada, seja usando dados isotópicos em rocha total ou em mineral.

A utilização de diversos sistemas isotópicos de maneira combinada é importante ferramenta para a identificação e caracterização da área fonte que gerou sedimentos, rochas sedimentares e metassedimentares. Neste caso, é possível identificar o tipo de rocha que atuou como fonte, seja juvenil, com diferentes tempos de residência crustal ou é produto de reciclagem sedimentar, permitindo a identificação geral do ambiente de deposição e do contexto geotectônico da época de sedimentação.

\section{Dados geocronológicos disponíveis do Grupo Península Trinity}

A idade de deposição do Grupo Península Trinity é definida como Triássica pelo raro conteúdo fossilífero de bivalves contidos na Formação Legoupil (Thomson, 1975), e pelas radiolárias contidas nos cherts pelágicos da Formação Grauvaca-Folhelho (Dalziel et al., 1984). Estes fósseis são evidências que restringem a idade de sedimentação do Grupo Península Trinity até recentemente, antes da disposição das diversas datações realizadas nas rochas por diversos métodos.

Para o Grupo Península Trinity, inúmeras isócronas Rb-Sr estão disponíveis. As isócronas de rocha total realizadas com amostras de lamitos da Formação Hope Bay datam de $281 \pm 16$ Ma, e são interpretadas como idade da diagênese (Pankhurst, 1983). Isócronas feitas a partir das rochas metassedimentares nas Ilhas Powell datam de $243 \pm$ 14 Ma e são consideradas como a idade de sedimentação da Formação GrauvacaFolhelho (Trouw et al., 1997b). Na Formação Miers Bluff as idades são determinadas pela errócrona $\mathrm{Rb}-\mathrm{Sr}$ de $243 \pm 8 \mathrm{Ma}$, e são interpretadas como diagênese (Willan et al., 2003). Em todas as rochas do Grupo Península Trinity e unidades correlacionadas os cristais de biotita detríticos são abundantes e a partir dessa observação, Smellie (1981) sugere que a interpretação das idades $\mathrm{Rb}-\mathrm{Sr}$ deve ser cautelosa, pois dados incoerentes podem ser gerados pela presença de grãos que não tiveram re-homogeneização isotópica 
total durante a diagênese. Outros autores consideram a possibilidade dessas idades serem referentes ao metamorfismo de baixo grau ocorrido na região (Hervé et al., 2006; Willan et al., 2003).

Os melhores dados que restringem a idade de deposição do Grupo Península Trinity e unidades correlacionadas provêm dos grãos detríticos de zircão. Os estudos de proveniência apontam para duas populações de grãos dos metarenitos das Ilhas Gandara, Formação Legoupil e Formação Miers Bluff. A primeira população é formada por cristais limpos, claros e euedrais, e a segunda população por cristais avermelhados e arredondados. Os cristais euedrais das duas formações são discordantes e estão entre 350 e 412 Ma (Miers Bluff) e entre 420 e 461 Ma (Legoupil), ambas as idades ${ }^{206} \mathrm{~Pb} /{ }^{238} \mathrm{U}$. A idade mais jovem é a mesma para as duas localidades em $322 \mathrm{Ma}$, já a idade mais antiga da Formação Legoupil data de 1157 Ma (Loske et al., 1988). Os cristais arredondados são muito discordantes e têm idades ${ }^{206} \mathrm{~Pb} /{ }^{238} \mathrm{U}$ entre 676 e 872 Ma, e as idades mais jovens e antigas são respectivamente, 560 e $2000 \mathrm{Ma}$ (Loske et al., 1988). A idade de 322 Ma é interpretada como a idade da rocha granítica que serviu de fonte para as unidades, sendo que também são constatadas idades Pré-Cambrianas para a fonte (Loske et al., 1988; Hervé et al., 2006).

Zircões de seixos de granitóides, provenientes dos conglomerados da Formação View Point, foram analisados com SHRIMP, resultando em idades ${ }^{206} \mathrm{~Pb} /{ }^{238} \mathrm{U}$ de $463 \pm$ 5 Ma. Em uma das amostras os resultados geraram um bom intercepto superior de 3161 \pm 13 Ma (Millar et al., 2002).

Os dados mais recentes de datações U-Pb em zircões detríticos, das formações Hope Bay e Legoupil, apresentam populações predominantes entre 240 e 320 Ma, fim do Paleozóico (Barbeau, et al., 2010) e da Formação Legoupil, idades de deposição de $302 \pm 3$ Ma, logo após o início o início do Crabonífero, e clastos com idades de 373 a $487 \mathrm{Ma}$, e $\varepsilon H f$ entre +0,3 e +7,6. (Bradshaw, et al., 2012).

Para o Grupo Península Trinity e Formação Miers Bluff, poucos dados Sm-Nd estão disponíveis. As idades $\mathrm{T}_{\mathrm{DM}}$ variam entre 1120 e $1490 \mathrm{Ma}$ com $\varepsilon_{\mathrm{Nd}}$ entre -3,3 e -5,8 indicando contribuição crustal de rochas Pré-Cambrianas (Adams et al., 2005).

A partir dos dados isotópicos disponíveis é possível concluir que as rochas do Grupo Península Trinity, da Formação Grauvaca-Folhelho e metamórficas associadas 
possuem idades das áreas fontes correlacionadas. A idade de deposição do Grupo Península Trinity é definida entre 243 a 213 Ma respectivamente pelo grão detrítico mais novo e a idade de metamorfismo na Ilha Powell. Entretanto as rochas da Formação Miers Bluff são mais novas, as idades em zircões detríticos evidenciam que sua deposição ocorreu após o metamorfismo Triássico (Hervé et al., 2006).

O Complexo Metamórfico de Scotia e suas variações metamórfica de menor ao mais alto grau de metamorfismo tem estudos em rochas metassedimentares que restingem a idade do Jurássico a o Pré-Cambrino, com a população mais nova de 200 290 Ma (Valadares, 2012).

\section{Geoquímica Isotópica de Rocha Total}

As análises de geoquímica isotópica em rocha total foram realizadas através do sistema Samário-Neodímio ( $\mathrm{Sm}-\mathrm{Nd}$ ), o qual além de amplamente utilizado e descrito na literatura, é o que oferece resultados interessantes no que diz respeito à identificação de proveniência sedimentar, a partir das idades modelo $(\mathrm{Sm}-\mathrm{Nd})$ é possível ter ideia da idade média da fonte. Para isto, foram analisadas cinco amostras, relacionadas na Tabela 7.

Tabela 7.Relação das amostras analisadas para Sm-Nd.

\begin{tabular}{ll}
\hline Fm. Legoupil & PMI-7 \\
GPT em Botany Bay & BBR-19-1, BBR-19-3, BBR-23-2, BBR- \\
& $87-7$ \\
\hline
\end{tabular}

\subsection{Sistema Samário - Neodímio (Sm-Nd)}

Diversos estudos (McLennan et al., 1990; Bahlburg et al., 2009) demostram que o sistema isotópico $\mathrm{Sm}-\mathrm{Nd}$, em rochas sedimentares, resulta em informações úteis da área-fonte dos sedimentos, já que grande fracionamento $\mathrm{Sm} / \mathrm{Nd}$ só é observado durante a formação da crosta por fusão parcial do manto, pois passados os estágios crustais a razão é relativamente resistente ao intemperismo e diagênese. Informação esta confirmada por White (2009), que demonstra que a razão da maioria das rochas crustais é uniforme e ao redor de 0,13 .

Devido ao fato de que $\mathrm{Nd}$ é mais incompatível com o manto do que $\mathrm{Sm}$, e que ${ }^{147} \mathrm{Sm}$ se transforma em ${ }^{143} \mathrm{Nd}$, a razão ${ }^{143} \mathrm{Nd} /{ }^{144} \mathrm{Nd}$ cresce mais rapidamente no manto do que na crosta. Rochas derivadas do manto tem razão ${ }^{143} \mathrm{Nd} /{ }^{144} \mathrm{Nd}$ inicial mais alta que as rochas crustais. 
$\mathrm{O} \varepsilon \mathrm{Nd}$ é a comparação entre a razão ${ }^{143} \mathrm{Nd} /{ }^{144} \mathrm{Nd}$ medida de certa amostra com a razão ${ }^{143} \mathrm{Nd} /{ }^{144} \mathrm{Nd}$ CHUR (Chondrite Uniform Reservoir). Com o tempo, o manto empobrecido evolui alcançando valor de $\varepsilon N d$ positivo, enquanto o material que se separa do manto, para ser parte da crosta continental, terá a evolução para valores mais baixos de $\varepsilon N d$. Em contrapartida, a idade modelo $\mathrm{T}_{\mathrm{DM}}$ calculada relativa ao CHUR, representa a idade em que o material crustal se separou da fonte mantélica. A partir de tais constatações a idade modelo, ou tempo de residência crustal, é método confiável de datação, pois, considerando ${ }^{143} \mathrm{Nd} /{ }^{144} \mathrm{Nd}$ e ${ }^{147} \mathrm{Sm} /{ }^{144} \mathrm{Nd}$ medidos, e assumindo que a razão ${ }^{147} \mathrm{Sm} /{ }^{144} \mathrm{Nd}$ era constante do tempo de formação, podemos estimar o tempo de residência destes elementos na crosta. Contudo, o método deve ser visto com olhar crítico quando pensamos em proveniência, pois os resultados podem variar de acordo com as diferentes áreas-fonte, e também pela influência da seleção nos sedimentos, diferenças em tamanhos de grãos e acumulação de minerais pesados (McLennan et al.,1989).

\subsection{Resultados Samário - Neodímio (Sm-Nd)}

Os dados obtidos em laboratório - razões isotópicas, idades modelo, $\varepsilon(0)$ e $\mathrm{T}_{\mathrm{DM}}$ - e recalculados para 220 Ma são apresentados de modo resumido nas Tabelas 8 e 9 e completos no Anexo III.

As razões ${ }^{147} \mathrm{Sm} /{ }^{144} \mathrm{Nd}$ para as amostras do Grupo Península Trinity em Botany Bay os valores de $\varepsilon(0)$ variam entre $-7,53$ e $-10,86$ e as idades modelo $\mathrm{T}_{\mathrm{DM}}$ variam de 1,34 a 1,63 Ga (Figura 12). Valores de $\varepsilon N d 220$ estão no intervalo $-5,48$ e $-8,58$. Já para a amostra da Fm. Legoupil o valor de $\varepsilon N d 220$ é de -5,28 e a idade modelo de 1,26 Ga.

As idades $\mathrm{T}_{\mathrm{DM}}$ se encontram no Mesoproterozóico, com uma amostra limite com idade no Paleoproterozóico, e variam de 1,63 a 1,34 Ga para as amostras do Grupo Península Trinity em Botany Bay e 1,26 Ga para a amostra da Fm. Legoupil.

Levando em consideração que idades-modelo de rochas sedimentares representam a mistura de diferentes rochas presentes na área-fonte (McCulloch \& Wasseburg, 1978), e que o sistema Sm-Nd não sofre alterações significativas durante o metamorfismo, as idades $\mathrm{T}_{\mathrm{DM}}$ obtidas majoritariamente no Mesoproterozóico podem refletir a mistura de fontes jovens de idade no Neoproterozóico e de fontes mais antigas que $1,63 \mathrm{Ga}$. 
Tabela 8. Dados isotópicos e elementais $\mathrm{Sm} / \mathrm{Nd}$ para as amostras analisadas

\begin{tabular}{ccccccc}
\hline Amostra & $\begin{array}{c}\mathbf{S m} \\
(\mathbf{p p m})\end{array}$ & $\begin{array}{c}\mathbf{N d} \\
(\mathbf{p p m})\end{array}$ & ${ }^{\mathbf{1 4 7}} \mathbf{S m} /{ }^{\mathbf{1 4 4}} \mathbf{N d}$ & ${ }^{\mathbf{1 4 3}} \mathbf{N d} /{ }^{\mathbf{1 4 4}} \mathbf{N d}$ & $\mathbf{\varepsilon N d}(\mathbf{0})$ & $\mathbf{T}_{\mathbf{D M}}(\mathbf{G a})$ \\
\hline BBR-19-1 & 7,862 & 39,846 & 0,1193 & 0,512159 & $-9,34$ & 1,43 \\
\hline BBR-19-3 & 10,219 & 47,904 & 0,1290 & 0,512134 & $-9,83$ & 1,63 \\
\hline BBR-23-2 & 7,480 & 39,123 & 0,1156 & 0,512081 & $-10,86$ & 1,49 \\
\hline BBR-87-7 & 6,603 & 32,316 & 0,1236 & 0,512252 & $-7,53$ & 1,34 \\
\hline PMI-7 & 6,960 & 35,476 & 0,1186 & 0,512255 & $-7,47$ & 1,26 \\
\hline
\end{tabular}

Tabela 9. $\varepsilon \mathrm{Nd}_{\mathrm{TDM}}$ e recalculado para $220 \mathrm{Ma}$.

\begin{tabular}{cccc}
\hline Amostra & $\mathbf{T}_{\text {DM }}(\mathbf{G a})$ & $\boldsymbol{\varepsilon}_{(\mathbf{T D M})}$ & $\boldsymbol{\varepsilon}_{(\mathbf{2 2 0 M a})}$ \\
\hline BBR-19-1 & 1,43 & 4,75 & $-7,17$ \\
\hline BBR-19-3 & 1,63 & 4,30 & $-7,93$ \\
\hline BBR-23-2 & 1,49 & 4,60 & $-8,58$ \\
\hline BBR-87-7 & 1,34 & 4,96 & $-5,48$ \\
\hline PMI-7 & 1,26 & 5,13 & $-5,28$ \\
\hline
\end{tabular}

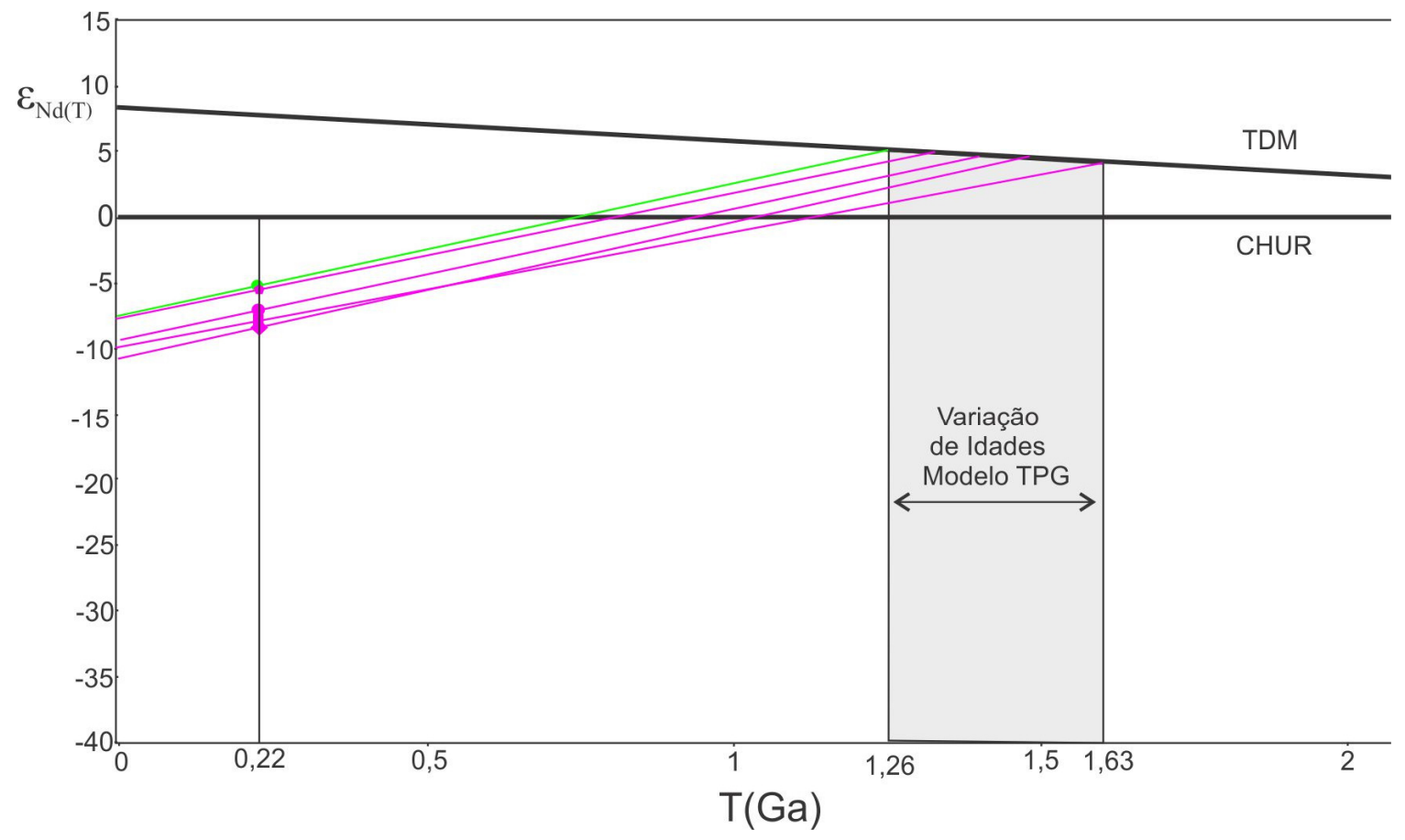

Figura 12. Gráfico $\varepsilon_{\mathrm{Nd}} v s$ tempo (Ga). CHUR: Chondritic Uniform Reservoir. Em verde a amostra da Formação Legoupil (PMI-7) e em rosa as amostras do TPG em Botany Bay (BBR-19-1, BBR-19-3, BBR-23-2, BBr-87-7).

\section{Geoquímica Isotópica Mineral - Datação de grãos detríticos de zircão}

As análises de geoquímica isotópica mineral foram realizadas através do sistema Urânio-Chumbo (U-Pb). Este sistema é amplamente descrito e utilizado na literatura, e em rochas sedimentares e metassedimentares revela a informação direta da idade das fontes através das idades dos grãos de zircão analisados. Para complementar este 
método foram realizadas análises no sistema Lutécio-Háfinio (Lu-Hf), que geram informações de gênese, e juntamente com os dados de U-Pb e Sm-Nd, revelam dados precisos e abrangentes para a análise de proveniência das rochas.

Para que as análises realizadas nos grãos de zircão não fossem tendenciosas ou distorcidas, valorizando sub-populações, foram datados grãos de todos os tipos morfológicos observados nas amostras, gerando assim conjunto de dados mais confiável e completo para a proveniência. Assim, foram realizadas análises nas amostras listadas na tabela abaixo e os dados estão no Anexo IV. A relação das amostras e dos métodos usados encontra-se na Tabela 12.

Tabela 10. Relação das amostras analisadas e métodos respectivos

\begin{tabular}{ccc}
\hline Formação & Método & Amostras \\
\hline Fm. Legoupil & U-Pb & IL-1 \\
\hline GPT em Botany Bay & U-Pb/Lu-Hf & BBR-D-8A, BBR-D-10 \\
\hline Fm. Grauvaca-Folhelho & U-Pb & L-2-4, L-4-8, L-4-12 \\
\hline
\end{tabular}

\subsection{Sistema Urânio - Chumbo (U-Pb)}

$\mathrm{O}$ método de datação U-Pb se baseia no fato de que o Urânio ocorre naturalmente em três isótopos diferentes: ${ }^{238} \mathrm{U},{ }^{235} \mathrm{U}$ e ${ }^{234} \mathrm{U}$. Destes, apenas os ${ }^{238} \mathrm{U}$ e ${ }^{235} \mathrm{U}$ geram isótopos de chumbo, sendo ${ }^{206} \mathrm{~Pb}$ e ${ }^{207} \mathrm{~Pb}$ respectivamente. O Chumbo apresenta ainda dois outros isótopos, o ${ }^{208} \mathrm{~Pb}$ e o ${ }^{204} \mathrm{~Pb}$, sendo que o primeiro deriva do decaimento do ${ }^{232} \mathrm{Th}$ e o segundo não é radiogênico. $\mathrm{O}$ isótopo ${ }^{204} \mathrm{~Pb}$ é portanto, utilizado como o isótopo estável de referência, o que possibilita o cálculo das idades geocronológicas.

Como são três os isótopos formadores de chumbo, obtêm-se três idades calculadas relacionando-se a constante de decaimento de cada elemento e suas razões em relação ao ${ }^{204} \mathrm{~Pb}$. Estas três idades obtidas devem ser concordantes entre si, desde que se satisfaçam as seguintes premissas: (i) O mineral se manteve fechado para U, Th e $\mathrm{Pb}$ e a todos os isótopos filhos destes ao longo da história; (ii) Valores de razões de $\mathrm{Pb}$ iniciais estão corretos; (iii) As constantes de decaimento radioativo de cada um dos três isótopos envolvidos é determinada com precisão; (iv) A composição do U é normal e não foi modificada por fracionamento isotópico ou pela ocorrência de reações em cadeia 
naturais baseadas na fissão do ${ }^{235} \mathrm{U}$; (v) Todos os resultados analíticos são exatos e sem erros (Faure, 1986). Na natureza, no entanto, não é possível encontrar todas as premissas satisfeitas e, na maioria dos casos, as idades obtidas são discordantes. Este problema foi sanado com o advento do diagrama da Concórdia, que relaciona o decaimento radioativo dos isótopos ${ }^{238} \mathrm{U}$ e ${ }^{235} \mathrm{U}$, e gera uma curva traçada a partir do

cálculo teórico do tempo de decaimento para razões conhecidas de ${ }^{206} \mathrm{~Pb} /{ }^{238} \mathrm{U}$ e ${ }^{207} \mathrm{~Pb} /{ }^{235} \mathrm{U}$ (Faure, 1986).

Para as rochas sedimentares, a idade U-Pb fornece idade de cristalização da fonte, permitindo pela análise do zircão mais antigo e mais novo restringir a idade de sedimentação da rocha, sendo assim, a partir da assembleia de idades mais novas encontradas nos sedimentos pode-se inferir a idade máxima de sedimentação da rocha. E pela correlação direta entre as idades encontradas no sedimento e as idades das possíveis áreas fontes, pode-se inferir a proveniência da rocha.

\subsubsection{Resultados Urânio - Chumbo (U-Pb)}

As idades U-Pb resultantes das análises realizadas permitem a subdivisão dos valores determinados em quatro grupos: Grupos A, idades permo-triássicas, Grupo B, idades carboníferas, Grupo C, idades silurianas, ordovicianas e cambrianas, e por fim o Grupo D, com idades pré-cambrianos. Esses dois últimos grupos ocorrem em menor frequência.

A amostra da Formação Legoupil, IL-1 foi coletada na Ilha Larga e apresenta grãos de zircão com morfologia variada, sendo a maioria deles prismáticos com tendências bipiramidais, alongados com bordas arredondadas e fragmentos com terminações bipiramidais e arredondadas. Os grãos apresentam tamanho pequeno, em parte por estarem fragmentados, variando de 80 a $150 \mu \mathrm{m}$, sendo que os maiores, em menor ocorrência, variam de 150 a 250 $\mathrm{m}$ (Figura 13C). Foram feitas 52 análises em 50 grãos, sendo que 53\% das análises apresentaram 99\% de concordância, 41,2\% das análises apresentaram $100 \%$ de concordância e 5,8\% das análises apresentaram 2 pontos percentuais de variação para mais e para menos de $100 \%$. Uma análise não foi utilizada pelo alto grau de discordância apresentado, resultando em 51 análises consideradas boas.

No diagrama Concórdia (Figura 13A) as análises apresentam concordâncias diversas e de idades variadas, sendo poucas as análises que ultrapassam os $647 \mathrm{Ma}$. No histograma de distribuição das idades U-Pb (Figura 12B), notam-se dois principais picos 
entre 265 e 295 Ma e entre 457 e 510 Ma. O pico mais jovem apresenta média de $293 \pm$ 2 Ma e está representado no Grupo A de idades, já o pico mais velho apresenta média $478 \pm 4$ Ma e está representado no Grupo C de idades.

As amostras do Grupo Península Trinity coletadas em Botany Bay, são arenitos das amostras BBR-D-8A e BBR-D-10. Foram realizadas 64 análises em cada uma das amostras, sendo que na amostra BBR-D-8A as análises foram realizadas em 57 grãos, dessas somente 53 foram utilizadas. Das 11 não utilizadas 5 foram desprezadas por apresentarem alta discordância e 7 por apresentarem alta quantidade de chumbo comum. Já na a amostra BBR-D-10 foram analisados 62 grãos, sendo que somente 49 dessas análises foram utilizadas, das 16 desprezadas, 4 apresentam alto grau de discordância e 12 com alto teor de chumbo comum.

A amostra BBR-D-8A apresenta resultados com alto grau de concordância, sendo $37,73 \%$ das análises $100 \%$ concordantes, 50,94\% das análises $99 \%$ concordantes e 11,32\% das análises com concordância entre 95 e 99\%. A morfologia dos grãos de zircão é predominantemente arredondada, ou ainda alongada com bordas arredondadas e em partes fragmentos com terminações arredondadas. Os grãos apresentam tamanho pequeno que variam de 50 a $150 \mu \mathrm{m}$, sendo que os maiores, em menor ocorrência,

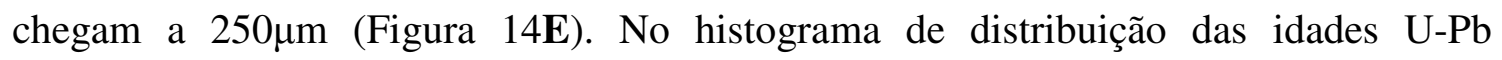
estimadas (Figura 14C) podem ser identificados três principais picos de idade entre 324 e 358 Ma, 512 e 541 Ma, e 1001 e 1091 Ma. Estes picos estão bem representados nos três principais pontos concordantes do diagrama concórdia (Figura 14A), com concordâncias diversas e idades variadas. O pico mais jovem apresenta média de $343 \pm$ 5 Ma e está morfologicamente representado no Grupo de idades B, já o pico intermediário tem média de $519 \pm 9$ Ma, e está representado no Grupo de idades $\mathrm{C}$, e por fim o pico mais velho apresenta média $1057 \pm 14$ Ma e está representado no Grupo D. 
A
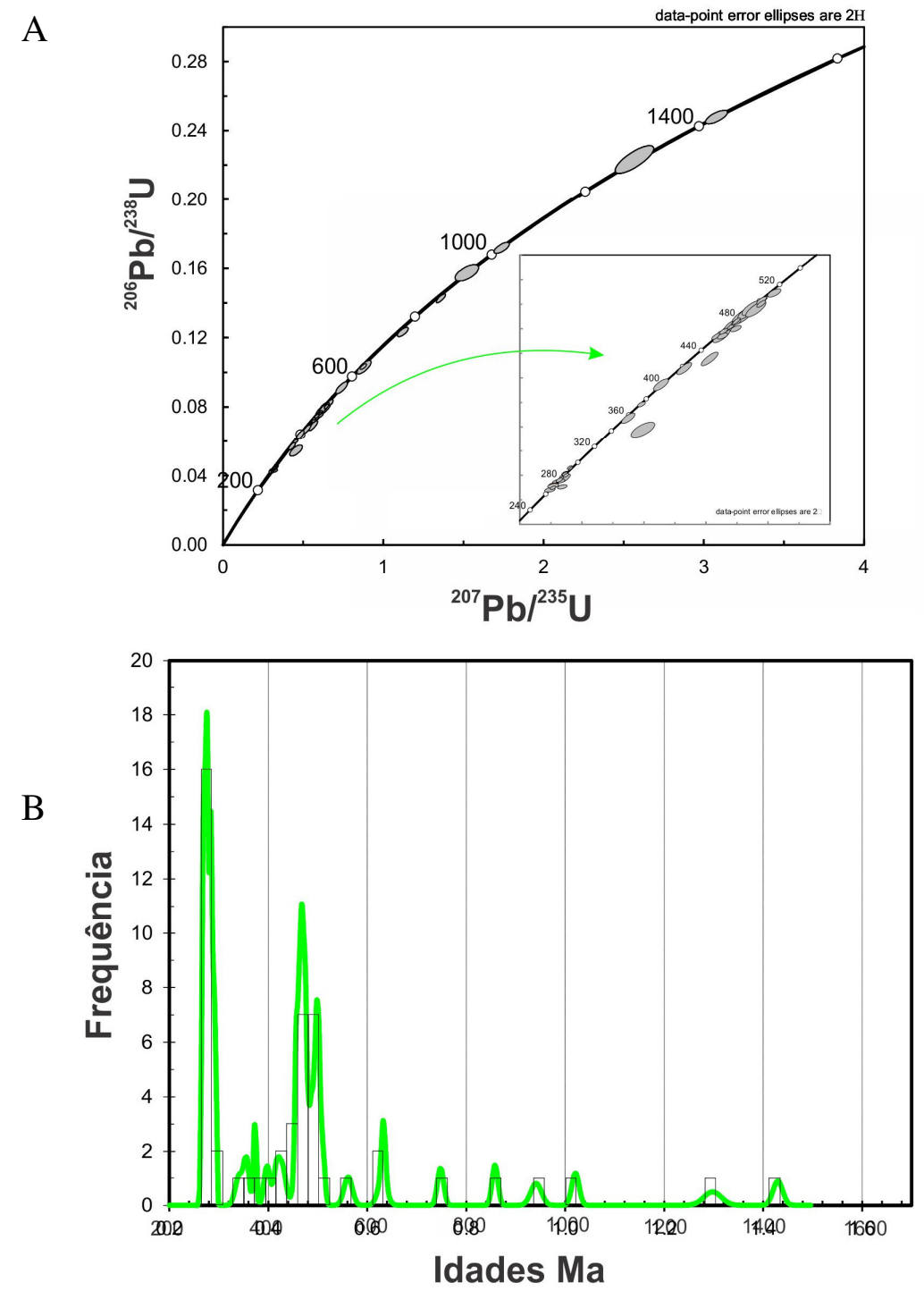

$\mathrm{C}$
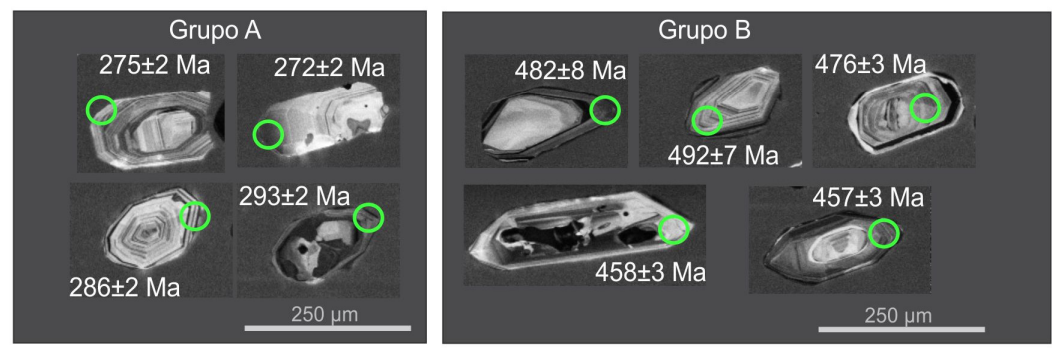

Figura 13. A. Diagrama da Concórdia U-Pb para a amostra IL-1, conglomerado da Formação. Legoupil B.: Frequência das idades ${ }^{206} \mathrm{~Pb} /{ }^{238} \mathrm{U}$ obtidas em cristais de zircão detrítico da amostra IL-1, as idades acima de $1300 \mathrm{Ma}$ usam a idade ${ }^{207} \mathrm{~Pb} /{ }^{206} \mathrm{~Pb}$. C. Imagem de catodoluminescência dos cristais de zircão detrítico analisados do Grupo A e $\mathrm{C}$ de idades estimadas. 
A amostra BBR-D-10 apresenta variados pontos de concordância em diversas idades (Figura 13B), sendo que os resultados são de alta concordância com 53,06\% dos resultados são $99 \%$ concordantes, $34,69 \%$ dos resultados são $100 \%$ concordantes e somente $12,24 \%$ concordantes entre 95 e 99\%. A morfologia dos grãos de zircão é extremamente semelhante com a encontrada na amostra BBR-D-8A, sendo eles arredondados, ou alongados com bordas arredondadas e em partes fragmentos com terminações arredondadas (Figura 14F). Os grãos apresentam tamanho pequeno que variam de 100 a $150 \mu \mathrm{m}$, sendo que alguns cristais chegam a $250 \mu \mathrm{m}$. No histograma de distribuição das idades (Figura 14D) podem-se perceber diversos picos pequenos, aglomerados entre 429 e $767 \mathrm{Ma}$, sendo que somente um é bem marcado entre 429 e 541 Ma. A média deste pico é de $525 \pm 6$ Ma e está representado morfologicamente no Grupo C

Para a Formação Grauvaca-Folhelho foram coletadas amostras na Ilha Laurie de conglomerado, L-2-4, e metarenito, L-4-8, L-4-12.

A amostra L-2-4 teve 86 zircões analisados totalizando em 94 análises. Dessas análises 8 foram desprezadas, pois 2 apresentaram alto grau de discordância e 6 com alto teor de chumbo comum. As análises utilizadas para produzir os dados apresentam alto grau de concordância, como visto no Diagrama Concórdia (Figura 15A), sendo que 46,51\% das análises tem $99 \%$ de concordância, 52,32\% das análises tem $100 \%$ de concordância, e somente $1,16 \%$ das análises tem concordância que varia 2 pontos percentuais para mais ou para menos de $100 \%$. Os grãos de zircão apresentam tamanhos variados, com os menores variando de 50 a $100 \mu \mathrm{m}$ e os maiores de 200 a $300 \mu \mathrm{m}$. A morfologia dos grãos é em sua maioria arredondada e alongada com terminações arredondadas, em menores ocorrências os fragmentos também com terminações arredondadas, sendo raramente com terminação bipiramidal (Figura 15C). No histograma das melhores idades U-Pb (Figura 15B) pode-se identificar dos principais picos, o mais jovem de 232 - $298 \mathrm{Ma}$, e o pico mais velho que varia de 504 - $594 \mathrm{Ma}$. O pico mais jovem apresenta média $259 \pm 2$ Ma e está representado no Grupo A, já o pico mais antigo tem média de $544 \pm 5$ Ma e está representado no Grupo B (Figura 15C).

O metarenito das amostras L-4-8 e L-4-12 tiveram 91 pontos de análise realizados, sendo que a amostra L-4-8 teve 86 grãos de zircão analisados e a amostra L4-12 teve 90 grãos. Destas a análises foram desprezadas 3 na amostra L-4-8, sendo 1 por apresentar alto grau de discordância e as outras 2 por apresentarem alto teor de chumbo comum, já na amostra L-4-12 somente 1 foi desprezada por apresentar alto teor de 
chumbo comum. Assim, para a produção de dados foram utilizadas 89 análises na amostra L-4-2 e 90 na amostra L-4-12.
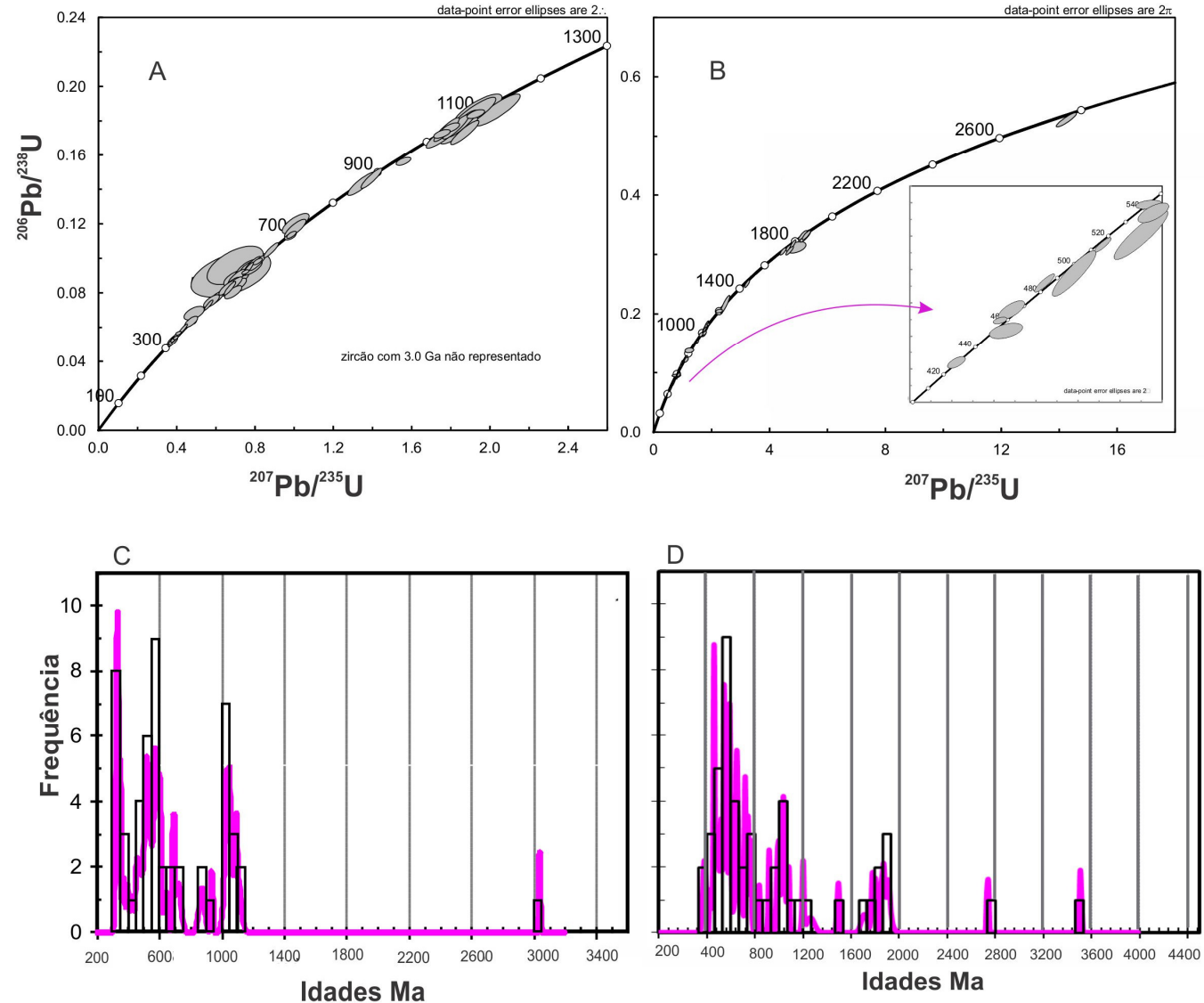

$E$
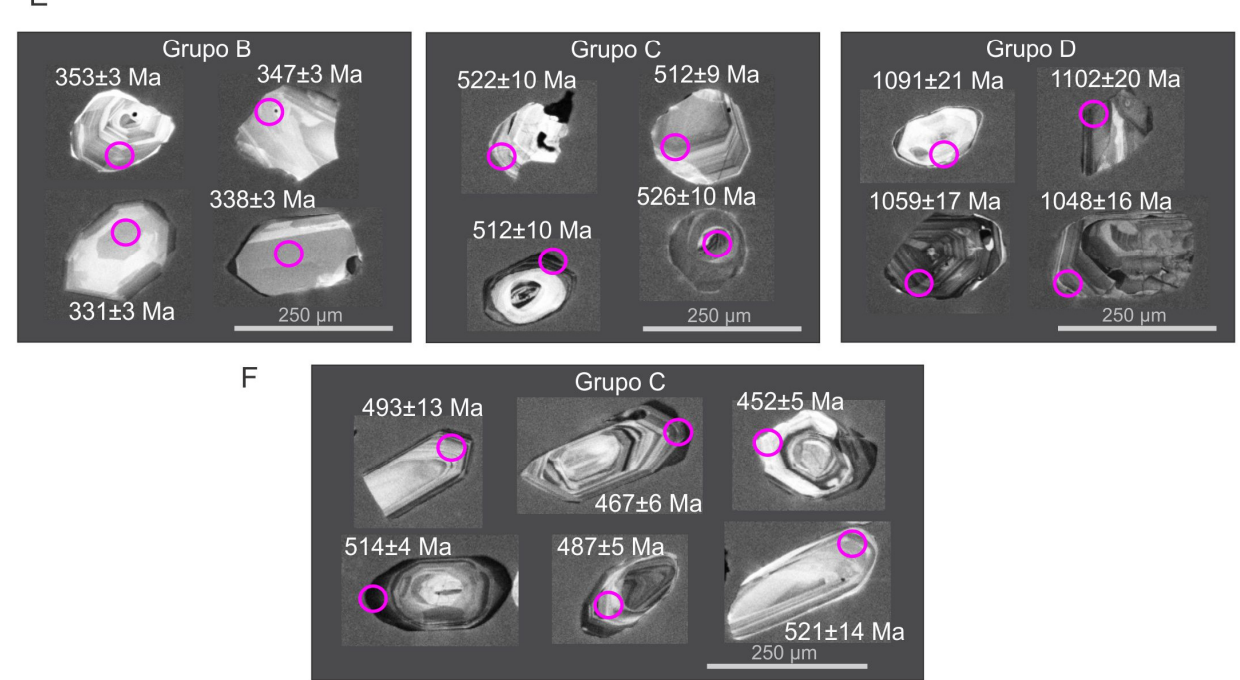

Figura 14. A.e B Diagrama da Concórdia U-Pb para as amostras BBR-D-8A e BBR-D-10, respectivamente, arenitos do TPG em Botany Bay. C e D. Frequência das idades ${ }^{206} \mathrm{~Pb} /{ }^{238} \mathrm{U}$ obtidas em cristais de zircão detrítico das amostras BBR-D-8A e BBR-D-10, as idades acima de $1300 \mathrm{Ma}$ usam a idade ${ }^{207} \mathrm{~Pb} /{ }^{206} \mathrm{~Pb}$.E e F. Imagem catodoluminescência dos cristais de zircão detrítico analisados do Grupo B, C e D de idades estimadas para a amostra BBR-D-8A e Grupo C de idades estimadas para a amostra BBR-D-10, respectivamente. 

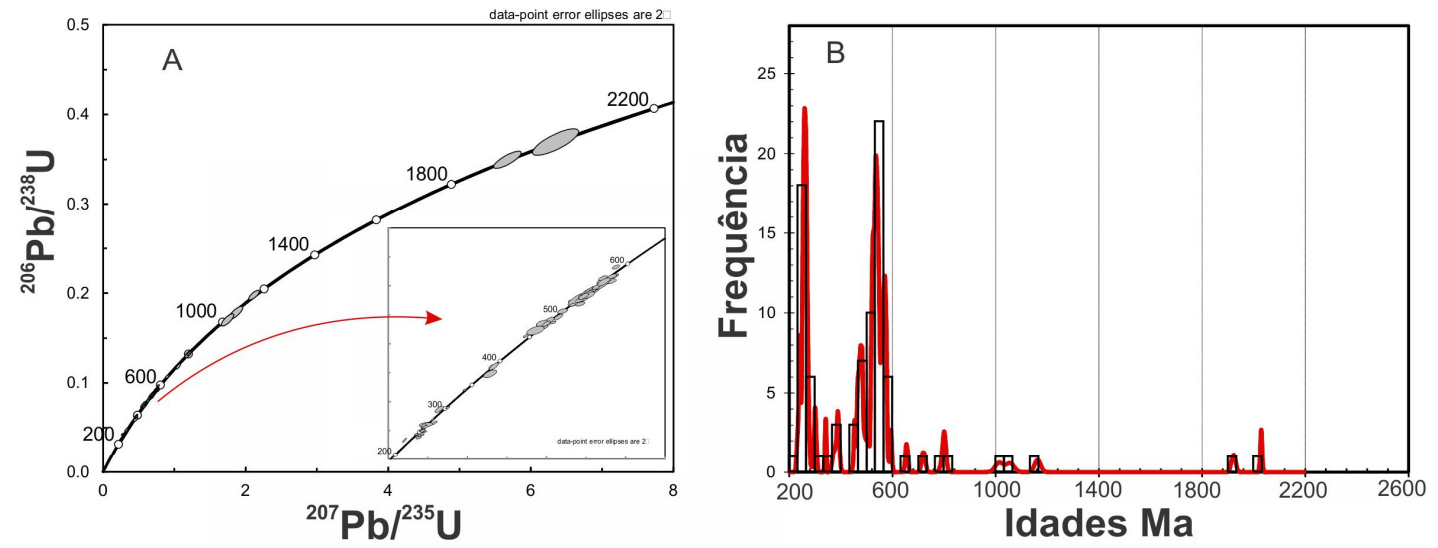

C
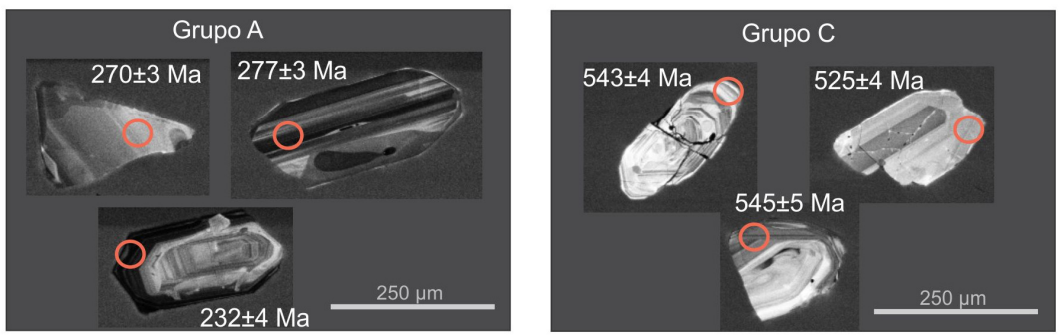

Figura 15. A. Diagrama da Concórdia U-Pb para a amostra L-2-4, conglomerado da Fm. Grauvaca-Folhelho. B. Frequência das idades ${ }^{206} \mathrm{~Pb} /{ }^{238} \mathrm{U}$ obtidas em cristais de zircão detrítico da amostra L-2-4, as idades acima de $1300 \mathrm{Ma}$ usam a idade ${ }^{207} \mathrm{~Pb} /{ }^{206} \mathrm{~Pb} . \mathrm{C}$. Imagem de catodoluminescência dos cristais de zircão detrítico analisados do Grupo A e C de idades estimadas para a amostra L-2-4.

A amostra L-4-8 apresenta pontos de concordância com variadas idades, o que pode ser observado no diagrama Concórdia (Figura 16A), e estes pontos são altamente concordantes, sendo que $51,65 \%$ das análises são $99 \%$ concordantes, 47,19\% das análises são $100 \%$ concordantes, e somente $1,12 \%$ das amostras tem concordância menor que 95\%. Os grãos de zircão são morfologicamente alongados com bordas arredondadas e bipiramidais, arredondados e fragmentos de grãos (Figura 16E). Em tamanho, os cristais variam de 80 a $250 \mu \mathrm{m}$, sendo que a maioria está entre 100 e 200 $\mu \mathrm{m}$., e em formato ocorrem os alongados com terminações bipiramidais e arredondadas e os arredondados. A partir do gráfico de distribuição das melhores idades U-Pb (Figura 16C) é possível identificar um pico principal de idade, que varia de 246-295 Ma, com média de $268 \pm 3 \mathrm{Ma}$, e se enquadra no Grupo A.

A amostra L-4-12 apresenta diversos pontos concordantes com altas concordâncias, e 38,20\% das análises são $100 \%$ concordantes, $41,57 \%$ são $99 \%$ concordantes e 3,48\% são entre 95 e $99 \%$ concordantes e $6,74 \%$ apresentam concordância maior que $100 \%$, que podem ser observadas no Diagrama Concórdia 
(Figura 16B). Os grãos de zircão analisados apresentam formato alongado, sendo eles com terminações arredondadas ou não, e em menor quantidade os arredondados e fragmentados. O tamanho é variado de $50-250 \mu \mathrm{m}$, sendo a maioria entre 100 e 150 $\mu \mathrm{m}$. A partir do histograma de distribuição das melhores idades U-Pb separam-se as idades em diversos pequenos picos, sendo os dois principais entre 216-292 Ma e 434598 Ma (Figura 16D). O pico mais jovem apresenta média de $258 \pm 2$ Ma e está representado no Grupo A de idades, e o pico mais antigo tem média de $544 \pm 5 \mathrm{Ma}$, e está representado no Grupo C de idades(Figura 16F).
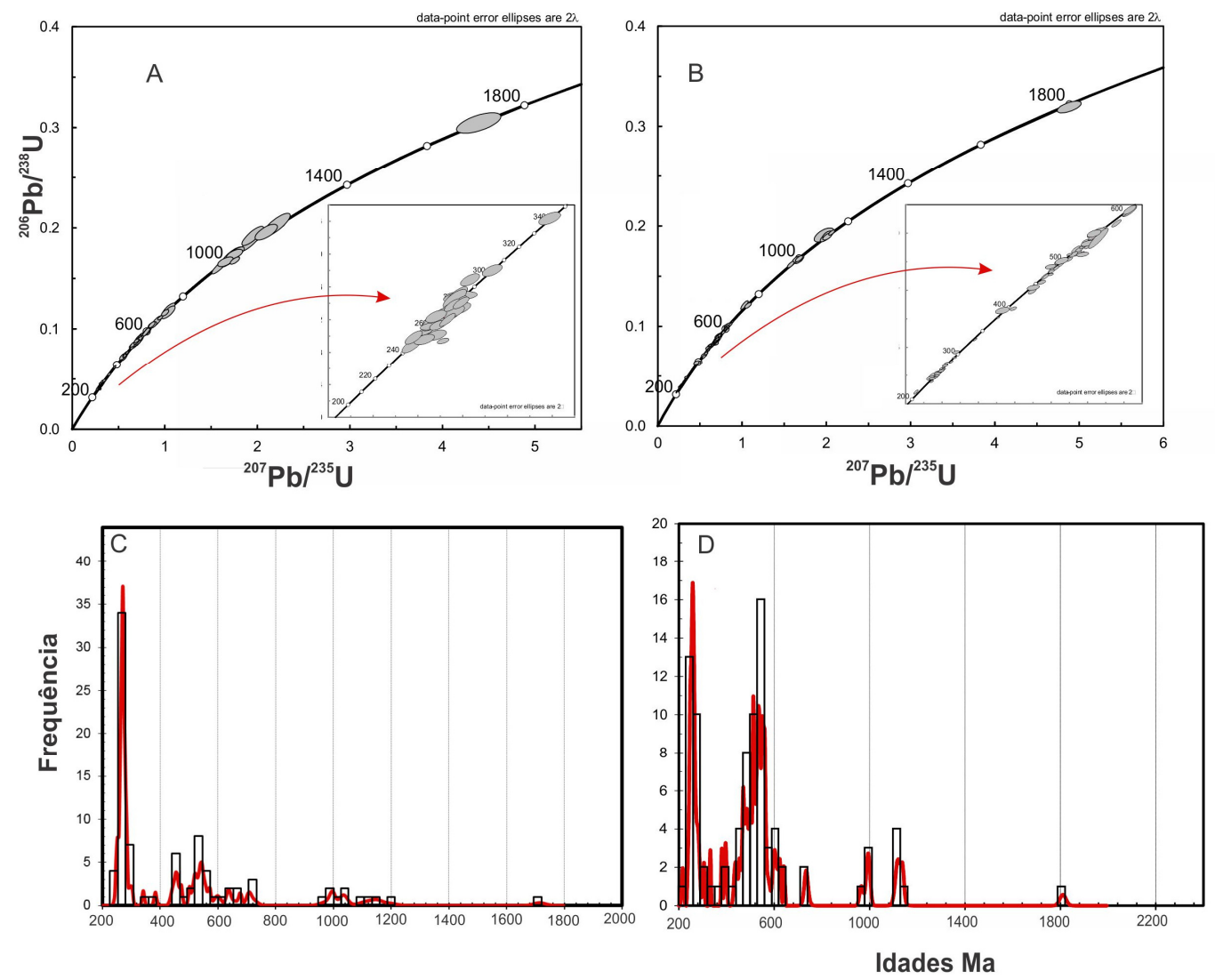

E

$\mathrm{F}$
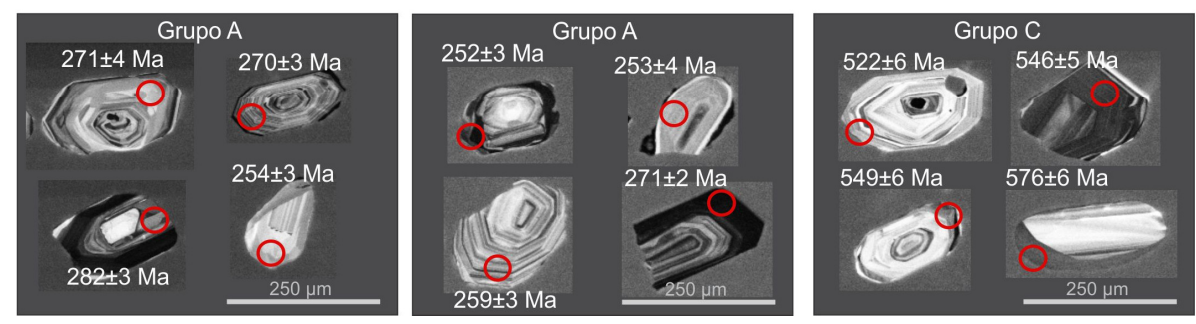

Figura 16. A e B Diagrama da Concórdia U-Pb para as amostras L-4-8 e L-4-12, respectivamente, para amostrasda Fm. Grauvaca-Folhelho. C e D. Frequência das idades ${ }^{206} \mathrm{~Pb} /{ }^{238} \mathrm{U}$ obtidas em cristais de zircão detrítico da amostra L-4-8 e L-4-12, respectivamente, as idades acima de $1300 \mathrm{Ma}$ usam a idade ${ }^{207} \mathrm{~Pb} /{ }^{206} \mathrm{~Pb}$. E e F. Imagem de catodoluminescência dos cristais de zircão detrítico analisados do Grupo A de idades estimadas para as amostras L-4-8 e L-4-12, respectivamente. 


\subsection{Sistema Lutécio-Háfnio (Lu-Hf)}

O lutécio (Lu) é um elemento terra rara pesado (com número atômico 71) que ocorre amplamente disperso em todos os tipos de rochas, naturalmente é encontrado em duas formas distintas, com números de massa ${ }^{175} \mathrm{Lu}$ e ${ }^{176} \mathrm{Lu}$, sendo que o elemento estável ${ }^{175} \mathrm{Lu}$ é mais abundante na Terra, perfazendo $97,4 \%$, já o radioativo ${ }^{176} \mathrm{Lu}$ perfaz 2,6\% (Holden \& Walker, 1972 apud Faure 1986). O háfnio (Hf) apresenta propriedades químicas e raio iônico muito similares ao zircônio ( $\mathrm{Zr}$ ), com o qual está largamente associado na natureza e ocorre disperso pela substituição de zircônio e titânio na estrutura cristalina dos minerais.

O háfnio ocorre naturalmente em seis diferentes isótopos ${ }^{174} \mathrm{Hf},{ }^{176} \mathrm{Hf},{ }^{177} \mathrm{Hf}$, ${ }^{178} \mathrm{Hf}$, ${ }^{179} \mathrm{Hf}$ e ${ }^{180} \mathrm{Hf}$, sendo que o ${ }^{176} \mathrm{Hf}$ é proveniente do decaimento do ${ }^{176} \mathrm{Lu}$. O decaimento do lutécio ${ }^{176} \mathrm{Lu}$ para o estável ${ }^{176} \mathrm{Hf}$ ocorre de forma ramificada por emissão de radiação $\beta$ e subsequente emissão de raios $\gamma$, este decaimento ocorre com constante de decaimento de 1,96 x 10-11y- ${ }^{1}$, e com meia vida de 3,5 x $10^{10}$ y (Faure, 1986).

A datação pelo método Lu-Hf pode ser apresentada em isócronas, pela correlação direta dos dados de concentração de lutécio e háfnio $\left({ }^{176} \mathrm{Lu} /{ }^{177} \mathrm{Hf}\right)$ e a razão isotópica de háfnio $\left({ }^{176} \mathrm{Hf} /{ }^{177} \mathrm{Hf}\right)$. Este método não é muito utilizado, pois as razões Lu/Hf são muito pequenas e de difícil determinação.

As propriedades geoquímicas do lutécio e do háfnio são similares às de samário e neodímio, pois o fracionamento isotópico do lutécio e do háfnio também ocorre durante a extração de material do manto, a diferença está no fato de o lutécio e o háfnio serem mais facilmente fracionados que o samário e o neodímio (Faure, 1986). Assim, os dados são interpretados igualmente a partir de $\varepsilon_{\mathrm{Hf}}$ para a interpretação de evolução crustal.

\subsubsection{Resultados Lutécio -Háfnio (Lu-Hf)}

Os valores de $\varepsilon_{\mathrm{Hf}}$ dos grãos de zircão estão calculados para as idades pontuais U-Pb nos dois arenitos do Grupo Península Trinity de Botany Bay analisados, BBR-D8A e BBR-D-10 e foram plotados no diagrama $\varepsilon_{\mathrm{Hf}} v s$ tempo (Ma) (Figura 17A e C).

Para a amostra BBR-D-8A, os grãos de zircão do Grupo B, com idades U-Pb entre 314 e $358 \mathrm{Ma}$ apresentam valores de $\varepsilon_{\mathrm{Hf}}$ que variam de $-1,2$ a $-5,7$ e idades modelo $\mathrm{T}_{\mathrm{DM}}$ entre 1,4 e 1,7 Ga. Já os cristais do Grupo C de idades entre 512 e $541 \mathrm{Ma}$ 
apresentam valores de $\varepsilon_{\mathrm{Hf}}$ que variam de $-3,3$ a $-7,3$, com idades modelo de 1,7 a 1,9 Ga. Diferente dos grupos de idade B e C, o Grupo D com idades U-Pb entre 1,0 e 1,09 Ga apresentam valores variados de $\varepsilon_{\text {Hf }}$ que vão de $-1,1$ a $-15,5$, e duas análises com valores positivos, 1,31 e 1,91. A idade $\mathrm{T}_{\mathrm{DM}}$ dessas análises varia de 1,8 a 2,8 Ga, indicando maior tempo de residência crustal. Os valores de $\varepsilon_{\mathrm{Hf}}$ que variam de 0 a -5 sugerem a contribuição de reservatório mais empobrecido - manto, enquanto que os cristais mais antigos com valores de até $\varepsilon_{\mathrm{Hf}}$ de $-15,5$ apresentam assinatura de crosta continental superior (Kinny \& Maas, 2003).

A amostra BBR-D-10, apresenta comportamento diferente da amostra BBR-D8A, os dados para os grãos de zircão do Grupo C de idades U-Pb entre $429-541 \mathrm{Ma}$ têm valores de $\varepsilon_{\mathrm{Hf}}$ que variam de -14 a $-29,7$ e idades $\mathrm{T}_{\mathrm{DM}}$ entre 1,8 e $2,7 \mathrm{Ga}$. O $\varepsilon_{\mathrm{Hf}}$ fortemente negativo de $-29,7$ indica fonte com longa residência crustal e pode sugerir que esta seja enriquecida e fortemente trabalhada. Entretanto Kinny \& Maas (2003) afirmam que valores de épsilon fortemente negativos, e muito enriquecidos em $\mathrm{Hf}$, podem ter como fonte crosta oceânica em subducção.

As idades modelo de Hf pontuais se mostram em parte coincidentes, em parte não, com os resultados das idades modelo $\mathrm{Nd}$ em rocha total. Essa diferença observada ocorre no método de datação de rocha total onde o resultado é uma média das idades das fontes envolvidas, em que o resultado indica a média do tempo de residência crustal (Kinny \& Maas 2003). O fato da análise de Hf pontual poder ser estudada com as idades U-Pb conhecidas, permite o cálculo de idades modelo por duplo estágio (Nedel et al., 2007).

No gráfico de dispersão para a amostra BBR-D-8A (Figura 17B), são observados com clareza dois diferentes tipos de fonte, a de idade por volta de 500 Ma com menor tempo de residência crustal, com valores de épsilon Hf entre 0 e -5. Já a idade por de $1000 \mathrm{Ma}$, que contribui dois tipos distintos de fontes, uma fonte juvenil com épsilon Hf positivo e baixa residência crustal, e uma segunda fonte épsilon Hf por volta de -15 e alta residência crustal. Já na amostra BBR-D-10(Figura 17D) não há tendência bem definida, somente pode-se observar que as principais contribuições são de reservatório com baixa residência crustal e épsilon Hf majoritariamente entre 0 e -10. 

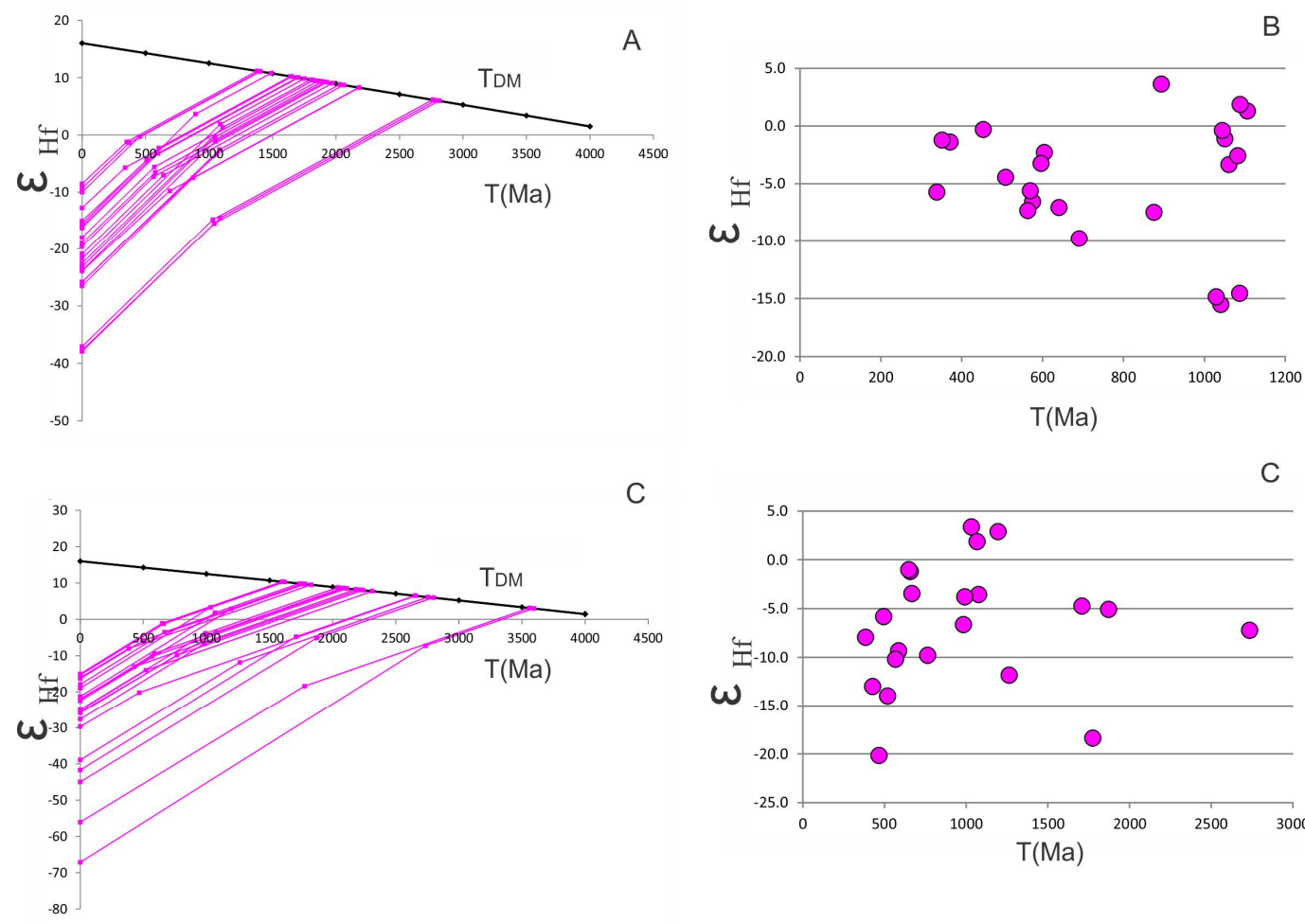

C

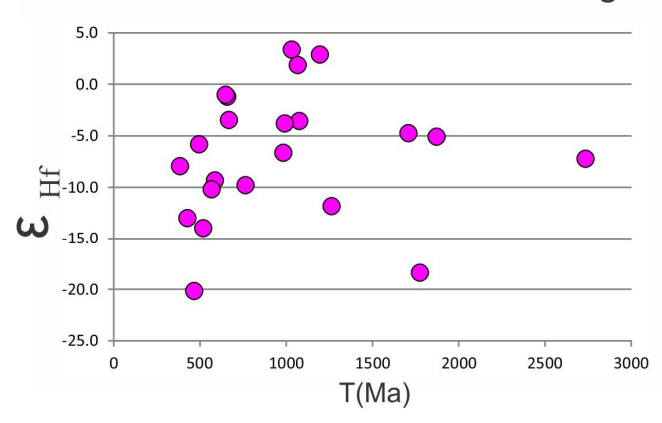

Figura 17. A. e C. Gráfico com valores $\varepsilon_{\mathrm{Hf}}$ calculados para as idades pontuais U-Pb e valores das idades modelo $\mathrm{T}_{\mathrm{DM}(\mathrm{Hf})}$ por duplo-estágio para as amostras de arenito BBR-D8A e BBR-D-10 do TPG em Botany Bay. B. e D. Gráfico de correlação entre $\varepsilon$ Hf e idades U-Pb para as amostras de arenito BBR-D-8A e BBR-D-10. 


\section{CAPÍTULO VII PROVENIÊNCIA SEDIMENTAR}

A proveniência sedimentar é um assunto muito estudado na literatura, e vem sendo cada vez mais aplicado por diversos autores na caracterização de contexto tectônico em escalas regional e local. Este estudo é o conjunto da análise de várias áreas da geologia, como mineralogia, geoquímica, geocronologia, sedimentologia e petrologia, sendo que as análises químicas e texturais de minerais detríticos e as análises químicas de rochas sedimentares são as ferramentas mais utilizadas na literatura nos dias atuais para a realização destes estudos (McLennan et al., 1990), pois diferentes tipos de rochas tendem a apresentar diferentes associações minerais que lhes são características (Pettijohn, 1975).

O conjunto de dados analisados para a determinação da proveniência é realizado a partir da associação mineral detrítica que compõe a amostra, apesar de serem realizadas análises pontuais, e para tanto existem fatores externos que controlam a associação mineral, como intemperismo, abrasão mecânica, processos hidráulicos, e consequentemente a composição geral da rocha sedimentar. Assim, é crucial a consideração e estudo destes fatores durante a identificação de proveniência (Morton \& Hallsworth, 1999).

O intemperismo pode afetar a rocha-fonte alterando sua composição antes mesmo do transporte do sedimento ou, na rocha sedimentar, a abrasão mecânica, que ocorre durante o transporte, pode diminuir a diversidade mineralógica pela cominuição dos grãos de menor dureza. Os parâmetros granulométricos do sedimento, tamanho e seleção dos grãos, são afetados pelos processos hidráulicos, que regulam a quantidade absoluta e relativa dos minerais durante o transporte e a deposição.

Em rochas metassedimentares, acrescentam-se a todos estes fatores citados as mudanças químicas e físicas que podem ocorrer durante o aumento de pressão e/ou temperatura do metamorfismo. Mesmo assim, em rochas metamórficas de baixo grau são raras as alterações químicas consideráveis, a não ser que ocorram processos hidrotermais. 
Assim, levando em consideração todas as variáveis, fragilidades e pontos fortes do método, é possível, a partir da combinação de todos os estudos supracitados, inferir a proveniência e o ambiente tectônico das áreas-fontes e da região de deposição.

\section{Petrografia}

Com os dados da análise petrográfica das rochas do Grupo Península Trinity, Formação Grauvaca-Folhelho e Formação Miers Bluff é possível utilizar o diagrama de proveniência tectônica de Dickinson (1985), para inferir o ambiente tectônico da área fonte. Para isso foi utilizada a técnica de contagem Gazzi-Dickinson, com qual são contados separadamente os grãos de quartzo, feldspato e fragmentos líticos com granulometria maior que silte. Assim, feita a contagem discriminada de GazziDickinson os arcósios e subarcósios das formações os resultados das contagens são colocados no diagrama (Figura 18A).

As amostras do Grupo Península Trinity das formações Hope Bay e Legoupil estão no campo de embasamento soerguido, por representarem areias quartzofeldspáticas, pobres em fragmentos líticos e quartzo policristalino, similar à área fonte que se encontram em ambiente de ruptura, segundo a classificação de Dickinson (1985). A amostra de View Point ocupa o campo de cráton, pois são areias quartzosas com altas razões de quartzo monocristalino/quartzo policristalino e feldspato potássico/plagioclásio, que se encontrava em ambiente intracontinental ou de plataforma passiva. As amostras do Grupo Península Trinity em Botany Bay são distribuídas entre os campos arco dissecado e embasamento soerguido, pois são ricas em quartzo e feldspato, com proporção de fragmento líticos baixa, mas variável, e em quartzo policristalino. Sua área fonte provavelmente se encontrava em ambiente de rift ou ruptura. Para a Formação Grauvaca-Folhelho as amostras ocupam, em parte o campo de reciclagem de orógenos, pois são areias quartzo-líticas, ricas em fragmentos líticos sedimentares e metassedimentares, pobres em feldspatos e fragmentos líticos vulcânicos, similares à área fonte que se encontrava em cinturão orogênico ou complexo de subducção. Já as amostras da Formação Miers Bluff estão dispostas no campo de embasamento soerguido, pois são derivadas de sedimentos tipo areia quartzofeldspática, pobre em fragmentos líticos e quartzo policristalino, similares à área fonte que se encontrava em ambiente de rift ou ruptura (Figura 18A).

Trabalhos anteriores sugerem proporções modais similares para as amostras do Grupo Península Trinity (Smellie, 1987, 1991; Birkenmajer et al., 1997; Willan, 2003), 
em localidades similares e complementares às estudadas neste trabalho. Os dados das petrofácies de Smellie foram plotados para complementação dos dados aqui coletados.

Smellie $(1987,1991)$ reconheceu três petrofácies nos arenitos que correspondem à distintas localidades, Petrofácies I, Cabo Legoupil e Península View Point, com proveniência de orógeno reciclado e arco dissecado, Pertrofácies II, Hope Bay e Ilha Joinville, em arco dissecado, e por fim a Petrofácies III, Estreito de Gerlache com características intermediárias às duas anteriores (Figura 18B). A partir das razões Q/F o autor sugere a evolução temporal a partir da diminuição da proporção de quartzo, sugerindo que as rochas mais antigas são mais quartzosas.

Neste contexto, o ambiente tectônico da fonte mais provável é arco continental que estava sendo cada vez mais dissecado, como indicado na Figura $18 \mathbf{B}$.
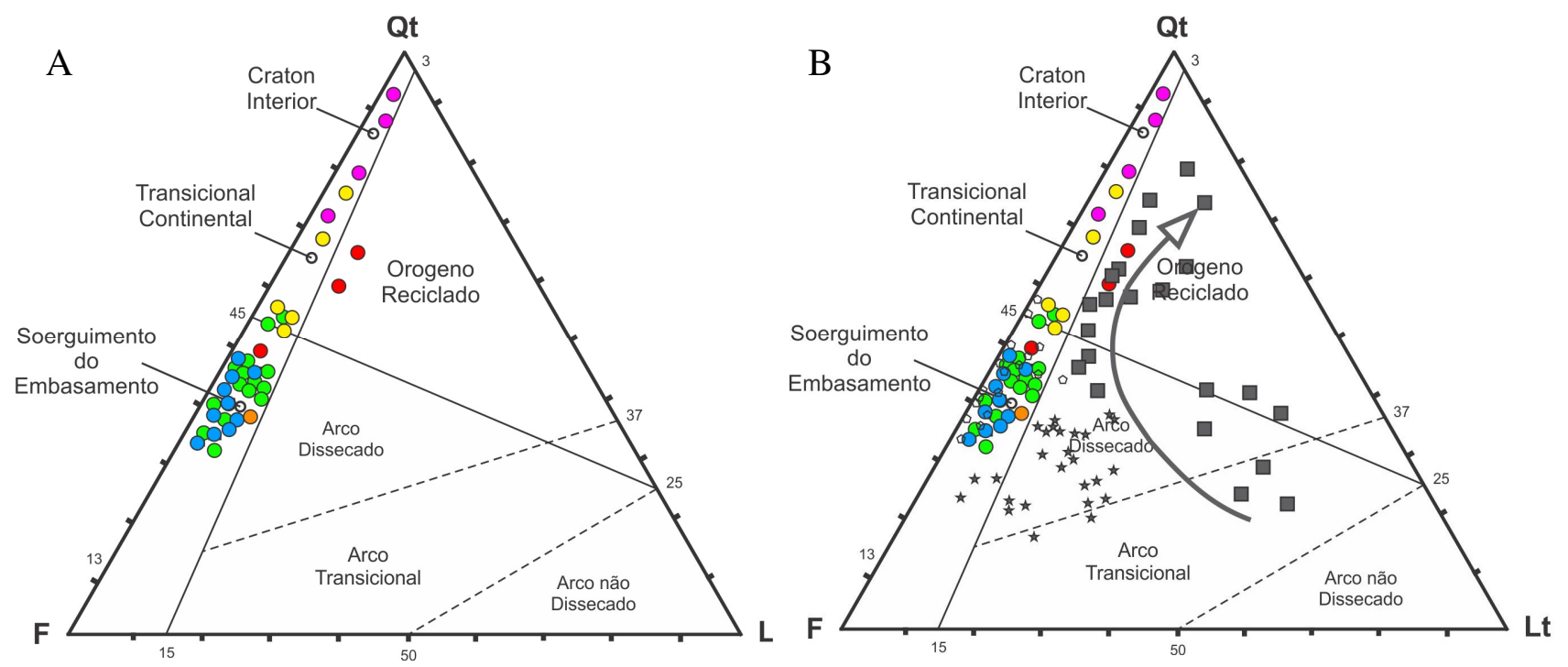

Figura 18. A. Diagrama de tipos de proveniência tectônica de Dickinson (1985), com as amostras de todas as formações plotadas. B. Diagrama com todos os dados plotados acrescidos dos dados de Hervé, 1987 e 1991. Em laranja Fm. Miers Bluff, em vermelho Fm. Grauvaca-Folhelho, em rosa TPG em Botany Bay, em amarelo Fm. View Point, verde Fm. Legoupil e em cinza os dados compilados de Smellie (1987, 1991), Petrofácies I - quadrados, Petrofácies II - estrelas, Petrofácies III - pentágono.

\section{Geoquímica}

Alguns autores elaboraram diferentes diagramas de discriminação tectônica para arenitos e siltitos, baseados em química de rocha total, com elementos maiores, menores e traço. Alguns são utilizados para inferir o tipo de área fonte e ambiente tectônico de deposição dos sedimentos das rochas analisadas. 
Roser \& Korsch (1986) geraram diagrama binário para discriminação do regime tectônico do depósito, embasado nas concentrações de $\mathrm{SiO}_{2}$ e na razão $\mathrm{K}_{2} \mathrm{O} / \mathrm{Na}_{2} \mathrm{O}$, parâmetros que haviam sido estudados por outros autores para aplicação em arenitos (Pettijohn et al., 1972), mas agora incluindo sedimentos finos. Os autores classificam os ambientes tectônicos em três grupos: Margem Continental Passiva, Margem Continental Ativa e Arco de Ilha Oceânica associado com zonas de subducção. O material derivado de arco de ilha oceânica é típico de ante-arco, retro-arco e das bacias de intra-arco formadas sobre a crosta oceânica, enquanto o material derivado de margem continental ativa é produzido em situações similares, mas sobre crosta continental e, por último, os sedimentos de margem continental passiva são derivados das zonas continentais estáveis e depositados em bacias intra-cratônicas ou em margem continental passiva.

Roser \& Korsch (1988) estudam as variações químicas entre sedimentos clásticos de quatro grupos de proveniência, tomando por base rochas sedimentares antigas da Nova Zelândia, cuja proveniência é bem estabelecida e são utilizadas para construir funções discriminantes a partir dos elementos maiores. O diagrama proposto discrimina quatro grupos de proveniência: máfica - P1: arco de ilha oceânica; intermediária - P2: arco de ilha maduro; félsica - P3: margem continental ativa; e reciclado - P4: granítico-gnáissico ou fonte sedimentar.

As amostras do Grupo Península Trinity são classificadas como de margem continental ativa (Figura 19A), por mais que ocorra variação significativa na porcentagem de $\mathrm{SiO}_{2}$. Exceção é a amostra da Fm. Hope Bay (HB-MC-8-6), com menor quantidade de $\mathrm{K}_{2} \mathrm{O}$ que reflete a menor porcentagem modal em feldspato potássico, constatada em lâmina, indicando possível diferença no ambiente tectônico da área fonte, segundo o diagrama de Roser \& Korsch (1986). Já para os tipos de fonte as rochas do Grupo Península Trinity mostram-se fortemente divididas entre fontes de ambiente de margem continental ativa e recicladas (Figura 19B). Sendo que as amostras da Fm. Miers Bluff e do Grupo Península Trinity em Botany Bay são félsica de ambiente ativo, enquanto que as da formações Grauvaca-Folhelho, View Point e Hope Bay são de ambiente reciclado, notando que somente uma amostra da Fm. Hope Bay (HB-2-9) é classificada como intermediária. As amostras da Fm. Legoupil encontram-se igualmente divididas entre félsica e reciclada. 

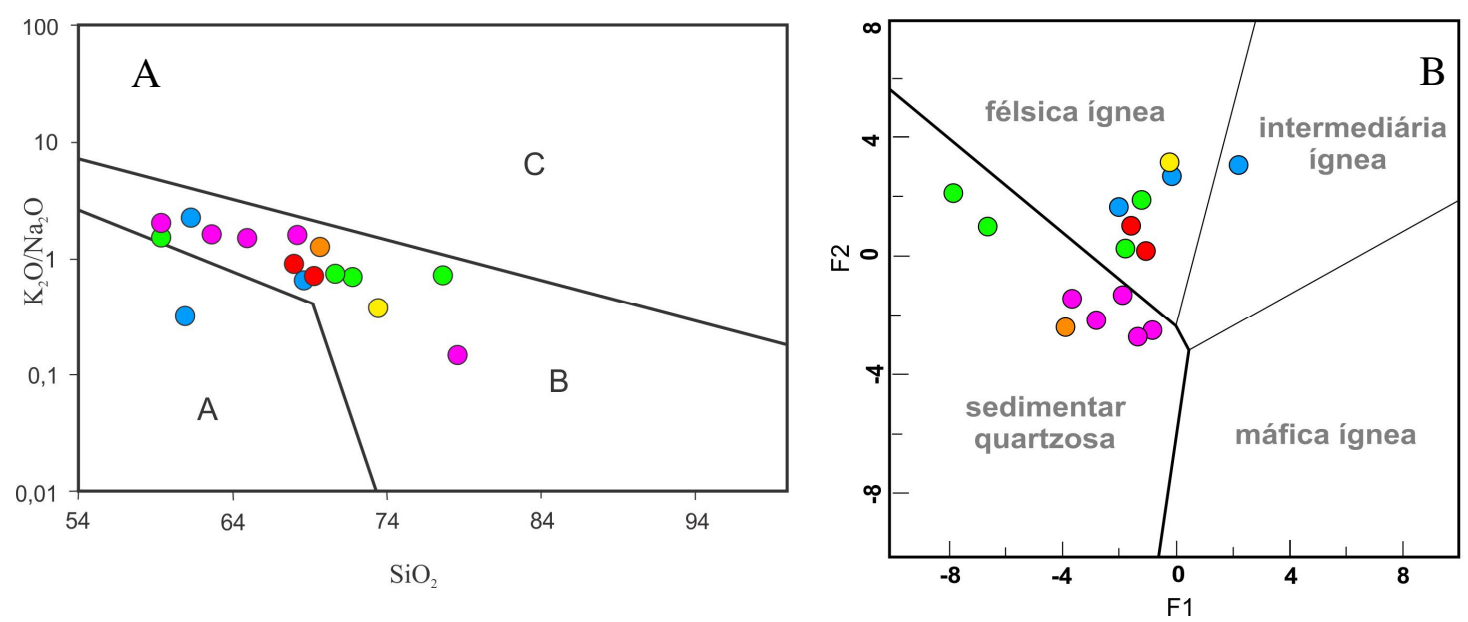

Figura 19. A. Diagrama de discriminação tectônica Roser \& Korsch (1986). A - Arco de Ilha Oceânica, B - Margem Continental Ativa e C - Margem Continental Passiva. B. Diagrama de Roser \& Korsch (1988). Em azul Fm. Hope Bay, em laranja Fm. Miers Bluff, em vermelho Fm. Grauvaca-Folhelho, em rosa TPG em Botany Bay, em amarelo Fm. View Point e em verde Fm. Legoupil.

Outro conjunto de diagramas que utiliza os elementos maiores para a inferência do ambiente tectônico foi elaborado por Bathia (1983), utilizando conjunto de amostras do leste da Austrália. Os gráficos são baseados no conceito geoquímico associado às variações químicas das rochas ao longo de sequência: arco de ilha oceânico - arco de ilha continental - margem continental ativa - margem passiva, em que decrescem as concentrações de $\mathrm{Fe}_{2} \mathrm{O}_{3(\mathrm{~T})}+\mathrm{MgO}, \mathrm{TiO}_{2}$ e $\mathrm{Al}_{2} \mathrm{O}_{3} / \mathrm{SiO}_{2}$ e crescem as concentrações de $\mathrm{K}_{2} \mathrm{O} / \mathrm{NaO}$ e $\mathrm{Al}_{2} \mathrm{O}_{3} /\left(\mathrm{CaO}+\mathrm{Na}_{2} \mathrm{O}\right)$. Os elementos $\mathrm{Fe}$ e Ti são úteis, pois sua baixa mobilidade geoquímica e seu baixo tempo de residência na água do mar impede uma alta concentração desses elementos em arenitos de margem continental depositadas em turbiditos (Blatt et al., 1980). Assim, a razão $\mathrm{Al}_{2} \mathrm{O}_{3} / \mathrm{SiO}_{2}$ indica o enriquecimento de quartzo nas amostras e a razão $\mathrm{K}_{2} \mathrm{O} / \mathrm{Na}_{2} \mathrm{O}$ é medida do conteúdo de feldspato potássico e mica, em contrapartida ao da de plagioclásio na rocha, enquanto que o parâmetro $\mathrm{Al}_{2} \mathrm{O}_{3} /\left(\mathrm{CaO}+\mathrm{Na}_{2} \mathrm{O}\right)$ é razão entre os elementos menos móveis aos mais móveis. $\mathrm{O}$ autor classifica os ambientes tectônicos em quatro grupos: A - Arco de Ilha Oceânica, B Arco de Ilha Continental, C- Margem Continental Ativa e D - Margem Passiva. Arco de ilha oceânica corresponde à bacias adjacentes a arcos de ilhas em crosta oceânica ou a arcos de ilha parcialmente formados sobre a crosta continental delgada. Arco de ilha continental corresponde à bacias sedimentares adjacentes a arcos de ilha formados sobre crosta continental bem desenvolvida ou em margens continentais delgadas. Margem continental ativa inclui bacias de retro-arco e marginais, e PM são margens continentais, 
bacias oceânicas remanescentes adjacentes a orógenos de colisão, e margens convergentes inativas ou extintas.
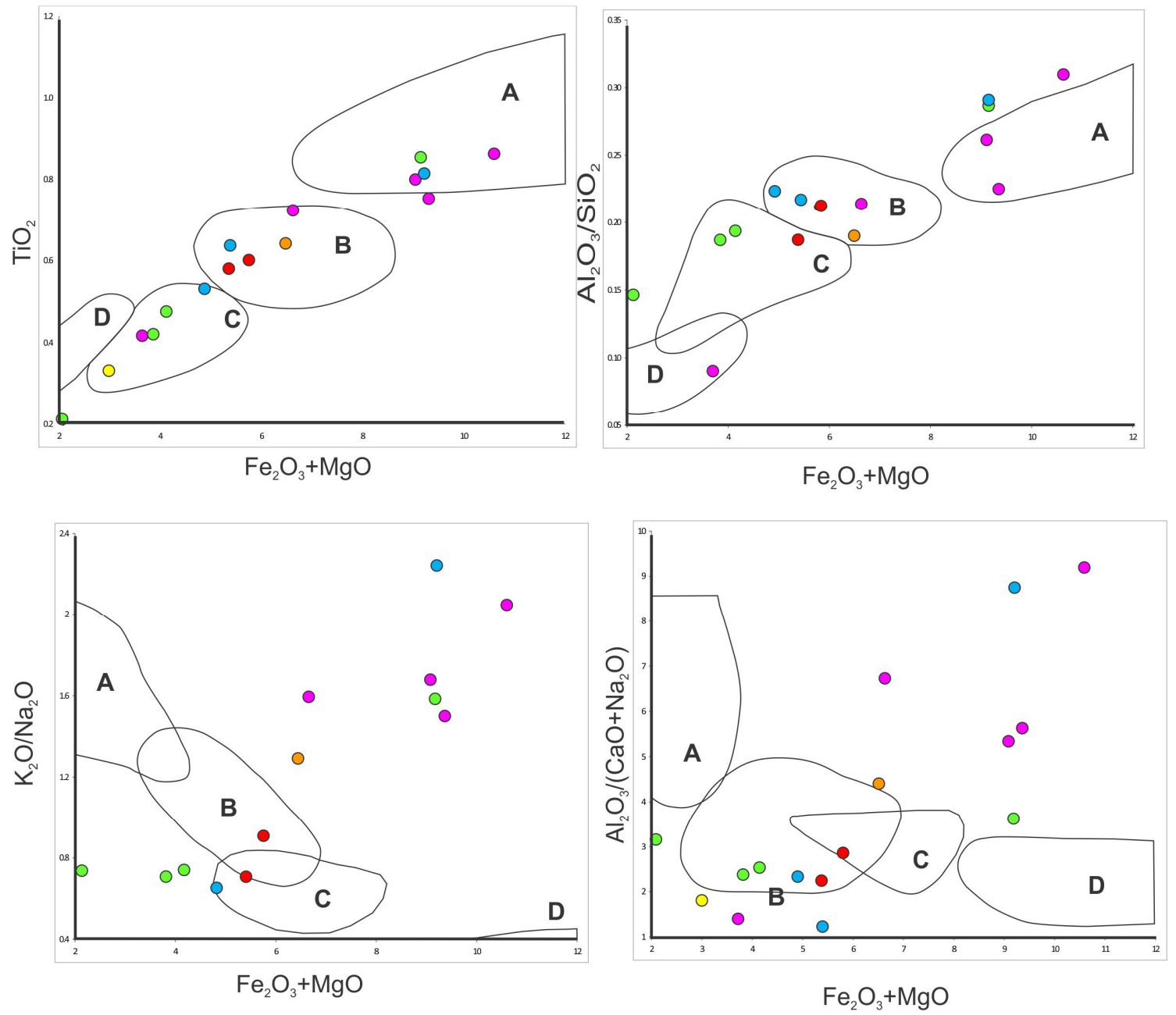

Figura 20. Amostras projetadas nos diagramas de discrimanação tectônica de Bathia (1983). Onde A - arco de ilha oceânica, B - arco de ilha continental, C - margem continental ativa, D - margem passiva. Em azul Fm. Hope Bay, em laranja Fm. Miers Bluff, em vermelho Fm. Grauvaca-Folhelho, em rosa TPG em Botany Bay, em amarelo Fm. View Point e em verde Fm. Legoupil.

As amostras do Grupo Península Trinity se encaixam pela descrição nos ambientes de arco de ilha continental e de margem continental ativa, em todas as comparações efetuadas, sendo que as amostras que classificam o Grupo nestes campos são as das formações Legoupil, View Point e Hope Bay. Já quando utilizada as comparações de $\mathrm{TiO}_{2}$ e $\mathrm{Al}_{2} \mathrm{O}_{3} / \mathrm{SiO}_{2}$, as amostras também se encaixam no campo de arco de ilhas oceânico, devido à alta afinidade com titânio e enriquecimento de quartzo, 
respectivamente. Em todos os casos, as amostras HB-MC-8-6 (Fm. Hope Bay), GA-2 (Fm. Legoupil) e BBR-87-7 (TPG em Botany Bay) se encontram separadas das demais amostras por conterem altas porcentagens de óxido de titânio (Figura 20).

A partir dos elementos traço foi possível usar o gráfico de Floyd \& Leveridge (1987), que se utiliza da razão La/Th vs Hf, onde as amostras do Grupo Península Trinity, Fm. Grauvaca-Folhelho e Fm. Miers Bluff estão alocadas no campo que indica fonte de arco andesítico e fonte mista félsica/básica, o que pode ser observado nas amostras pela presença de fragmentos líticos vulcânicos. Já as amostras do Grupo Península Trinity em Botany Bay e a amostra HB-MC-8-6, Fm. Hope Bay são projetadas no campo de fonte félsica, comprovada na petrografia com altas porcentagens de quartzo e feldspato (Figura 21). Uma das amostras analisadas do Grupo Península Trinity em Botany Bay, BBR-D-8A, não segue nenhuma tendência formada pelas outras amostras.

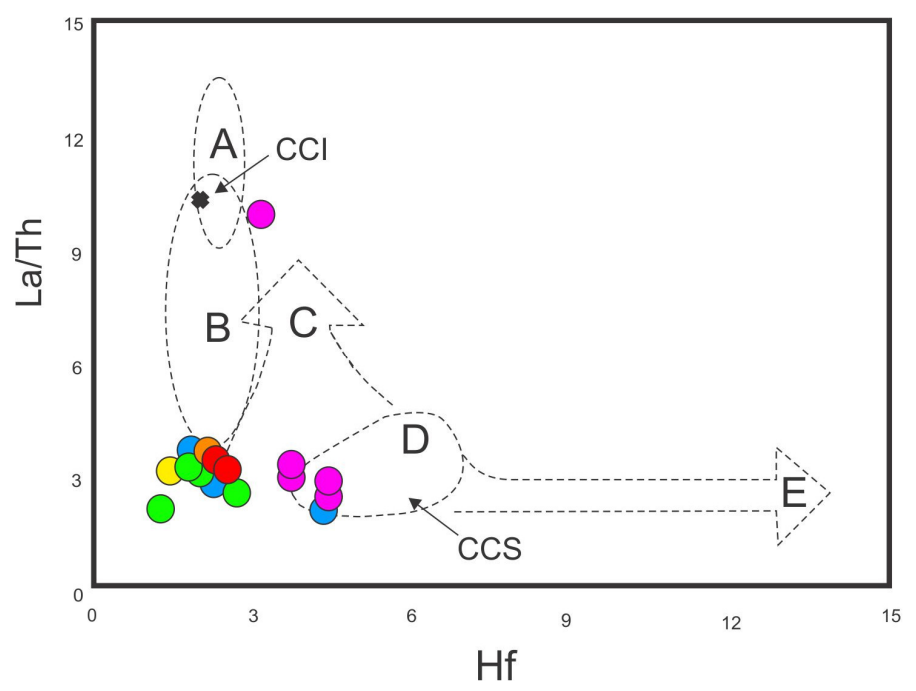

Figura 21. Diagrama discriminante modificado por Gu et al. (2002) a partir de Floyd \& Leveridge (1987). A - ilha oceânica (fonte toleítica), B - fonte de arco andesítico, C fonte mista félsica/básica, D - fonte félsica, E - sedimentos maduros, CCI - crosta continental inferior e CCS - crosta continental superior. Em azul Fm. Hope Bay, em laranja Fm. Miers Bluff, em vermelho Fm. Grauvaca-Folhelho, em rosa TPG em Botany Bay, em amarelo Fm. View Point e em verde Fm. Legoupil.

Existem ainda diversos gráficos para a caracterização da área fonte a partir do tratamento dos dados dos elementos traço, como o estudo de fontes evoluídas e primitivas a partir da razão $\mathrm{Th} / \mathrm{Sc}$ juntamente com as anomalias de Eu proposto por McLennan et al. (1999), análise da reciclagem sedimentar da rocha a partir das razões 
$\mathrm{Th} / \mathrm{Sc}$ vs $\mathrm{Zr} / \mathrm{Sc}$ também proposto por McLennan et al. (1993), o tipo de fonte por análises das razões $\mathrm{Co} / \mathrm{Th}$ vs La/Sc proposto por Gu et al. (2000) e épsilon neodímio vs Th/Sc sugerido por McLennan et al. (1993), são alguns dos principais exemplos. Para as amostras analisadas não foi possível fazer o estudo, pois as amostras apresentaram valores de Th e Sc abaixo dos limites de detecção das análises feitas.

\section{Geocronologia}

As amostras analisadas para o Grupo Península Trinity em Botany Bay apresentam valores de $\varepsilon N d$ entre -5 e -8 , calculados para $220 \mathrm{Ma}$, que indicam influência de fontes crustais com residência crustal, e idades $\mathrm{T}_{\mathrm{DM}}$ pouco variáveis, entre 1,2 e 1,6 Ga, indicando menor variedade de material fonte. As idades $\mathrm{U}-\mathrm{Pb}$ indicam contribuição de fontes antigas entre 1,0 a 1,09 Ga, condizentes com as idades $\mathrm{T}_{\mathrm{DM}}$, e idade concordante mais jovem de $324 \pm 8 \mathrm{Ma}$, com uma gama maior de idades para a área-fonte, indicando reciclagem sedimentar e fontes diversas, com idades Carboníferas, Cambrianas e Pré-Cambrianas. O $\varepsilon \mathrm{Hf}$ calculado para as idades de U-Pb mais jovens variam de $-1,2$ a $-5,7$, condizentes com o resultado de $\varepsilon N d$, e também indicam fonte com residência crustal, pois as idades $\mathrm{T}_{\mathrm{DM}}$ Hf entre 1,4 e 3,6 Ga, indicam reciclagem sedimentar e retrabalhamento de crosta do Mesoproterozóico em tempos mais recentes. A amostra da Formação Legoupil, que complementa os dados U-Pb para o Grupo Península Trinity, apresenta idade de grão de zircão mais jovem de $265 \pm 2$, restringindo a idade máxima de sedimentação ao Permiano.

Para as amostras da Formação Grauvaca-Folhelho as idades U-Pb de grãos detríticos de zircão apresentam duas concentrações de idades bem definidas, permotriássica e cambriana, com idade concordante mais jovem de $216 \pm 2$ Ma e mais velha de 1,8 $\pm 13 \mathrm{Ga}$. Idades condizentes com as datadas para o Grupo Península Trinity.

\section{4. Áreas fontes}

\subsection{América do Sul}

Na América do Sul afloram granitoides de idades permianas no maciço Nortepatagônico, que teve início de magmatismo no início do Permiano (Pankhurst et al., 2006) e tem sido interpretado como possível fonte dos complexos sedimentares permotriássicos da Patagônia, junto com o Grupo Choiyoi (Hervé et al., 2003). 
O Grupo Choiyoi consiste de sucessão de rochas vulcânicas félsicas de grande extensão, cuja atividade durou cerca de $30 \mathrm{Ma}$, durante o fim do Paleozóico, com três pulsos magmáticos reconhecidos em 281, 264 e 251 Ma (Rocha-Campos et al., 2011). No maciço Norte-patagônico também afloram rochas ordovicianas, análogas às do Arco Famantiniano do noroeste Argentino, granitoides devonianos, seguidos de granitos do tipo I e S do Carbonífero (Pankhurst et al., 2006). No maciço Deseado, ao sul do maciço Norte-patagônico também afloram granitoides do Siluriano e Devoniano (Pankhurst et al., 2003).

Na Terra do Fogo de Fuegohan, Hervé et al. (2010) reconheceram idades cambrianas de cristalização ígnea e evento metamórfico permiano de alto grau, que denominaram Complexo Ígneo e Metamórfico da Terra do Fogo.

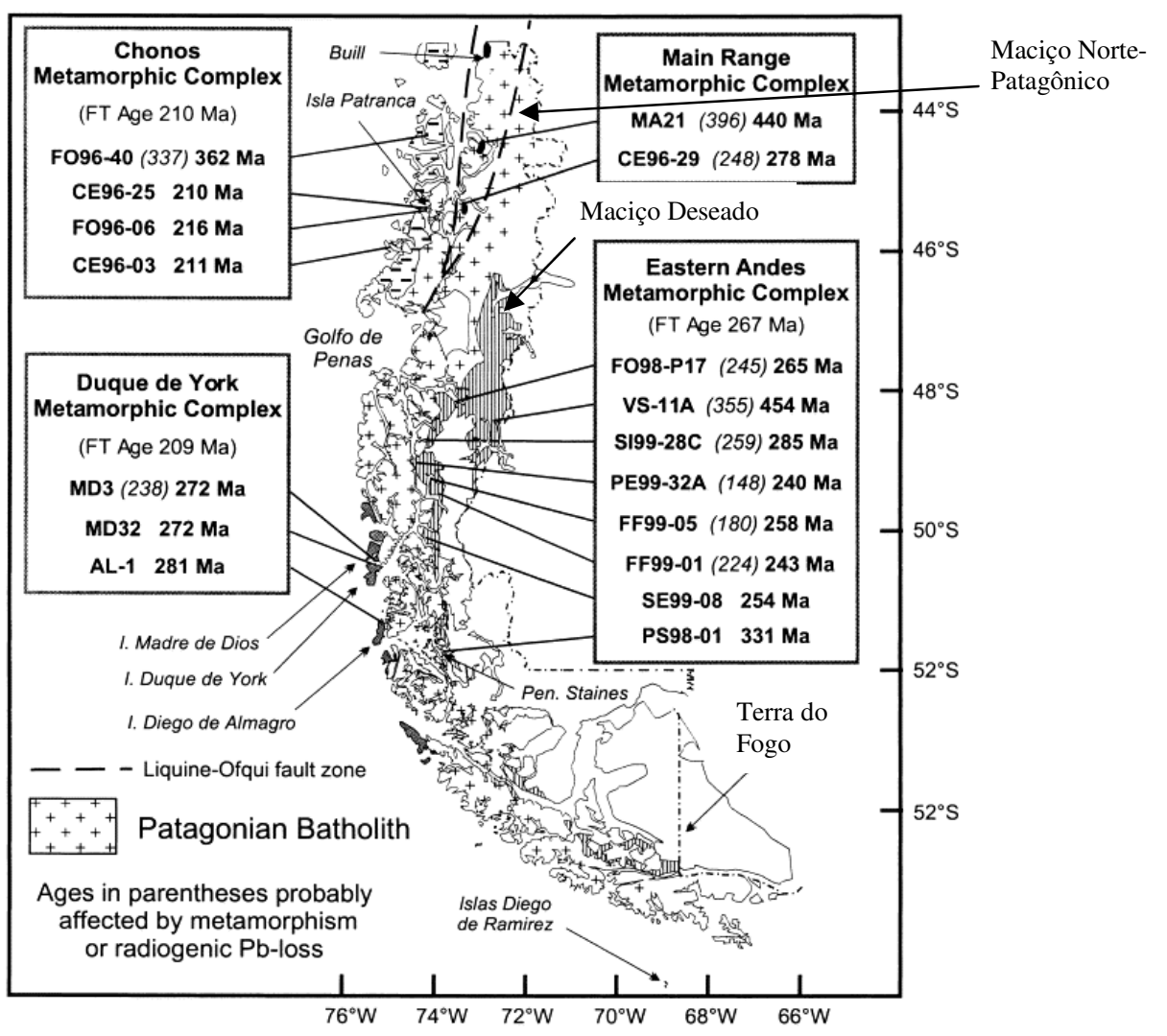

Figura 22. Figura extraída e modificada de Hervé et al. 2003 com as idades do sul dos Andes, indicando as fontes prováveis ao Grupo Península Trinity.

\subsection{Antártica}

A Antártica Ocidental é composta por quatro (Dalziel \& Elliot, 1982) ou cinco (Storey et al., 1988) blocos tectônicos, dentro dos quais está a Península Antártica e a 
Terra de Mary Byrd, onde afloram rochas de idade permiana (Pankhurst et al., 1998; Musaka \& Dalziel, 2000; Flowerdew et al., 2006; Millar et al., 2002).

Na Península Antártica, Millar et al. (2002) reconheceram episódio magmático importante de idade permiana, nas Terra de Palmer e Graham, no qual relacionou com os granitos permianos que afloram na Terra de Mary Byrd. Essas rochas representam episódio magmático cálcio-alcalino (Pankhurst et al., 1998), relacionado a arco vulcânico permiano (Musaka \& Dalziel, 2000) e serviram de fonte para as rochas vulcanoclásticas das montanhas Ellsworth e Transantárticas. Contudo os afloramentos deste arco magmático permiano são escassos tanto na Península Antártica como em Mary Bird.

Na terra de Mary Bird, especificamente na província de Ross, também afloram turbiditos ordovicianos, que estão intrudidos por granitoides do Devoniano e Carbonífero, correlacionados com os granitoides da Terra de Graham (Millar et al., 2002). Na província de Amundsen também afloram rochas intrusivas cálcio-alcalinas do Ordoviciano e Siluriano, idades que também ocorrem na Terra de Palmer (Millar et al., 2002; Flowerdew et al., 2006).

Assim sendo, na Antártica Ocidental e Patagônia ocorrem todas as idades e tipos de fontes estimadas para o Grupo Península Trinity em Botany Bay, Formação Legoupil e Formação Grauvaca-Folhelho, que foram estabelecidas com os dados apresentados neste trabalho. 


\section{CAPÍTULO VIII CONCLUSÃO}

Os gráficos usados para a classificação do ambiente tectônico de deposição de rochas sedimentares e segundo estes as amostras do Grupo Península Trinity indicam que os sedimentos foram depositados sobre bacia em margem continental passiva, com ambientes de áreas fontes diversas, possivelmente relacionadas à arcos de ilha continental. O mesmo ambiente é inferido para as amostras das formações Miers Bluff e Grauvaca-Folhelho.

A análise dos elementos traço e maiores indica que a fonte apresenta composição félsica, tipicamente de crosta continental, o que é apoiado pelo formato dos grãos de zircão e por sua química isotópica de Hf.

Os sedimentos do Grupo Península Trinity possuem afinidade com o ambiente de arco por apresentarem valores de $\varepsilon N d$ negativos a positivos, condizentes com os dados $\varepsilon H f$, indicando fonte crustal evoluída a juvenil. Ocorre fonte mais antiga e menos expressiva de longa residência crustal com $\varepsilon N d$ e $\varepsilon H f$ muito negativos. O tempo de residência crustal é de 1260 a 1630 Ma para as idades Sm, e entre 1399 a 3595 Ma, indicando a reciclagem sedimentar das fontes, o que pode ser constatado também por alguns grãos detríticos de zircão com núcleos herdados de idades muito antigas.

A partir dos dados de grãos detríticos de zircão pode-se definir como a idade principal das fontes para as formações Legoupil e Grauvaca-Folhelho como sendo permo-triássica, e para as rochas do Grupo Península Trinity em Botany Bay como cambrianas. Idades essas observadas em rochas da Patagônia, no maciço Nortepatagônico, e na Antártica Ocidental, na Terra de Mary Byrd. Estas condizem tanto em idade como em tipo de fonte, com fontes félsica, ígnea e metamórfica, com contribuição sedimentar.

Assim sendo, a melhor posição para a bacia sedimentar que originou as rochas aqui investigadas se coloca a oeste da posição atual da costa da América do Sul, com subsequente acresção na margem Pacífica, com posterior ruptura do Gondwana, rotação e migração para a atual posição da Península Antártica. 


\section{CAPÍTULO IX BIBLIOGRAFIA}

Adams, C.J., Pankhurst, R.J., Maas, R., Millar, I. L. 2005. Nd and Sr isotopic signatures of metasedimentary rocks around the South Pacific margin and implications for their provenance. Geological Society, London, Special Publications, 246: 113-141.

Adie, R.J. 1957. The Petrology of Graham Land: III. Metamorphic Rocks of the Trinity Peninsula. Series.Scientific ReportFalklandsIsland. Depend. Survey, 2026.

Andreis, R.R., Ribeiro. A., Trouw, R.A.J. 1997. Remarks on facies, paleocurrents and petrofacies of Triassic submarine fans from the Antarctic Peninsula, South Shetland Islands and South Orkney Islands. In: Ricci,C.A. (ed.), The Antarctic Region: Geological Evolution and Processes, 401-407.

Bahlburg, H., Vervoort, J.D., Du Frane, S.A., Barbara Bock, B., Augustsson, C., Reimann, C. 2009. Timing of crust formation and recycling in accretionary orogens: Insights learned from the western margin of South America. EarthScience Reviews, 97: 215-241.

Barbeau Jr, D. L., Davis, J. T., Murray, K. E., Valencia, V.,Gehrels, G. E., Zahid, K. M., Gombosi, D. J.. 2010. Detrital-zircon geochronology of the metasedimentary rocks of north-western Graham Land. Antarctic Scienc, 22(1): 65 - 78.

Bathia, M.R. 1983. Plate tectonics and geochemical composition of sandstone. Journal of Geology, 91: 611-627.

Bhatia, M. R. 1985. Rare Earth Element geochemistry of Australian Paleozoic graywackes and mudrocks: provenance and tectonic control. Sedimentary Geology, 45: 97 - 113.

Bathia, M.R., Crook, K.A.W. 1986. Trace element characteristics of greywackes and tectonic setting discrimination of sedimentary basins. Contributions to Mineralogy and Petrology, 92: 181-193.

Birkenmajer, K. 1993a. Jurassic terrestrial clastics (Mount Flora Formation) at Hope Bay, Trinity Peninsula (West Antarctica). Bulletin of the Polish Academy of Sciences: Earth Sciences, 41(1): 23-38.

Birkenmajer, K. 1993b. Geology of late Mesozoic magmatic rocks at Hope Bay, Trinity Peninsula (West Antarctica). Bulletin of the Polish Academy of Sciences: Earth Sciences, 41(1): 49-62.

Birkenmajer, K., Doktor, M., Swierczewska, A. 1997. A turbidite sedimentary log of the Trinity Peninsula Group (?Upper Permian-Triassic) at Paradise Harbour, Danco Coast (Antarctic Peninsula): sedimentology and petrology. Studia Geologica Polonica, 110: 61-90.

Bradshaw, J. D., Vaughan, A. P. M., Millar, I. L., Flowerdew, J. M., Trouw, R. A. J., 2012. Permo-Carboniferous conglomerates in the Trinity Peninsula Group at View 
Point, Antarctica Peninsula:sedimentologty, geochronology and isotope evidence for provenence and tectonic setting in Gondwana. Geological Magazine, 1-19.

Brito Neves, B.B., Cordani, U.G. 1991. Tectonic evolution of South América during the late Proterozoic.Precambrian Research, 53: 23-40.

BritoNeves, B.B., Campos Neto, M.C., Fuck, R.A.. 1999. From Rodinia to Western Gondwana: an approach to the Brasiliano-Pan African Cycle and orogenic collage. Episodes, 22: 155-166.

Blatt, H., Middleton, G., Murray, R. 1980. Origin of Sedimentary Rocks. Prentice-Hal,. New Jersey, 782.

Dalziel, I.W.D. 1984. Tectonic evolution of a forearcterrane, southern Scotia ridge, Antarctica.Geological Society of America Special Paper, 220: 32.

Dalziel, I. W. D., D. H. Elliot. 1982. West Antarctica: Problem child of Gondwanaland, Tectonics, 1(1): 3-19.

Dickinson, W.R. 1970. Interpreting detrital modes of graywacke and arkose. Journal of Sedimentary Petrology, 40: 695-707.

Dickinson, W.R., Suczek, C.A. 1979. Plate tectonic and sandstone compositions. American Association of Petroleum Geologist Bulletin, 63: 2164-2182.

Dickinson, W. R., 1985, Interpreting provenence relations from detrital modes of sandstones, Zuffa G.G. (ed.) Provenence of arenites, 333-361.

Del Valle, R. A., Heredia, N., Montes, M., Nozal, F., Mártin-Serrano, A., 2007. El Grupo Trinity Peninsula, extremo norte de la Península Antártica, Revista de laAsociación Geológica Argentina, 62(4), 498 - 505.

Farquharson, G.W. 1984. Late-Mesozoic, non-marine conglomeratic sequences of northern Antarctic Peninsula (the Botany Bay Group). British Antarctic Survey Bulletin, 65: 1-32

Faure, G., 1986. Principles of Isotope Geology, John Wiley \& Sons, Inc., Canada, pp 249-261; 282-304.

Ferris, J.K., Vaughan, A.P.M., Storey, B.C. 2000. Relics of a complex triple junction in the Weddell Sea embayment, Antarctica. Earth and Planetary Science Letters, 178 (3-4): 215-230.

Floyd, P.A., Leveridge, B.E. 1987. Tectonic environment of the Devonian Gramscatho basin, south Cornwall:framework mode and geochemical evidence from turbiditic sandstones. Journal of the Geological Society of London, 144: 531-542.

Flowerdew, M. J., Millar, I.L., Vaughan, A. P. M., Horstwood, M. S. A., Fanning, C.M. 2006. The source of granitic gneisses and migmatites in the Antarctic Peninsula: a combined U-Pb SHRIMP and laser ablation Hf isotope study of complex zircons. Contributions Mineralogy Petrology, 151: 751-768 
Flowerdew M.J., Millar I.L., Curtis M.L., Vaughan A.P.M., Horstwood M.S.A., Whitehouse M.J., Fanning C.M. 2007. Combined U-Pb geochronology and Hf isotope geochemistry of detrital zircons from early Paleozoic sedimentary rocks, Ellsworth-Whitmore Mountains block. Antarctica: Geological Society of America Bulletin, 119 (3-4): 275-288.

Flowerdew, M. J.; Riley, T. R.; Daley. S.; Leat, P. T. 2008. Summary of the geology and tectonic evolution of the South Orkney Islands, Antarctica. In: International Geological Congress, 33. Oslo, Noruega.Anais.

Gu, X.X., Liu, J.M., Zheng, M.H., Tang, J.X., Qi, L. 2002. Provenance and Tectonic Setting of the Proterozoic Turbidites in Hunan, South China: Geochemical Evidence. Journal of Sedimentary Research, 72(3): 393-407.

Halpern, M. 1965. The geology of the General Bernardo O’Higgins area, northwest Antarctic Peninsula, Geology and Paleontology of the Antarctic. Antarctic Research, 6: 177-209.

Haughton, P.D.W., Todd, S.P. y Morton, A.C. 1991. Sedimentary provenance studies. En Developments in Sedimentary Provenance Studies (Morton, A.C., Todd,S.P. y Haughton, P.D.W. editores). Geological Society Special Publication, 57: 1-12.

Hervé, F., Bahlburg, H., Fanning, C.M., Pankhurst, R.J., Thomson, S.N., Faúndez, V., Calderón, M., Augustsson, C. 2000. Field observations in the Patagonian Andes during the Penguin 2000 cruise: some considerations about the geological significance of previously unknown lithological units. IX Chilean Geological Congress (Puerto Varas, Chile).

Hervé, F., Fanning, C.M., Pankhurst, R.J. 2003. Detrital zircon age patterns and provenance of the metamorphic complexes of southern Chile. Journal of South American Earth Sciences, 16: 107-123.

Hervé, F., Faúndez, V., Brix, M., Fanning, M. 2006 Jurassic sedimentation of the Miers Bluff Formation, LivingstonIsland, Antarctica: evidence from SHRIMP U-Pb ages of detrital and plutonic zircons. Antarctic Science 18 (2), 229-238.

Hervé, F., Calderón, M., Fanning, C.M., Kraus, S., Pankhurst, R.J. 2010. SHRIMP chronology of the Magallanes Basin basement, Tierra del Fuego: Cambrian plutonism and Permian high-grade metamorphism. Andean Geology, 37(2): 253275.

Herron, M.M. 1988. Geochemical classification of terrigenous sands and shales from core or log data. Journal of Sedimentary Petrology, 58: 820-829.

Hobbs, G.J. 1968. The Geology of the South Shetland Islands: IV. LivingstonIsland: British Antarctic Survey Scientific Report, 47: 34p.

Hyden, G. \& Tanner, P.W.G., 1981.Late Paleozoic-early Mesozoic fore-arc basin sedimentary rocks at the Pacific margin in western Antarctica.GeologisheRundschau, 70, 529-541.

Hoffman, P.F. 1991. Did the breakout of turn Gondwanaland inside out? Science, 252: 
1409-1412.

Kinny, P. D., Mass, P.. 2003. Lu-Hf and Sm-Nd isotope systems in zircon. In: Hanchar, J. M. \& Hoskin, P. W. O. (eds): Zircon. Reviews in mineralogy and geochemistry. 53: $327-341$.

King, E.C., Barker, P.F. 1988. The margins of the South Orkney Microcontinent. Journal of the Geological Society of London, 145: 317-31.

Kraus, S., Miller, H., Dimov, D. Hegner, E., McWilliams, M., Pecskay, Z. 2008. Structural geology of the Mesozoic Miers Bluff Formation and crosscutting paleogene dikes (Livingston Island, South Shetland Islands, Antarctica) - Insights into the geodynamic history of the northern Antarctic Peninsula. Journal of South American Earth Sciences, 26: 498-512.

Leat, P.T., Scarrow, J.H., Millar, I.L. 1995. On the Antarctic Peninsula batholith. Geological Magazine, 132(4): 399-412.

Loske, W., Miller, H., Kramm, U. 1988. U-Pb systematics of detrital zircons from lowgrade metamorphic sandstones of the Trinity Peninsula Group (Antarctica). Journal of South American Earth Sciences, 1: 301-307.

Loske, W., Miller, H., Milne, A., Hervé, F. 1990. U-Pb zircon ages of xenoliths from Cape Dubouzet, northern Antarctic Peninsula. Zentralblatt für Paläontologie, 1: 87-95.

Loske, W., Miller, H. 1991. U-Pb and Rb-Sr geochronology on conglomerate boulders from View Point, Graham Land, Antarctic Peninsula. Abstracts, Sixth International Symposium on Antarctic Earth Sciences: Japan, National Institute of Polar Research, 369-373.

Mcculloch, M. T.; Wasserburg, 1978. Sm-Nd and Rb-Sr chronology of continental crust formation. Science, 200 (4345),1003-1011.

McLennan, S.M., McCulloch, M.T., Taylor, S.R., Maynard, J.B. 1989. Effects of sedimentary sorting on Nd-isotopes in deep-sea turbidites. Nature, 337: 547-549.

McLennan, S.M., Taylor, S.R., McCulloch, M.T., Maynard, J.B. 1990. Geochemical an $\mathrm{Nd}-\mathrm{Sr}$ isotopic composition of deep-sea turbidites: crustal evolution and plate tectonics associations. Geochimica et Cosmochimica Acta, 54: 2015- 2050.

McLennan, S.M., Taylor, S. 1991. Sedimentary rocks and crustal evolution: Tectonic setting and secular trends. Journal of Geology, 99: 1-21.

McLennan, S.M., Hemming, S., McDaniel, D.K., Hanson, G.N. 1993. Geochemical approaches to sedimentation, provenance and tectonics. En Processes controlling the composition of clastic sediments (Johnnson, M.J. y Basu, A. editores.). Geological Society of America Special Papers, 285: 21-40.

Mclennan, S. M. 2001. Relationships between the trace element composition of sedimentary rocks and upper continental crust. Geochemistry, Geophysics, Geosystems, 2. 
Millar, I.L., Pankhurst, R.J., Fanning, C.M. 2002. Basement Chronology of the Antarctic Peninsula: recurrent magmatism and anatexis in the Paleozoic Gondwana Margin. Journal of the Geological Society, 159, 145-157.

Moraes, R.; Valadares, D. M. P.; Trouw, R. A.; Dantas, E. L.; Simões, L. S; Tavares, F.; Ribeiro, A.; Paciullo, F. V. (in memoriam). 2012. Sm-Nd for tracing provenance of the Trinity Peninsula Group and correlated units, Antarctica: Implications for Late Paleozoic-Mesozoic Evolution of Gondwana Margin. Geological Society Special Publication: Antarctica and Supercontinent Evolution. (submetido)

Mori, P. E.; Reeves, S.; Correia, C. T.; Haukka, M. 1999. Development of a fused glass disc XRF facility and comparison with pressed powder pellet technique at Instituo de Geociências, São Paulo University. Revista Brasileira de Geociências, 2 (3), 441-446.

Morton A.C. y Hallsworth C.R. 1999. Processes controlling the composition of heavy mineral assemblages in sandstones. Sedimentary Geology, 124: 3-29.

Mukasa, S., Dalziel, I. 2000. Marie Byrd Land, West Antarctica: Evolution of Gondwana's Pacific margin constrained by zircon U-Pb geochronology and feldspar common-Pb isotopic compositions. Geological Society of America Bulletin, 112: 611-627.

Navarro, M. S., Andrade, S., Ulbrich, H., Gomes, C. B., Giraldi, V. A. V. 2008. The direct determination of rare Earth elements in basaltic and related rocks using ICPMS: Testing the efficiency of microwave oven sample decomposition procedures. Geostandards and geoanalytical research, 32(2): 167-168.

Nesbitt, H.W., Young, G.M. 1982. Early Proterozoic climates and plate motions infered from mayor element chemistry of lutites. Nature, 199: 715-717.

Nesbitt, H.W., Young, G.M. 1984. Prediction of some weathering trends of plutonic and volcanic rocks based on thermodynamic and kinetic considerations. Geochimica et Cosmochimica Acta, 48: 1523-1534.

Paciullo, F.V.P.; Andreis, R.R.; Ribeiro, A. \& Trouw, R.A.J. 2001. Facies and facies association of the Hope Bay Formation at Hope Bay, Antarctic Peninsula. In: Gamble, J.A.; Skinner, D.N.B.; Henrys, S. \& Linch, R. (editors) "Antarctica at the close of a Milenium", Proceedings 8th International Symposia on Antarctic Earth Sciences, Royal Society of New Zealand Bulletin 35.

Pankhurst, R.J., 1983. Rb-Sr constraints on the ages of basement rocks of the Antarctic Peninsula. In: Oliver, R.L., James, P.R., Jago, J.B. (Eds.), Antarctic Earth Science - Proceedings of the Fourth International Symposium on Antarctic Earth Sciences, Adelaide, South Australia. AustralianAcademy of Sciences, CambridgeUniversity Press, Canberra, 367-371.

Pankhurst, R.J.,Weaver, S. D., Bradshaw, J. D., Storey, B. C., Ireland, T. R. 1998. Geochronology and geochemistry of pre-Jurassic superterranes in Marie Byrd Land, Antarctica: Journal of Geophysical Research, 103: 2529-2547. 
Pankhurst, R.J., Rapela, C.W., Loske, W.P., Fanning, C.M., Márquez, M. 2003. Chronological study of the pre- Permian basement rocks of southern Patagonia. Journal of South American Earth Sciences, 16: 27-44.

Pankhurst, R.J., Rapela, C.W., Fanning, C.M., Márquez, M. 2006. Gondwanide Continental collision and the origin of Patagonia. Earth-Science Reviews 76: 235257.

Pettijohn, F.J. Potter, P.E., Siever, R. 1972. Sand and Sandstones. Springer- Verlag, New York. 618.

Pimpirev, C., Ivanov, M., Dimov, D., Nikolov, T. 2002. First find of the Upper Tithonian ammonite genus Blandfordiceras from the Miers Bluff Formation, LivingstonIsland, South Shetland Islands. NeuesJahrbuchfürGeologie und Paläotologie, 6, 377-384.

Ramos, V.A., Aleman, A., 2000. Tectonic Evolution of the Andes, in Cordani, U., Milani, E.J., ThomazFilho, A., and Campos Neto, M.C., eds., Tectonic Evolution of South America: Rio de Janeiro, 635-685.

Ramos, V.A. 2008. A paleozoic continental drift? Journal of South American Earth Sciences.26: $235-251$.

Rocha-Campos, A.C., Basei, M.A., Nutman, A.P., Kleiman, Laura E., Varela, R., Llambias, E., Canile, F.M., da Rosa, O.C.R. 2011. 30 million years of Permian volcanism recorded in the Choiyoi igneous province (W Argentina) and their source for younger ash fall deposits in the Paraná Basin: SHRIMP U-Pb zircon geochronology evidence. Gondwana Research, 19(2): 509-523.

Roser, B.P., Korsch, R.J. 1986. Determination of tectonic setting of sandstonesmudstone suites using $\mathrm{SiO}_{2}$ content and $\mathrm{K}_{2} \mathrm{O} / \mathrm{Na}_{2} \mathrm{O}$ ratio. Journal of Geology, 94(5): 635-650.

Roser, B.P., Korsch, R.J. 1988. Provenance signatures of sandstone-mudstone suites determined using discriminant function analysis of major-element data. Chemical Geology, 67: 119-139.

Roser, B.P. 2000. Whole-rock geochemical studies of clastic sedimentary suites. Memoirs of the Geological Society of Japan, 57: 73-89.

Sato K., Tassinari C. C. G., Kawashita K., Petronilho, L.A. 1995. O método geocronológico Sm-Nd no IGc-USP e suas aplicações. Academia Brasileira de Geociências, 67 (3): 313-336.

Smellie, J.L., 1987, Sandstone detrital modes and basinal settings of the Trinity Peninsula Group, Northern Graham Land, Antarctic Peninsula: A preliminary survey. Tectonics and Geophysics: American Geophysical Union, Geophysical Monograph 40, p. 199-207.

Smellie, J.L. y Millar, I.L. 1995. New K-Ar isotopic ages of schists from Nordenskjold Coast, Antarctic Peninsula:oldest part of the Trinity Peninsula Group? Antarctic Science, 7: 191-96. 
Storey, B.C., \& Garrett, S.W., 1985, Crustal growth of the Antarctic Peninsula by accretion, magmatism and extension: Geological Magazine, 122: 5-14.

Storey, B.C., Hole, M.J., Pankhurst, R.J., Millar, I.L., Vennum, W. 1988. Middle Jurassic within-plate granites in west Antarctica and their bearing on the break-up of Gondwanaland. Journal of the Geological Society, London, 145: 997- 1007.

Smellie, J.L. 1981. A complete arc-trench system recognized in Gondwana sequences of the Antarctic Peninsula region.Geological Magazine, 118 (2): 139-159.

Smellie, J.L. 1991. Stratigraphy, provenance and tectonic setting of (?) late PaleozoicTriassic sedimentary sequences in northern Graham Land and South Scotia Ridge. In: Thomson M.R.A.; Crame, J.A.; Thomson, J. W. (eds.). Geological evolution of Antartctica, Cambrigde: Cambrigde University Press, 411-417.

Tanner, P.W.G.; Pankhurst, R.J.; Hyden,G. 1982. Radiometric evidence for the age of the subduction complex in the South Orkney and South Shetland Islands, West Antarctica. Journal of the Geological Society, London 139, 683-90.

Taylor, S. R.; Mclenann, S. M. 1985. The Continental Crust: Its composition an evolution. Oxford: Blackwell, 312p.

Taylor, S. R.; Mclenann, S. M. 1995. The geochemical evolution of the continental crust. Reviews of Geophysics, (33): 241-265,

Thomson, J. W. 1975. New palaentological and lithological observations on the Legoupil Formation, North-westAntarticPeninsula.Bulletin of British Antarctic Survey, 41/42, 169-185.

Trouw, R.A.J., Passchier, C.W., Simões, L.S.A., Andreis, R.R. \&Valeriano, C.M. 1997a. Mesosoic tectonic evolution of the South Orkney Microcontinent, Scotia Arc. Antarctica.Geological Magagazine, 134 (3): 383-401.

Trouw, R. A. J., Pnkhurst, R. J., Ribeiro, A., 1997b. On the relation between the Scotia metamorphic complex and the Trinity Peninsula Group, Antarctic Península, The Antarctic Region: Geological Evolution and Processes, 383-389.

Valadares, D.M.P., 2012. Evolução metamórfica das rochas da região de Stene Point, Ilha Coronation, Microcontinente das Orcadas do Sul - Antártica. Tese de mestrado, IGc-USP.

Vaughan, A.P.M., Storey, B. C. 2000. The eastern Palmer Land shear zone: a new terrane accretion model for the Mesoic development of the Antarctic Peninsula. In Journal of the Geological Society, London, British Antarctic Survey, 157: 12431256.

Vaughan, A.P.M., Pankhurst, R.J.,2008. Tectonic overview of the West Gondwana Margin. Gondwana Research, 13: 150-162.

White, W. M. Radiogenic Isotope Geochemistry. Ithaca: Cornell University, 2009. Disponível em: www.geo.cornell.edu/geology/classes/Chapters/Chapter08.pdf. Acesso em: 15 Dec de 2012. 
Willan, R.C.R. 2003. Provenance of Triassic-Cretaceous Sandstones in the Antarctic Peninsula: Implications for Terrane Models During Gondwana Breakup. Journal of Sedimentary Research, 73 (6): 1062-1077.

Xiguang, D., Xiangshen, Z., Xiaohan, L., Ouyang, S., Yanbin, S. 2002. Terrestrial palynomorphs from teh Miers Bluff Formation of Livingston Island, West Antarctica.Antarctica at the close of a millennium. Royal Society of New Zealend Bulletin 35, 269-273. 


\section{ANEXO I}

RESULTADOS FLUORESCÊNCIA DE RAIOS-X (FRX) 


\begin{tabular}{|c|c|c|c|c|c|c|c|c|c|c|c|c|c|}
\hline & HB-2.9 & $\begin{array}{c}\text { HB- } \\
94.87 .2\end{array}$ & $\begin{array}{c}\text { HB-MC- } \\
8.6\end{array}$ & COP-4-I & PMI-7 & $\begin{array}{c}\text { PMI-7 } \\
\text { duplicata }\end{array}$ & GA-2 & ILP-1 & IL4-3 & $\begin{array}{c}\text { LV- } \\
\text { RFS-21 }\end{array}$ & L-2.1 & $\begin{array}{c}\text { L-2.1 } \\
\text { duplicata }\end{array}$ & L-4a-2 \\
\hline $\mathrm{SiO}_{2}$ & 61.03 & 68.67 & 61.39 & 73.46 & 59.51 & 59.58 & 77.77 & 71.76 & 70.92 & 69.74 & 68.08 & 68.16 & 69.37 \\
\hline $\mathrm{TiO}_{2}$ & 0.636 & 0.531 & 0.816 & 0.330 & 0.852 & 0.853 & 0.204 & 0.420 & 0.478 & 0.642 & 0.603 & 0.601 & 0.580 \\
\hline $\mathrm{Al}_{2} \mathbf{O}_{3}$ & 13.20 & 15.25 & 17.82 & 12.04 & 17.10 & 17.10 & 11.43 & 13.39 & 13.71 & 13.18 & 14.39 & 14.44 & 13.05 \\
\hline $\mathrm{Fe}_{2} \mathrm{O}_{3}$ & 3.81 & 3.40 & 6.72 & 2.29 & 6.40 & 6.39 & 1.35 & 2.75 & 3.03 & 4.69 & 4.07 & 4.08 & 3.88 \\
\hline MnO & 0.170 & 0.053 & 0.125 & 0.087 & 0.088 & 0.088 & 0.022 & 0.053 & 0.040 & 0.070 & 0.053 & 0.052 & 0.052 \\
\hline MgO & 1.60 & 1.48 & 2.48 & 0.70 & 2.75 & 2.72 & 0.73 & 1.06 & 1.10 & 1.78 & 1.68 & 1.67 & 1.49 \\
\hline $\mathrm{CaO}$ & 6.98 & 2.42 & 0.34 & 1.95 & 2.23 & 2.22 & 0.42 & 1.90 & 1.89 & 0.42 & 1.95 & 1.96 & 2.49 \\
\hline $\mathrm{Na}_{2} \mathrm{O}$ & 3.90 & 4.09 & 1.70 & 4.78 & 2.53 & 2.50 & 3.20 & 3.69 & 3.51 & 2.56 & 3.15 & 3.15 & 3.26 \\
\hline $\mathbf{K}_{2} \mathbf{O}$ & 1.90 & 2.66 & 3.81 & 1.76 & 4.00 & 3.98 & 2.38 & 2.54 & 2.60 & 3.29 & 2.86 & 2.87 & 2.30 \\
\hline P2O5 & 0.117 & 0.113 & 0.159 & 0.099 & 0.205 & 0.205 & 0.034 & 0.112 & 0.144 & 0.156 & 0.148 & 0.147 & 0.145 \\
\hline Loi & 5.78 & 0.28 & 3.65 & 1.54 & 3.06 & 3.00 & 1.24 & 1.25 & 1.21 & 2.04 & 1.83 & 1.92 & 2.34 \\
\hline Total & 99.12 & 98.95 & 99.01 & 99.04 & 98.73 & 98.64 & 98.78 & 98.93 & 98.63 & 98.57 & 98.81 & 99.05 & 98.96 \\
\hline
\end{tabular}




\begin{tabular}{|c|c|c|c|c|c|c|c|c|c|}
\hline & BBR-87-7 & BBR-23.2 & BBR-19.1 & BBR-18.3 & $\begin{array}{l}\text { BBR-18.3 } \\
\text { duplicata }\end{array}$ & BBR-D-8A & \multicolumn{2}{|c|}{ JB 1a } & LD \\
\hline & & & & & & \multicolumn{4}{|c|}{ Obtida Recomendada } \\
\hline $\mathrm{SiO}_{2}$ & 59.45 & 68.26 & 62.64 & 65.06 & 64.92 & 78.54 & 52.54 & 52.16 & 0.03 \\
\hline $\mathrm{TiO}_{2}$ & 0.861 & 0.725 & 0.801 & 0.754 & 0.754 & 0.418 & 1.295 & 1.3 & 0.003 \\
\hline $\mathbf{A l}_{2} \mathbf{O}_{3}$ & 18.39 & 14.59 & 16.34 & 14.65 & 14.61 & 7.15 & 14.63 & 14.51 & 0.02 \\
\hline $\mathrm{Fe}_{2} \mathrm{O}_{3}$ & 7.92 & 4.70 & 6.66 & 7.20 & 7.20 & 2.63 & 9.01 & 9.1 & 0.01 \\
\hline MnO & 0.085 & 0.111 & 0.090 & 0.097 & 0.098 & 0.094 & 0.148 & 0.15 & 0.002 \\
\hline MgO & 2.67 & 1.93 & 2.40 & 2.15 & 2.13 & 1.05 & 7.87 & 7.75 & 0.01 \\
\hline $\mathrm{CaO}$ & 0.27 & 0.20 & 0.95 & 0.74 & 0.73 & 2.26 & 9.24 & 9.23 & 0.01 \\
\hline $\mathrm{Na}_{2} \mathrm{O}$ & 1.73 & 1.97 & 2.09 & 1.86 & 1.88 & 2.92 & 2.75 & 2.74 & 0.02 \\
\hline $\mathbf{K}_{2} \mathbf{O}$ & 3.55 & 3.14 & 3.50 & 2.79 & 2.78 & 0.43 & 1.4 & 1.42 & 0.01 \\
\hline P2O5 & 0.179 & 0.144 & 0.229 & 0.475 & 0.471 & 0.074 & 0.259 & 0.26 & 0.003 \\
\hline Loi & 4.00 & 3.02 & 3.14 & 3.30 & 3.30 & 3.26 & 1.1 & 1.1 & 0.01 \\
\hline Total & 99.11 & 98.79 & 98.84 & 99.08 & 98.87 & 98.83 & 100.24 & 99.72 & \\
\hline
\end{tabular}




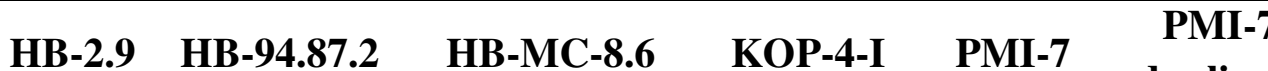

duplicata

\section{GA-2 ILP-1 IL4-3 LV-RFS-}

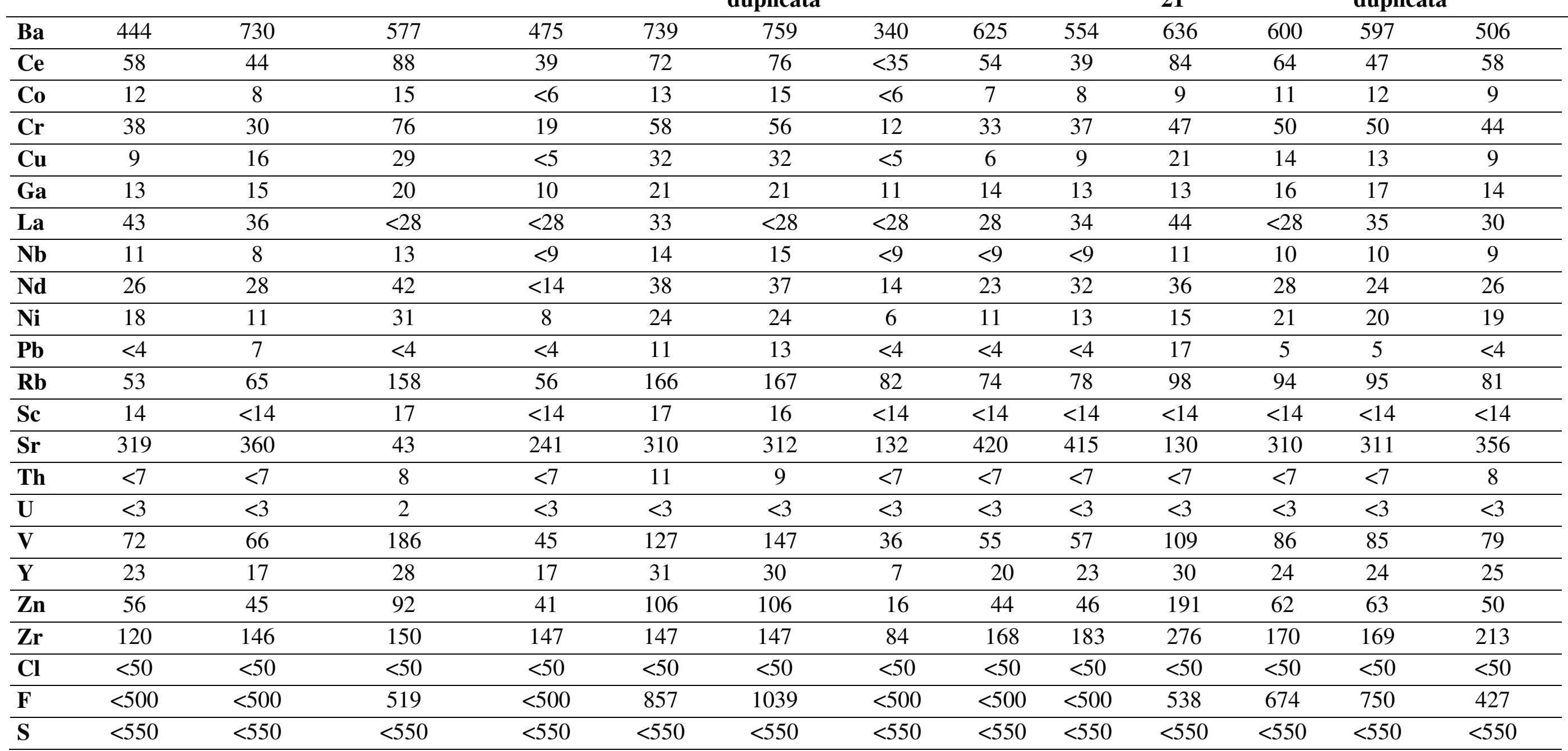




\begin{tabular}{|c|c|c|c|c|c|c|c|c|c|}
\hline & BBR-87-7 & BBR-23.2 & $\begin{array}{c}\text { BBR- } \\
19.1\end{array}$ & BBR-18.3 & $\begin{array}{l}\text { BBR-18.3 } \\
\text { duplicata }\end{array}$ & BBR-D-8A & & $1 a$ & LD \\
\hline $\mathbf{B a}$ & 776 & 549 & 581 & 567 & 542 & 110 & 523 & 497 & 37 \\
\hline $\mathrm{Ce}$ & 72 & 75 & 85 & 94 & 88 & $<35$ & 90 & 66.1 & 35 \\
\hline Co & 18 & 20 & 18 & 20 & 23 & $<6$ & 38 & 39.5 & 6 \\
\hline $\mathrm{Cr}$ & 76 & 77 & 73 & 69 & 74 & 27 & 414 & 415 & 13 \\
\hline $\mathrm{Cu}$ & 26 & 23 & 23 & 25 & 26 & $<5$ & 55 & 55.5 & 5 \\
\hline Ga & 21 & 18 & 21 & 16 & 16 & $<9$ & 16 & 18 & 9 \\
\hline La & 45 & 37 & 37 & 47 & 51 & $<28$ & 34 & 38.1 & 28 \\
\hline $\mathbf{N b}$ & 12 & 13 & 14 & 13 & 13 & $<9$ & 27 & 27 & 9 \\
\hline Nd & 37 & 36 & 45 & 56 & 43 & 20 & 50 & 25.5 & 14 \\
\hline $\mathbf{N i}$ & 33 & 42 & 36 & 32 & 31 & 9 & 144 & 140 & 5 \\
\hline $\mathbf{P b}$ & $<4$ & 35 & 7 & 11 & 11 & $<4$ & 9 & 7.2 & 4 \\
\hline $\mathbf{R b}$ & 150 & 137 & 147 & 114 & 114 & 19 & 38 & 41 & 3 \\
\hline Sc & 20 & $<14$ & 16 & 14 & 15 & $<14$ & 26 & 27.9 & 14 \\
\hline $\mathrm{Sr}$ & 47 & 38 & 142 & 61 & 60 & 111 & 447 & 443 & 2 \\
\hline Th & 8 & $<7$ & 8 & 9 & 9 & $<7$ & $<7$ & 8.8 & 7 \\
\hline $\mathbf{U}$ & $<3$ & $<3$ & $<3$ & $<3$ & $<3$ & $<3$ & $<3$ & 1.6 & 3 \\
\hline $\mathbf{V}$ & 139 & 117 & 117 & 96 & 101 & 61 & 212 & 220 & 9 \\
\hline $\mathbf{Y}$ & 33 & 30 & 33 & 44 & 43 & 21 & 23 & 24 & 2 \\
\hline $\mathbf{Z n}$ & 119 & 80 & 99 & 103 & 103 & 29 & 81 & 82 & 2 \\
\hline $\mathbf{Z r}$ & 148 & 168 & 148 & 147 & 147 & 245 & 141 & 146 & 2 \\
\hline $\mathbf{F}$ & 809 & 911 & 760 & 980 & 887 & $<500$ & $<500$ & 385 & 500 \\
\hline $\mathbf{S}$ & $<550$ & $<550$ & $<550$ & 1592 & 1590 & $<550$ & $<550$ & 9 & 550 \\
\hline
\end{tabular}




\section{ANEXO II}

RESULTADOS ESPECTROMETRIA DE MASSA (ICP-MS) 


\begin{tabular}{|c|c|c|c|c|c|c|c|c|c|}
\hline & HB-2-9 & HB-94-87-2 & HB-MC8-6 & KOP-4-I & PMI-7 & GA-2 & ILP-1 & IL4-3 & LV-RFS-21 \\
\hline $\mathbf{R b}$ & 56.9 & 74.8 & 169 & 62.5 & 163 & 88.7 & 80.7 & 89.7 & 114 \\
\hline Sr & 340 & 414 & 52.2 & 272 & 322 & 137 & 472 & 480 & 147 \\
\hline $\mathbf{Y}$ & 22.3 & 17.3 & 31.7 & 18.0 & 30.7 & 6.75 & 20.3 & 23.7 & 26.7 \\
\hline $\mathbf{Z r}$ & 64.7 & 78.2 & 162 & 51.2 & 91.9 & 45.5 & 63.8 & 74.1 & 78.6 \\
\hline $\mathbf{N b}$ & 12.0 & 9.22 & 14.6 & 6.55 & 15.9 & 4.20 & 8.60 & 9.62 & 11.8 \\
\hline Cs & 1.18 & 1.90 & 6.62 & 0.67 & 7.50 & 1.83 & 1.81 & 2.36 & 2.47 \\
\hline $\mathbf{B a}$ & 492 & 859 & 644 & 537 & 761 & 362 & 679 & 637 & 706 \\
\hline La & 43.0 & 29.4 & 34.2 & 27.0 & 37.0 & 11.9 & 32.2 & 34.8 & 55.8 \\
\hline $\mathrm{Ce}$ & 89.0 & 59.5 & 78.3 & 54.9 & 75.3 & 24.6 & 63.5 & 68.9 & 109 \\
\hline Pr & 10.1 & 6.80 & 8.77 & 6.43 & 9.24 & 2.85 & 7.64 & 8.44 & 12.8 \\
\hline Nd & 37.1 & 25.3 & 33.4 & 24.1 & 35.7 & 10.5 & 28.6 & 31.8 & 47.3 \\
\hline $\mathrm{Sm}$ & 6.68 & 4.74 & 6.82 & 4.67 & 7.35 & 1.97 & 5.43 & 6.15 & 8.53 \\
\hline $\mathbf{E u}$ & 1.26 & 1.09 & 1.27 & 0.92 & 1.35 & 0.43 & 1.11 & 1.23 & 1.40 \\
\hline Gd & 4.81 & 3.66 & 5.80 & 3.68 & 6.27 & 1.47 & 4.31 & 4.89 & 6.25 \\
\hline $\mathbf{T b}$ & 0.77 & 0.57 & 0.97 & 0.59 & 1.00 & 0.22 & 0.67 & 0.78 & 0.92 \\
\hline Dy & 4.17 & 3.16 & 5.57 & 3.26 & 5.55 & 1.27 & 3.67 & 4.34 & 4.98 \\
\hline Ho & 0.88 & 0.66 & 1.24 & 0.68 & 1.18 & 0.26 & 0.77 & 0.91 & 1.03 \\
\hline Er & 2.34 & 1.79 & 3.51 & 1.81 & 3.20 & 0.76 & 2.06 & 2.41 & 2.76 \\
\hline Tm & 0.34 & 0.26 & 0.53 & 0.26 & 0.47 & 0.11 & 0.30 & 0.35 & 0.40 \\
\hline $\mathbf{Y b}$ & 2.17 & 1.71 & 3.51 & 1.62 & 3.00 & 0.82 & 1.90 & 2.25 & 2.65 \\
\hline Lu & 0.32 & 0.25 & 0.53 & 0.23 & 0.44 & 0.12 & 0.28 & 0.32 & 0.39 \\
\hline Hf & 1.99 & 2.28 & 4.46 & 1.57 & 2.74 & 1.29 & 1.91 & 2.16 & 2.30 \\
\hline $\mathbf{P b}$ & 18.8 & 24.4 & 14.4 & 10.0 & 26.4 & 3.04 & 17.3 & 18.8 & 40.7 \\
\hline Th & 11.5 & 10.4 & 15.4 & 8.52 & 14.0 & 5.43 & 10.1 & 11.0 & 17.4 \\
\hline $\mathbf{U}$ & 2.41 & 2.51 & 2.76 & 1.93 & 3.58 & 1.00 & 1.96 & 2.24 & 3.48 \\
\hline
\end{tabular}




\begin{tabular}{|c|c|c|c|c|c|c|c|c|}
\hline & L-2-1 & $\begin{array}{c}\text { L-2-1 } \\
\text { duplicata }\end{array}$ & L-4a-2 & BBR-87-7 & BBR 23-2 & BBR 19-1 & BBR 18-3 & BBR D-8A \\
\hline $\mathbf{R b}$ & 109 & 108 & 99.5 & 167 & 148 & 157 & 127 & 21.3 \\
\hline $\mathbf{S r}$ & 350 & 349 & 431 & 52.6 & 44.4 & 145 & 66.6 & 115 \\
\hline $\mathbf{Y}$ & 24.6 & 24.3 & 29.2 & 36.5 & 33.1 & 35.8 & 44.9 & 20.4 \\
\hline $\mathbf{Z r}$ & 82.7 & 83.5 & 82.5 & 169 & 166 & 134 & 139 & 119 \\
\hline $\mathbf{N b}$ & 11.6 & 11.6 & 12.2 & 14.3 & 14.6 & 15.9 & 14.8 & 6.60 \\
\hline Cs & 3.75 & 3.71 & 4.25 & 5.72 & 4.30 & 6.81 & 5.47 & 0.77 \\
\hline Ba & 641 & 638 & 581 & 847 & 590 & 600 & 573 & 112 \\
\hline La & 34.6 & 35.0 & 42.0 & 33.4 & 43.3 & 43.8 & 48.9 & 15.4 \\
\hline $\mathrm{Ce}$ & 67.6 & 68.5 & 81.3 & 70.1 & 88.3 & 84.0 & 97.6 & 32.7 \\
\hline Pr & 8.45 & 8.54 & 10.2 & 8.93 & 10.9 & 10.9 & 12.3 & 4.05 \\
\hline Nd & 32.2 & 32.7 & 39.0 & 35.0 & 41.3 & 42.1 & 49.6 & 16.4 \\
\hline Sm & 6.39 & 6.41 & 7.57 & 7.45 & 8.21 & 8.58 & 11.0 & 3.90 \\
\hline $\mathbf{E u}$ & 1.31 & 1.32 & 1.43 & 1.42 & 1.26 & 1.56 & 2.07 & 1.03 \\
\hline Gd & 5.30 & 5.31 & 6.12 & 6.62 & 6.76 & 7.52 & 10.5 & 3.87 \\
\hline $\mathbf{T b}$ & 0.81 & 0.82 & 0.96 & 1.10 & 1.08 & 1.16 & 1.52 & 0.66 \\
\hline Dy & 4.47 & 4.47 & 5.24 & 6.35 & 5.96 & 6.34 & 7.91 & 3.80 \\
\hline Ho & 0.93 & 0.93 & 1.10 & 1.40 & 1.27 & 1.35 & 1.63 & 0.79 \\
\hline $\mathbf{E r}$ & 2.51 & 2.50 & 2.96 & 3.86 & 3.45 & 3.62 & 4.21 & 2.14 \\
\hline Tm & 0.36 & 0.36 & 0.43 & 0.59 & 0.51 & 0.53 & 0.60 & 0.31 \\
\hline $\mathbf{Y b}$ & 2.38 & 2.33 & 2.74 & 3.82 & 3.29 & 3.44 & 3.76 & 2.02 \\
\hline Lu & 0.34 & 0.34 & 0.40 & 0.58 & 0.48 & 0.51 & 0.56 & 0.29 \\
\hline Hf & 2.35 & 2.41 & 2.37 & 4.43 & 4.45 & 3.77 & 3.80 & 3.16 \\
\hline $\mathbf{P b}$ & 22.0 & 22.4 & 19.4 & 13.3 & 66.7 & 23.7 & 28.2 & 10.2 \\
\hline Th & 11.3 & 11.5 & 13.4 & 13.7 & 14.9 & 15.2 & 15.2 & 5.46 \\
\hline $\mathbf{U}$ & 2.62 & 2.63 & 2.42 & 2.87 & 3.31 & 3.37 & 3.85 & 1.51 \\
\hline
\end{tabular}




\begin{tabular}{|c|c|c|c|c|c|}
\hline & Branco & BR & $B R$ & JGb-1 & $J G b-1$ \\
\hline & Branco & obtido & cert. & obtido & recom. \\
\hline $\mathbf{R b}$ & $<0,01$ & 47.9 & $47 \pm 3$ & 5.94 & $6,87 \pm 3,0$ \\
\hline $\mathbf{S r}$ & $<0,01$ & 1381 & $1320 \pm 51$ & 339 & $327 \pm 39$ \\
\hline $\mathbf{Y}$ & $<0,01$ & 27.6 & $30 \pm 1,5$ & 9.42 & $10,4 \pm 2,4$ \\
\hline $\mathbf{Z r}$ & $<0,03$ & 283 & $260 \pm 16$ & 29.2 & $32,8 \pm 6,8$ \\
\hline $\mathbf{N b}$ & $<0,01$ & 109 & $98 \pm 6$ & 2.38 & $3,34 \pm 1,33$ \\
\hline Cs & $<0,01$ & 0.78 & $0,8 \pm 0,15$ & 0.22 & $0,26 \pm 0,076$ \\
\hline $\mathbf{B a}$ & $<0,5$ & 1108 & $1050 \pm 44$ & 64.1 & $64,3 \pm 17,1$ \\
\hline La & $<0,01$ & 83.5 & $82 \pm 1,5$ & 3.64 & $3,6 \pm 0,56$ \\
\hline $\mathrm{Ce}$ & $<0,01$ & 155 & $151 \pm 4$ & 8.08 & $8,17 \pm 1$ \\
\hline Pr & $<0,01$ & 17.5 & $17 \pm 0,6$ & 1.16 & $1,13 \pm 0,14$ \\
\hline Nd & $<0,08$ & 67.8 & $65 \pm 2$ & 5.46 & $5,47 \pm 0,83$ \\
\hline Sm & $<0,01$ & 12.4 & $12,2 \pm 0,3$ & 1.46 & $1,49 \pm 0,19$ \\
\hline $\mathbf{E u}$ & $<0,01$ & 3.64 & $3,7 \pm 0,2$ & 0.60 & $0,62 \pm 0,052$ \\
\hline Gd & $<0,01$ & 9.74 & $9,5 \pm 0,6$ & 1.68 & $1,61 \pm 0,14$ \\
\hline $\mathbf{T b}$ & $<0,01$ & 1.31 & $1,25 \pm 0,1$ & 0.27 & $0,29 \pm 0,071$ \\
\hline Dy & $<0,01$ & 6.18 & $6,4 \pm 0,2$ & 1.66 & $1,56 \pm 0,37$ \\
\hline Ho & $<0,01$ & 1.11 & $1,1 \pm 0,13$ & 0.36 & $0,33 \pm 0,052$ \\
\hline Er & $<0,01$ & 2.56 & $2,5 \pm 0,1$ & 0.98 & $1,04 \pm 0,24$ \\
\hline Tm & $<0,01$ & 0.31 & $0,3 \pm 0,04$ & 0.14 & $0,16 \pm 0,033$ \\
\hline $\mathbf{Y b}$ & $<0,01$ & 1.79 & $1,8 \pm 0,2$ & 0.92 & $1,06 \pm 0,3$ \\
\hline $\mathbf{L u}$ & $<0,01$ & 0.25 & $0,25 \pm 0,03$ & 0.13 & $0,15 \pm 0,025$ \\
\hline Hf & $<0,01$ & 5.75 & $5,6 \pm 0,2$ & 0.81 & $0,88 \pm 0,19$ \\
\hline $\mathbf{P b}$ & $<0,02$ & 5.23 & $5 \pm 2,5$ & 1.63 & $1,92 \pm 0,74$ \\
\hline Th & $<0,01$ & 10.6 & $11 \pm 1$ & 0.40 & $0,48 \pm 0,1$ \\
\hline $\mathbf{U}$ & $<0,01$ & 2.47 & $2,5 \pm 0,3$ & 0.09 & $0,13 \pm 0,048$ \\
\hline
\end{tabular}

Observações:

1)JGb-1 (gabro) - material de referência do GSJ (Japão).

2) BR (basalto) - CRPG (Centre de Recherches Pétrographiques et Géochimiques (França).

3)Valores em ppm . 


\section{ANEXO III}

RESULTADOS GEOQUÍMICA ISOTÓPICA DE ROCHA TOTAL Sm-Nd 


\begin{tabular}{ccccccccccc}
\hline AMOSTRA & MATERIAL & Sm $(\mathbf{p p m})$ & $\mathbf{N d}(\mathbf{p p m})$ & ${ }^{\mathbf{1 4 7}} \mathbf{S m} /{ }^{\mathbf{1 4 4}} \mathbf{N d}$ & erro $^{\mathbf{1}}$ & ${ }^{\mathbf{1 4 3}} \mathbf{N d} /{ }^{\mathbf{4 4 4}} \mathbf{N d}$ & erro (2s) & $\mathbf{f}_{\text {Sm/Nd }}$ & $\mathbf{T}_{\mathbf{D M}}{ }^{\mathbf{1}}(\mathbf{G a})$ & $\mathbf{e N d}(\mathbf{0})$ \\
\hline BBR-19-1 & RTOT/Filito & 7.862 & 39.846 & 0.1193 & 0.0007 & 0.512159 & 0.000010 & -0.39 & 1.4 & -9.34 \\
\hline BBR-19-3 & RTOT/Filito & 10.219 & 47.904 & 0.1290 & 0.0008 & 0.512134 & 0.000010 & -0.34 & 1.6 & -9.83 \\
\hline BBR-23-2 & RTOT/Filito & 7.480 & 39.123 & 0.1156 & 0.0007 & 0.512081 & 0.000012 & -0.41 & 1.5 & -10.86 \\
\hline BBR-87-7 & RTOT/Filito & 6.603 & 32.316 & 0.1236 & 0.0007 & 0.512252 & 0.000009 & -0.37 & 1.3 & -7.53 \\
\hline PMI-7 & RTOT/Siltito & 6.960 & 35.476 & 0.1186 & 0.0007 & 0.512255 & 0.000010 & -0.40 & 1.3 & -7.47 \\
\hline
\end{tabular}

\begin{tabular}{ccc}
\hline Amostra & $\boldsymbol{\varepsilon}_{(\mathbf{T D M})}$ & $\boldsymbol{\varepsilon}_{(\mathbf{2 2 0 M a})}$ \\
\hline BBR-19-1 & 4,75 & $-7,17$ \\
\hline BBR-19-3 & 4,30 & $-7,93$ \\
\hline BBR-23-2 & 4,60 & $-8,58$ \\
\hline BBR-87-7 & 4,96 & $-5,48$ \\
\hline PMI-7 & 5,13 & $-5,28$ \\
\hline
\end{tabular}




\section{Observações:}

1)As concentrações de Sm e Nd foram obtidas por DI.

2)A razão isotópica ${ }^{147} \mathrm{Sm} /{ }^{144} \mathrm{~N}$ é calculada a partir da equação $=[($ Conc $\mathrm{Sm} / \mathrm{Conc}$ $\mathrm{Nd}) * 0,604491]$.

3) ${ }^{1}$ Erros para a razão isotópica ${ }^{147} \mathrm{Sm} /{ }^{144} \mathrm{Nd}$ e para a idade modelo $\mathrm{T}_{\mathrm{DM}}$ são calculados a partir da propagação de erros analíticos das variáveis usadas nas respectivas equações. 4) As razões isotópicas ${ }^{143} \mathrm{Nd} /{ }^{144} \mathrm{Nd}$ (medidas como $\mathrm{Nd}^{+}$) foram normalizadas para o valor de ${ }^{146} \mathrm{Nd} /{ }^{144} \mathrm{Nd}=0,7219$ (De Paolo, 1981).

5) A idade modelo $\mathrm{T}_{\mathrm{DM}}$ é calculada segundo a equação: $=1 / 1^{147} \mathrm{Sm} * \ln$ $\left\{\left[\left({ }^{143} \mathrm{Nd} /{ }^{144} \mathrm{Nd}\right)_{\mathrm{am}}-\left({ }^{143} \mathrm{Nd} /{ }^{144} \mathrm{Nd}\right)_{\mathrm{DM}}\right] /\left[\left({ }^{147} \mathrm{Sm} /{ }^{144} \mathrm{Nd}\right)_{\mathrm{am}}-\left({ }^{147} \mathrm{Sm} /{ }^{144} \mathrm{Nd}\right)_{\mathrm{DM}}\right]+1\right\}$.

6) $\mathrm{O}$ parâmetro $\mathrm{eNd}(0)$ corresponde ao valor atual $(\mathrm{t}=0)$ e é calculado segundo a equação: $=\left\{\left[\left({ }^{143} \mathrm{Nd} /{ }^{144} \mathrm{Nd}\right)_{\mathrm{am}} / 0,512638\right]-1\right\}^{*} 10^{4}$, onde ${ }^{143} \mathrm{Nd} /{ }^{144} \mathrm{Nd}_{\mathrm{CHUR}}=0,512638$ (Hamilton et al., 1983).

7) $\mathrm{O}$ parâmetro $\mathrm{f}_{\mathrm{Sm} / \mathrm{Nd}}$ é calculado segundo a equação: $\left.=\left\{\left[\left({ }^{147} \mathrm{Sm} /{ }^{144} \mathrm{Nd}\right)_{\mathrm{am}} / 0,1967\right)\right]-1\right\}$, onde ${ }^{147} \mathrm{Sm} /{ }^{144} \mathrm{Nd}_{\mathrm{CHUR}}=0,1967$ (Hamilton et al., 1983)

8) Valor médio para a razão ${ }^{143} \mathrm{Nd} /{ }^{144} \mathrm{Nd}$ do padrão JNDi durante Janeiro a Outubro/2012 $=0.512100 \pm 0.000008$. 


\section{ANEXO IV}

RESULTADOS ICP-LA U-Pb 
Resultados para a amostra L-2-4, com as razões 207/235, 206/238, 238/206, 207/206, 208/206 e respectivos erros.

\begin{tabular}{c|ccccccccccc}
\hline & & & & & coef. & & & & & \\
SPOT & $\mathbf{2 0 7 / 2 3 5}$ & 1sigma & $\mathbf{2 0 6 / 2 3 8}$ & 1 sigma & corr & $\mathbf{2 3 8 / 2 0 6}$ & 1 sigma & $\mathbf{2 0 7 / 2 0 6}$ & 1 sigma & 208/206 & 1 sigma \\
\hline 1.1 & 0.6929 & 0.0070 & 0.0856 & 0.0006 & 0.73 & 11.6869 & 0.0868 & 0.0582 & 0.0005 & 0.2193 & 0.0193 \\
\hline 2.1 & 0.5481 & 0.0052 & 0.0728 & 0.0005 & 0.76 & 13.7402 & 0.0998 & 0.0561 & 0.0004 & 0.1384 & 0.0130 \\
\hline 3.2 & 0.7757 & 0.0061 & 0.0935 & 0.0005 & 0.68 & 10.6910 & 0.0575 & 0.0594 & 0.0003 & 0.0429 & 0.0040 \\
\hline 4.1 & 0.7395 & 0.0060 & 0.0908 & 0.0005 & 0.68 & 11.0177 & 0.0601 & 0.0589 & 0.0003 & 0.1540 & 0.0134 \\
\hline 5.1 & 0.2875 & 0.0033 & 0.0410 & 0.0002 & 0.51 & 24.4145 & 0.1446 & 0.0514 & 0.0005 & 0.2932 & 0.0256 \\
\hline 6.1 & 0.6679 & 0.0102 & 0.0848 & 0.0006 & 0.43 & 11.7977 & 0.0781 & 0.0578 & 0.0007 & 0.2532 & 0.0222 \\
\hline 7.1 & 0.5808 & 0.0046 & 0.0748 & 0.0004 & 0.72 & 13.3714 & 0.0762 & 0.0564 & 0.0003 & 0.2127 & 0.0184 \\
\hline 8.1 & 1.2018 & 0.0106 & 0.1324 & 0.0010 & 0.83 & 7.5547 & 0.0553 & 0.0660 & 0.0003 & 0.1448 & 0.0128 \\
\hline 9.1 & 0.7762 & 0.0076 & 0.0965 & 0.0006 & 0.61 & 10.3597 & 0.0619 & 0.0599 & 0.0005 & 0.0237 & 0.0033 \\
\hline 10.1 & 0.3060 & 0.0027 & 0.0425 & 0.0002 & 0.63 & 23.5500 & 0.1327 & 0.0517 & 0.0003 & 0.0553 & 0.0054 \\
\hline 10.2 & 0.3934 & 0.0036 & 0.0541 & 0.0003 & 0.62 & 18.4884 & 0.1047 & 0.0534 & 0.0003 & 0.0409 & 0.0039 \\
\hline 11.1 & 0.7665 & 0.0057 & 0.0928 & 0.0005 & 0.67 & 10.7701 & 0.0537 & 0.0593 & 0.0003 & 0.0323 & 0.0029 \\
\hline 12.1 & 0.2720 & 0.0049 & 0.0387 & 0.0003 & 0.36 & 25.8323 & 0.1693 & 0.0511 & 0.0007 & 0.2575 & 0.0146 \\
\hline 13.1 & 0.7374 & 0.0053 & 0.0910 & 0.0005 & 0.82 & 10.9842 & 0.0643 & 0.0590 & 0.0002 & 0.1788 & 0.0094 \\
\hline 14.1 & 0.6809 & 0.0054 & 0.0847 & 0.0005 & 0.75 & 11.8084 & 0.0698 & 0.0580 & 0.0002 & 0.2560 & 0.0133 \\
\hline 15.1 & 0.3006 & 0.0056 & 0.0426 & 0.0003 & 0.36 & 23.4699 & 0.1585 & 0.0517 & 0.0009 & 0.1982 & 0.0118 \\
\hline 16.1 & 0.7611 & 0.0128 & 0.0916 & 0.0007 & 0.48 & 10.9134 & 0.0876 & 0.0591 & 0.0004 & 0.0701 & 0.0196 \\
\hline 17.1 & 0.7581 & 0.0094 & 0.0924 & 0.0007 & 0.59 & 10.8237 & 0.0798 & 0.0592 & 0.0003 & 0.1540 & 0.0423 \\
\hline 18.1 & 0.6907 & 0.0098 & 0.0863 & 0.0007 & 0.54 & 11.5831 & 0.0881 & 0.0583 & 0.0004 & 0.3524 & 0.0967 \\
\hline 19.1 & 0.7015 & 0.0089 & 0.0871 & 0.0006 & 0.56 & 11.4800 & 0.0818 & 0.0584 & 0.0003 & 0.2784 & 0.0764 \\
\hline & & & & & & & & & & \\
\hline
\end{tabular}




\begin{tabular}{|c|c|c|c|c|c|c|c|c|c|c|c|}
\hline 20.1 & 0.7670 & 0.0092 & 0.0933 & 0.0006 & 0.58 & 10.7133 & 0.0744 & 0.0593 & 0.0002 & 0.1140 & 0.0313 \\
\hline 21.1 & 0.2722 & 0.0034 & 0.0381 & 0.0003 & 0.60 & 26.2607 & 0.1936 & 0.0510 & 0.0002 & 0.0456 & 0.0125 \\
\hline 21.2 & 0.6410 & 0.0107 & 0.0813 & 0.0007 & 0.51 & 12.3021 & 0.1045 & 0.0575 & 0.0006 & 0.3576 & 0.0985 \\
\hline 23.1 & 0.7088 & 0.0097 & 0.0879 & 0.0007 & 0.56 & 11.3803 & 0.0875 & 0.0585 & 0.0004 & 0.2687 & 0.0738 \\
\hline 24.1 & 0.3001 & 0.0043 & 0.0423 & 0.0003 & 0.52 & 23.6555 & 0.1758 & 0.0516 & 0.0005 & 0.5075 & 0.1393 \\
\hline 24.2 & 0.2911 & 0.0048 & 0.0397 & 0.0003 & 0.43 & 25.2185 & 0.1806 & 0.0512 & 0.0006 & 0.3273 & 0.0899 \\
\hline 25.1 & 0.6809 & 0.0107 & 0.0848 & 0.0006 & 0.48 & 11.7972 & 0.0896 & 0.0581 & 0.0006 & 0.2183 & 0.0601 \\
\hline 26.1 & 0.7250 & 0.0080 & 0.0884 & 0.0008 & 0.83 & 11.3176 & 0.1040 & 0.0586 & 0.0003 & 0.1882 & 0.0529 \\
\hline 27.1 & 0.7036 & 0.0078 & 0.0866 & 0.0008 & 0.86 & 11.5439 & 0.1100 & 0.0583 & 0.0003 & 0.1555 & 0.0440 \\
\hline 28.1 & 0.7112 & 0.0092 & 0.0882 & 0.0008 & 0.74 & 11.3414 & 0.1086 & 0.0585 & 0.0004 & 0.0310 & 0.0091 \\
\hline 29.1 & 0.6024 & 0.0067 & 0.0766 & 0.0007 & 0.86 & 13.0630 & 0.1255 & 0.0568 & 0.0002 & 0.0432 & 0.0122 \\
\hline 30.1 & 0.2896 & 0.0036 & 0.0408 & 0.0004 & 0.79 & 24.4887 & 0.2423 & 0.0514 & 0.0004 & 0.4011 & 0.1128 \\
\hline 31.2 & 0.2411 & 0.0042 & 0.0367 & 0.0006 & 0.90 & 27.2369 & 0.4480 & 0.0508 & 0.0002 & 0.3766 & 0.1114 \\
\hline 32.1 & 0.3122 & 0.0040 & 0.0438 & 0.0005 & 0.88 & 22.8090 & 0.2561 & 0.0518 & 0.0004 & 0.6218 & 0.1749 \\
\hline 34.1 & 0.3173 & 0.0048 & 0.0427 & 0.0005 & 0.75 & 23.4006 & 0.2679 & 0.0517 & 0.0006 & 0.3697 & 0.1043 \\
\hline 35.1 & 0.4632 & 0.0074 & 0.0621 & 0.0007 & 0.67 & 16.1008 & 0.1727 & 0.0545 & 0.0006 & 0.3189 & 0.0898 \\
\hline 36.1 & 0.7373 & 0.0081 & 0.0918 & 0.0009 & 0.86 & 10.8877 & 0.1021 & 0.0592 & 0.0002 & 0.1984 & 0.0559 \\
\hline 37.1 & 0.2949 & 0.0040 & 0.0417 & 0.0005 & 0.89 & 23.9824 & 0.2931 & 0.0515 & 0.0003 & 1.0290 & 0.2894 \\
\hline 38.1 & 0.7408 & 0.0155 & 0.0906 & 0.0015 & 0.78 & 11.0436 & 0.1808 & 0.0589 & 0.0001 & 0.1733 & 0.0425 \\
\hline 39.1 & 0.6984 & 0.0157 & 0.0865 & 0.0015 & 0.79 & 11.5635 & 0.2053 & 0.0583 & 0.0003 & 0.1141 & 0.0282 \\
\hline 40.1 & 1.8639 & 0.0393 & 0.1779 & 0.0030 & 0.79 & 5.6208 & 0.0932 & 0.0746 & 0.0001 & 0.0479 & 0.0118 \\
\hline 41.1 & 0.4673 & 0.0099 & 0.0622 & 0.0010 & 0.77 & 16.0686 & 0.2629 & 0.0546 & 0.0002 & 0.2161 & 0.0531 \\
\hline 42.1 & 0.6981 & 0.0191 & 0.0868 & 0.0021 & 0.90 & 11.5263 & 0.2824 & 0.0583 & 0.0002 & 0.0315 & 0.0089 \\
\hline 43.1 & 0.6796 & 0.0202 & 0.0853 & 0.0019 & 0.76 & 11.7243 & 0.2652 & 0.0581 & 0.0003 & 0.0283 & 0.0076 \\
\hline 44.1 & 0.6964 & 0.0152 & 0.0861 & 0.0014 & 0.76 & 11.6146 & 0.1917 & 0.0582 & 0.0003 & 0.2497 & 0.0613 \\
\hline
\end{tabular}




\begin{tabular}{|c|c|c|c|c|c|c|c|c|c|c|c|}
\hline 45.1 & 0.7012 & 0.0147 & 0.0875 & 0.0015 & 0.80 & 11.4345 & 0.1914 & 0.0585 & 0.0002 & 0.1133 & 0.0278 \\
\hline 46.1 & 0.6042 & 0.0128 & 0.0777 & 0.0013 & 0.77 & 12.8652 & 0.2108 & 0.0569 & 0.0002 & 0.0429 & 0.0106 \\
\hline 47.1 & 0.7109 & 0.0153 & 0.0881 & 0.0015 & 0.78 & 11.3457 & 0.1906 & 0.0586 & 0.0002 & 0.0952 & 0.0235 \\
\hline 48.1 & 0.4578 & 0.0137 & 0.0597 & 0.0011 & 0.62 & 16.7571 & 0.3111 & 0.0541 & 0.0013 & 0.1722 & 0.0443 \\
\hline 49.1 & 6.3515 & 0.1324 & 0.3690 & 0.0060 & 0.79 & 2.7099 & 0.0444 & 0.1251 & 0.0002 & 0.3310 & 0.0812 \\
\hline 49.2 & 1.7449 & 0.0364 & 0.1702 & 0.0028 & 0.78 & 5.8762 & 0.0960 & 0.0730 & 0.0001 & 0.0022 & 0.0009 \\
\hline 50.1 & 0.7164 & 0.0082 & 0.0884 & 0.0006 & 0.64 & 11.3065 & 0.0830 & 0.0586 & 0.0003 & 0.1547 & 0.0569 \\
\hline 51.1 & 0.6841 & 0.0084 & 0.0851 & 0.0006 & 0.61 & 11.7531 & 0.0871 & 0.0581 & 0.0004 & 0.2582 & 0.0949 \\
\hline 52.1 & 0.9043 & 0.0105 & 0.1069 & 0.0008 & 0.66 & 9.3531 & 0.0716 & 0.0616 & 0.0003 & 0.0442 & 0.0163 \\
\hline 53.1 & 0.6860 & 0.0092 & 0.0838 & 0.0006 & 0.54 & 11.9336 & 0.0860 & 0.0578 & 0.0005 & 0.2762 & 0.1016 \\
\hline 54.2 & 0.2898 & 0.0034 & 0.0408 & 0.0003 & 0.62 & 24.4841 & 0.1811 & 0.0514 & 0.0004 & 0.2773 & 0.1019 \\
\hline 55.1 & 0.3500 & 0.0041 & 0.0480 & 0.0003 & 0.62 & 20.8365 & 0.1516 & 0.0525 & 0.0003 & 0.3667 & 0.1348 \\
\hline 56.1 & 0.2930 & 0.0068 & 0.0418 & 0.0004 & 0.43 & 23.9045 & 0.2413 & 0.0515 & 0.0012 & 0.4114 & 0.1518 \\
\hline 57.1 & 0.5953 & 0.0068 & 0.0757 & 0.0005 & 0.62 & 13.2048 & 0.0935 & 0.0566 & 0.0003 & 0.0071 & 0.0032 \\
\hline 58.1 & 2.1177 & 0.0309 & 0.1976 & 0.0022 & 0.76 & 5.0606 & 0.0562 & 0.0783 & 0.0004 & 0.2721 & 0.1003 \\
\hline 59.1 & 0.7430 & 0.0089 & 0.0927 & 0.0007 & 0.64 & 10.7902 & 0.0825 & 0.0592 & 0.0004 & 0.2698 & 0.0994 \\
\hline 60.1 & 0.7275 & 0.0089 & 0.0897 & 0.0008 & 0.70 & 11.1497 & 0.0953 & 0.0588 & 0.0003 & 0.2014 & 0.0740 \\
\hline 61.1 & 0.7084 & 0.0088 & 0.0876 & 0.0006 & 0.59 & 11.4199 & 0.0838 & 0.0584 & 0.0004 & 0.1370 & 0.0504 \\
\hline 62.1 & 0.6169 & 0.0057 & 0.0774 & 0.0004 & 0.56 & 12.9176 & 0.0671 & 0.0568 & 0.0003 & 0.0507 & 0.0278 \\
\hline 63.1 & 1.0550 & 0.0137 & 0.1182 & 0.0012 & 0.77 & 8.4600 & 0.0844 & 0.0635 & 0.0004 & 0.4072 & 0.2243 \\
\hline 64.1 & 0.2853 & 0.0045 & 0.0386 & 0.0003 & 0.46 & 25.8976 & 0.1880 & 0.0511 & 0.0007 & 0.6713 & 0.3674 \\
\hline 65.1 & 0.2931 & 0.0071 & 0.0416 & 0.0004 & 0.42 & 24.0231 & 0.2464 & 0.0515 & 0.0012 & 0.5732 & 0.3138 \\
\hline 66.1 & 0.5725 & 0.0179 & 0.0746 & 0.0012 & 0.53 & 13.4036 & 0.2237 & 0.0565 & 0.0017 & 0.2340 & 0.1298 \\
\hline 67.1 & 0.5892 & 0.0120 & 0.0771 & 0.0009 & 0.54 & 12.9679 & 0.1436 & 0.0568 & 0.0006 & 0.3985 & 0.2182 \\
\hline 68.1 & 0.7088 & 0.0111 & 0.0868 & 0.0009 & 0.68 & 11.5148 & 0.1229 & 0.0583 & 0.0006 & 0.2637 & 0.1444 \\
\hline
\end{tabular}




\begin{tabular}{|c|c|c|c|c|c|c|c|c|c|c|c|}
\hline 69.1 & 0.6904 & 0.0076 & 0.0864 & 0.0004 & 0.47 & 11.5698 & 0.0594 & 0.0583 & 0.0003 & 0.2302 & 0.1260 \\
\hline 70.1 & 5.6751 & 0.0793 & 0.3491 & 0.0039 & 0.81 & 2.8643 & 0.0324 & 0.1177 & 0.0005 & 0.5722 & 0.3130 \\
\hline 71.1 & 0.6661 & 0.0063 & 0.0835 & 0.0004 & 0.53 & 11.9786 & 0.0602 & 0.0579 & 0.0003 & 0.3202 & 0.1752 \\
\hline 72.1 & 0.2831 & 0.0039 & 0.0400 & 0.0003 & 0.50 & 24.9788 & 0.1735 & 0.0513 & 0.0005 & 0.6996 & 0.3831 \\
\hline 73.1 & 0.2766 & 0.0055 & 0.0376 & 0.0004 & 0.53 & 26.5722 & 0.2767 & 0.0509 & 0.0011 & 0.8049 & 0.4405 \\
\hline 73.2 & 0.2873 & 0.0043 & 0.0399 & 0.0003 & 0.49 & 25.0598 & 0.1823 & 0.0513 & 0.0005 & 0.6839 & 0.3742 \\
\hline 75.1 & 1.1974 & 0.0193 & 0.1317 & 0.0016 & 0.74 & 7.5949 & 0.0901 & 0.0659 & 0.0004 & 0.0473 & 0.0109 \\
\hline 76.1 & 0.2951 & 0.0139 & 0.0421 & 0.0006 & 0.31 & 23.7644 & 0.3437 & 0.0516 & 0.0021 & 0.2385 & 0.0533 \\
\hline 77.1 & 0.5999 & 0.0086 & 0.0769 & 0.0008 & 0.75 & 12.9974 & 0.1396 & 0.0568 & 0.0003 & 0.1753 & 0.0387 \\
\hline 78.1 & 0.2884 & 0.0049 & 0.0414 & 0.0004 & 0.64 & 24.1753 & 0.2592 & 0.0515 & 0.0005 & 0.4260 & 0.0941 \\
\hline 79.1 & 0.3287 & 0.0089 & 0.0474 & 0.0009 & 0.72 & 21.1016 & 0.4113 & 0.0524 & 0.0004 & 0.2105 & 0.0466 \\
\hline 80.1 & 0.7456 & 0.0129 & 0.0914 & 0.0011 & 0.72 & 10.9401 & 0.1351 & 0.0591 & 0.0005 & 0.1709 & 0.0378 \\
\hline 82.1 & 0.6941 & 0.0100 & 0.0864 & 0.0009 & 0.71 & 11.5733 & 0.1187 & 0.0582 & 0.0004 & 0.2268 & 0.0501 \\
\hline 83.1 & 0.2933 & 0.0051 & 0.0413 & 0.0004 & 0.60 & 24.2061 & 0.2536 & 0.0515 & 0.0005 & 0.3559 & 0.0787 \\
\hline 84.1 & 0.6305 & 0.0090 & 0.0793 & 0.0008 & 0.71 & 12.6170 & 0.1280 & 0.0572 & 0.0003 & 0.2247 & 0.0496 \\
\hline 85.1 & 0.2870 & 0.0052 & 0.0400 & 0.0004 & 0.59 & 24.9752 & 0.2715 & 0.0513 & 0.0005 & 0.3319 & 0.0734 \\
\hline 86.1 & 0.2895 & 0.0050 & 0.0418 & 0.0005 & 0.69 & 23.8950 & 0.2870 & 0.0516 & 0.0006 & 0.4093 & 0.0905 \\
\hline 22.1 & 0.2882 & 0.0051 & 0.0348 & 0.0005 & 0.80 & 28.7218 & 0.4105 & 0.0586 & 0.0003 & 0.0863 & 0.0237 \\
\hline 31.1 & 0.1955 & 0.0025 & 0.0273 & 0.0003 & 0.84 & 36.6943 & 0.3912 & 0.0516 & 0.0002 & 0.3740 & 0.1052 \\
\hline 3.1 & 0.2945 & 0.0148 & 0.0441 & 0.0006 & 0.28 & 22.6811 & 0.3247 & 0.0519 & 0.0026 & 0.0336 & 0.0169 \\
\hline 22.2 & 0.6669 & 0.0088 & 0.0833 & 0.0006 & 0.59 & 12.0112 & 0.0928 & 0.0578 & 0.0003 & 0.3118 & 0.0856 \\
\hline 33.1 & 0.7385 & 0.0093 & 0.0907 & 0.0009 & 0.76 & 11.0224 & 0.1061 & 0.0590 & 0.0005 & 0.3982 & 0.1123 \\
\hline 54.1 & 0.2505 & 0.0038 & 0.0340 & 0.0003 & 0.52 & 29.4061 & 0.2343 & 0.0504 & 0.0006 & 0.3270 & 0.1202 \\
\hline 74.1 & 1.4571 & 0.0206 & 0.1489 & 0.0015 & 0.72 & 6.7155 & 0.0680 & 0.0690 & 0.0003 & 0.0413 & 0.0091 \\
\hline 81.1 & 0.5994 & 0.0135 & 0.0765 & 0.0010 & 0.56 & 13.0660 & 0.1653 & 0.0568 & 0.0010 & 0.0803 & 0.0182 \\
\hline
\end{tabular}


Resultados para a amostra L-2-4: Pb total comum e radioativo, Th, U, idades 206/238 e 207/206 com os erros, e a concordância.

\begin{tabular}{|c|c|c|c|c|c|c|c|c|c|c|}
\hline SPOT & $\begin{array}{l}\mathrm{Pb} \text { total } \\
\text { comum }\end{array}$ & $\begin{array}{c}\mathrm{Pb} \text { rad } \\
\mathrm{ppm}\end{array}$ & $\begin{array}{c}\text { Th } \\
\mathrm{ppm}\end{array}$ & $\begin{array}{c}\mathrm{U} \\
\mathrm{ppm}\end{array}$ & $\mathrm{Th} / \mathrm{U}$ & T206/238 & 1 sigma & $\begin{array}{l}\text { AGES } \\
\text { T207/206 }\end{array}$ & 1 sigma & $\begin{array}{c}\text { conc. } \\
\text { 206/238 } \\
207 / 206\end{array}$ \\
\hline 1.1 & $<0.001$ & 24.7 & 134.3 & 215.3 & 0.6238 & 0.529 & 0.004 & 0.529 & 0.019 & 100 \\
\hline 2.1 & $<0.001$ & 21.9 & 48.0 & 248.8 & 0.193 & 0.453 & 0.003 & 0.452 & 0.015 & 100 \\
\hline 3.2 & $<0.001$ & 53.9 & 61.2 & 509.7 & 0.120 & 0.576 & 0.003 & 0.574 & 0.012 & 100 \\
\hline 4.1 & 0.08 & 34.2 & 125.7 & 295.1 & 0.426 & 0.560 & 0.003 & 0.558 & 0.012 & 100 \\
\hline 5.1 & $<0.001$ & 17.8 & 255.4 & 320.5 & 0.797 & 0.259 & 0.002 & 0.259 & 0.022 & 100 \\
\hline 6.1 & $<0.001$ & 13.1 & 75.5 & 116.3 & 0.650 & 0.524 & 0.003 & 0.516 & 0.026 & 102 \\
\hline 7.1 & 0.22 & 41.4 & 255.5 & 420.0 & 0.608 & 0.465 & 0.003 & 0.463 & 0.014 & 100 \\
\hline 8.1 & 0.10 & 105.9 & 150.1 & 659.1 & 0.228 & 0.801 & 0.006 & 0.804 & 0.010 & 100 \\
\hline 9.1 & $<0.001$ & 21.6 & 15.1 & 198.8 & 0.076 & 0.594 & 0.003 & 0.594 & 0.017 & 100 \\
\hline 10.1 & 0.04 & 24.2 & 74.8 & 482.0 & 0.155 & 0.268 & 0.001 & 0.269 & 0.014 & 100 \\
\hline 10.2 & 0.79 & 41.5 & 64.4 & 675.6 & 0.095 & 0.340 & 0.002 & 0.340 & 0.014 & 100 \\
\hline 11.1 & 0.12 & 70.6 & 65.5 & 654.5 & 0.100 & 0.572 & 0.003 & 0.571 & 0.011 & 100 \\
\hline 12.1 & 0.89 & 15.3 & 186.6 & 291.1 & 0.6411 & 0.245 & 0.002 & 0.244 & 0.032 & 100 \\
\hline
\end{tabular}




\begin{tabular}{c|ccccc|cccc|c}
\hline 13.1 & 0.03 & 39.8 & 171.9 & 348.1 & 0.494 & 0.562 & 0.003 & 0.561 & 0.006 & 100 \\
\hline 14.1 & $<0.001$ & 40.7 & 236.8 & 355.5 & 0.666 & 0.524 & 0.003 & 0.522 & 0.009 & 100 \\
\hline 15.1 & $<0.001$ & 11.6 & 110.7 & 215.8 & 0.513 & 0.269 & 0.002 & 0.269 & 0.037 & 100 \\
\hline 16.1 & $<0.001$ & 22.8 & 40.6 & 195.9 & 0.2070 & 0.565 & 0.004 & 0.563 & 0.016 & 100 \\
\hline 17.1 & 0.02 & 68.7 & 198.1 & 587.0 & 0.337 & 0.570 & 0.004 & 0.569 & 0.010 & 100 \\
\hline 18.1 & 0.88 & 36.3 & 201.5 & 279.0 & 0.722 & 0.534 & 0.004 & 0.533 & 0.015 & 100 \\
\hline 19.1 & 0.62 & 52.0 & 265.0 & 442.5 & 0.599 & 0.538 & 0.004 & 0.539 & 0.012 & 100 \\
\hline 20.1 & 0.03 & 90.6 & 199.0 & 790.1 & 0.252 & 0.575 & 0.004 & 0.574 & 0.009 & 100 \\
\hline 21.1 & 3.58 & 164.2 & 423.6 & 3661.1 & 0.116 & 0.241 & 0.002 & 0.242 & 0.009 & 100 \\
\hline 21.2 & $<0.001$ & 12.0 & 80.8 & 105.3 & 0.768 & 0.504 & 0.004 & 0.504 & 0.023 & 100 \\
\hline 23.1 & 0.58 & 27.1 & 123.9 & 226.0 & 0.548 & 0.543 & 0.004 & 0.540 & 0.015 & 100 \\
\hline 24.1 & 2.12 & 17.3 & 278.5 & 276.5 & 1.007 & 0.267 & 0.002 & 0.267 & 0.019 & 100 \\
\hline 24.2 & $<0.001$ & 14.0 & 176.3 & 256.6 & 0.687 & 0.251 & 0.002 & 0.250 & 0.024 & 100 \\
\hline 25.1 & 1.00 & 14.8 & 67.2 & 130.9 & 0.513 & 0.525 & 0.004 & 0.527 & 0.021 & 100 \\
\hline 26.1 & $<0.001$ & 48.6 & 178.0 & 427.6 & 0.4162 & 0.546 & 0.005 & 0.547 & 0.010 & 100 \\
\hline 27.1 & $<0.001$ & 52.0 & 172.0 & 471.1 & 0.365 & 0.536 & 0.005 & 0.536 & 0.010 & 100 \\
\hline 28.1 & 0.18 & 25.7 & 18.7 & 250.2 & 0.075 & 0.545 & 0.005 & 0.543 & 0.016 & 100 \\
\hline 29.1 & 0.32 & 48.8 & 52.3 & 536.7 & 0.097 & 0.476 & 0.004 & 0.478 & 0.009 & 100 \\
\hline 30.1 & 0.50 & 33.3 & 472.1 & 560.6 & 0.842 & 0.258 & 0.003 & 0.258 & 0.015 & 100 \\
\hline & & & & & & & & & & 100 \\
\hline
\end{tabular}




\begin{tabular}{c|ccccc|cccc|c}
\hline 31.2 & $<0.001$ & 15.0 & 679.8 & 284.4 & 2.390 & 0.232 & 0.004 & 0.232 & 0.010 & 100 \\
\hline 32.1 & 0.02 & 40.3 & 719.4 & 577.5 & 1.246 & 0.277 & 0.003 & 0.275 & 0.018 & 100 \\
\hline 34.1 & $<0.001$ & 11.8 & 148.7 & 196.8 & 0.756 & 0.270 & 0.003 & 0.269 & 0.024 & 100 \\
\hline 35.1 & $<0.001$ & 13.2 & 103.5 & 155.5 & 0.665 & 0.388 & 0.004 & 0.388 & 0.023 & 100 \\
\hline 36.1 & 0.82 & 43.4 & 174.9 & 350.6 & 0.499 & 0.566 & 0.005 & 0.567 & 0.009 & 100 \\
\hline 37.1 & 0.16 & 97.7 & 2337.3 & 1273.6 & 1.835 & 0.263 & 0.003 & 0.262 & 0.014 & 100 \\
\hline 38.1 & $<0.001$ & 106.4 & 312.2 & 884.4 & 0.3530 & 0.559 & 0.009 & 0.557 & 0.006 & 100 \\
\hline 39.1 & 0.07 & 32.1 & 74.7 & 280.3 & 0.267 & 0.535 & 0.009 & 0.534 & 0.013 & 100 \\
\hline 40.1 & 0.30 & 100.6 & 51.8 & 448.4 & 0.115 & 1.056 & 0.016 & 1.059 & 0.004 & 100 \\
\hline 41.1 & 0.21 & 35.0 & 187.0 & 409.0 & 0.457 & 0.389 & 0.006 & 0.390 & 0.006 & 100 \\
\hline 42.1 & $<0.001$ & 15.6 & -24.8 & 182.6 & -0.136 & 0.536 & 0.013 & 0.534 & 0.009 & 100 \\
\hline 43.1 & 0.07 & 23.2 & -2.0 & 256.5 & -0.008 & 0.528 & 0.011 & 0.526 & 0.010 & 100 \\
\hline 44.1 & 0.23 & 33.6 & 148.3 & 277.7 & 0.534 & 0.532 & 0.008 & 0.530 & 0.010 & 100 \\
\hline 45.1 & 0.16 & 68.1 & 147.1 & 592.7 & 0.248 & 0.540 & 0.009 & 0.541 & 0.006 & 100 \\
\hline 46.1 & 0.23 & 75.9 & 86.6 & 814.5 & 0.106 & 0.483 & 0.008 & 0.482 & 0.009 & 100 \\
\hline 47.1 & $<0.001$ & 21.7 & 37.8 & 195.0 & 0.194 & 0.545 & 0.009 & 0.544 & 0.009 & 100 \\
\hline 48.1 & $<0.001$ & 7.7 & 41.1 & 95.8 & 0.429 & 0.374 & 0.007 & 0.373 & 0.052 & 100 \\
\hline 49.1 & 0.89 & 106.7 & 141.2 & 194.4 & 0.726 & 2.025 & 0.028 & 2.029 & 0.003 & 100 \\
\hline 49.2 & 1.02 & 145.5 & 5.6 & 669.0 & 0.008 & 1.013 & 0.015 & 1.014 & 0.003 & 100 \\
\hline & & & & & & & & & & 100 \\
\hline
\end{tabular}




\begin{tabular}{c|ccccc|cccc|c}
\hline 50.1 & 0.02 & 60.7 & 167.6 & 533.9 & 0.3139 & 0.546 & 0.004 & 0.546 & 0.011 & 100 \\
\hline 51.1 & 0.25 & 24.7 & 111.8 & 211.6 & 0.528 & 0.526 & 0.004 & 0.527 & 0.016 & 100 \\
\hline 52.1 & $<0.001$ & 106.2 & 78.9 & 834.3 & 0.095 & 0.655 & 0.005 & 0.655 & 0.012 & 100 \\
\hline 53.1 & 1.65 & 20.9 & 100.9 & 181.2 & 0.557 & 0.519 & 0.004 & 0.518 & 0.018 & 100 \\
\hline 54.2 & $<0.001$ & 45.5 & 481.5 & 811.4 & 0.593 & 0.258 & 0.002 & 0.259 & 0.015 & 100 \\
\hline 55.1 & $<0.001$ & 39.1 & 441.9 & 568.8 & 0.777 & 0.302 & 0.002 & 0.304 & 0.012 & 99 \\
\hline 56.1 & 0.89 & 7.0 & 88.5 & 116.0 & 0.763 & 0.264 & 0.003 & 0.263 & 0.049 & 100 \\
\hline 57.1 & $<0.001$ & 35.8 & 4.6 & 403.4 & 0.011 & 0.471 & 0.003 & 0.469 & 0.012 & 100 \\
\hline 58.1 & $<0.001$ & 68.2 & 138.5 & 229.7 & 0.603 & 1.162 & 0.012 & 1.157 & 0.011 & 100 \\
\hline 59.1 & 0.38 & 37.6 & 160.6 & 306.9 & 0.523 & 0.571 & 0.004 & 0.569 & 0.014 & 100 \\
\hline 60.1 & $<0.001$ & 78.1 & 275.9 & 666.3 & 0.414 & 0.554 & 0.005 & 0.552 & 0.011 & 100 \\
\hline 61.1 & 0.13 & 37.6 & 96.3 & 340.5 & 0.283 & 0.541 & 0.004 & 0.539 & 0.013 & 100 \\
\hline 62.1 & 0.18 & 63.1 & 54.1 & 695.6 & 0.0778 & 0.481 & 0.002 & 0.479 & 0.011 & 100 \\
\hline 63.1 & $<0.001$ & 31.6 & 120.8 & 165.9 & 0.728 & 0.720 & 0.007 & 0.719 & 0.013 & 100 \\
\hline 64.1 & 0.08 & 11.7 & 206.5 & 203.5 & 1.015 & 0.244 & 0.002 & 0.244 & 0.030 & 100 \\
\hline 65.1 & $<0.001$ & 7.9 & 118.0 & 132.7 & 0.889 & 0.263 & 0.003 & 0.264 & 0.051 & 100 \\
\hline 66.1 & 0.39 & 3.9 & 16.4 & 41.7 & 0.393 & 0.464 & 0.007 & 0.466 & 0.063 & 100 \\
\hline 67.1 & 1.80 & 11.5 & 63.3 & 111.9 & 0.566 & 0.479 & 0.005 & 0.478 & 0.022 & 100 \\
\hline 68.1 & 0.14 & 48.6 & 205.8 & 436.9 & 0.471 & 0.537 & 0.005 & 0.534 & 0.024 & 100 \\
\hline & & & & & & & & & & 100 \\
\hline
\end{tabular}




\begin{tabular}{c|ccccc|cccc|c}
\hline 69.1 & 0.34 & 22.4 & 73.8 & 204.0 & 0.362 & 0.534 & 0.003 & 0.535 & 0.013 & 100 \\
\hline 70.1 & 0.16 & 134.9 & 226.5 & 266.6 & 0.850 & 1.930 & 0.019 & 1.922 & 0.008 & 100 \\
\hline 71.1 & 0.21 & 56.3 & 257.6 & 509.6 & 0.505 & 0.517 & 0.002 & 0.519 & 0.011 & 100 \\
\hline 72.1 & 2.41 & 4.4 & 34.7 & 86.8 & 0.400 & 0.253 & 0.002 & 0.253 & 0.023 & 100 \\
\hline 73.1 & 0.11 & 25.2 & 488.1 & 411.8 & 1.185 & 0.238 & 0.002 & 0.237 & 0.046 & 100 \\
\hline 73.2 & 0.21 & 19.8 & 346.2 & 326.4 & 1.061 & 0.252 & 0.002 & 0.253 & 0.024 & 100 \\
\hline 75.1 & $<0.001$ & 28.6 & 18.1 & 177.0 & 0.103 & 0.797 & 0.009 & 0.799 & 0.012 & 100 \\
\hline 76.1 & 1.44 & 13.7 & 129.9 & 222.0 & 0.585 & 0.266 & 0.004 & 0.266 & 0.088 & 100 \\
\hline 77.1 & 0.04 & 49.8 & 213.5 & 485.6 & 0.440 & 0.478 & 0.005 & 0.478 & 0.011 & 100 \\
\hline 78.1 & 0.42 & 26.2 & 450.0 & 409.0 & 1.100 & 0.261 & 0.003 & 0.262 & 0.023 & 100 \\
\hline 79.1 & $<0.001$ & 14.2 & 133.8 & 217.9 & 0.614 & 0.298 & 0.006 & 0.300 & 0.019 & 100 \\
\hline 80.1 & 0.21 & 51.3 & 184.7 & 418.1 & 0.442 & 0.564 & 0.007 & 0.564 & 0.017 & 100 \\
\hline 82.1 & $<0.001$ & 37.9 & 188.9 & 316.3 & 0.597 & 0.534 & 0.005 & 0.532 & 0.013 & 100 \\
\hline 83.1 & $<0.001$ & 16.8 & 217.5 & 270.4 & 0.804 & 0.261 & 0.003 & 0.262 & 0.022 & 100 \\
\hline 84.1 & $<0.001$ & 112.3 & 586.6 & 991.4 & 0.592 & 0.492 & 0.005 & 0.492 & 0.012 & 100 \\
\hline 85.1 & 0.62 & 18.7 & 255.9 & 311.0 & 0.823 & 0.253 & 0.003 & 0.252 & 0.020 & 100 \\
\hline 86.1 & 0.04 & 22.0 & 350.6 & 340.3 & 1.030 & 0.264 & 0.003 & 0.265 & 0.027 & 100 \\
\hline 22.1 & 8.48 & 169.6 & 903.9 & 3484.9 & 0.259 & 0.221 & 0.003 & 0.545 & 0.010 & 40 \\
\hline 31.1 & 1.12 & 101.8 & 2218.4 & 2503.4 & 0.886 & 0.173 & 0.002 & 0.267 & 0.010 & 65 \\
\hline & & & & & & & & & & 100 \\
\hline
\end{tabular}




\begin{tabular}{c|ccccc|cccc|c}
\hline 3.1 & 7.07 & 3.8 & 2.5 & 79.0 & 0.032 & 0.278 & 0.004 & 0.279 & 0.108 & 100 \\
\hline 22.2 & 8.93 & 73.9 & 407.9 & 586.5 & 0.695 & 0.516 & 0.004 & 0.515 & 0.010 & 100 \\
\hline 33.1 & 7.96 & 22.3 & 134.2 & 175.8 & 0.763 & 0.560 & 0.005 & 0.562 & 0.017 & 100 \\
\hline 54.1 & 24.89 & 67.6 & 1483.2 & 1544.8 & 0.960 & 0.216 & 0.002 & 0.214 & 0.024 & 101 \\
\hline 74.1 & 12.60 & 92.9 & 54.2 & 498.4 & 0.1088 & 0.895 & 0.008 & 0.896 & 0.011 & 100 \\
\hline 81.1 & 11.08 & 26.8 & 62.5 & 277.2 & 0.226 & 0.475 & 0.006 & 0.477 & 0.038 & 100 \\
\hline
\end{tabular}


Resultados para a amostra L-4-8, com as razões 207/235, 206/238, 238/206, 207/206, 208/206 e respectivos erros.

\begin{tabular}{|c|c|c|c|c|c|c|c|c|c|c|c|}
\hline SPOT & $207 / 235$ & 1sigma & $206 / 238$ & 1 sigma & coef. corr & $238 / 206$ & 1 sigma & $207 / 206$ & 1 sigma & $208 / 206$ & 1 sigma \\
\hline 1.1 & & & & & 0.71 & & & & & & \\
\hline 2.1 & 082 & 0075 & & 0.0006 & 0.58 & & 0.3326 & & & & .0372 \\
\hline 3.1 & & 0057 & & 0.0005 & 0.61 & & 0.2930 & & & 0.1768 & 0.0187 \\
\hline 4.1 & & 0.0054 & & 0.0005 & 0.65 & & & & & & 0.0088 \\
\hline 5.1 & 043 & 0.0171 & 0.1159 & 0.0013 & 0.66 & 8.6313 & 0.0962 & 0.0631 & 0.0004 & 0.1238 & 0.0129 \\
\hline 6.1 & & 0.0059 & 0.0415 & 0.0005 & 0.60 & 24.1036 & 0.2930 & & 0.0006 & & 0.0165 \\
\hline 7.1 & & 0.0147 & & 0.0012 & 0.69 & & & & & & 0.0246 \\
\hline 8.1 & 982 & 0.0080 & 0.0544 & 0.0006 & 0.58 & 18.3 & 0.2134 & 34 & 0.0007 & 128 & 0.0228 \\
\hline 9.1 & & 0.0053 & & 0.0005 & 0.65 & & & & & & 0.0173 \\
\hline 10.1 & 964 & 0.0120 & 72 & 0.0010 & 0.68 & & & & 0.0 & & 0.0099 \\
\hline 11.1 & 118 & 0.0091 & & 0.0011 & 0.85 & & 91 & & & & 157 \\
\hline 12.1 & 787 & 0.0342 & & 0.0024 & 0.70 & & 0.07 & & 0.0005 & 394 & 0.0196 \\
\hline 13.1 & 964 & 0.0078 & 0.0401 & 0.0005 & 0.50 & 24. & 257 & & 0.0 & & 0.0206 \\
\hline & & & & & 90 & & & & & & \\
\hline 15.1 & & 0.0383 & & 0.0034 & 0.88 & & & & & & 0.0375 \\
\hline 16.1 & 3017 & 0.0075 & 0.0424 & 0.0008 & 0.81 & 23.5604 & 0.4701 & 0.0516 & 0.0005 & 0.2400 & 0.0640 \\
\hline 17.1 & & 0.0146 & & 0.0017 & 0.90 & & & & & & 0.0244 \\
\hline 18.1 & 0.8053 & 0.0183 & 0.0970 & 0.0019 & 0.87 & 10.3082 & 0.2048 & 0.0600 & 0.0005 & 0.0942 & 0.0254 \\
\hline 20.1 & 0.2980 & 0.0072 & & 0.0008 & 0.82 & & 0.4725 & & 0.0005 & & 0.0251 \\
\hline 21.1 & 0.6860 & 0.0160 & 0.0847 & 0.0017 & 0.84 & & 0.2312 & 0.0580 & 0.0005 & 0.1633 & 0.0437 \\
\hline 22.1 & & 0.0476 & & & 0.83 & & 0.1055 & & 0.0006 & & 0.1644 \\
\hline 23.1 & 0.3095 & 0.0072 & 0.0433 & 0.0008 & 0.83 & 23.1123 & 0.4499 & 0.0518 & 0.0005 & 0.2058 & 0.0548 \\
\hline
\end{tabular}




\begin{tabular}{|c|c|c|c|c|c|c|c|c|c|c|c|}
\hline 24.1 & 0.2754 & 0.0076 & 0.0389 & 0.0008 & 0.75 & 25.6890 & 0.5307 & 0.0511 & 0.0007 & 0.1630 & 0.0436 \\
\hline 25.1 & 0.2943 & 0.0088 & 0.0417 & 0.0009 & 0.69 & 23.9735 & 0.4950 & 0.0516 & 0.0010 & 0.2974 & 0.0795 \\
\hline 26.1 & 0.5499 & 0.0131 & 0.0717 & 0.0014 & 0.85 & 13.9469 & 0.2816 & 0.0560 & 0.0004 & 0.1618 & 0.0431 \\
\hline 27.1 & 0.6432 & 0.0072 & 0.0808 & 0.0006 & 0.63 & 12.3804 & 0.0868 & 0.0574 & 0.0004 & 0.1219 & 0.0333 \\
\hline 28.1 & 0.2915 & 0.0038 & 0.0413 & 0.0003 & 0.52 & 24.2251 & 0.1644 & 0.0515 & 0.0005 & 0.5686 & 0.1548 \\
\hline 29.1 & 0.3035 & 0.0037 & 0.0427 & 0.0002 & 0.45 & 23.4011 & 0.1297 & 0.0517 & 0.0004 & 0.6449 & 0.1755 \\
\hline 30.1 & 0.3189 & 0.0119 & 0.0449 & 0.0004 & 0.26 & 22.2488 & 0.2121 & 0.0520 & 0.0018 & 0.2088 & 0.0580 \\
\hline 31.1 & 0.4572 & 0.0063 & 0.0612 & 0.0007 & 0.83 & 16.3 & 863 & 44 & 0.0002 & 181 & 0.0053 \\
\hline 32.1 & 0.3122 & 0.0028 & 0.0436 & 0.0002 & 0.62 & 22.9571 & 0.1308 & 0.0518 & 0.0002 & 0.4162 & 0.1132 \\
\hline 33.1 & 0.3111 & 0.0064 & 0.0447 & 0.0004 & 0.45 & 22.3771 & 0.2058 & 0.0505 & 0.0011 & 0.0748 & 0.0223 \\
\hline 34.1 & 0.7322 & 0.0070 & 0.0926 & 0.0007 & 0.79 & 10.8012 & 0.0814 & 0.0593 & 0.0004 & 0.1638 & 0.0448 \\
\hline 35.1 & 0.3011 & 0.0051 & 0.0421 & 0.0003 & 0.37 & 23.7532 & 0.1472 & 0.0516 & 0.0005 & 0.2798 & 0.0762 \\
\hline 36.1 & 0.3056 & 0.0033 & 0.0426 & 0.0003 & 0.72 & 23.4788 & 0.1832 & 517 & 0.0003 & 0.2610 & 0.0712 \\
\hline 37.1 & 0.7018 & 0.0148 & 0.0864 & 0.0010 & 0.56 & 11.5714 & 0.1365 & 0.0583 & 0.0008 & 0.1971 & 0.0542 \\
\hline 38.1 & 0.3029 & 0.0043 & 0.0394 & 0.0003 & 0.51 & 25.3654 & 0.1814 & 0.0512 & 0.0003 & 0.0673 & 0.0186 \\
\hline 39.1 & 0.3071 & 0.0055 & 0.0428 & 0.0003 & 0.34 & 23.3522 & 0.1404 & 0.0517 & 0.0009 & 0.2832 & 0.0774 \\
\hline 40.1 & 0.6750 & 0.0175 & 0.0842 & 0.0008 & 0.36 & 11.8725 & 0.1103 & 579 & 0.0012 & 0.6031 & 0.1517 \\
\hline 41.1 & 1.7603 & 0.0213 & 0.1673 & 0.0015 & 0.72 & 5.9786 & 0.0524 & 0.0755 & 0.0007 & 0.0053 & 0.0021 \\
\hline 42.1 & 0.9553 & 0.0112 & 0.1107 & 0.0009 & 0.69 & 9.0294 & 0.0728 & 0.0623 & 0.0005 & 0.1664 & 0.0418 \\
\hline 43.1 & 0.2904 & 0.0065 & 0.0412 & 0.0004 & 0.38 & 24.2812 & 0.2087 & 0.0515 & 0.0010 & 0.3367 & 0.0847 \\
\hline 44.1 & 0.3056 & 0.0085 & 0.0425 & 0.0004 & 0.37 & 23.5487 & 0.2395 & 0.0516 & 0.0012 & 0.3836 & 0.0970 \\
\hline 45.1 & 0.5745 & 0.0116 & 0.0743 & 0.0012 & 0.79 & 13.4567 & 0.2158 & 0.0564 & 0.0008 & 0.1470 & 0.0376 \\
\hline 46.1 & 0.6975 & 0.0095 & 0.0879 & 0.0008 & 0.63 & 11.3802 & 0.0973 & & 0.0005 & 0.0995 & 0.0262 \\
\hline 47.1 & 0.5686 & 0.0081 & 0.0734 & 0.0007 & 0.71 & 13.6250 & 0.1375 & 0.0562 & 0.0005 & 0.2538 & 0.0638 \\
\hline 48.1 & 0.3004 & 0.0056 & 0.0423 & 0.0004 & 0.55 & 23.6377 & 0.2419 & 0.0517 & 0.0007 & 0.3327 & 0.0837 \\
\hline 49.1 & 0.6615 & 0.0124 & 0.0841 & 0.0012 & 0.76 & 11.8935 & 0.1709 & 0.0580 & 0.0006 & 0.0169 & 0.0046 \\
\hline
\end{tabular}




\begin{tabular}{|c|c|c|c|c|c|c|c|c|c|c|c|}
\hline 50.1 & 0.2997 & 0.0063 & 0.0419 & 0.0004 & 0.45 & 23.8397 & 0.2245 & 0.0516 & 0.0008 & 0.4876 & 0.1226 \\
\hline 51.1 & 0.5947 & 0.0070 & 0.0762 & 0.0006 & 0.70 & 13.1315 & 0.1081 & 0.0567 & 0.0005 & 0.3201 & 0.0805 \\
\hline 52.1 & 2987 & 0.0037 & 0.0424 & 0.0003 & 0.65 & 23.5808 & 0.1921 & 0.0516 & 0.0005 & 0.2186 & 0.0549 \\
\hline 53.1 & 0.9143 & 0.0234 & 0.1075 & 0.0022 & 0.79 & 9.3030 & 0.1884 & 0.0617 & 0.0006 & 0.1673 & 0.0418 \\
\hline 54.1 & 0.3149 & 0.0081 & 0.0449 & 0.0009 & 0.78 & 22.2616 & 0.4470 & 0.0520 & 0.0005 & 0.2699 & 0.0674 \\
\hline 55.1 & 0.8082 & 0.0205 & 0.0976 & 0.0020 & 0.81 & 10.2448 & 0.2116 & 0.0601 & 0.0006 & 0.0165 & 0.0042 \\
\hline 56.1 & 0.7116 & 0.0182 & 0.0877 & 0.0018 & 0.80 & 11.4049 & 0.2338 & 0.0584 & 0.0007 & 0.7075 & 0.1769 \\
\hline 57.1 & 0.7265 & 0.0184 & 0.0890 & 0.0018 & 0.79 & 11.2314 & 0.2237 & 0.0587 & 0.0006 & 0.2365 & 0.0591 \\
\hline 58.1 & 0.5601 & 0.0143 & 0.0712 & 0.0014 & 0.78 & 14.0470 & 0.2786 & 0.0559 & 0.0006 & 0.1019 & 0.0255 \\
\hline 59.1 & 0.7144 & 0.0229 & 0.0880 & 0.0024 & 0.84 & 11.3577 & 0.3051 & 0.0586 & 0.0007 & 0.3334 & 0.0834 \\
\hline 60.1 & 2.2083 & 0.0615 & 0.2028 & 0.0046 & 0.82 & 4.9298 & 0.1122 & 0.0796 & 0.0008 & 0.2381 & 0.0598 \\
\hline 61.1 & 1.0412 & 0.0286 & 0.1188 & 0.0026 & 0.81 & 8.4208 & 0.1866 & 0.0636 & 0.0006 & 0.3457 & 0.0864 \\
\hline 61.2 & 1.0392 & 0.0299 & 0.1162 & 0.0026 & 0.77 & 8.6054 & 0.1912 & 0632 & 0.0009 & 0.3328 & 0.0833 \\
\hline 62.1 & 0.7156 & 0.0206 & 0.0901 & 0.0023 & 0.90 & 11.1006 & 0.2889 & 0.0588 & 0.0006 & 0.2634 & 0.0659 \\
\hline 63.1 & 0.3134 & 0.0086 & 0.0446 & 0.0009 & 0.76 & 22.4299 & 0.4674 & 0.0519 & 0.0007 & 0.1924 & 0.0482 \\
\hline 64.1 & 1.7169 & 0.0506 & 0.1710 & 0.0041 & 0.82 & 5.8491 & 0.1411 & 0.0731 & 0.0008 & 0.2226 & 0.0556 \\
\hline 65.1 & 1.6578 & 0.0339 & 0.1663 & 0.0020 & 0.59 & 6.0141 & 0.0729 & 0.0723 & 0.0007 & 0.2834 & 0.1099 \\
\hline 66.1 & 0.5509 & 0.0150 & 0.0723 & 0.0013 & 0.67 & 13.8362 & 0.2528 & 0.0561 & 0.0007 & 0.2496 & 0.0970 \\
\hline 67.1 & 0.2861 & 0.0075 & 0.0396 & 0.0005 & 0.51 & 25.2519 & 0.3335 & 0.0513 & 0.0008 & 0.5391 & 0.2094 \\
\hline 68.1 & 0.3095 & 0.0064 & 0.0431 & 0.0005 & 0.60 & 23.1989 & 0.2874 & 0.0517 & 0.0005 & 0.2917 & 0.1133 \\
\hline 69.1 & 0.3469 & 0.0073 & 0.0480 & 0.0006 & 0.59 & 20.8257 & 0.2568 & 0.0524 & 0.0006 & 0.3986 & 0.1546 \\
\hline 70.1 & 0.3195 & 0.0068 & 0.0434 & 0.0006 & 0.60 & 23.0412 & 0.2939 & 0.0518 & 0.0005 & 0.0129 & 0.0055 \\
\hline 70.2 & 0.3117 & 0.0077 & 0.0435 & 0.0006 & 0.55 & 22.9844 & 0.3134 & 0.0518 & 0.0007 & 0.1669 & 0.0650 \\
\hline 71.1 & 1.7561 & 0.0356 & 0.1736 & 0.0021 & 0.60 & 5.7612 & 0.0700 & 0.0735 & 0.0007 & 0.2013 & 0.0781 \\
\hline 72.1 & 4.3933 & 0.0975 & 0.3044 & 0.0042 & 0.62 & 3.2852 & 0.0449 & 0.1047 & 0.0011 & 0.6427 & 0.2496 \\
\hline 73.1 & 0.8664 & 0.0191 & 0.1036 & 0.0014 & 0.60 & 9.6555 & 0.1278 & 0.0611 & 0.0007 & 0.2021 & 0.0785 \\
\hline
\end{tabular}




\begin{tabular}{l|cllllllllll}
74.1 & 0.2983 & 0.0061 & 0.0413 & 0.0005 & 0.58 & 24.1902 & 0.2857 & 0.0515 & 0.0005 & 0.2951 & 0.1144 \\
75.1 & 2.0947 & 0.0497 & 0.1958 & 0.0032 & 0.68 & 5.1082 & 0.0828 & 0.0781 & 0.0008 & 0.3285 & 0.1274 \\
76.1 & 0.6542 & 0.0161 & 0.0828 & 0.0011 & 0.53 & 12.0811 & 0.1574 & 0.0577 & 0.0009 & 0.7726 & 0.2998 \\
77.1 & 0.3079 & 0.0056 & 0.0428 & 0.0005 & 0.69 & 23.3407 & 0.2921 & 0.0517 & 0.0005 & 0.3415 & 0.1000 \\
78.1 & 0.3180 & 0.0050 & 0.0442 & 0.0005 & 0.78 & 22.6000 & 0.2779 & 0.0519 & 0.0002 & 0.3968 & 0.1159 \\
79.1 & 0.2767 & 0.0064 & 0.0398 & 0.0007 & 0.73 & 25.1018 & 0.4193 & 0.0513 & 0.0005 & 0.4306 & 0.1261 \\
79.2 & 0.3071 & 0.0051 & 0.0432 & 0.0005 & 0.76 & 23.1588 & 0.2911 & 0.0517 & 0.0003 & 0.4005 & 0.1170 \\
80.1 & 0.2987 & 0.0056 & 0.0426 & 0.0007 & 0.83 & 23.4539 & 0.3614 & 0.0517 & 0.0005 & 0.4573 & 0.1339 \\
81.2 & 0.3120 & 0.0082 & 0.0430 & 0.0006 & 0.57 & 23.2663 & 0.3482 & 0.0517 & 0.0009 & 0.0736 & 0.0242 \\
82.1 & 0.2968 & 0.0077 & 0.0424 & 0.0006 & 0.57 & 23.5735 & 0.3478 & 0.0517 & 0.0007 & 0.1367 & 0.0406 \\
82.2 & 0.3114 & 0.0059 & 0.0438 & 0.0006 & 0.75 & 22.8389 & 0.3266 & 0.0518 & 0.0004 & 0.2968 & 0.0869 \\
83.1 & 0.3190 & 0.0058 & 0.0441 & 0.0006 & 0.73 & 22.6911 & 0.2997 & 0.0519 & 0.0004 & 0.2610 & 0.0768 \\
84.1 & 0.3069 & 0.0058 & 0.0420 & 0.0007 & 0.82 & 23.8155 & 0.3710 & 0.0516 & 0.0003 & 0.5409 & 0.1590 \\
86.1 & 0.3270 & 0.0070 & 0.0469 & 0.0006 & 0.62 & 21.3379 & 0.2817 & 0.0523 & 0.0003 & 0.1386 & 0.0408 \\
\hline 19.1 & 0.4229 & 0.0102 & 0.0580 & 0.0012 & 0.84 & 17.2441 & 0.3470 & 0.0557 & 0.0003 & 0.2235 & 0.0595 \\
81.1 & 1.1206 & 0.0281 & 0.1205 & 0.0022 & 0.72 & 8.3016 & 0.1505 & 0.0681 & 0.0006 & 0.4149 & 0.1380 \\
85.1 & 0.3013 & 0.0061 & 0.0431 & 0.0006 & 0.64 & 23.1865 & 0.3029 & 0.0518 & 0.0006 & 0.6134 & 0.1792 \\
\hline
\end{tabular}


Resultados para a amostra L-4-8: Pb total comum e radioativo, Th, U, idades 206/238 e 207/206 com os erros, e a concordância.

\begin{tabular}{|c|c|c|c|c|c|c|c|c|c|c|}
\hline \multirow[b]{2}{*}{ SPOT } & \multirow[b]{2}{*}{$\begin{array}{l}\mathrm{Pb} \text { total } \\
\text { comum }\end{array}$} & \multirow[b]{2}{*}{$\begin{array}{c}\mathrm{Pb} \text { rad } \\
\mathrm{ppm}\end{array}$} & \multirow[b]{2}{*}{$\begin{array}{c}\text { Th } \\
\text { ppm }\end{array}$} & \multirow[b]{2}{*}{$\begin{array}{c}\mathrm{U} \\
\mathrm{ppm}\end{array}$} & \multirow[b]{2}{*}{$\mathrm{Th} / \mathrm{U}$} & \multirow[b]{2}{*}{ T206/238 } & \multicolumn{3}{|c|}{ AGES } & \multirow{2}{*}{$\begin{array}{c}\text { conc. } \\
\text { 206/238 } \\
\text { 207/206 }\end{array}$} \\
\hline & & & & & & & 1 sigma & T207/206 & 1 sigma & \\
\hline 1.1 & 0.47 & 53.0 & 38.6 & 554.2 & 0.0697 & 0.553 & 0.007 & 0.555 & 0.015 & 100 \\
\hline 2.1 & $<0.001$ & 10.8 & 164.4 & 191.3 & 0.860 & 0.271 & 0.004 & 0.272 & 0.034 & 100 \\
\hline 3.1 & 1.44 & 14.4 & 161.2 & 294.0 & 0.548 & 0.257 & 0.003 & 0.256 & 0.022 & 100 \\
\hline 4.1 & 0.33 & 63.7 & 281.2 & 1298.6 & 0.217 & 0.282 & 0.003 & 0.282 & 0.015 & 100 \\
\hline 5.1 & 0.46 & 43.4 & 105.5 & 329.2 & 0.320 & 0.707 & 0.007 & 0.705 & 0.015 & 100 \\
\hline 6.1 & 1.55 & 24.8 & 220.7 & 500.3 & 0.441 & 0.262 & 0.003 & 0.263 & 0.024 & 100 \\
\hline 7.1 & 0.37 & 52.4 & 212.1 & 398.6 & 0.532 & 0.637 & 0.007 & 0.635 & 0.016 & 100 \\
\hline 8.1 & 1.54 & 12.3 & 123.9 & 185.0 & 0.670 & 0.341 & 0.004 & 0.340 & 0.027 & 100 \\
\hline 9.1 & 0.19 & 43.1 & 361.3 & 860.2 & 0.420 & 0.270 & 0.003 & 0.270 & 0.016 & 100 \\
\hline 10.1 & $<0.001$ & 24.0 & 48.9 & 258.6 & 0.189 & 0.539 & 0.006 & 0.538 & 0.016 & 100 \\
\hline 11.1 & 0.39 & 102.0 & 1266.1 & 2197.0 & 0.576 & 0.275 & 0.007 & 0.275 & 0.016 & 100 \\
\hline 12.1 & 0.02 & 191.3 & 401.5 & 896.1 & 0.448 & 1.041 & 0.013 & 1.041 & 0.014 & 100 \\
\hline 13.1 & 0.19 & 11.1 & 101.2 & 229.8 & 0.440 & 0.254 & 0.003 & 0.254 & 0.043 & 100 \\
\hline 14.1 & 0.14 & 23.0 & 18.5 & 110.9 & 0.1673 & 1.104 & 0.023 & 1.088 & 0.014 & 102 \\
\hline 15.1 & $<0.001$ & 59.1 & 85.5 & 324.1 & 0.264 & 0.970 & 0.019 & 0.974 & 0.013 & 100 \\
\hline 16.1 & 0.31 & 45.0 & 590.7 & 853.5 & 0.692 & 0.268 & 0.005 & 0.268 & 0.020 & 100 \\
\hline 17.1 & 0.00 & 32.0 & 84.0 & 387.7 & 0.217 & 0.461 & 0.010 & 0.461 & 0.016 & 100 \\
\hline 18.1 & $<0.001$ & 12.1 & 26.9 & 109.3 & 0.246 & 0.597 & 0.011 & 0.598 & 0.019 & 100 \\
\hline 20.1 & 2.91 & 12.4 & 56.4 & 253.9 & 0.222 & 0.267 & 0.005 & 0.267 & 0.022 & 100 \\
\hline 21.1 & $<0.001$ & 14.9 & 43.6 & 146.8 & 0.297 & 0.524 & 0.010 & 0.522 & 0.020 & 100 \\
\hline
\end{tabular}




\begin{tabular}{l|ccccc|cccc|c}
22.1 & $<0.001$ & 45.7 & 228.2 & 172.0 & 1.326 & 1.131 & 0.021 & 1.126 & 0.015 & 100 \\
23.1 & $<0.001$ & 21.4 & 212.8 & 409.6 & 0.520 & 0.273 & 0.005 & 0.273 & 0.019 & 100 \\
24.1 & 0.78 & 12.7 & 110.2 & 266.8 & 0.413 & 0.246 & 0.005 & 0.246 & 0.032 & 100 \\
25.1 & $<0.001$ & 7.6 & 97.4 & 143.4 & 0.679 & 0.263 & 0.005 & 0.264 & 0.041 & 100 \\
26.1 & 0.45 & 18.2 & 81.3 & 220.6 & 0.369 & 0.446 & 0.009 & 0.447 & 0.017 & 100 \\
27.1 & $<0.001$ & 20.8 & 53.1 & 237.6 & 0.2237 & 0.501 & 0.003 & 0.499 & 0.014 & 100 \\
28.1 & $<0.001$ & 12.4 & 251.8 & 222.9 & 1.130 & 0.261 & 0.002 & 0.261 & 0.022 & 100 \\
29.1 & 0.33 & 17.8 & 375.3 & 297.3 & 1.263 & 0.270 & 0.001 & 0.269 & 0.018 & 100 \\
30.1 & 0.80 & 11.7 & 117.2 & 231.5 & 0.506 & 0.283 & 0.003 & 0.284 & 0.076 & 100 \\
31.1 & 0.30 & 28.4 & 17.9 & 455.4 & 0.039 & 0.383 & 0.004 & 0.382 & 0.009 & 100 \\
32.1 & 0.42 & 25.0 & 381.6 & 467.4 & 0.816 & 0.275 & 0.002 & 0.275 & 0.009 & 100 \\
33.1 & 0.23 & 9.7 & 32.7 & 204.2 & 0.160 & 0.282 & 0.003 & 0.220 & 0.046 & 128 \\
34.1 & $<0.001$ & 21.9 & 60.4 & 220.8 & 0.274 & 0.571 & 0.004 & 0.572 & 0.016 & 100 \\
35.1 & 0.73 & 23.2 & 261.3 & 454.6 & 0.575 & 0.266 & 0.002 & 0.267 & 0.022 & 100 \\
36.1 & $<0.001$ & 9.4 & 94.4 & 189.5 & 0.498 & 0.269 & 0.002 & 0.269 & 0.014 & 100 \\
37.1 & 0.70 & 8.8 & 35.1 & 89.8 & 0.391 & 0.534 & 0.006 & 0.535 & 0.029 & 100 \\
38.1 & 0.31 & 42.8 & 152.1 & 973.0 & 0.156 & 0.249 & 0.002 & 0.250 & 0.012 & 100 \\
39.1 & 0.98 & 9.5 & 103.8 & 188.7 & 0.550 & 0.270 & 0.002 & 0.268 & 0.036 & 101 \\
40.1 & 1.50 & 13.2 & 126.8 & 111.4 & 1.1383 & 0.521 & 0.005 & 0.520 & 0.043 & 100 \\
41.1 & 0.56 & 142.9 & 11.7 & 780.1 & 0.015 & 0.997 & 0.008 & 1.082 & 0.018 & 92 \\
42.1 & $<0.001$ & 56.5 & 150.9 & 453.2 & 0.333 & 0.677 & 0.005 & 0.678 & 0.018 & 100 \\
43.1 & 1.11 & 11.8 & 147.3 & 231.7 & 0.636 & 0.260 & 0.002 & 0.260 & 0.044 & 100 \\
44.1 & $<0.001$ & 8.1 & 119.6 & 149.3 & 0.801 & 0.268 & 0.003 & 0.268 & 0.052 & 100 \\
45.1 & 0.37 & 24.5 & 98.8 & 302.2 & 0.327 & 0.462 & 0.007 & 0.463 & 0.032 & 100 \\
46.1 & 0.14 & 38.5 & 76.5 & 404.2 & 0.189 & 0.543 & 0.004 & 0.543 & 0.020 & 100 \\
47.1 & 0.38 & 58.0 & 325.4 & 673.4 & 0.483 & 0.457 & 0.004 & 0.455 & 0.020 & 100
\end{tabular}




\begin{tabular}{l|ccccc|cccc|c}
48.1 & 1.24 & 14.7 & 218.0 & 286.6 & 0.760 & 0.267 & 0.003 & 0.268 & 0.031 & 100 \\
49.1 & 1.54 & 55.8 & 23.3 & 631.3 & 0.037 & 0.520 & 0.007 & 0.523 & 0.023 & 100 \\
50.1 & $<0.001$ & 11.0 & 181.9 & 199.3 & 0.913 & 0.265 & 0.002 & 0.265 & 0.033 & 100 \\
51.1 & 0.07 & 217.3 & 1468.8 & 2330.2 & 0.630 & 0.473 & 0.004 & 0.474 & 0.018 & 100 \\
52.1 & 3.91 & 76.7 & 599.9 & 1609.0 & 0.373 & 0.268 & 0.002 & 0.268 & 0.021 & 100 \\
53.1 & $<0.001$ & 39.1 & 115.4 & 314.4 & 0.3671 & 0.658 & 0.013 & 0.660 & 0.022 & 100 \\
54.1 & 3.83 & 38.9 & 431.2 & 718.4 & 0.600 & 0.283 & 0.006 & 0.284 & 0.022 & 100 \\
55.1 & 0.03 & 82.2 & 31.2 & 784.3 & 0.040 & 0.600 & 0.012 & 0.600 & 0.020 & 100 \\
56.1 & $<0.001$ & 12.9 & 146.5 & 98.3 & 1.491 & 0.542 & 0.011 & 0.539 & 0.024 & 100 \\
57.1 & 0.39 & 16.7 & 83.4 & 154.1 & 0.541 & 0.550 & 0.010 & 0.549 & 0.023 & 100 \\
58.1 & 0.08 & 67.8 & 185.3 & 850.1 & 0.218 & 0.443 & 0.008 & 0.442 & 0.022 & 100 \\
59.1 & 0.68 & 24.3 & 149.0 & 218.1 & 0.683 & 0.544 & 0.014 & 0.545 & 0.026 & 100 \\
60.1 & $<0.001$ & 55.6 & 111.2 & 204.9 & 0.543 & 1.191 & 0.025 & 1.190 & 0.020 & 100 \\
61.1 & $<0.001$ & 124.1 & 588.8 & 814.0 & 0.723 & 0.723 & 0.015 & 0.724 & 0.021 & 100 \\
61.2 & 0.28 & 66.3 & 324.4 & 495.7 & 0.655 & 0.709 & 0.015 & 0.710 & 0.030 & 100 \\
62.1 & $<0.001$ & 12.2 & 67.8 & 135.3 & 0.501 & 0.556 & 0.014 & 0.554 & 0.024 & 100 \\
63.1 & 0.68 & 13.9 & 127.5 & 270.4 & 0.471 & 0.281 & 0.006 & 0.280 & 0.028 & 100 \\
64.1 & 0.28 & 20.9 & 55.6 & 91.5 & 0.608 & 1.017 & 0.023 & 1.018 & 0.022 & 100 \\
65.1 & $<0.001$ & 100.7 & 241.5 & 513.2 & 0.4706 & 0.992 & 0.011 & 0.995 & 0.020 & 100 \\
66.1 & 3.38 & 20.9 & 93.2 & 248.9 & 0.375 & 0.450 & 0.008 & 0.449 & 0.026 & 100 \\
67.1 & 0.95 & 36.7 & 609.5 & 692.7 & 0.880 & 0.250 & 0.003 & 0.251 & 0.035 & 100 \\
68.1 & 0.32 & 21.1 & 208.8 & 414.1 & 0.504 & 0.272 & 0.003 & 0.271 & 0.022 & 100 \\
69.1 & 0.70 & 46.6 & 512.9 & 800.2 & 0.641 & 0.302 & 0.004 & 0.302 & 0.024 & 100 \\
70.1 & 0.27 & 42.2 & 23.4 & 905.6 & 0.026 & 0.274 & 0.003 & 0.275 & 0.022 & 100 \\
70.2 & 0.60 & 36.0 & 170.9 & 711.9 & 0.240 & 0.275 & 0.004 & 0.275 & 0.030 & 100 \\
71.1 & 0.12 & 95.5 & 161.7 & 474.4 & 0.341 & 1.032 & 0.012 & 1.028 & 0.020 & 100
\end{tabular}




\begin{tabular}{l|ccccc|cccc|c}
72.1 & $<0.001$ & 42.4 & 139.5 & 101.6 & 1.373 & 1.713 & 0.021 & 1.713 & 0.019 & 100 \\
73.1 & 0.39 & 21.8 & 71.5 & 185.3 & 0.386 & 0.635 & 0.008 & 0.635 & 0.023 & 100 \\
74.1 & 0.19 & 43.9 & 441.4 & 879.4 & 0.502 & 0.261 & 0.003 & 0.262 & 0.022 & 100 \\
75.1 & $<0.001$ & 73.5 & 179.6 & 268.5 & 0.669 & 1.153 & 0.017 & 1.152 & 0.020 & 100 \\
76.1 & 0.89 & 11.3 & 118.6 & 95.5 & 1.242 & 0.513 & 0.006 & 0.510 & 0.036 & 100 \\
77.1 & $<0.001$ & 21.7 & 292.6 & 415.4 & 0.7045 & 0.270 & 0.003 & 0.272 & 0.022 & 100 \\
78.1 & 0.13 & 86.9 & 1242.9 & 1535.5 & 0.809 & 0.279 & 0.003 & 0.279 & 0.010 & 100 \\
79.1 & 1.18 & 24.5 & 448.6 & 482.2 & 0.930 & 0.252 & 0.004 & 0.252 & 0.023 & 100 \\
79.2 & 0.54 & 33.9 & 513.8 & 623.0 & 0.825 & 0.273 & 0.003 & 0.272 & 0.013 & 100 \\
80.1 & 0.61 & 19.8 & 317.2 & 367.9 & 0.862 & 0.269 & 0.004 & 0.270 & 0.021 & 100 \\
81.2 & 1.70 & 11.2 & 40.3 & 250.8 & 0.161 & 0.271 & 0.004 & 0.271 & 0.038 & 100 \\
82.1 & 0.75 & 11.9 & 68.9 & 255.2 & 0.270 & 0.268 & 0.004 & 0.269 & 0.031 & 100 \\
82.2 & 0.08 & 34.4 & 384.4 & 652.6 & 0.589 & 0.276 & 0.004 & 0.275 & 0.018 & 100 \\
83.1 & 0.86 & 21.7 & 267.4 & 418.1 & 0.640 & 0.278 & 0.004 & 0.279 & 0.019 & 100 \\
84.1 & 0.79 & 35.1 & 597.2 & 595.5 & 1.003 & 0.265 & 0.004 & 0.265 & 0.013 & 100 \\
86.1 & 0.11 & 39.8 & 258.5 & 776.1 & 0.333 & 0.295 & 0.004 & 0.296 & 0.012 & 100 \\
\hline 19.1 & 7.08 & 115.9 & 1114.0 & 1682.1 & 0.662 & 0.363 & 0.007 & 0.436 & 0.014 & 83 \\
81.1 & 3.32 & 96.6 & 771.2 & 669.2 & 1.152 & 0.733 & 0.013 & 0.870 & 0.017 & 84 \\
85.1 & 13.57 & 18.1 & 383.5 & 306.7 & 1.250 & 0.272 & 0.003 & 0.273 & 0.025 & 100 \\
\hline
\end{tabular}


Resultados para a amostra L-4-12, com as razões 207/235, 206/238, 238/206, 207/206, 208/206 e respectivos erros.

\begin{tabular}{c|cccccccccc}
\hline SPOT & $\mathbf{2 0 7 / 2 3 5}$ & 1 sigma & $\mathbf{2 0 6 / 2 3 8}$ & 1 sigma & coef. corr & $\mathbf{2 3 8 / 2 0 6}$ & 1 sigma & $\mathbf{2 0 7 / 2 0 6}$ & 1 sigma & $\mathbf{2 0 8 / 2 0 6}$ \\
\hline 1.1 & 0.6677 & 0.0094 & 0.0844 & 0.0010 & 0.81 & 11.8509 & 0.1342 & 0.0579 & 0.0005 & 0.2278 \\
2.1 & 0.7111 & 0.0088 & 0.0884 & 0.0009 & 0.83 & 11.3170 & 0.1160 & 0.0586 & 0.0003 & 0.1538 \\
3.1 & 0.4663 & 0.0158 & 0.0630 & 0.0009 & 0.44 & 15.8788 & 0.2374 & 0.0547 & 0.0015 & 0.1922 \\
4.1 & 0.2966 & 0.0044 & 0.0415 & 0.0004 & 0.72 & 24.1241 & 0.2566 & 0.0515 & 0.0003 & 0.2107 \\
5.1 & 0.7203 & 0.0099 & 0.0890 & 0.0010 & 0.84 & 11.2416 & 0.1302 & 0.0585 & 0.0004 & 0.0926 \\
6.1 & 1.0312 & 0.0179 & 0.1208 & 0.0018 & 0.85 & 8.2770 & 0.1226 & 0.0622 & 0.0005 & 0.0765 \\
8.1 & 0.7798 & 0.0107 & 0.0935 & 0.0011 & 0.83 & 10.6929 & 0.1223 & 0.0595 & 0.0003 & 0.0432 \\
9.1 & 0.5823 & 0.0082 & 0.0749 & 0.0009 & 0.82 & 13.3495 & 0.1540 & 0.0566 & 0.0003 & -0.0014 \\
10.1 & 0.7185 & 0.0094 & 0.0885 & 0.0010 & 0.84 & 11.2954 & 0.1243 & 0.0587 & 0.0003 & 0.1887 \\
11.1 & 0.5849 & 0.0077 & 0.0749 & 0.0008 & 0.81 & 13.3584 & 0.1416 & 0.0565 & 0.0003 & 0.0442 \\
12.1 & 0.6270 & 0.0085 & 0.0793 & 0.0009 & 0.84 & 12.6173 & 0.1431 & 0.0571 & 0.0003 & 0.0658 \\
13.1 & 0.7406 & 0.0094 & 0.0912 & 0.0010 & 0.84 & 10.9615 & 0.1169 & 0.0591 & 0.0003 & 0.2077 \\
14.1 & 0.6724 & 0.0093 & 0.0830 & 0.0008 & 0.72 & 12.0461 & 0.1198 & 0.0585 & 0.0005 & 0.1902 \\
15.1 & 1.9908 & 0.0264 & 0.1885 & 0.0018 & 0.74 & 5.3062 & 0.0520 & 0.0764 & 0.0006 & 0.1512 \\
15.2 & 0.2812 & 0.0041 & 0.0398 & 0.0005 & 0.80 & 25.1008 & 0.2893 & 0.0513 & 0.0004 & 0.0038 \\
16.1 & 1.6806 & 0.0221 & 0.1664 & 0.0017 & 0.76 & 6.0088 & 0.0601 & 0.0734 & 0.0006 & 0.3899 \\
17.1 & 0.6778 & 0.0091 & 0.0844 & 0.0008 & 0.72 & 11.8535 & 0.1139 & 0.0580 & 0.0005 & 0.1005 \\
18.1 & 0.3030 & 0.0053 & 0.0420 & 0.0005 & 0.61 & 23.7941 & 0.2568 & 0.0516 & 0.0005 & 0.0300 \\
19.1 & 0.2728 & 0.0067 & 0.0400 & 0.0006 & 0.65 & 25.0309 & 0.3938 & 0.0513 & 0.0005 & 0.0547 \\
20.1 & 0.7310 & 0.0095 & 0.0901 & 0.0009 & 0.74 & 11.1043 & 0.1069 & 0.0589 & 0.0005 & 0.0699 \\
21.1 & 0.6894 & 0.0090 & 0.0856 & 0.0008 & 0.73 & 11.6856 & 0.1116 & 0.0582 & 0.0005 & 0.0931 \\
22.1 & 0.7061 & 0.0112 & 0.0862 & 0.0009 & 0.65 & 11.6005 & 0.1199 & 0.0582 & 0.0006 & 0.2762 \\
23.1 & 0.2938 & 0.0054 & 0.0410 & 0.0004 & 0.57 & 24.3791 & 0.2571 & 0.0515 & 0.0007 & 0.3833
\end{tabular}




\begin{tabular}{|c|c|c|c|c|c|c|c|c|c|c|}
\hline 24.1 & 0.6980 & 0.0100 & 0.0867 & 0.0009 & 0.69 & 11.5340 & 0.1142 & 0.0583 & 0.0005 & 0.1934 \\
\hline 25.1 & 2997 & 0.0053 & 0.0417 & 0.0005 & 0.69 & 23.9580 & 0.2909 & 0.0518 & 0.0006 & 0.1760 \\
\hline .1 & 1.6452 & 0.0207 & 0.1664 & 0.0014 & 0.66 & 6.0114 & 0.0500 & 0.0739 & 0.0006 & 0.1455 \\
\hline .1 & 0.6958 & 0.0085 & 0.0871 & .0007 & 62 & 11.4769 & 0.0865 & 0584 & 0005 & 1163 \\
\hline & .3047 & 0.0036 & 0.0429 & 0.0003 & 0.63 & 23.3157 & 748 & 0.0517 & .0004 & 0.0969 \\
\hline 9.1 & 0.2975 & 0.0036 & 0.0423 & 0.0003 & 0.62 & 23.6541 & 0.1787 & .0516 & 0.0004 & 0.4704 \\
\hline .1 & 0.3387 & 0.0070 & 0.0483 & 0.0005 & 0.46 & 20.6903 & 0.1984 & 0.0525 & 0.0008 & 0.0667 \\
\hline .1 & .7169 & 0.0116 & 0.0890 & 0.0011 & .79 & 1.2307 & 433 & & & 3825 \\
\hline. .1 & 0.5480 & 0.0090 & 0.0697 & 0.0008 & 0.68 & 461 & 0.1611 & 0.0565 & 0.0005 & 0.1553 \\
\hline .1 & 6619 & 0.0092 & 0.08 & & 0.69 & 977 & 72 & & & 995 \\
\hline 4.1 & 0.3136 & 0.0062 & & & 0.43 & & & & & 3328 \\
\hline 5.1 & 4.8816 & 0.0580 & 0.3193 & 0.0024 & 0.62 & 3.1317 & 0.0232 & 105 & 008 & 0.0617 \\
\hline 6.1 & 1.0720 & 0.0154 & 0.1205 & 0.0011 & 0.66 & 2987 & 0.0782 & 638 & 0.0006 & 0.1335 \\
\hline 7.1 & 0.7265 & 0.0106 & 0.0904 & 0.0008 & 0.57 & 11.0613 & 0.0924 & 589 & 0.0006 & 0.3342 \\
\hline 8.1 & 0.2283 & 0.0049 & 0.0341 & 0.0006 & 0.82 & 2948 & 0.5181 & 505 & 0.0005 & 0.4436 \\
\hline 9.1 & 2.0661 & 0.0153 & 0.1933 & 0.0010 & 0.72 & 5.1731 & 0.0277 & 776 & 0.0005 & 3309 \\
\hline 0.1 & 0.6502 & 0.0056 & 0.0826 & 0.0004 & 0.50 & 12.1090 & 0.0517 & 578 & 0.0004 & 0.2506 \\
\hline 41.1 & 0.5992 & 0.0058 & 0.0756 & 0.0003 & 0.46 & & & 0.0566 & 0.0005 & 0.1464 \\
\hline 42.1 & 0.6238 & 0.0116 & 0.0801 & 0.0009 & 0.59 & 861 & 384 & 573 & 0.0012 & 0.0390 \\
\hline 43.1 & 0.8880 & 0.0049 & 0.1047 & 0.0004 & 0.61 & 9.5551 & 0.0325 & 0.0612 & 0.0004 & 0.1763 \\
\hline 44.1 & 0.6851 & 0.0057 & 0.0830 & 0.0005 & 0.74 & 12.0446 & 0.0738 & 0.0577 & 0.0004 & 0.1063 \\
\hline 45.1 & 0.2830 & 0.0046 & 0.0393 & 0.0004 & 0.55 & 25.4211 & 0.2276 & 0.0512 & 0.0006 & -0.0028 \\
\hline 46.1 & 0.5509 & 0.0138 & 0.0710 & 0.0008 & 0.43 & 14.0890 & 0.1504 & 0.0559 & 0.0016 & 0.1518 \\
\hline 47.1 & 0.4545 & 0.0033 & 0.0605 & 0.0003 & 0.61 & 16.5386 & 0.0728 & 0.0543 & 0.0004 & 0.1359 \\
\hline 48.1 & 0.7062 & 0.0054 & 0.0891 & 0.0004 & 0.60 & 11.2184 & 0.0513 & 0.0587 & 0.0004 & 0.2384 \\
\hline 49.1 & 0.3339 & 0.0050 & 0.0464 & 0.0002 & 0.31 & 21.5607 & 0.1002 & 0.0522 & 0.0007 & 0.1085 \\
\hline
\end{tabular}




\begin{tabular}{|c|c|c|c|c|c|c|c|c|c|c|}
\hline 50.1 & 0.2931 & 0.0025 & 0.0407 & 0.0002 & 0.68 & 24.5682 & 0.1448 & 0.0514 & 0.0004 & 0.0310 \\
\hline 51.1 & 0.8154 & 0.0163 & 0.0978 & 0.0016 & 0.81 & 0.2213 & 0.1656 & & & 0.1420 \\
\hline 2.1 & 3911 & .0038 & 0.0528 & .0004 & 0.78 & 18.9474 & 0.1427 & .0532 & .0004 & 0.0051 \\
\hline 53.1 & 0.2808 & 0.0030 & 0.0398 & 0.0003 & .74 & 25.1028 & 0.1959 & .0513 & .0004 & 0.2482 \\
\hline 54.1 & 0.2734 & 0.0037 & 0.0387 & 0.0003 & 0.61 & 25.8501 & 0.2120 & .0511 & .0006 & 0.3490 \\
\hline 5.1 & .2864 & 0.0052 & 0.0399 & 0.0003 & .48 & 25.0906 & 0.2184 & 513 & & 3703 \\
\hline 56.1 & 0.7010 & 0.0080 & 0.0855 & 0.0007 & 0.72 & 11.7020 & 0.0962 & 0.0582 & 0.0005 & -0.0011 \\
\hline 7.1 & & & & & .73 & & & & & \\
\hline 8.1 & 1.5800 & 0.0163 & 0.1615 & 0.0013 & .76 & & 0489 & 713 & 005 & 522 \\
\hline 9.1 & .8076 & 0.0090 & 0.0973 & .0010 & 0.90 & 812 & 045 & 596 & & 0.1069 \\
\hline 0.1 & 0.4960 & 0.0072 & 0.0636 & 0.0005 & 0.56 & 207 & 0.1282 & & 0.0006 & 2014 \\
\hline 1.1 & 0.6023 & 0.0080 & 0.0772 & 0.0007 & 0.71 & 12.9 & 0.1221 & 68 & 0.0006 & 1800 \\
\hline 2.1 & 0.3255 & 0.0038 & 0.0449 & & 0.66 & 22 . & 585 & & & 0.2374 \\
\hline 3.1 & 0.8621 & 0.0086 & 0.1016 & 0.0008 & 0.76 & 9.8406 & 0.0743 & 0.0607 & 0.0004 & 0.0855 \\
\hline 4.1 & 0.6139 & 0.0069 & 0.0779 & 0.0007 & 0.79 & 12.8438 & 0.1137 & 569 & 004 & 0.2799 \\
\hline 5.1 & 2.0148 & 0.0230 & 0.1915 & & 0.66 & & & & & 0.2080 \\
\hline 6.1 & 0.6010 & 0.0064 & 0.0767 & & 0.64 & 13.0 & 881 & 568 & 0.0002 & 0.2037 \\
\hline 67.1 & 0.5741 & 0.0086 & 0.0729 & 0.0006 & 0.50 & 13.7219 & 0.1038 & 0.0562 & 0.0004 & 0.4165 \\
\hline 68.1 & 1.6788 & 0.0193 & 0.1672 & & 0.67 & 5.9823 & & 0.0725 & 0.0002 & 0.1592 \\
\hline 69.1 & 0.7345 & 0.0079 & 0.0906 & 0.0006 & 0.63 & 11.0345 & 0.0750 & 0.0590 & 0.0002 & 0.1073 \\
\hline 70.1 & 0.6938 & 0.0087 & 0.0860 & 0.0006 & 0.59 & 11.6242 & 0.0856 & 0.0582 & 0.0003 & 0.3757 \\
\hline 71.1 & 0.2716 & 0.0039 & 0.0378 & 0.0003 & 0.61 & 26.4280 & 0.2349 & 0.0510 & 0.0004 & 0.7459 \\
\hline 72.1 & & 0.0079 & & & 0.62 & & & & 0.0002 & 0.1786 \\
\hline 73.1 & 0.8158 & 0.0142 & 0.0983 & 0.0013 & 0.76 & 10.1779 & 0.1347 & 0.0602 & 0.0005 & 0.1925 \\
\hline 74.1 & 0.2891 & 0.0075 & 0.0410 & 0.0004 & 0.37 & 24.3775 & 0.2375 & 0.0514 & 0.0009 & 0.3661 \\
\hline 75.1 & 0.8297 & 0.0164 & 0.1004 & 0.0013 & 0.63 & 9.9588 & 0.1246 & 0.0603 & 0.0007 & 0.1635 \\
\hline
\end{tabular}




\begin{tabular}{l|llllllllll}
76.1 & 2.0101 & 0.0221 & 0.1892 & 0.0013 & 0.65 & 5.2848 & 0.0377 & 0.0761 & 0.0003 & 0.2025 \\
77.1 & 0.2924 & 0.0053 & 0.0412 & 0.0004 & 0.53 & 24.2479 & 0.2315 & 0.0515 & 0.0007 & 0.4522 \\
78.1 & 0.7355 & 0.0145 & 0.0910 & 0.0008 & 0.45 & 10.9903 & 0.0984 & 0.0583 & 0.0006 & 0.1794 \\
79.1 & 1.9752 & 0.0484 & 0.1907 & 0.0029 & 0.61 & 5.2442 & 0.0784 & 0.0769 & 0.0009 & 0.3394 \\
80.1 & 0.5984 & 0.0119 & 0.0783 & 0.0006 & 0.42 & 12.7646 & 0.1059 & 0.0565 & 0.0006 & 0.0978 \\
81.1 & 0.6995 & 0.0138 & 0.0865 & 0.0008 & 0.48 & 11.5643 & 0.1097 & 0.0583 & 0.0006 & 0.0708 \\
82.1 & 0.3087 & 0.0064 & 0.0435 & 0.0003 & 0.39 & 22.9751 & 0.1847 & 0.0518 & 0.0006 & 0.1580 \\
83.1 & 0.6290 & 0.0148 & 0.0804 & 0.0010 & 0.52 & 12.4428 & 0.1530 & 0.0573 & 0.0010 & 0.4001 \\
84.1 & 0.2871 & 0.0067 & 0.0405 & 0.0004 & 0.39 & 24.6690 & 0.2236 & 0.0514 & 0.0009 & 0.2407 \\
85.1 & 0.7300 & 0.0221 & 0.0883 & 0.0029 & 0.90 & 11.3312 & 0.3711 & 0.0586 & 0.0006 & 0.1562 \\
86.1 & 0.6870 & 0.0134 & 0.0827 & 0.0006 & 0.40 & 12.0975 & 0.0939 & 0.0583 & 0.0006 & 0.1840 \\
87.1 & 0.7183 & 0.0156 & 0.0899 & 0.0011 & 0.55 & 11.1178 & 0.1319 & 0.0584 & 0.0007 & 0.1590 \\
88.1 & 0.2682 & 0.0087 & 0.0390 & 0.0006 & 0.47 & 25.6244 & 0.3927 & 0.0511 & 0.0015 & 0.1406 \\
89.1 & 0.2728 & 0.0069 & 0.0389 & 0.0003 & 0.33 & 25.7258 & 0.2166 & 0.0512 & 0.0009 & 0.3649 \\
90.1 & 0.2974 & 0.0061 & 0.0415 & 0.0003 & 0.41 & 24.0976 & 0.2020 & 0.0515 & 0.0007 & 0.3844 \\
\hline 7.1 & 0.6178 & 0.0094 & 0.0787 & 0.0010 & 0.81 & 12.7041 & 0.1564 & 0.0571 & 0.0004 & 0.2004 \\
\hline
\end{tabular}


Resultados para a amostra L-4-12: Pb total comum e radioativo, Th, U, idades 206/238 e 207/206 com os erros, e a concordância.

\begin{tabular}{c|ccccc|cccc|c}
\hline & & & & & AGES & & conc. \\
SPOT & Pb total & Pb rad & Th & $\mathrm{U}$ & Th/U & T206/238 & 1 sigma & T207/206 & 1 sigma & $\begin{array}{c}\text { Pb total } \\
\text { comum }\end{array}$ \\
\hline 1.1 & $<0.001$ & 19.2 & 102.2 & 188.5 & 0.5423 & 0.522 & 0.006 & 0.520 & 0.018 & 100 \\
2.1 & 0.09 & 97.5 & 351.4 & 956.4 & 0.367 & 0.546 & 0.005 & 0.545 & 0.011 & 100 \\
3.1 & 1.84 & 5.6 & 43.6 & 74.5 & 0.586 & 0.394 & 0.006 & 0.394 & 0.060 & 100 \\
4.1 & 0.98 & 31.2 & 345.0 & 617.8 & 0.558 & 0.262 & 0.003 & 0.263 & 0.015 & 100 \\
5.1 & $<0.001$ & 55.0 & 127.0 & 564.4 & 0.225 & 0.549 & 0.006 & 0.543 & 0.014 & 101 \\
6.1 & $<0.001$ & 31.3 & 54.5 & 233.2 & 0.234 & 0.735 & 0.010 & 0.675 & 0.018 & 109 \\
8.1 & 1.66 & 47.7 & 65.8 & 477.8 & 0.138 & 0.576 & 0.006 & 0.578 & 0.012 & 100 \\
9.1 & $<0.001$ & 38.4 & 3.2 & 496.0 & 0.006 & 0.466 & 0.005 & 0.468 & 0.013 & 100 \\
10.1 & 0.08 & 214.8 & 943.8 & 2098.3 & 0.450 & 0.547 & 0.006 & 0.549 & 0.011 & 100 \\
11.1 & 0.12 & 37.2 & 46.8 & 473.9 & 0.099 & 0.465 & 0.005 & 0.464 & 0.012 & 100 \\
12.1 & 0.26 & 35.4 & 65.6 & 418.5 & 0.157 & 0.492 & 0.005 & 0.490 & 0.012 & 100 \\
13.1 & 0.17 & 62.7 & 282.1 & 587.9 & 0.480 & 0.563 & 0.006 & 0.563 & 0.011 & 100 \\
14.1 & 0.00 & 68.6 & 302.9 & 651.6 & 0.4648 & 0.514 & 0.005 & 0.541 & 0.017 & 95 \\
15.1 & 0.49 & 36.6 & 58.2 & 155.6 & 0.374 & 1.113 & 0.010 & 1.108 & 0.017 & 100 \\
15.2 & 0.16 & 100.8 & 25.7 & 2257.6 & 0.011 & 0.252 & 0.003 & 0.255 & 0.018 & 99 \\
16.1 & 0.23 & 76.9 & 303.3 & 321.2 & 0.944 & 0.992 & 0.009 & 1.026 & 0.016 & 97 \\
17.1 & 0.16 & 58.6 & 136.4 & 570.6 & 0.239 & 0.522 & 0.005 & 0.523 & 0.018 & 100 \\
18.1 & 0.37 & 91.2 & 192.8 & 1873.1 & 0.103 & 0.265 & 0.003 & 0.264 & 0.020 & 100 \\
19.1 & $<0.001$ & 10.5 & 28.7 & 245.1 & 0.117 & 0.253 & 0.004 & 0.254 & 0.022 & 100
\end{tabular}




\begin{tabular}{l|ccccc|cccc|c}
20.1 & 0.06 & 398.4 & 676.9 & 3796.4 & 0.178 & 0.556 & 0.005 & 0.558 & 0.017 & 100 \\
21.1 & 0.42 & 40.0 & 86.9 & 391.6 & 0.222 & 0.529 & 0.005 & 0.530 & 0.018 & 100 \\
22.1 & 1.40 & 14.9 & 83.9 & 132.2 & 0.634 & 0.533 & 0.005 & 0.531 & 0.023 & 100 \\
23.1 & $<0.001$ & 24.6 & 363.6 & 428.4 & 0.849 & 0.259 & 0.003 & 0.260 & 0.029 & 100 \\
24.1 & 0.04 & 41.6 & 181.8 & 372.1 & 0.489 & 0.536 & 0.005 & 0.535 & 0.020 & 100 \\
25.1 & 0.34 & 28.6 & 235.1 & 553.1 & 0.425 & 0.264 & 0.003 & 0.275 & 0.024 & 96 \\
26.1 & 0.52 & 48.6 & 75.1 & 225.2 & 0.3335 & 0.992 & 0.008 & 1.039 & 0.016 & 96 \\
27.1 & 0.16 & 78.4 & 204.9 & 822.5 & 0.249 & 0.539 & 0.004 & 0.539 & 0.017 & 100 \\
28.1 & 0.03 & 124.7 & 518.4 & 2593.9 & 0.200 & 0.271 & 0.002 & 0.272 & 0.016 & 100 \\
29.1 & $<0.001$ & 84.2 & 1430.8 & 1517.5 & 0.943 & 0.267 & 0.002 & 0.267 & 0.017 & 100 \\
30.1 & 0.47 & 10.5 & 18.0 & 205.5 & 0.088 & 0.304 & 0.003 & 0.305 & 0.035 & 100 \\
31.1 & $<0.001$ & 53.0 & 358.7 & 465.5 & 0.770 & 0.550 & 0.007 & 0.549 & 0.017 & 100 \\
32.1 & 0.05 & 37.4 & 112.3 & 458.1 & 0.245 & 0.434 & 0.005 & 0.465 & 0.018 & 93 \\
33.1 & 0.30 & 24.7 & 113.2 & 261.3 & 0.433 & 0.512 & 0.005 & 0.511 & 0.017 & 100 \\
34.1 & 0.95 & 11.0 & 145.1 & 201.1 & 0.722 & 0.280 & 0.002 & 0.281 & 0.035 & 100 \\
35.1 & 0.14 & 106.5 & 40.2 & 278.9 & 0.144 & 1.786 & 0.012 & 1.811 & 0.013 & 99 \\
36.1 & 0.07 & 32.2 & 70.3 & 232.5 & 0.303 & 0.733 & 0.007 & 0.730 & 0.019 & 100 \\
37.1 & 1.22 & 20.2 & 118.3 & 179.1 & 0.661 & 0.558 & 0.004 & 0.559 & 0.023 & 100 \\
38.1 & 3.23 & 29.4 & 417.5 & 550.3 & 0.759 & 0.216 & 0.004 & 0.217 & 0.021 & 100 \\
39.1 & 0.78 & 20.7 & 59.8 & 84.1 & 0.7111 & 1.139 & 0.006 & 1.140 & 0.013 & 100 \\
40.1 & 0.28 & 23.3 & 131.6 & 230.5 & 0.571 & 0.512 & 0.002 & 0.514 & 0.016 & 100 \\
41.1 & 0.84 & 12.9 & 51.2 & 148.7 & 0.344 & 0.470 & 0.002 & 0.471 & 0.019 & 100 \\
42.1 & 0.73 & 17.1 & 24.4 & 208.7 & 0.117 & 0.497 & 0.005 & 0.497 & 0.045 & 100 \\
43.1 & 0.02 & 164.4 & 568.4 & 1330.2 & 0.427 & 0.642 & 0.002 & 0.641 & 0.012 & 100 \\
44.1 & 0.94 & 39.6 & 128.8 & 424.2 & 0.304 & 0.514 & 0.003 & 0.514 & 0.015 & 100 \\
45.1 & 1.44 & 25.6 & 10.4 & 609.9 & 0.017 & 0.249 & 0.002 & 0.250 & 0.025 & 100
\end{tabular}




\begin{tabular}{l|ccccc|cccc|c}
46.1 & 1.41 & 9.4 & 25.0 & 128.5 & 0.195 & 0.442 & 0.005 & 0.441 & 0.061 & 100 \\
47.1 & 0.42 & 27.4 & 145.1 & 398.2 & 0.364 & 0.378 & 0.002 & 0.378 & 0.015 & 100 \\
48.1 & 0.12 & 153.5 & 683.2 & 1449.8 & 0.471 & 0.550 & 0.002 & 0.551 & 0.015 & 100 \\
49.1 & 1.07 & 21.0 & 117.1 & 401.6 & 0.292 & 0.292 & 0.001 & 0.293 & 0.029 & 100 \\
50.1 & 0.50 & 55.9 & 114.2 & 1265.0 & 0.090 & 0.257 & 0.001 & 0.256 & 0.016 & 100 \\
51.1 & $<0.001$ & 60.2 & 203.6 & 595.8 & 0.342 & 0.602 & 0.009 & 0.599 & 0.017 & 100 \\
52.1 & 0.08 & 55.4 & 9.1 & 995.8 & 0.0091 & 0.332 & 0.002 & 0.332 & 0.015 & 100 \\
53.1 & 1.13 & 27.2 & 353.8 & 556.8 & 0.635 & 0.252 & 0.002 & 0.253 & 0.017 & 100 \\
54.1 & 1.35 & 23.8 & 359.1 & 473.1 & 0.759 & 0.245 & 0.002 & 0.246 & 0.028 & 100 \\
55.1 & 1.08 & 13.8 & 211.3 & 265.9 & 0.795 & 0.252 & 0.002 & 0.251 & 0.040 & 100 \\
56.1 & 0.21 & 31.1 & 2.8 & 339.3 & 0.008 & 0.529 & 0.004 & 0.530 & 0.017 & 100 \\
57.1 & 0.11 & 168.3 & 410.9 & 1870.1 & 0.220 & 0.502 & 0.004 & 0.534 & 0.016 & 94 \\
58.1 & $\# \mathrm{DIV} / 0 !$ & 23.9 & 85.9 & 113.2 & 0.759 & 0.965 & 0.007 & 0.965 & 0.014 & 100 \\
59.1 & 2.09 & 59.0 & 116.1 & 533.9 & 0.217 & 0.598 & 0.006 & 0.583 & 0.015 & 103 \\
60.1 & $<0.001$ & 17.8 & 99.8 & 231.6 & 0.431 & 0.398 & 0.003 & 0.396 & 0.025 & 100 \\
61.1 & 0.33 & 18.1 & 82.8 & 196.9 & 0.421 & 0.479 & 0.004 & 0.479 & 0.022 & 100 \\
62.1 & 0.21 & 26.4 & 246.8 & 476.5 & 0.518 & 0.283 & 0.002 & 0.282 & 0.019 & 100 \\
63.1 & $<0.001$ & 110.4 & 186.3 & 958.9 & 0.194 & 0.624 & 0.004 & 0.624 & 0.014 & 100 \\
64.1 & 0.25 & 40.6 & 262.4 & 412.0 & 0.637 & 0.483 & 0.004 & 0.481 & 0.016 & 100 \\
65.1 & 0.34 & 35.0 & 69.1 & 153.5 & 0.4498 & 1.130 & 0.008 & 1.125 & 0.008 & 100 \\
66.1 & 0.18 & 102.3 & 490.3 & 1107.6 & 0.443 & 0.476 & 0.003 & 0.477 & 0.006 & 100 \\
67.1 & 0.71 & 38.6 & 276.5 & 390.6 & 0.708 & 0.453 & 0.003 & 0.453 & 0.017 & 100 \\
68.1 & 0.01 & 135.1 & 262.5 & 671.8 & 0.391 & 0.996 & 0.007 & 0.999 & 0.006 & 100 \\
69.1 & 0.21 & 79.2 & 177.1 & 779.2 & 0.227 & 0.559 & 0.004 & 0.561 & 0.006 & 100 \\
70.1 & 0.71 & 42.4 & 299.6 & 363.9 & 0.823 & 0.532 & 0.004 & 0.530 & 0.011 & 100 \\
71.1 & 0.47 & 32.6 & 808.3 & 538.2 & 1.502 & 0.239 & 0.002 & 0.239 & 0.016 & 100
\end{tabular}




\begin{tabular}{c|ccccc|cccc|c}
72.1 & 0.13 & 47.0 & 177.8 & 459.0 & 0.387 & 0.539 & 0.004 & 0.543 & 0.009 & 99 \\
73.1 & 0.76 & 18.0 & 68.4 & 157.4 & 0.434 & 0.604 & 0.008 & 0.603 & 0.018 & 100 \\
74.1 & 3.73 & 16.5 & 225.6 & 282.4 & 0.799 & 0.259 & 0.002 & 0.259 & 0.040 & 100 \\
75.1 & $<0.001$ & 10.8 & 39.0 & 92.9 & 0.420 & 0.617 & 0.007 & 0.610 & 0.027 & 101 \\
76.1 & 0.13 & 58.7 & 111.8 & 256.8 & 0.436 & 1.117 & 0.007 & 1.101 & 0.007 & 101 \\
77.1 & $<0.001$ & 14.7 & 237.4 & 259.3 & 0.916 & 0.261 & 0.002 & 0.263 & 0.028 & 99 \\
78.1 & 0.12 & 214.2 & 1090.5 & 1972.3 & 0.5529 & 0.561 & 0.005 & 0.533 & 0.023 & 105 \\
79.1 & 0.26 & 348.4 & 1182.0 & 1554.9 & 0.760 & 1.125 & 0.015 & 1.121 & 0.023 & 100 \\
80.1 & 1.27 & 20.1 & 47.5 & 241.8 & 0.196 & 0.486 & 0.004 & 0.466 & 0.024 & 104 \\
81.1 & 0.07 & 179.0 & 467.0 & 1771.0 & 0.264 & 0.535 & 0.005 & 0.534 & 0.023 & 100 \\
82.1 & $<0.001$ & 9.7 & 76.6 & 188.8 & 0.406 & 0.275 & 0.002 & 0.274 & 0.027 & 100 \\
83.1 & 0.07 & 12.8 & 130.1 & 115.7 & 1.124 & 0.498 & 0.006 & 0.497 & 0.036 & 100 \\
84.1 & $<0.001$ & 9.0 & 118.2 & 179.2 & 0.659 & 0.256 & 0.002 & 0.258 & 0.038 & 99 \\
85.1 & 0.02 & 190.6 & 788.6 & 1828.2 & 0.431 & 0.545 & 0.017 & 0.547 & 0.024 & 100 \\
86.1 & 1.00 & 52.2 & 372.9 & 500.9 & 0.744 & 0.512 & 0.004 & 0.535 & 0.024 & 96 \\
87.1 & 0.14 & 44.7 & 201.4 & 421.8 & 0.477 & 0.555 & 0.006 & 0.537 & 0.024 & 103 \\
88.1 & 1.83 & 16.6 & 182.1 & 368.3 & 0.494 & 0.247 & 0.004 & 0.246 & 0.065 & 100 \\
89.1 & 0.46 & 28.5 & 708.6 & 528.7 & 1.340 & 0.246 & 0.002 & 0.247 & 0.039 & 100 \\
90.1 & 0.57 & 42.0 & 774.7 & 745.9 & 1.039 & 0.262 & 0.002 & 0.261 & 0.029 & 100 \\
\hline 7.1 & 11.85 & 36.8 & 187.6 & 379.3 & 0.495 & 0.488 & 0.006 & 0.490 & 0.015 & 100 \\
\hline
\end{tabular}


Resultados para a amostra IL-1, com as razões 207/235, 206/238, 238/206, 207/206, 208/206 e respectivos erros.

\begin{tabular}{|c|c|c|c|c|c|c|c|c|c|c|c|}
\hline$\overline{\text { SPOT }}$ & $207 / 235$ & 1sigma & $206 / 238$ & 1 sigma & coef. corr & $238 / 206$ & 1 sigma & $207 / 206$ & 1 sigma & $208 / 206$ & 1 sigma \\
\hline 1.1 & 0.7335 & 0.0149 & 0.0910 & 0.0014 & 0.77 & 10.9881 & 0.1720 & 0.0591 & 0.0008 & 0.0613 & 0.0104 \\
\hline 2.1 & 2.5611 & 0.0488 & 0.2230 & 0.0034 & 0.79 & 4.4834 & 0.0674 & 0.0828 & 0.0010 & 0.1227 & 0.0099 \\
\hline 3.1 & 0.6099 & 0.0140 & 0.0776 & 0.0014 & 0.77 & 12.8890 & 0.2274 & 0.0568 & 0.0007 & 0.0322 & 0.0029 \\
\hline 4.1 & 0.4256 & 0.0089 & 0.0568 & 0.0009 & 0.74 & 17.6039 & 0.2725 & 0.0538 & 0.0007 & 0.0435 & 0.0045 \\
\hline 5.1 & 0.6168 & 0.0118 & 0.0784 & 0.0012 & 0.79 & 12.7556 & 0.1926 & 0.0571 & 0.0007 & 0.1353 & 0.0110 \\
\hline 6.1 & 0.5160 & 0.0098 & 0.0669 & 0.0010 & 0.79 & 14.9441 & 0.2246 & 0.0553 & 0.0007 & 0.0018 & 0.0009 \\
\hline 7.1 & 0.6246 & 0.0127 & 0.0792 & 0.0012 & 0.75 & 12.6184 & 0.1937 & 0.0571 & 0.0008 & 0.1621 & 0.0133 \\
\hline 8.1 & 0.4785 & 0.0100 & 0.0636 & 0.0010 & 0.75 & 15.7176 & 0.2453 & 0.0548 & 0.0009 & 0.0558 & 0.0058 \\
\hline 9.1 & 0.3244 & 0.0063 & 0.0444 & 0.0007 & 0.78 & 22.5108 & 0.3435 & 0.0519 & 0.0007 & 0.3247 & 0.0264 \\
\hline 10.1 & 0.5761 & 0.0112 & 0.0736 & 0.0011 & 0.78 & 13.5915 & 0.2071 & 0.0563 & 0.0007 & 0.2732 & 0.0221 \\
\hline 11.1 & 0.6315 & 0.0133 & 0.0790 & 0.0013 & 0.79 & 12.6533 & 0.2102 & 0.0572 & 0.0007 & 0.0306 & 0.0033 \\
\hline 12.1 & 0.8737 & 0.0176 & 0.1028 & 0.0016 & 0.76 & 9.7274 & 0.1487 & 0.0609 & 0.0008 & 0.0950 & 0.0080 \\
\hline 12.2 & 0.4494 & 0.0156 & 0.0544 & 0.0013 & 0.68 & 18.3782 & 0.4362 & 0.0535 & 0.0011 & 0.0434 & 0.0072 \\
\hline 13.1 & 0.6431 & 0.0059 & 0.0810 & 0.0006 & 0.76 & 12.3514 & 0.0866 & 0.0574 & 0.0003 & 0.0946 & 0.0242 \\
\hline 14.1 & 0.3087 & 0.0047 & 0.0437 & 0.0004 & 0.54 & 22.9030 & 0.1890 & 0.0518 & 0.0006 & 0.2195 & 0.0563 \\
\hline
\end{tabular}




\begin{tabular}{l|lllllllllll}
15.1 & 0.5669 & 0.0054 & 0.0735 & 0.0005 & 0.76 & 13.6101 & 0.0976 & 0.0563 & 0.0003 & 0.0156 & 0.0041 \\
16.1 & 0.3135 & 0.0037 & 0.0439 & 0.0003 & 0.60 & 22.7588 & 0.1614 & 0.0518 & 0.0005 & 0.0636 & 0.0165 \\
17.1 & 0.3049 & 0.0062 & 0.0431 & 0.0003 & 0.34 & 23.2081 & 0.1635 & 0.0517 & 0.0009 & 0.2832 & 0.0726 \\
18.1 & 0.3098 & 0.0027 & 0.0431 & 0.0003 & 0.72 & 23.2273 & 0.1471 & 0.0517 & 0.0003 & 0.0844 & 0.0216 \\
19.1 & 0.3238 & 0.0037 & 0.0455 & 0.0003 & 0.61 & 21.9930 & 0.1519 & 0.0521 & 0.0004 & 0.2743 & 0.0704 \\
20.1 & 0.3176 & 0.0048 & 0.0439 & 0.0003 & 0.50 & 22.8048 & 0.1702 & 0.0519 & 0.0007 & 0.0597 & 0.0156 \\
21.1 & 1.5151 & 0.0301 & 0.1572 & 0.0019 & 0.62 & 6.3604 & 0.0789 & 0.0706 & 0.0013 & 0.1092 & 0.0289 \\
22.1 & 0.3181 & 0.0033 & 0.0444 & 0.0003 & 0.70 & 22.5130 & 0.1638 & 0.0519 & 0.0004 & 0.2074 & 0.0531 \\
23.1 & 3.0709 & 0.0279 & 0.2475 & 0.0016 & 0.71 & 4.0398 & 0.0261 & 0.0899 & 0.0005 & 0.3266 & 0.0837 \\
24.1 & 1.7336 & 0.0196 & 0.1716 & 0.0013 & 0.69 & 5.8281 & 0.0456 & 0.0733 & 0.0004 & 0.0543 & 0.0140 \\
25.1 & 0.2992 & 0.0069 & 0.0420 & 0.0004 & 0.37 & 23.7859 & 0.2051 & 0.0516 & 0.0010 & 0.2510 & 0.0646 \\
26.1 & 0.4470 & 0.0051 & 0.0596 & 0.0004 & 0.61 & 16.7646 & 0.1176 & 0.0542 & 0.0004 & 0.1606 & 0.0474 \\
27.1 & 0.5778 & 0.0069 & 0.0736 & 0.0005 & 0.59 & 13.5901 & 0.0959 & 0.0563 & 0.0005 & 0.1103 & 0.0326 \\
28.1 & 0.3045 & 0.0073 & 0.0429 & 0.0004 & 0.38 & 23.3252 & 0.2114 & 0.0517 & 0.0011 & 0.6271 & 0.1850 \\
29.1 & 0.5843 & 0.0060 & 0.0750 & 0.0005 & 0.72 & 13.3393 & 0.0975 & 0.0565 & 0.0003 & 0.2269 & 0.0669 \\
30.1 & 0.3227 & 0.0039 & 0.0454 & 0.0003 & 0.61 & 22.0486 & 0.1613 & 0.0521 & 0.0005 & 0.1848 & 0.0547 \\
31.1 & 0.3310 & 0.0033 & 0.0466 & 0.0003 & 0.68 & 21.4601 & 0.1440 & 0.0522 & 0.0003 & 0.0024 & 0.0011 \\
32.1 & 0.5569 & 0.0112 & 0.0689 & 0.0011 & 0.82 & 14.5169 & 0.2393 & 0.0555 & 0.0016 & 0.0266 & 0.0089 \\
33.1 & 0.5992 & 0.0070 & 0.0751 & 0.0005 & 0.60 & 13.3199 & 0.0935 & 0.0565 & 0.0005 & 0.4018 & 0.1184 \\
34.1 & 0.6406 & 0.0064 & 0.0808 & 0.0006 & 0.76 & 12.3743 & 0.0940 & 0.0574 & 0.0003 & 0.1950 & 0.0575 \\
& & & & & & & & & & & \\
\end{tabular}




\begin{tabular}{l|lllllllllll}
35.1 & 0.6612 & 0.0087 & 0.0823 & 0.0007 & 0.64 & 12.1448 & 0.1027 & 0.0577 & 0.0006 & 0.5904 & 0.1743 \\
36.1 & 0.5907 & 0.0059 & 0.0756 & 0.0005 & 0.68 & 13.2340 & 0.0895 & 0.0566 & 0.0004 & 0.0508 & 0.0151 \\
37.1 & 0.3192 & 0.0063 & 0.0427 & 0.0004 & 0.43 & 23.4370 & 0.1982 & 0.0517 & 0.0009 & 0.2874 & 0.0849 \\
39.1 & 0.5795 & 0.0054 & 0.0745 & 0.0005 & 0.71 & 13.4195 & 0.0887 & 0.0565 & 0.0003 & 0.0547 & 0.0171 \\
40.1 & 0.3145 & 0.0042 & 0.0441 & 0.0004 & 0.61 & 22.6990 & 0.1838 & 0.0519 & 0.0004 & 0.3324 & 0.1036 \\
41.1 & 0.6401 & 0.0059 & 0.0801 & 0.0006 & 0.76 & 12.4826 & 0.0881 & 0.0573 & 0.0004 & 0.2131 & 0.0664 \\
42.1 & 0.5996 & 0.0063 & 0.0764 & 0.0005 & 0.63 & 13.0973 & 0.0864 & 0.0567 & 0.0004 & 0.4372 & 0.1365 \\
43.1 & 0.3042 & 0.0038 & 0.0425 & 0.0003 & 0.58 & 23.5415 & 0.1697 & 0.0517 & 0.0006 & 0.4095 & 0.1277 \\
44.1 & 1.1148 & 0.0138 & 0.1231 & 0.0011 & 0.73 & 8.1248 & 0.0729 & 0.0644 & 0.0004 & 0.0974 & 0.0304 \\
44.2 & 0.5874 & 0.0053 & 0.0758 & 0.0006 & 0.90 & 13.2009 & 0.1108 & 0.0567 & 0.0004 & 0.0564 & 0.0178 \\
45.1 & 0.3233 & 0.0034 & 0.0453 & 0.0003 & 0.63 & 22.0765 & 0.1471 & 0.0521 & 0.0004 & 0.3543 & 0.1104 \\
46.1 & 0.3327 & 0.0028 & 0.0464 & 0.0003 & 0.78 & 21.5380 & 0.1405 & 0.0522 & 0.0004 & 0.0635 & 0.0198 \\
47.1 & 0.3252 & 0.0036 & 0.0450 & 0.0003 & 0.66 & 22.2205 & 0.1635 & 0.0520 & 0.0005 & 0.2955 & 0.0921 \\
48.1 & 0.5999 & 0.0052 & 0.0766 & 0.0006 & 0.83 & 13.0585 & 0.0940 & 0.0567 & 0.0003 & 0.0316 & 0.0099 \\
49.1 & 1.3538 & 0.0121 & 0.1424 & 0.0010 & 0.83 & 7.0218 & 0.0518 & 0.0678 & 0.0003 & 0.0839 & 0.0262 \\
50.1 & 0.8686 & 0.0077 & 0.1031 & 0.0007 & 0.73 & 9.6955 & 0.0628 & 0.0609 & 0.0003 & 0.2020 & 0.0629 \\
\hline 38.1 & 0.7621 & 0.0083 & 0.0896 & 0.0007 & 0.74 & 11.1602 & 0.0892 & 0.0616 & 0.0004 & 0.0102 & 0.0033 \\
\hline
\end{tabular}


Resultados para a amostra IL-1: Pb total comum e radioativo, Th, U, idades 206/238 e 207/206 com os erros, e a concordância.

\begin{tabular}{c|ccccc|cccc|c}
\hline SPOT & $\begin{array}{c}\mathrm{Pb} \text { total } \\
\mathrm{comum}\end{array}$ & $\begin{array}{c}\mathrm{Pb} \mathrm{rad} \\
\mathrm{ppm}\end{array}$ & $\begin{array}{c}\mathrm{Th} \\
\mathrm{ppm}\end{array}$ & $\begin{array}{c}\mathrm{U} \\
\mathrm{ppm}\end{array}$ & $\mathrm{Th} / \mathrm{U}$ & T206/238 & $\begin{array}{c}\text { A } \text { sigma } \\
\text { T207/206 }\end{array}$ & 1 sigma & $\begin{array}{c}\text { conc. } \\
\text { Pb total } \\
\text { comum }\end{array}$ \\
\hline 1.1 & $<0.001$ & 20.6 & 55.0 & 200.4 & 0.2743 & 0.561 & 0.008 & 0.563 & 0.030 & 100 \\
2.1 & 0.04 & 61.2 & 82.5 & 230.0 & 0.359 & 1.298 & 0.018 & 1.270 & 0.024 & 102 \\
3.1 & $<0.001$ & 34.5 & 40.7 & 417.2 & 0.098 & 0.482 & 0.008 & 0.476 & 0.028 & 101 \\
4.1 & 0.71 & 17.7 & 30.2 & 278.6 & 0.108 & 0.356 & 0.005 & 0.357 & 0.030 & 100 \\
5.1 & $<0.001$ & 40.6 & 182.3 & 445.1 & 0.410 & 0.487 & 0.007 & 0.487 & 0.028 & 100 \\
6.1 & 1.68 & 43.7 & 16.4 & 628.0 & 0.026 & 0.418 & 0.006 & 0.417 & 0.027 & 100 \\
7.1 & $<0.001$ & 19.5 & 98.8 & 206.9 & 0.477 & 0.492 & 0.007 & 0.490 & 0.031 & 100 \\
8.1 & 0.55 & 12.5 & 32.8 & 180.6 & 0.182 & 0.398 & 0.006 & 0.399 & 0.034 & 100 \\
9.1 & 0.08 & 27.4 & 410.8 & 461.5 & 0.890 & 0.280 & 0.004 & 0.280 & 0.029 & 100 \\
10.1 & 1.09 & 55.5 & 459.2 & 578.5 & 0.794 & 0.458 & 0.007 & 0.460 & 0.027 & 100 \\
11.1 & 0.36 & 49.6 & 47.3 & 581.4 & 0.081 & 0.490 & 0.008 & 0.492 & 0.027 & 100 \\
12.1 & $<0.001$ & 19.4 & 49.1 & 167.0 & 0.294 & 0.631 & 0.009 & 0.631 & 0.028 & 100 \\
12.2 & 0.48 & 18.8 & 59.0 & 320.9 & 0.184 & 0.342 & 0.008 & 0.347 & 0.046 & 99 \\
13.1 & 0.13 & 64.0 & 169.6 & 715.5 & 0.2371 & 0.502 & 0.003 & 0.500 & 0.012 & 100
\end{tabular}




\begin{tabular}{l|ccccc|cccc|c}
14.1 & $<0.001$ & 18.9 & 205.9 & 355.1 & 0.580 & 0.275 & 0.002 & 0.276 & 0.023 & 100 \\
15.1 & 1.11 & 51.5 & 34.8 & 681.8 & 0.051 & 0.457 & 0.003 & 0.458 & 0.011 & 100 \\
16.1 & 0.38 & 19.8 & 72.7 & 419.3 & 0.173 & 0.277 & 0.002 & 0.276 & 0.022 & 100 \\
17.1 & 4.34 & 11.9 & 129.0 & 218.6 & 0.590 & 0.272 & 0.002 & 0.271 & 0.039 & 100 \\
18.1 & 0.11 & 46.2 & 197.6 & 979.0 & 0.202 & 0.272 & 0.002 & 0.271 & 0.012 & 100 \\
19.1 & $<0.001$ & 18.1 & 207.1 & 320.6 & 0.646 & 0.287 & 0.002 & 0.287 & 0.019 & 100 \\
20.1 & 0.86 & 13.0 & 57.2 & 276.0 & 0.207 & 0.277 & 0.002 & 0.277 & 0.029 & 100 \\
21.1 & $<0.001$ & 32.8 & 93.2 & 175.7 & 0.530 & 0.941 & 0.011 & 0.946 & 0.038 & 100 \\
22.1 & $<0.001$ & 32.7 & 319.1 & 615.7 & 0.518 & 0.280 & 0.002 & 0.279 & 0.016 & 100 \\
23.1 & 0.66 & 83.6 & 225.5 & 252.0 & 0.895 & 1.426 & 0.008 & 1.430 & 0.010 & 100 \\
24.1 & 0.48 & 37.4 & 27.6 & 201.3 & 0.137 & 1.021 & 0.007 & 1.023 & 0.012 & 100 \\
25.1 & 2.26 & 12.0 & 187.7 & 232.4 & 0.808 & 0.265 & 0.002 & 0.266 & 0.043 & 100 \\
26.1 & $<0.001$ & 38.5 & 201.7 & 554.6 & 0.3636 & 0.373 & 0.003 & 0.373 & 0.017 & 100 \\
27.1 & 1.25 & 17.5 & 52.9 & 213.5 & 0.248 & 0.458 & 0.003 & 0.456 & 0.019 & 100 \\
28.1 & 0.32 & 23.1 & 564.9 & 357.4 & 1.581 & 0.271 & 0.002 & 0.270 & 0.046 & 100 \\
29.1 & 0.00 & 51.3 & 264.7 & 549.1 & 0.482 & 0.466 & 0.003 & 0.465 & 0.013 & 100 \\
30.1 & 0.71 & 25.8 & 209.4 & 484.6 & 0.432 & 0.286 & 0.002 & 0.285 & 0.022 & 100 \\
& & & & & & & & & \\
\end{tabular}




\begin{tabular}{l|ccccc|cccc|c}
31.1 & $<0.001$ & 46.0 & 13.2 & 969.3 & 0.014 & 0.294 & 0.002 & 0.294 & 0.014 & 100 \\
32.1 & 1.50 & 50.0 & 40.2 & 605.8 & 0.066 & 0.429 & 0.007 & 0.428 & 0.063 & 100 \\
33.1 & $<0.001$ & 22.8 & 197.9 & 228.0 & 0.868 & 0.467 & 0.003 & 0.465 & 0.021 & 100 \\
34.1 & 0.17 & 64.0 & 304.3 & 656.7 & 0.463 & 0.501 & 0.004 & 0.500 & 0.013 & 100 \\
35.1 & 0.82 & 40.6 & 450.1 & 342.8 & 1.313 & 0.510 & 0.004 & 0.512 & 0.022 & 100 \\
36.1 & 0.02 & 32.2 & 46.0 & 390.8 & 0.118 & 0.470 & 0.003 & 0.468 & 0.014 & 100 \\
37.1 & 1.46 & 8.6 & 98.8 & 162.7 & 0.608 & 0.269 & 0.002 & 0.269 & 0.038 & 100 \\
39.1 & $<0.001$ & 61.3 & 84.3 & 762.6 & 0.1105 & 0.463 & 0.003 & 0.465 & 0.012 & 100 \\
40.1 & 0.42 & 22.2 & 254.1 & 402.3 & 0.632 & 0.278 & 0.002 & 0.279 & 0.019 & 100 \\
41.1 & 0.16 & 26.1 & 122.1 & 280.1 & 0.436 & 0.497 & 0.003 & 0.496 & 0.016 & 100 \\
42.1 & $<0.001$ & 35.2 & 335.3 & 337.1 & 0.995 & 0.474 & 0.003 & 0.475 & 0.017 & 100 \\
43.1 & $<0.001$ & 13.4 & 210.8 & 241.6 & 0.872 & 0.268 & 0.002 & 0.268 & 0.024 & 100 \\
44.1 & 1.49 & 44.7 & 73.6 & 334.7 & 0.220 & 0.748 & 0.006 & 0.751 & 0.012 & 100 \\
44.2 & 1.34 & 22.0 & 49.3 & 273.6 & 0.180 & 0.471 & 0.004 & 0.473 & 0.015 & 100 \\
45.1 & 0.60 & 20.5 & 252.7 & 358.7 & 0.704 & 0.286 & 0.002 & 0.287 & 0.017 & 100 \\
46.1 & 0.47 & 28.2 & 70.1 & 569.5 & 0.123 & 0.293 & 0.002 & 0.293 & 0.015 & 100 \\
47.1 & 0.58 & 15.7 & 177.4 & 283.5 & 0.626 & 0.284 & 0.002 & 0.283 & 0.021 & 100
\end{tabular}




\begin{tabular}{c|ccccc|cccc|c}
48.1 & 0.17 & 47.6 & 38.4 & 583.4 & 0.066 & 0.476 & 0.003 & 0.474 & 0.011 & 100 \\
49.1 & 7.55 & 130.1 & 19.6 & 977.3 & 0.020 & 0.858 & 0.006 & 0.859 & 0.009 & 100 \\
50.1 & 0.14 & 36.3 & 130.9 & 300.3 & 0.436 & 0.633 & 0.004 & 0.631 & 0.012 & 100 \\
\hline 38.1 & 0.22 & 96.1 & 24.2 & 1015.7 & 0.024 & 0.553 & 0.004 & 0.653 & 0.013 & 85 \\
\hline
\end{tabular}


Resultados para a amostra BBR-D-8A, com as razões 207/235, 206/238, 238/206, 207/206, 208/206 e respectivos erros.

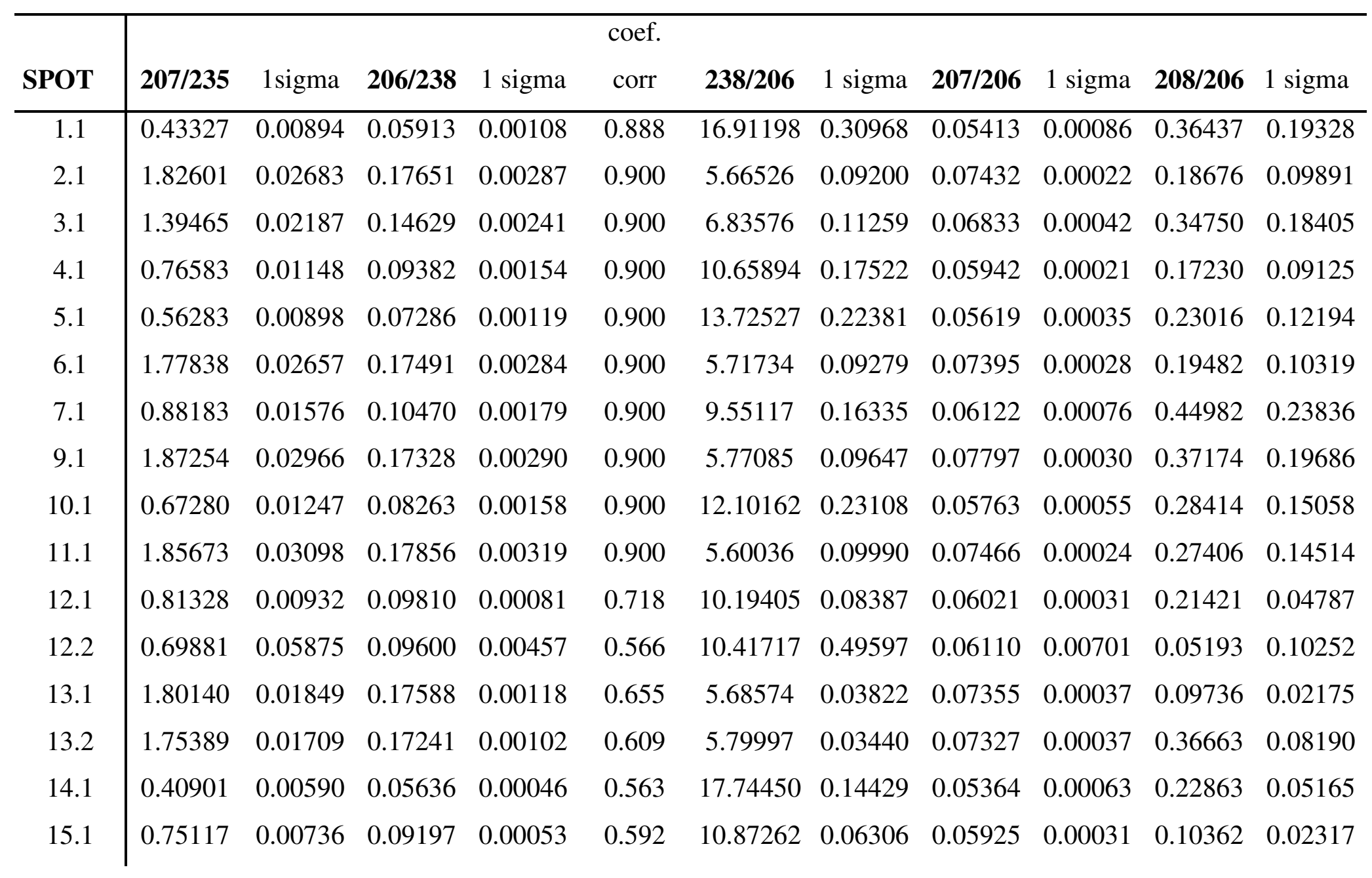




\begin{tabular}{l|lllllllllll}
16.1 & 0.38264 & 0.00531 & 0.05262 & 0.00051 & 0.699 & 19.00433 & 0.18448 & 0.05315 & 0.00068 & 0.43795 & 0.09810 \\
17.1 & 1.92747 & 0.01864 & 0.18394 & 0.00105 & 0.589 & 5.43665 & 0.03099 & 0.07571 & 0.00038 & 0.19847 & 0.04436 \\
18.1 & 0.98667 & 0.01029 & 0.11361 & 0.00086 & 0.724 & 8.80241 & 0.06645 & 0.06266 & 0.00035 & 0.43091 & 0.09650 \\
18.2 & 0.97957 & 0.01116 & 0.11255 & 0.00077 & 0.601 & 8.88499 & 0.06085 & 0.06253 & 0.00053 & 0.19564 & 0.04394 \\
19.1 & 0.40320 & 0.00653 & 0.05538 & 0.00049 & 0.550 & 18.05587 & 0.16096 & 0.05354 & 0.00086 & 0.28632 & 0.06474 \\
20.1 & 1.55787 & 0.01537 & 0.15620 & 0.00097 & 0.628 & 6.40225 & 0.03967 & 0.07249 & 0.00038 & 0.15754 & 0.03522 \\
21.1 & 0.39450 & 0.00523 & 0.05384 & 0.00043 & 0.601 & 18.57406 & 0.14786 & 0.05334 & 0.00061 & 0.40716 & 0.09118 \\
22.1 & 1.76443 & 0.03673 & 0.17191 & 0.00317 & 0.885 & 5.81690 & 0.10712 & 0.07411 & 0.00034 & 0.20334 & 0.02346 \\
23.1 & 1.00622 & 0.02275 & 0.11721 & 0.00218 & 0.821 & 8.53177 & 0.15846 & 0.06331 & 0.00066 & 0.04923 & 0.00717 \\
24.1 & 1.34597 & 0.03000 & 0.14322 & 0.00282 & 0.884 & 6.98244 & 0.13757 & 0.06891 & 0.00031 & 0.03876 & 0.00506 \\
24.2 & 0.81205 & 0.01688 & 0.09734 & 0.00180 & 0.887 & 10.27302 & 0.18948 & 0.06001 & 0.00023 & 0.12750 & 0.01466 \\
26.1 & 0.77882 & 0.02326 & 0.09453 & 0.00189 & 0.671 & 10.57897 & 0.21188 & 0.05957 & 0.00108 & 0.03717 & 0.00578 \\
27.1 & 0.70948 & 0.01968 & 0.08430 & 0.00168 & 0.718 & 11.86228 & 0.23626 & 0.05821 & 0.00116 & 0.21296 & 0.02544 \\
29.1 & 0.78789 & 0.01698 & 0.09659 & 0.00182 & 0.872 & 10.35269 & 0.19467 & 0.05998 & 0.00039 & 0.20383 & 0.02351 \\
30.1 & 0.69453 & 0.01684 & 0.08497 & 0.00173 & 0.838 & 11.76849 & 0.23921 & 0.05808 & 0.00035 & 0.10071 & 0.01203 \\
30.2 & 0.68913 & 0.01829 & 0.08029 & 0.00156 & 0.733 & 12.45505 & 0.24229 & 0.05878 & 0.00074 & 0.25881 & 0.02983 \\
31.1 & 1.84185 & 0.03856 & 0.17453 & 0.00321 & 0.879 & 5.72971 & 0.10550 & 0.07549 & 0.00037 & 0.25558 & 0.02943 \\
34.1 & 1.00719 & 0.02778 & 0.12004 & 0.00243 & 0.735 & 8.33028 & 0.16876 & 0.06387 & 0.00086 & 0.34817 & 0.07220 \\
35.1 & 0.67656 & 0.08356 & 0.09077 & 0.00542 & 0.484 & 11.01659 & 0.65835 & 0.05891 & 0.00175 & 0.13754 & 0.03658 \\
36.1 & 0.65507 & 0.01579 & 0.08273 & 0.00167 & 0.836 & 12.08685 & 0.24354 & 0.05776 & 0.00050 & 0.14343 & 0.02985 \\
& & & & & & & & & & & \\
\end{tabular}




\begin{tabular}{|c|c|c|c|c|c|c|c|c|c|c|c|}
\hline 38.1 & 2.04038 & 0.04715 & 0.18642 & 0.00377 & 0.876 & 5.36437 & 0.10857 & 0.07902 & 0.00057 & 0.23855 & 0.04946 \\
\hline 39.1 & 0.37908 & 0.00898 & 0.05237 & 0.00110 & 0.888 & 19.09365 & 0.40196 & 0.05305 & 0.00054 & 0.36679 & 0.07717 \\
\hline 40.1 & 1.91927 & 0.04510 & 0.18447 & 0.00379 & 0.873 & 5.42103 & 0.11124 & 0.07638 & 0.00066 & 0.49001 & 0.10195 \\
\hline 41.1 & 0.47300 & 0.01390 & 0.06329 & 0.00134 & 0.719 & 15.80031 & 0.33397 & 0.05487 & 0.00095 & 0.22801 & 0.04758 \\
\hline 42.1 & 0.39062 & 0.00958 & 0.05382 & 0.00109 & 0.826 & 18.58061 & 0.37625 & 0.05334 & 0.00047 & 0.46799 & 0.09701 \\
\hline 43.1 & 0.37515 & 0.01036 & 0.05236 & 0.00119 & 0.820 & 19.09931 & 0.43255 & 0.05312 & 0.00100 & 0.35398 & 0.07476 \\
\hline 44.1 & 0.70694 & 0.01792 & 0.08913 & 0.00184 & 0.816 & 11.21908 & 0.23201 & 0.05909 & 0.00079 & 0.19018 & 0.04035 \\
\hline 45.1 & 0.57788 & 0.01629 & 0.07517 & 0.00152 & 0.718 & 13.30247 & 0.26934 & 0.05648 & 0.00103 & 0.22380 & 0.04672 \\
\hline 46.1 & 0.48960 & 0.02126 & 0.06819 & 0.00165 & 0.557 & 14.66409 & 0.35458 & 0.05546 & 0.00154 & 0.40217 & 0.18261 \\
\hline 48.1 & 1.93826 & 0.05047 & 0.18623 & 0.00385 & 0.793 & 5.36958 & 0.11090 & 0.07565 & 0.00068 & 0.37212 & 0.16848 \\
\hline 49.1 & 0.38164 & 0.01009 & 0.05155 & 0.00138 & 0.900 & 19.40045 & 0.52028 & 0.05298 & 0.00088 & 0.40624 & 0.18570 \\
\hline 51.1 & 0.68216 & 0.01768 & 0.08478 & 0.00171 & 0.780 & 11.79471 & 0.23835 & 0.05806 & 0.00049 & 0.06727 & 0.03066 \\
\hline 51.2 & 0.70336 & 0.02673 & 0.08836 & 0.00203 & 0.605 & 11.31721 & 0.26033 & 0.05873 & 0.00179 & 0.06960 & 0.03318 \\
\hline 52.1 & 0.75150 & 0.02201 & 0.09389 & 0.00218 & 0.794 & 10.65080 & 0.24761 & 0.05945 & 0.00094 & 0.36720 & 0.16634 \\
\hline 53.1 & 0.60169 & 0.01673 & 0.07701 & 0.00169 & 0.789 & 12.98514 & 0.28494 & 0.05676 & 0.00078 & 0.27803 & 0.12605 \\
\hline 55.1 & 0.38071 & 0.01031 & 0.05163 & 0.00116 & 0.828 & 19.36899 & 0.43457 & 0.05296 & 0.00080 & 0.46336 & 0.21015 \\
\hline 8.1 & 16.88486 & 0.24922 & 0.53810 & 0.00869 & 0.900 & 1.85839 & 0.03001 & 0.22643 & 0.00070 & 0.08806 & 0.04663 \\
\hline 25.1 & 10.37552 & 0.24327 & 0.40710 & 0.00825 & 0.865 & 2.45642 & 0.04980 & 0.18133 & 0.00069 & 0.16570 & 0.01906 \\
\hline 33.1 & 1.46626 & 0.03360 & 0.14486 & 0.00291 & 0.875 & 6.90327 & 0.13847 & 0.07320 & 0.00048 & 0.07482 & 0.01558 \\
\hline 37.1 & 2.14678 & 0.06404 & 0.18468 & 0.00539 & 0.900 & 5.41487 & 0.15801 & 0.08565 & 0.00169 & 0.16071 & 0.05105 \\
\hline
\end{tabular}




\begin{tabular}{c|ccccccccccc}
56.1 & 2.04221 & 0.05474 & 0.18230 & 0.00397 & 0.813 & 5.48541 & 0.11954 & 0.08127 & 0.00070 & 0.33427 & 0.15141 \\
57.1 & 0.79128 & 0.04158 & 0.09479 & 0.00239 & 0.479 & 10.54967 & 0.26552 & 0.06154 & 0.00192 & 0.39832 & 0.18098 \\
3.2 & 0.55716 & 0.03468 & 0.07157 & 0.00155 & 0.349 & 13.97311 & 0.30317 & 0.05614 & 0.00333 & 0.14425 & 0.07931 \\
28.1 & 0.59560 & 0.01671 & 0.07380 & 0.00187 & 0.900 & 13.55002 & 0.34319 & 0.05634 & 0.00100 & 0.20363 & 0.02421 \\
32.1 & 1.20927 & 0.02674 & 0.13268 & 0.00258 & 0.881 & 7.53700 & 0.14680 & 0.06607 & 0.00044 & 0.01748 & 0.00269 \\
47.1 & 0.67082 & 0.02122 & 0.08384 & 0.00176 & 0.662 & 11.92733 & 0.24994 & 0.05795 & 0.00112 & 0.32250 & 0.14619 \\
50.1 & 1.03213 & 0.03384 & 0.11793 & 0.00247 & 0.639 & 8.47966 & 0.17763 & 0.06369 & 0.00150 & 0.16940 & 0.07717 \\
54.1 & 0.54119 & 0.01763 & 0.07064 & 0.00151 & 0.657 & 14.15577 & 0.30294 & 0.05581 & 0.00106 & 0.33171 & 0.15054 \\
1.2 & 0.44705 & 0.00975 & 0.05870 & 0.00100 & 0.778 & 17.03475 & 0.28899 & 0.05406 & 0.00060 & 0.16459 & 0.08739 \\
\hline
\end{tabular}


Resultados para a amostra BBR-D-8A: Pb total comum e radioativo, Th, U, idades 206/238 e 207/206 com os erros, e a concordância

\begin{tabular}{|c|c|c|c|c|c|c|c|c|c|c|}
\hline SPOT & $\begin{array}{l}\mathrm{Pb} \text { total } \\
\text { comum }\end{array}$ & $\begin{array}{c}\mathrm{Pb} \mathrm{rad} \\
\mathrm{ppm}\end{array}$ & $\begin{array}{c}\text { Th } \\
\text { ppm }\end{array}$ & $\begin{array}{c}\mathrm{U} \\
\mathrm{ppm}\end{array}$ & $\mathrm{Th} / \mathrm{U}$ & T206/238 & $\begin{array}{c}\text { AGES } \\
1 \text { sigma }\end{array}$ & T207/206 & 1 sigma & $\begin{array}{l}\text { conc. } \\
\text { Pb total } \\
\text { comum }\end{array}$ \\
\hline 1.1 & $<0.001$ & 8.21 & 74.93 & 110.42 & 0.68 & 0.370 & 0.007 & 0.372 & 0.035 & 100 \\
\hline 2.1 & $<0.001$ & 46.99 & 76.94 & 227.35 & 0.34 & 1.048 & 0.016 & 1.051 & 0.006 & 100 \\
\hline 3.1 & 0.34 & 25.38 & 83.55 & 136.87 & 0.61 & 0.880 & 0.014 & 0.876 & 0.013 & 100 \\
\hline 4.1 & 0.17 & 47.76 & 139.64 & 445.82 & 0.31 & 0.578 & 0.009 & 0.576 & 0.008 & 100 \\
\hline 5.1 & 0.53 & 23.03 & 121.81 & 271.01 & 0.45 & 0.453 & 0.007 & 0.454 & 0.013 & 100 \\
\hline 6.1 & 0.06 & 60.38 & 115.32 & 293.04 & 0.39 & 1.039 & 0.016 & 1.041 & 0.008 & 100 \\
\hline 7.1 & 0.32 & 8.70 & 51.89 & 63.24 & 0.82 & 0.642 & 0.010 & 0.641 & 0.027 & 100 \\
\hline 9.1 & $<0.001$ & 65.60 & 195.57 & 292.46 & 0.67 & 1.030 & 0.016 & 1.149 & 0.008 & 90 \\
\hline 10.1 & $<0.001$ & 12.60 & 54.97 & 125.74 & 0.44 & 0.512 & 0.009 & 0.509 & 0.021 & 100 \\
\hline 11.1 & 0.02 & 57.69 & 132.15 & 267.26 & 0.49 & 1.059 & 0.017 & 1.061 & 0.007 & 100 \\
\hline 12.1 & 0.07 & 59.30 & 212.95 & 523.95 & 0.41 & 0.603 & 0.005 & 0.605 & 0.011 & 100 \\
\hline 12.2 & $<0.001$ & 1.08 & 0.76 & 12.11 & 0.06 & 0.591 & 0.027 & 0.637 & 0.232 & 93 \\
\hline 13.1 & $<0.001$ & 163.78 & 149.21 & 859.01 & 0.17 & 1.044 & 0.006 & 1.030 & 0.010 & 101 \\
\hline 13.2 & 0.02 & 65.14 & 210.95 & 296.14 & 0.71 & 1.025 & 0.006 & 1.022 & 0.010 & 100 \\
\hline 14.1 & $<0.001$ & 7.72 & 40.51 & 115.49 & 0.35 & 0.353 & 0.003 & 0.352 & 0.026 & 100 \\
\hline
\end{tabular}




\begin{tabular}{l|ccccc|cccc|c}
15.1 & 0.02 & 58.71 & 116.62 & 584.06 & 0.20 & 0.567 & 0.003 & 0.570 & 0.012 & 100 \\
16.1 & 1.09 & 7.75 & 97.79 & 112.90 & 0.87 & 0.331 & 0.003 & 0.331 & 0.028 & 100 \\
17.1 & 0.04 & 67.22 & 122.96 & 316.79 & 0.39 & 1.088 & 0.006 & 1.089 & 0.010 & 100 \\
18.1 & $<0.001$ & 59.03 & 320.35 & 400.22 & 0.80 & 0.694 & 0.005 & 0.691 & 0.012 & 100 \\
18.2 & 0.08 & 11.99 & 32.94 & 92.83 & 0.35 & 0.688 & 0.004 & 0.687 & 0.018 & 100 \\
19.1 & $<0.001$ & 6.93 & 62.99 & 105.42 & 0.60 & 0.347 & 0.003 & 0.348 & 0.035 & 100 \\
20.1 & 0.81 & 46.16 & 73.61 & 265.00 & 0.28 & 0.936 & 0.005 & 1.000 & 0.011 & 94 \\
21.1 & $<0.001$ & 9.16 & 105.06 & 132.60 & 0.79 & 0.338 & 0.003 & 0.340 & 0.025 & 100 \\
22.1 & 0.01 & 22.68 & 48.13 & 113.96 & 0.42 & 1.023 & 0.017 & 1.045 & 0.009 & 98 \\
23.1 & $<0.001$ & 14.55 & 3.95 & 122.97 & 0.03 & 0.714 & 0.013 & 0.713 & 0.022 & 100 \\
24.1 & 0.14 & 84.42 & 61.29 & 592.96 & 0.10 & 0.863 & 0.016 & 0.894 & 0.009 & 97 \\
24.2 & $<0.001$ & 47.43 & 121.79 & 452.52 & 0.27 & 0.599 & 0.011 & 0.598 & 0.008 & 100 \\
26.1 & 1.10 & 27.56 & 48.57 & 281.86 & 0.17 & 0.582 & 0.011 & 0.582 & 0.039 & 100 \\
27.1 & 2.80 & 19.10 & 149.61 & 192.42 & 0.78 & 0.522 & 0.010 & 0.531 & 0.043 & 98 \\
29.1 & $<0.001$ & 25.88 & 91.67 & 237.46 & 0.39 & 0.594 & 0.011 & 0.597 & 0.014 & 100 \\
30.1 & 0.43 & 43.78 & 109.54 & 469.58 & 0.23 & 0.526 & 0.010 & 0.526 & 0.013 & 100 \\
30.2 & 3.19 & 21.72 & 191.06 & 225.70 & 0.85 & 0.498 & 0.009 & 0.552 & 0.027 & 90 \\
31.1 & 0.35 & 20.85 & 72.42 & 100.92 & 0.72 & 1.037 & 0.018 & 1.083 & 0.010 & 96 \\
34.1 & $<0.001$ & 49.84 & 216.04 & 333.93 & 0.65 & 0.731 & 0.014 & 0.732 & 0.029 & 100 \\
35.1 & 0.23 & 64.57 & 135.57 & 512.43 & 0.26 & 0.560 & 0.032 & 0.557 & 0.064 & 100
\end{tabular}




\begin{tabular}{c|ccccc|cccc|c}
36.1 & 1.42 & 46.99 & 221.68 & 506.94 & 0.44 & 0.512 & 0.010 & 0.515 & 0.019 & 100 \\
38.1 & 0.92 & 54.49 & 130.07 & 242.44 & 0.54 & 1.102 & 0.020 & 1.176 & 0.014 & 94 \\
39.1 & $<0.001$ & 9.46 & 89.05 & 143.14 & 0.62 & 0.329 & 0.007 & 0.327 & 0.022 & 100 \\
40.1 & $<0.001$ & 14.79 & 63.99 & 58.44 & 1.10 & 1.091 & 0.021 & 1.107 & 0.018 & 99 \\
41.1 & 0.33 & 23.30 & 159.66 & 310.79 & 0.51 & 0.396 & 0.008 & 0.402 & 0.038 & 99 \\
42.1 & $<0.001$ & 29.00 & 324.33 & 401.50 & 0.81 & 0.338 & 0.007 & 0.339 & 0.019 & 100 \\
43.1 & $<0.001$ & 6.66 & 69.88 & 102.21 & 0.68 & 0.329 & 0.007 & 0.330 & 0.041 & 100 \\
44.1 & 0.77 & 10.60 & 33.73 & 104.73 & 0.32 & 0.550 & 0.011 & 0.564 & 0.029 & 98 \\
45.1 & $<0.001$ & 20.52 & 80.96 & 235.40 & 0.34 & 0.467 & 0.009 & 0.465 & 0.040 & 100 \\
46.1 & 5.31 & 24.00 & 226.65 & 260.17 & 0.87 & 0.425 & 0.010 & 0.425 & 0.060 & 100 \\
48.1 & 0.76 & 53.65 & 128.66 & 227.63 & 0.57 & 1.101 & 0.021 & 1.088 & 0.018 & 101 \\
49.1 & $\# \mathrm{DIV} / 0 !$ & 5.20 & 54.72 & 81.45 & 0.67 & 0.324 & 0.008 & 0.324 & 0.036 & 100 \\
51.1 & $<0.001$ & 58.29 & 67.63 & 633.74 & 0.11 & 0.525 & 0.010 & 0.526 & 0.018 & 100 \\
51.2 & 4.20 & 28.91 & 69.76 & 299.31 & 0.23 & 0.546 & 0.012 & 0.551 & 0.065 & 99 \\
52.1 & 4.12 & 19.70 & 64.36 & 173.98 & 0.37 & 0.579 & 0.013 & 0.577 & 0.034 & 100 \\
53.1 & $<0.001$ & 23.85 & 95.19 & 263.84 & 0.36 & 0.478 & 0.010 & 0.476 & 0.030 & 100 \\
55.1 & $<0.001$ & 8.53 & 92.73 & 127.31 & 0.73 & 0.325 & 0.007 & 0.323 & 0.033 & 100 \\
8.1 & $<0.001$ & 124.60 & 32.68 & 185.91 & 0.18 & 2.775 & 0.036 & 3.032 & 0.005 & 92 \\
\hline 25.1 & 0.87 & 61.02 & 47.04 & 122.04 & 0.39 & 2.202 & 0.038 & 2.667 & 0.006 & 83 \\
33.1 & $\# \mathrm{DIV} / 0 !$ & 58.87 & 47.34 & 369.14 & 0.13 & 0.872 & 0.016 & 1.020 & 0.013 & 86
\end{tabular}




\begin{tabular}{c|ccccc|cccc|c}
37.1 & $<0.001$ & 14.97 & 54.79 & 77.41 & 0.71 & 1.092 & 0.029 & 1.336 & 0.038 & 82 \\
56.1 & $\#$ DIV/0! & 20.63 & 62.83 & 90.33 & 0.70 & 1.080 & 0.022 & 1.232 & 0.017 & 88 \\
57.1 & 2.21 & 18.70 & 142.97 & 156.99 & 0.91 & 0.584 & 0.014 & 0.652 & 0.066 & 89 \\
3.2 & 30.13 & 4.59 & 42.06 & 58.04 & 0.72 & 0.446 & 0.009 & 0.452 & 0.126 & 99 \\
28.1 & 10.99 & 16.89 & 116.76 & 203.88 & 0.57 & 0.459 & 0.011 & 0.460 & 0.039 & 100 \\
32.1 & 11.57 & 114.91 & 260.35 & 887.39 & 0.29 & 0.803 & 0.015 & 0.805 & 0.014 & 100 \\
47.1 & 14.78 & 21.76 & 93.37 & 218.78 & 0.43 & 0.519 & 0.010 & 0.521 & 0.042 & 100 \\
50.1 & 13.98 & 22.21 & 123.37 & 194.32 & 0.63 & 0.719 & 0.014 & 0.726 & 0.050 & 99 \\
54.1 & 7.95 & 13.27 & 102.82 & 155.60 & 0.66 & 0.440 & 0.009 & 0.439 & 0.041 & 100 \\
1.2 & 11.13 & 19.60 & 184.22 & 290.24 & 0.63 & 0.368 & 0.006 & 0.369 & 0.024 & 100 \\
\hline
\end{tabular}


Resultados para a amostra BBR-D-10, com as razões 207/235, 206/238, 238/206, 207/206, 208/206 e respectivos erros.

\begin{tabular}{|c|c|c|c|c|c|c|c|c|c|c|c|}
\hline & & & & & coef. & & & & & & \\
\hline SPOT & $207 / 235$ & 1 sigma & $206 / 238$ & 1 sigma & corr & $238 / 206$ & 1 sigma & $207 / 206$ & 1 sigma & $208 / 206$ & 1 sigma \\
\hline 2.1 & 0.66407 & 0.00650 & 0.08296 & 0.00071 & 0.880 & 12.05462 & 0.10373 & 0.05779 & 0.00032 & 0.05898 & 0.02486 \\
\hline 3.1 & 14.26744 & 0.14448 & 0.52797 & 0.00498 & 0.900 & 1.89404 & 0.01788 & 0.18891 & 0.00079 & 0.41247 & 0.17113 \\
\hline 4.1 & 0.72651 & 0.01270 & 0.08994 & 0.00110 & 0.700 & 11.11841 & 0.13611 & 0.05889 & 0.00116 & 0.97017 & 0.40309 \\
\hline 6.1 & 0.71777 & 0.00699 & 0.09000 & 0.00087 & 0.900 & 11.11072 & 0.10729 & 0.05889 & 0.00048 & 0.26413 & 0.10990 \\
\hline 7.1 & 1.63768 & 0.02740 & 0.16523 & 0.00147 & 0.532 & 6.05206 & 0.05386 & 0.07193 & 0.00094 & 0.25291 & 0.10506 \\
\hline 7.2 & 0.77603 & 0.06338 & 0.09491 & 0.00091 & 0.117 & 10.53603 & 0.10096 & 0.06032 & 0.00427 & 0.07081 & 0.03794 \\
\hline 8.1 & 0.90962 & 0.00986 & 0.10662 & 0.00102 & 0.883 & 9.37897 & 0.08979 & 0.06201 & 0.00026 & 0.01179 & 0.00503 \\
\hline 9.1 & 1.83354 & 0.01698 & 0.17454 & 0.00146 & 0.900 & 5.72921 & 0.04797 & 0.07670 & 0.00035 & 0.42985 & 0.17837 \\
\hline 11.1 & 4.80597 & 0.04993 & 0.31658 & 0.00349 & 0.900 & 3.15876 & 0.03480 & 0.10846 & 0.00049 & 0.11186 & 0.04645 \\
\hline 12.1 & 1.23342 & 0.05995 & 0.13755 & 0.00157 & 0.235 & 7.27011 & 0.08295 & 0.06695 & 0.00243 & 0.28915 & 0.12119 \\
\hline 15.1 & 0.63674 & 0.01699 & 0.07954 & 0.00224 & 0.900 & 12.57226 & 0.35348 & 0.05722 & 0.00065 & 0.21698 & 0.03239 \\
\hline 16.1 & 1.77063 & 0.04704 & 0.17422 & 0.00504 & 0.900 & 5.73988 & 0.16598 & 0.07372 & 0.00065 & 0.08154 & 0.01214 \\
\hline 18.1 & 0.95317 & 0.02466 & 0.11265 & 0.00318 & 0.900 & 8.87719 & 0.25064 & 0.06190 & 0.00060 & 0.14626 & 0.02215 \\
\hline 19.1 & 0.70047 & 0.02096 & 0.08414 & 0.00240 & 0.900 & 11.88473 & 0.33843 & 0.05791 & 0.00097 & 0.13289 & 0.02066 \\
\hline 20.1 & 0.44001 & 0.01210 & 0.05934 & 0.00168 & 0.900 & 16.85201 & 0.47708 & 0.05413 & 0.00067 & 0.07344 & 0.01135 \\
\hline 21.1 & 0.87279 & 0.02462 & 0.10424 & 0.00294 & 0.900 & 9.59359 & 0.27013 & 0.06120 & 0.00085 & 0.17274 & 0.02593 \\
\hline
\end{tabular}




\begin{tabular}{|c|c|c|c|c|c|c|c|c|c|c|c|}
\hline 22.1 & 1.79003 & 0.04865 & 0.17629 & 0.00502 & 0.900 & 5.67261 & 0.16164 & 0.07431 & 0.00079 & 0.13150 & 0.01962 \\
\hline 23.1 & 0.45914 & 0.01212 & 0.06170 & 0.00174 & 0.900 & 16.20728 & 0.45775 & 0.05447 & 0.00060 & 0.34924 & 0.05208 \\
\hline 24.1 & 0.91942 & 0.02363 & 0.10738 & 0.00300 & 0.900 & 9.31257 & 0.26049 & 0.06177 & 0.00058 & 0.08669 & 0.01294 \\
\hline 25.1 & 2.46807 & 0.06513 & 0.21596 & 0.00614 & 0.900 & 4.63050 & 0.13156 & 0.08257 & 0.00077 & 0.14818 & 0.02212 \\
\hline 6.1 & 4.69133 & 0.05407 & 0.30602 & 0.00303 & 0.860 & 3.26780 & 0.03238 & 0.10999 & 0.00053 & 0.14579 & 0.01061 \\
\hline 27.1 & 3.22637 & 0.04007 & 0.25072 & 0.00258 & 0.829 & 3.98852 & 0.04104 & 0.09292 & 0.00047 & 0.13257 & 0.00978 \\
\hline 29.1 & 1.76175 & 0.02382 & 0.17385 & 0.00192 & 0.818 & 5.75211 & 0.06362 & 0.07365 & 0.00053 & 0.16543 & 0.01252 \\
\hline 30.1 & 1.06828 & 0.01224 & 0.12217 & 0.00120 & 0.858 & 8.18518 & 0.08053 & 0.06351 & 0.00031 & 0.16865 & 0.01230 \\
\hline 33.1 & 0.60855 & 0.00777 & 0.07839 & 0.00089 & 0.889 & 12.75661 & 0.14492 & 0.05700 & 0.00035 & 0.13843 & 0.01035 \\
\hline 36.1 & 5.28094 & 0.06111 & 0.33253 & 0.00330 & 0.858 & 3.00724 & 0.02986 & 0.11445 & 0.00054 & 0.23026 & 0.01666 \\
\hline 36.2 & 5.14505 & 0.06016 & 0.33201 & 0.00332 & 0.855 & 3.01194 & 0.03013 & 0.11315 & 0.00058 & 0.17563 & 0.01273 \\
\hline 36.3 & 5.24423 & 0.08077 & 0.33108 & 0.00426 & 0.835 & 3.02046 & 0.03882 & 0.11682 & 0.00086 & 0.19809 & 0.01440 \\
\hline 37.1 & 0.57193 & 0.01294 & 0.07265 & 0.00076 & 0.462 & 13.76481 & 0.14396 & 0.05617 & 0.00079 & 0.32016 & 0.07300 \\
\hline 39.1 & 0.78980 & 0.00872 & 0.09593 & 0.00094 & 0.890 & 10.42461 & 0.10246 & 0.05975 & 0.00055 & 0.41844 & 0.09538 \\
\hline 40.1 & 1.11593 & 0.03258 & 0.12171 & 0.00168 & 0.473 & 8.21628 & 0.11351 & 0.06414 & 0.00172 & -0.02355 & 0.00795 \\
\hline 41.1 & 0.88734 & 0.00784 & 0.10616 & 0.00076 & 0.806 & 9.41986 & 0.06710 & 0.06146 & 0.00021 & 0.18056 & 0.04130 \\
\hline 42.1 & 0.52470 & 0.00690 & 0.06878 & 0.00057 & 0.636 & 14.53818 & 0.12146 & 0.05556 & 0.00035 & 0.11779 & 0.02698 \\
\hline 44.1 & 0.57700 & 0.01030 & 0.07514 & 0.00093 & 0.692 & 13.30910 & 0.16445 & 0.05654 & 0.00037 & 0.13746 & 0.03137 \\
\hline 48.1 & 1.75679 & 0.02464 & 0.16756 & 0.00128 & 0.543 & 5.96800 & 0.04542 & 0.07325 & 0.00040 & 0.13188 & 0.03004 \\
\hline 50.1 & 1.13040 & 0.01340 & 0.12630 & 0.00086 & 0.573 & 7.91756 & 0.05375 & 0.06489 & 0.00067 & 0.01914 & 0.01121 \\
\hline
\end{tabular}




\begin{tabular}{|c|c|c|c|c|c|c|c|c|c|c|c|}
\hline 51.1 & 1.88401 & 0.01763 & 0.18188 & 0.00074 & 0.433 & 5.49817 & 0.02228 & 0.07527 & 0.00074 & 0.19799 & 0.04915 \\
\hline 52.1 & 0.75204 & 0.00809 & 0.09208 & 0.00032 & 0.327 & 10.86055 & 0.03819 & 0.05923 & 0.00058 & & 0.03330 \\
\hline 3.1 & 1.03242 & 0.01032 & 0.11754 & 0.00052 & 0.446 & 8.50771 & 0.03793 & 0.06332 & 0.00064 & 0.18561 & 0.04610 \\
\hline 54.1 & 0.81381 & 0.01294 & 0.09521 & 0.00296 & 0.900 & 10.50275 & 0.32662 & 0.06101 & 0.00096 & -0.02126 & 0.01173 \\
\hline 55.1 & 4.91279 & & 0.31164 & 0.00385 & 0.433 & & & & & & \\
\hline 30.1 & 0.56632 & 0.00530 & 0.07390 & 0.00033 & 0.478 & 13.53154 & 0.06058 & 0.05632 & 0.00057 & 0.27253 & 0.06757 \\
\hline 57.1 & 1.51770 & 0.01664 & 0.15266 & 0.00098 & 0.584 & 6.55070 & 0.04197 & 0.07210 & 0.00060 & 0.15126 & 0.03772 \\
\hline 58.1 & 4.46835 & 0.04471 & 0.30497 & 0.00237 & 0.777 & 3.27899 & 0.02550 & 0.10450 & 0.00148 & 0.14979 & 0.03772 \\
\hline 59.1 & 0.86438 & 0.02117 & 0.09633 & 0.00132 & 0.558 & 10.38100 & 0.14189 & 0.06070 & 0.00069 & -0.00310 & 0.00529 \\
\hline 60.1 & 2.25899 & 0.04704 & 0.20436 & 0.00126 & 0.296 & & & 0.07983 & 0.00150 & & 0.02565 \\
\hline 61.1 & 0.70760 & 0.00993 & 0.08780 & 0.00043 & 0.349 & 11.38909 & 0.05581 & 0.05849 & 0.00075 & 0.07618 & 0.01925 \\
\hline 62.1 & 0.71218 & 0.01195 & 0.08681 & 0.00096 & 0.662 & 11.51950 & 0.12792 & 0.05841 & 0.00058 & -0.01109 & 0.00509 \\
\hline 5.1 & 27.92763 & 0.25810 & 0.65563 & 0.00558 & 0.900 & & & & & & 0.13517 \\
\hline & & & & & 0.900 & & & & & & \\
\hline 34.1 & 1.48155 & 0.03109 & 0.14800 & 0.00177 & 0.569 & 6.75687 & 0.08068 & 0.07249 & 0.00125 & 0.12804 & 0.01038 \\
\hline 38.1 & 1.63255 & 0.03276 & 0.15550 & 0.00138 & 0.444 & 6.43103 & 0.05726 & 0.07569 & 0.00138 & 0.15464 & 0.03539 \\
\hline 49.1 & 10.09312 & 0.10473 & 0.42093 & 0.00342 & 0.783 & 2.37570 & 0.01930 & 0.18275 & 0.00054 & 0.17040 & 0.03872 \\
\hline 10.1 & 0.72411 & 0.08611 & 0.09032 & 0.00228 & 0.212 & 11.07169 & 0.27947 & 0.05958 & 0.00667 & 0.27541 & 0.12917 \\
\hline 17.1 & 0.34667 & 0.02824 & 0.04947 & 0.00156 & 0.387 & 20.21360 & 0.63643 & 0.05267 & 0.00361 & 0.18936 & 0.03200 \\
\hline 28.1 & 0.66677 & 0.03806 & 0.08659 & 0.00118 & 0.239 & 11.54881 & 0.15788 & 0.05831 & 0.00238 & 0.14320 & 0.01635 \\
\hline
\end{tabular}




\begin{tabular}{c|ccccccccccc}
31.1 & 0.67687 & 0.04482 & 0.08001 & 0.00126 & 0.238 & 12.49878 & 0.19697 & 0.05847 & 0.00244 & 0.38062 & 0.02929 \\
32.1 & 1.94021 & 0.04216 & 0.18060 & 0.00313 & 0.799 & 5.53700 & 0.09611 & 0.07830 & 0.00057 & 0.19882 & 0.01531 \\
35.1 & 0.65878 & 0.09282 & 0.08745 & 0.00116 & 0.094 & 11.43506 & 0.15208 & 0.05939 & 0.00581 & 0.16450 & 0.02006 \\
43.1 & 0.95661 & 0.01259 & 0.10687 & 0.00113 & 0.805 & 9.35722 & 0.09912 & 0.06243 & 0.00486 & 0.05155 & 0.01690 \\
45.1 & 0.65257 & 0.01639 & 0.07976 & 0.00104 & 0.518 & 12.53764 & 0.16316 & 0.05728 & 0.00117 & 0.06619 & 0.01590 \\
46.1 & 1.66552 & 0.02992 & 0.16738 & 0.00221 & 0.736 & 5.97439 & 0.07896 & 0.07226 & 0.00917 & 0.16965 & 0.03909 \\
47.1 & 1.94683 & 0.03757 & 0.18470 & 0.00259 & 0.727 & 5.41425 & 0.07594 & 0.07612 & 0.00088 & -0.13785 & 0.03367 \\
1.1 & 0.54704 & 0.02495 & 0.07316 & 0.00117 & 0.350 & 13.66840 & 0.21809 & 0.05627 & 0.00213 & 0.60275 & 0.25151 \\
13.1 & 0.72970 & 0.02241 & 0.09133 & 0.00259 & 0.900 & 10.94917 & 0.31097 & 0.05925 & 0.00085 & 0.01613 & 0.00411 \\
\hline
\end{tabular}

Resultados para a amostra BBR-D-8A: Pb total comum e radioativo, Th, U, idades 206/238 e 207/206 com os erros, e a concordância

\begin{tabular}{|c|c|c|c|c|c|c|c|c|c|c|}
\hline SPOT & $\begin{array}{l}\mathrm{Pb} \text { total } \\
\text { comum }\end{array}$ & $\begin{array}{c}\mathrm{Pb} \mathrm{rad} \\
\mathrm{ppm}\end{array}$ & $\begin{array}{c}\text { Th } \\
\mathrm{ppm}\end{array}$ & $\begin{array}{c}\mathrm{U} \\
\mathrm{ppm}\end{array}$ & $\mathrm{Th} / \mathrm{U}$ & T206/238 & $\begin{array}{c}\text { AGES } \\
1 \text { sigma }\end{array}$ & T207/206 & 1 sigma & $\begin{array}{c}\text { conc. } \\
\mathrm{Pb} \text { total } \\
\text { comum }\end{array}$ \\
\hline 2.1 & $<0.001$ & 48.81 & 42.48 & 544.91 & 0.08 & 0.514 & 0.004 & 0.515 & 0.012 & 100 \\
\hline 3.1 & $<0.001$ & 391.60 & 285.51 & 557.68 & 0.51 & 2.733 & 0.021 & 2.736 & 0.007 & 100 \\
\hline 4.1 & $<0.001$ & 9.12 & 74.48 & 70.20 & 1.06 & 0.555 & 0.007 & 0.557 & 0.043 & 100 \\
\hline 6.1 & $<0.001$ & 13.27 & 47.64 & 129.01 & 0.37 & 0.556 & 0.005 & 0.557 & 0.018 & 100 \\
\hline 7.1 & $<0.001$ & 117.09 & 192.33 & 622.85 & 0.31 & 0.986 & 0.008 & 0.984 & 0.027 & 100 \\
\hline 7.2 & 102.98 & 37.86 & 27.89 & 354.34 & 0.08 & 0.585 & 0.005 & 0.609 & 0.148 & 96 \\
\hline
\end{tabular}




\begin{tabular}{c|ccccc|cccc|c}
8.1 & $\#$ DIV/0! & 98.05 & 11.68 & 881.40 & 0.01 & 0.653 & 0.006 & 0.669 & 0.009 & 98 \\
9.1 & 5.32 & 47.19 & 109.49 & 218.84 & 0.50 & 1.037 & 0.008 & 1.116 & 0.009 & 93 \\
11.1 & $<0.001$ & 151.08 & 49.30 & 431.49 & 0.11 & 1.773 & 0.017 & 1.777 & 0.008 & 100 \\
12.1 & 1.09 & 33.48 & 148.42 & 193.95 & 0.77 & 0.831 & 0.009 & 0.833 & 0.075 & 100 \\
15.1 & $<0.001$ & 17.75 & 91.02 & 187.62 & 0.49 & 0.493 & 0.013 & 0.494 & 0.025 & 100 \\
16.1 & 0.06 & 140.90 & 137.34 & 761.59 & 0.18 & 1.035 & 0.028 & 1.034 & 0.018 & 100 \\
18.1 & $<0.001$ & 58.65 & 176.83 & 461.15 & 0.38 & 0.688 & 0.018 & 0.665 & 0.021 & 103 \\
19.1 & $<0.001$ & 10.60 & 36.65 & 112.94 & 0.32 & 0.521 & 0.014 & 0.520 & 0.036 & 100 \\
20.1 & $<0.001$ & 23.93 & 67.01 & 377.10 & 0.18 & 0.372 & 0.010 & 0.372 & 0.027 & 100 \\
21.1 & 4.44 & 26.43 & 77.26 & 221.93 & 0.35 & 0.639 & 0.017 & 0.640 & 0.030 & 100 \\
22.1 & $<0.001$ & 49.52 & 79.09 & 252.55 & 0.31 & 1.047 & 0.027 & 1.051 & 0.022 & 100 \\
23.1 & $<0.001$ & 27.36 & 267.73 & 344.31 & 0.78 & 0.386 & 0.011 & 0.385 & 0.024 & 100 \\
24.1 & $<0.001$ & 59.78 & 94.98 & 507.15 & 0.19 & 0.658 & 0.017 & 0.660 & 0.020 & 100 \\
25.1 & 0.22 & 53.64 & 108.36 & 209.32 & 0.52 & 1.260 & 0.032 & 1.264 & 0.018 & 100 \\
26.1 & 3.76 & 119.42 & 146.52 & 337.95 & 0.43 & 1.721 & 0.015 & 1.802 & 0.009 & 96 \\
27.1 & $<0.001$ & 48.52 & 44.61 & 171.12 & 0.26 & 1.442 & 0.013 & 1.492 & 0.009 & 97 \\
29.1 & $<0.001$ & 20.27 & 34.87 & 102.75 & 0.34 & 1.033 & 0.011 & 1.033 & 0.015 & 100 \\
30.1 & $<0.001$ & 39.61 & 99.89 & 285.95 & 0.35 & 0.743 & 0.007 & 0.720 & 0.010 & 103 \\
33.1 & $<0.001$ & 19.37 & 47.02 & 234.47 & 0.20 & 0.487 & 0.005 & 0.485 & 0.014 & 100 \\
36.1 & $<0.001$ & 138.68 & 163.51 & 338.41 & 0.48 & 1.851 & 0.016 & 1.873 & 0.008 & 99
\end{tabular}




\begin{tabular}{l|ccccc|cccc|c}
36.2 & 2.48 & 98.17 & 95.11 & 251.39 & 0.38 & 1.848 & 0.016 & 1.852 & 0.009 & 100 \\
36.3 & 3.02 & 264.31 & 434.58 & 674.97 & 0.64 & 1.844 & 0.021 & 1.909 & 0.013 & 97 \\
37.1 & 2.69 & 30.11 & 227.58 & 313.37 & 0.73 & 0.452 & 0.005 & 0.453 & 0.030 & 100 \\
39.1 & $<0.001$ & 12.95 & 87.39 & 99.58 & 0.88 & 0.590 & 0.006 & 0.588 & 0.020 & 100 \\
40.1 & 1.56 & 140.73 & -3.40 & 1123.72 & 0.00 & 0.740 & 0.010 & 0.741 & 0.057 & 100 \\
41.1 & $<0.001$ & 55.44 & 195.38 & 452.27 & 0.43 & 0.650 & 0.004 & 0.650 & 0.007 & 100 \\
42.1 & $<0.001$ & 68.19 & 240.55 & 870.02 & 0.28 & 0.429 & 0.003 & 0.429 & 0.014 & 100 \\
44.1 & 2.77 & 54.65 & 263.22 & 609.15 & 0.43 & 0.467 & 0.006 & 0.468 & 0.014 & 100 \\
48.1 & 3.12 & 62.64 & 117.20 & 324.61 & 0.36 & 0.999 & 0.007 & 1.021 & 0.011 & 98 \\
50.1 & $<0.001$ & 110.79 & 57.43 & 890.34 & 0.06 & 0.767 & 0.005 & 0.766 & 0.022 & 100 \\
51.1 & $<0.001$ & 32.35 & 47.44 & 163.55 & 0.29 & 1.077 & 0.004 & 1.077 & 0.020 & 100 \\
52.1 & 3.33 & 48.40 & 143.50 & 479.99 & 0.30 & 0.568 & 0.002 & 0.569 & 0.021 & 100 \\
53.1 & $<0.001$ & 32.94 & 77.46 & 249.46 & 0.31 & 0.716 & 0.003 & 0.714 & 0.021 & 100 \\
54.1 & 3.77 & 46.33 & 28.98 & 474.15 & 0.06 & 0.586 & 0.017 & 0.633 & 0.034 & 93 \\
55.1 & 5.52 & 135.31 & 132.06 & 363.70 & 0.36 & 1.749 & 0.019 & 1.911 & 0.028 & 92 \\
56.1 & $\# \mathrm{DIV} / 0 !$ & 36.20 & 187.83 & 420.84 & 0.45 & 0.460 & 0.002 & 0.459 & 0.022 & 100 \\
57.1 & $\# \mathrm{DIV} / 0 !$ & 96.31 & 157.84 & 564.54 & 0.28 & 0.916 & 0.005 & 0.989 & 0.017 & 93 \\
58.1 & $\# \mathrm{DIV} / 0 !$ & 33.99 & 27.57 & 98.16 & 0.28 & 1.716 & 0.012 & 1.710 & 0.025 & 100 \\
59.1 & $\# \mathrm{DIV} / 0 !$ & 72.94 & 62.94 & 653.99 & 0.10 & 0.593 & 0.008 & 0.622 & 0.024 & 95 \\
60.1 & $<0.001$ & 124.90 & 131.58 & 564.97 & 0.23 & 1.199 & 0.007 & 1.196 & 0.037 & 100
\end{tabular}




\begin{tabular}{c|ccccc|cccc|c}
61.1 & $<0.001$ & 41.60 & 55.72 & 449.36 & 0.12 & 0.543 & 0.003 & 0.542 & 0.028 & 100 \\
62.1 & 3.00 & 74.03 & 32.47 & 792.53 & 0.04 & 0.537 & 0.006 & 0.539 & 0.021 & 100 \\
5.1 & $<0.001$ & 103.64 & 47.54 & 111.92 & 0.42 & 3.250 & 0.022 & 3.509 & 0.007 & 93 \\
\hline 14.1 & 0.05 & 34.66 & 117.52 & 165.53 & 0.71 & 0.989 & 0.027 & 1.113 & 0.029 & 89 \\
34.1 & 45.47 & 48.30 & 61.93 & 298.13 & 0.21 & 0.890 & 0.010 & 1.000 & 0.035 & 89 \\
38.1 & $<0.001$ & 34.53 & 67.98 & 198.29 & 0.34 & 0.932 & 0.008 & 1.089 & 0.037 & 86 \\
49.1 & 0.44 & 134.88 & 75.72 & 238.75 & 0.32 & 2.265 & 0.016 & 2.680 & 0.005 & 85 \\
10.1 & 14.92 & 5.71 & 23.78 & 53.83 & 0.44 & 0.557 & 0.013 & 0.582 & 0.229 & 96 \\
17.1 & 17.65 & 8.06 & 85.89 & 131.72 & 0.65 & 0.311 & 0.010 & 0.312 & 0.146 & 100 \\
28.1 & 28.74 & 18.23 & 85.09 & 184.10 & 0.46 & 0.535 & 0.007 & 0.535 & 0.087 & 100 \\
31.1 & 51.57 & 22.29 & 191.32 & 213.73 & 0.90 & 0.496 & 0.008 & 0.541 & 0.089 & 92 \\
32.1 & 10.79 & 57.77 & 112.56 & 276.29 & 0.41 & 1.070 & 0.017 & 1.157 & 0.015 & 92 \\
35.1 & 83.04 & 19.68 & 103.53 & 205.35 & 0.50 & 0.540 & 0.007 & 0.575 & 0.201 & 94 \\
43.1 & 31.66 & 48.61 & 18.46 & 432.18 & 0.04 & 0.655 & 0.007 & 0.683 & 0.160 & 96 \\
45.1 & 8.10 & 35.49 & 107.52 & 375.07 & 0.29 & 0.495 & 0.006 & 0.496 & 0.044 & 100 \\
46.1 & 23.89 & 24.17 & 73.68 & 126.39 & 0.58 & 0.998 & 0.012 & 0.993 & 0.243 & 100 \\
47.1 & 34.93 & 113.96 & 230.79 & 625.14 & 0.37 & 1.093 & 0.014 & 1.100 & 0.023 & 99 \\
1.1 & 7.10 & 11.12 & 108.33 & 116.52 & 0.93 & 0.455 & 0.007 & 0.457 & 0.081 & 100 \\
13.1 & 19.58 & 37.75 & 22.34 & 392.95 & 0.06 & 0.563 & 0.015 & 0.570 & 0.031 & 99 \\
\hline
\end{tabular}


ANEXO V

RESULTADOS ICP-LA Lu-Hf 
Resultados Lu-Hf para a amostra BBR-D-8A.

\begin{tabular}{|c|c|c|c|c|c|c|c|c|c|c|c|c|}
\hline $\begin{array}{l}\text { Grain } \\
\text { /spot }\end{array}$ & $176 \mathrm{Hf} / 177 \mathrm{Hf}$ & $\pm 2 \mathrm{se}$ & 176Lu/177Hf & $\pm 2 \mathrm{se}$ & $\begin{array}{l}\text { U-Pb } \\
\text { Age }\end{array}$ & e $H f(0)$ & $176 \mathrm{Hf} / 177 \mathrm{Hf}$ & e Hf & $176 \mathrm{Hf} / 177 \mathrm{Hf}$ & T DM & $176 \mathrm{Hf} / 177 \mathrm{Hf}$ & e Hf \\
\hline & & & & & & & (T1) & (T1) & $\mathrm{DM}(\mathrm{T})$ & (Ga) & $\mathrm{DM}(\mathrm{T})$ & (TDM) \\
\hline 1.1 & 0.282509 & 0.000042 & 0.001112 & 0.000006 & 372 & $\begin{array}{l}-9.3 \\
\end{array}$ & 0.282501 & -1.4 & 0.282957 & 1.4 & 0.282202 & $\overline{11.1}$ \\
\hline 2.1 & 0.282099 & 0.000030 & 0.000824 & 0.000008 & 1051 & -23.8 & 0.282082 & -1.1 & 0.282462 & 1.9 & 0.281825 & 9.2 \\
\hline 3.1 & 0.282022 & 0.000039 & 0.000549 & 0.000005 & 876 & -26.5 & 0.282013 & -7.5 & 0.28259 & 2.2 & 0.281625 & 8.3 \\
\hline 4.1 & 0.282235 & 0.000028 & 0.000672 & 0.000025 & 576 & -19.0 & 0.282227 & -6.6 & 0.2828086 & 1.9 & 0.281842 & 9.3 \\
\hline 6.1 & 0.281699 & 0.000029 & 0.000880 & 0.000004 & 1041 & -37.9 & 0.281682 & -15.5 & 0.282469 & 2.8 & 0.281149 & 6.0 \\
\hline 7.1 & 0.282180 & 0.000045 & 0.000628 & 0.000001 & 641 & -20.9 & 0.282173 & -7.1 & 0.282761 & 2.0 & 0.281781 & 9.0 \\
\hline 10.1 & 0.282346 & 0.000041 & 0.001747 & 0.000007 & 509 & -15.1 & 0.282329 & -4.5 & 0.282857 & 1.7 & 0.281980 & 10.0 \\
\hline 11.1 & 0.282041 & 0.000046 & 0.001399 & 0.000006 & 1061 & -25.8 & 0.282013 & $\begin{array}{l}-3.4 \\
\end{array}$ & 0.282455 & 2.1 & 0.281714 & 8.7 \\
\hline 12.1 & 0.282331 & 0.000025 & 0.000097 & 0.000003 & 605 & -15.6 & 0.282330 & -2.3 & 0.282788 & 1.6 & 0.282026 & 10.2 \\
\hline 13.1 & 0.281723 & 0.000029 & 0.000796 & 0.000002 & 1030 & -37.1 & 0.281708 & -14.9 & 0.282477 & 2.8 & 0.281187 & 6.1 \\
\hline 14.1 & 0.282530 & 0.000041 & 0.001843 & 0.000009 & 352 & -8.5 & 0.282518 & -1.2 & 0.282971 & 1.4 & 0.282221 & 11.2 \\
\hline 15.1 & 0.282263 & 0.000026 & 0.000443 & 0.000041 & 570 & -18.0 & 0.282258 & -5.6 & 0.282813 & 1.8 & 0.281890 & 9.6 \\
\hline 48.1 & 0.281704 & 0.000083 & 0.001188 & 0.000011 & 1088.0 & -37.8 & 0.281680 & -14.6 & 0.282435 & 2.8 & 0.281168 & 6.0 \\
\hline 18.1 & 0.282095 & 0.000083 & 0.002393 & 0.000031 & 691 & -23.9 & 0.282064 & -9.8 & 0.282725 & 2.2 & 0.281624 & 8.3 \\
\hline 31.1 & 0.282040 & 0.000055 & 0.000947 & 0.000044 & 1083.0 & -25.9 & 0.282021 & -2.6 & 0.282438 & 2.0 & 0.281738 & 8.8 \\
\hline 44.1 & 0.282217 & 0.000030 & 0.000396 & 0.000010 & 564 & -19.6 & 0.282213 & -7.3 & 0.282817 & 1.9 & 0.281813 & 9.2 \\
\hline 22.1 & 0.282117 & 0.000033 & 0.000520 & 0.000010 & 1045 & -23.2 & 0.282107 & -0.4 & 0.282466 & 1.9 & 0.281863 & 9.4 \\
\hline 40.1 & 0.282133 & 0.000033 & 0.000892 & 0.000031 & 1107 & -22.6 & 0.282115 & 1.3 & 0.282421 & 1.8 & 0.281907 & 9.6 \\
\hline 17.1 & 0.282157 & 0.000041 & 0.000702 & 0.000010 & 1089 & -21.8 & 0.282142 & 1.9 & 0.282434 & 1.8 & 0.281945 & 9.8 \\
\hline
\end{tabular}




\begin{tabular}{|c|c|c|c|c|c|c|c|c|c|c|c|c|}
\hline 29.1 & 0.282310 & 0.000035 & 0.000227 & 0.000002 & 597 & -16.3 & 0.282308 & -3.3 & 0.282793 & 1.7 & 0.281986 & 10.0 \\
\hline 42.1 & 0.282411 & 0.000050 & 0.001883 & 0.000011 & 339 & -12.8 & 0.282399 & -5.7 & 0.2829805 & 1.7 & 0.282017 & 10.2 \\
\hline 24.1 & 0.282319 & 0.000038 & 0.000204 & 0.000011 & 894 & -16.0 & 0.282315 & 3.6 & 0.282577 & 1.5 & 0.282140 & 10.8 \\
\hline 5.1 & 0.282488 & 0.000036 & 0.000929 & 0.000004 & 454.0 & -10.0 & 0.282480 & -0.3 & 0.282897 & 1.4 & 0.282206 & 11.1 \\
\hline
\end{tabular}

Resultados Lu-Hf para a amostra BBR-D-10.

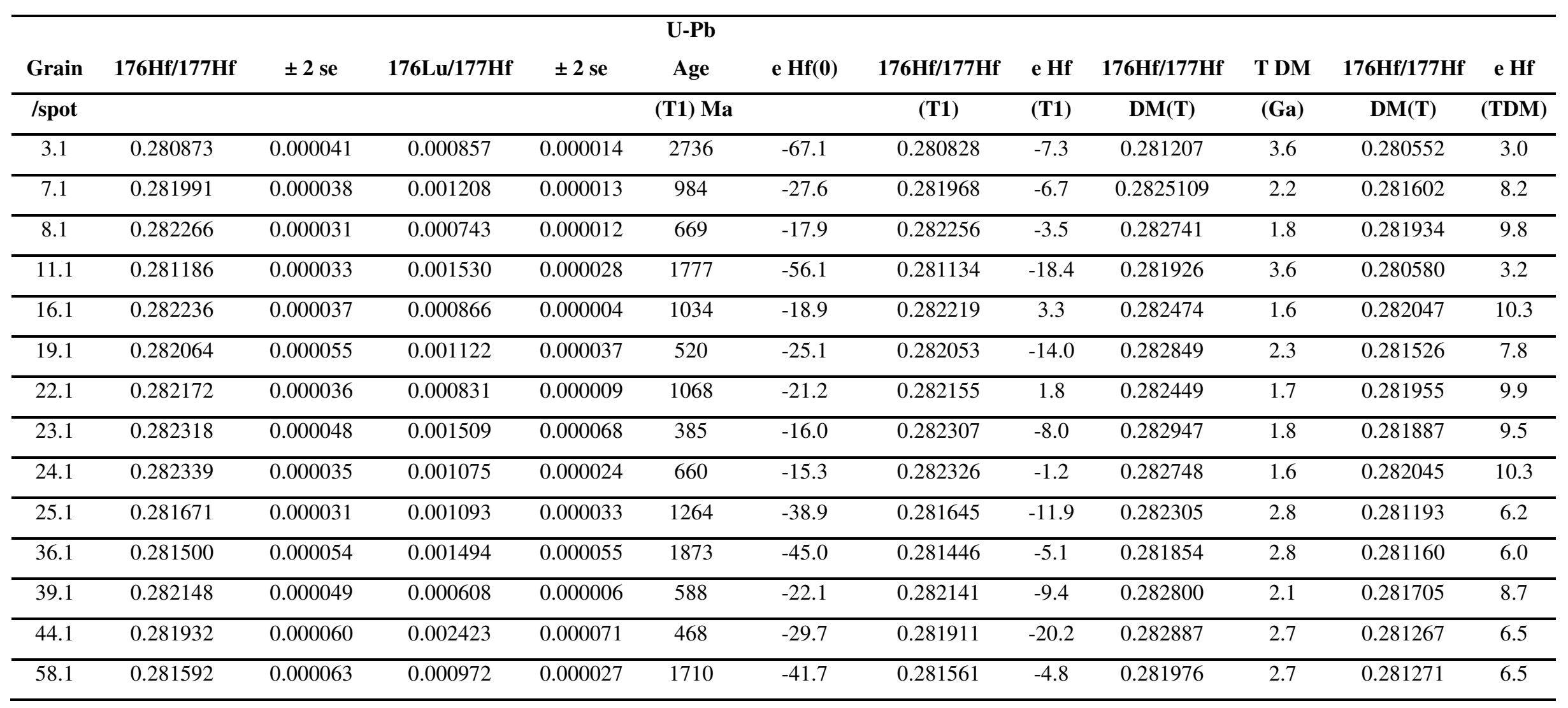




\begin{tabular}{cccccccccccccccccc}
\hline 50.1 & 0.282040 & 0.000084 & 0.001604 & 0.000032 & 766 & -25.9 & 0.282017 & -9.8 & 0.282670 & 2.2 & 0.281579 & 8.0 & 0.0 \\
\hline 42.1 & 0.282154 & 0.000054 & 0.002057 & 0.000045 & 429 & -21.9 & 0.282138 & -13.0 & 0.282915 & 2.2 & 0.281626 & 8.3 \\
\hline 52.1 & 0.282151 & 0.000075 & 0.002042 & 0.000114 & 569 & -22.0 & 0.282129 & -10.2 & 0.282814 & 2.1 & 0.281675 & 8.5 \\
\hline 51.1 & 0.282048 & 0.000058 & 0.002551 & 0.000030 & 1077 & -25.6 & 0.281996 & -3.6 & 0.2824428 & 2.1 & 0.281694 & 8.6 \\
\hline 46.1 & 0.282068 & 0.000093 & 0.001353 & 0.000075 & 993 & -24.9 & 0.282043 & -3.8 & 0.282504 & 2.0 & 0.281731 & 8.8 \\
\hline 45.1 & 0.282311 & 0.000079 & 0.001422 & 0.000079 & 496 & -16.3 & 0.282298 & -5.8 & 0.282867 & 1.8 & 0.281923 & 9.7 \\
\hline 60.1 & 0.282137 & 0.000044 & 0.001498 & 0.000032 & 1196 & -22.5 & 0.282103 & 2.9 & 0.282355 & 1.8 & 0.281931 & 9.8 \\
\hline 41.1 & 0.282347 & 0.000045 & 0.000844 & 0.000026 & 650 & -15.0 & 0.282337 & -1.1 & 0.282755 & 1.6 & 0.282059 & 10.4 \\
\hline
\end{tabular}

\section{Observações:}

1) Decaimento de 176Lu - Soderlund et al. EPSL 219, 311-324 (2004).

2) Valor de Chondritic - Blichert-Toft \& Albarede EPSL 148, 243-258, (1997).

3) Valor de "Depleted Mantle" no presente dia - Vervoort \& Blichert-Toft, GCA 63, 533-557 (1999), ver tambem Vervoort, EPSL 243, 711731 (2006). 